\title{
Estudio de la construcción de los elementos caligráficos en el proceso de alfabetización de adultos en la Amazonia brasileña
}

Tesis Doctoral

Almir de Souza Pacheco

Directoras: Profa. Dra. Da. María Begoña J ordá Albiñana

Profa. Dra. Da. Jimena González del Rio Cogorno

Valencia, Diciembre de 2012 



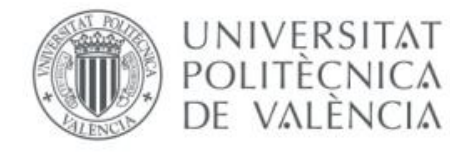

\author{
Universitat Politècnica de València \\ Escuela Técnica Superior de Ingeniería del Diseño \\ Departamento de Ingeniería Gráfica
}

\title{
Estudio de la construcción de los elementos caligráficos en el proceso de alfabetización de adultos en la Amazonia brasileña
}

Programa de Doctorado: Diseño, Fabricación y Gestión de Proyectos Industriales 

Tesis realizada bajo la dirección de las profesoras: Dra. Da. María Begoña Jordá Albiñana y Dra. Da. Jimena González del Rio Cogorno en la Escuela Técnica Superior de Ingeniería del Diseño, a través del Departamento de Ingeniería Gráfica, de la Universitat Politècnica de València, y que para la obtención del grado de doctor presenta D. Almir de Souza Pacheco. 



\section{Dedicatoria}

A Dios que ilumina nuestro camino y nuestras victorias.

A mis padres llo dos Santos Pacheco y Raimunda de Souza Pacheco, por las enseñanzas y los valores que me permitieron llegar hasta aquí.

A mí querida y amada esposa Karla Mazarelo Maciel Pacheco, por su amor, su afecto y su presencia en mi vida.

En memoria de mi querido tío Antonio Carvalho de Souza (tío "Toinho") a quien le debo la inspiración para estudiar Diseño.

A toda mi familia. 



\section{Agradecimientos}

En estas líneas quisiera manifestar de forma explícita mi agradecimiento a todas aquellas personas que directa e indirectamente han contribuido a la culminación de esta Tesis.

En primer lugar a las dos Directoras de Tesis: Dra. María Begoña J ordá Albiñana y Dra. Jimena González del Rio Cogorno, cuyo apoyo constante, motivación, paciencia y sugerencias han sido fundamentales y determinantes para el desarrollo y finalización de este trabajo de investigación.

Mi agradecimiento muy especial al Prof. Dr. Bernabé Hernandis Ortuño por toda la atención, la orientación, el apoyo a nosotros desde el primer contacto en la UPV.

A mis compañeros de doctorado: Susana Paixão-Barradas, Andrea Medina Gómez, John Jairo Cardozo Vásquez, Nélida Yaneth Ramírez Triana, J osé Rafael González Díaz, Elingth Simoné Rosales Marquina y Mauricio Guerrero por su amistad, apoyo y confianza en los períodos más arduos y que me motivaron en la recuperación de la fuerza para seguir adelante en la culminación de este trabajo.

Al Programa de Becas Euro Brazilian Windows II - EBWII, a través de la Universidad del Porto (UV), por concederme la oportunidad de cursar un doctorado en el área del Diseño en Europa.

Al equipo de la Oficina de Acción Internacional de la UPV, en especial a Da. Begoña Lluzar J ulian, Da. Maria J osé Oltra y Da. Geraldine Bustamante Reyes por su atenciosa disponibilidad en ayudar a los becarios del Programa EBWII de Brasil. A mi amigo Daniel Castro por toda ayuda dada en los momentos de dificultades.

A Universidad Federal de Amazonas (UFAM), sobre todo al ex Director de la Facultad de Tecnología (FT), Prof. Dr. Waltair Vieira Machado y Raquel Queiroz su secretaria por toda ayuda en el proceso de selección del doctorado.

Quisiera reconocer todo el apoyo y cariño de mi sogro J osé Nogueira Maciel, mis tios Leila Ferreira, Antonio y Evangelina Gama y mis acuñados Marcos y Marcel.

A mis hermanos Edmar, Francisca, Nanci, Lourdes y Socorro Pacheco, primos, sobrinos y tíos por todo su cariño, oraciones e incentivo. 
Estudio de la construcción de los elementos caligráficos en el proceso de alfabetización de adultos en la Amazonia brasileña

A Fernanda de Melo Parente y sus padres Valdenei y Fernando Parente por recibir a mí y mi esposa en su casa cuando llegamos a Valencia y por la siempre cordial atención con nosotros.

A Dios y la Virgen María por estar siempre presentes en mi vida, dándome fuerza, salud, paz de espíritu y perseverancia para alcanzar mis sueños como ser humano y profesional.

¡Muchísimas Gracias!

Muito obrigado! 
Estudio de la construcción de los elementos caligráficos en el proceso de alfabetización de adultos en la Amazonia brasileña

"El aprendizaje es la única cosa que la mente se cansa nunca, nunca tiene miedo, y nunca se arrepiente."

Leonardo da Vinci 



\section{Resumen}

El analfabetismo es uno de los principales problemas sociales que plagan la humanidad, alcanzando casi el $20 \%$ de la población adulta en el mundo y más de 10 millones de personas en Brasil. La Amazonia brasileña, por sus problemas logísticos y las características geográficas, muestra un número significativamente mayor en comparación con la falta de educación, sobre todo para la alfabetización de adultos. Esta tesis, que lleva por título: Estudio de la construcción de elementos caligráficos en el proceso de alfabetización de adultos en la Amazonia brasileña, tiene como objetivo aunar esfuerzos en la lucha para reducir estas tasas elevadas. La investigación examina la cuestión del poco material educativo accesible y específico para el adulto analfabeto, estudiando, específicamente, la morfología de las letras. El trabajo tiene como objetivo estudiar la construcción de elementos caligráficos y su uso más adecuado en el proceso de alfabetización de adultos en la Amazonia brasileña. El estudio presenta un enfoque metodológico cualitativo, utilizando elementos también cuantitativos, con una integración de trabajos acerca de las opiniones de expertos de las áreas técnicas relacionadas con el tema y a través de un compendio de publicaciones basados en un referencial teórico y sistematizado a través del diseño. También es importante destacar el uso de la línea de pensamiento de la enseñanza de Ferreiro y Teberosky (1999) que afirman que el sistema alfabético es una integración entre el lenguaj e y la realidad, lo que corrobora el método de Freire (1990), lo cual consiste en el uso del cotidiano como fuente de conocimiento en el proceso de alfabetización. Desde el punto de vista formal, los argumentos de Frutiger (2001), Heitlinger (2006) y Montesinos y Hurtuna (2007) suman contribuciones importantes de la tipografía y el diseño. En conclusión, la investigación presenta recomendaciones acerca de los aspectos formales, para posibles construcciones de caracteres de uso en el proceso de alfabetización de adultos en la Amazonia brasileña.

\section{Palabras clave:}

Diseño gráfico, tipografía, alfabetización de adultos

\section{Líneas de investigación:}

Diseño gráfico, escritura manual, proceso de alfabetización de adultos 



\begin{abstract}
Illiteracy is a major of social problems that humanity plaguing, reaching almost $20 \%$ of the adult population in the world and more than 10 million people in Brazil. The Brazilian Amazon, according their logistical challenges and geographical features, shows significantly higher numbers in relation to the lack of education, especially for the adult literacy. This thesis, which is entitled: Study of the calligraphic elements' construction in the adult literacy process in Brazilian Amazon, which aims to join forces in the fight to reduce these high rates. The research examines about issue of the little educational material available and applied for adult literacy, studying, specifically, the morphology of the letters. The work aims to study the construction of calligraphic elements and their most appropriate use in the process of adult literacy in the Brazilian Amazon. The methodological approach applied in this study is qualitative character, using also quantitative elements, with an integration of expert opinion, and the use of the technical aspects related to the subject areas, through a compendium of publications based on theoretical and systematized through design. It also important to note the thought teaching line used by Ferreiro and Teberosky (1999), claiming to be the alphabetic system integration between language and reality, corroborating the method of Freire (1990), which consists of everyday use as a source of knowledge in the literacy process. About view formal point, the arguments of Frutiger (2001), Heitlinger (2006) and Montesinos \& Hurtuna (2007) brought significant contributions of typography and design, and as a conclusion, the study presents a series of recommendations on the formal calligraphic aspects to be used in the process of adult literacy.
\end{abstract}

\title{
Keywords:
}

Graphic Design, Typography, Literacy Adult

\section{Research lines:}

Graphic Design, Handwriting, Literacy Adult Process 



\section{Resum}

L'analfabetisme és un dels principals problemes socials que pateix la humanitat, amb prop del $20 \%$ de la població adulta en el món i més de 10 milions de persones al Brasil. L'Amazònia brasilera, pels seus problemes logístics i les característiques geogràfiques, mostra un nombre significativament major en comparació amb la falta d'educació, sobretot per l'alfabetització d'adults. Aquesta tesi, que porta per títol: Estudi de la construcció d'elements cal-ligràfics en el procés d'alfabetització d'adults a I'Amazònia brasilera, té com a objectiu unir esforços en la lluita per reduir aquestes taxes elevades. La investigació examina la qüestió del poc material educatiu accessible i específic per a l'adult analfabet, i estudia, específicament, la morfologia de les lletres. El treball té per objectiu estudiar la construcció d'elements cal-ligràfics i el seu ús més adequat en el procés d'alfabetització d'adults a l'Amazònia brasilera. L'estudi presenta un enfocament metodològic qualitatiu, que utilitza elements també quantitatius, amb una integració de treballs sobre les opinions d'experts de les àrees tècniques relacionades amb el tema i a través d'un compendi de publicacions basats en un referencial teòric i sistematitzat a través del disseny. També és important destacar l'ús de la línia de pensament de l'ensenyament de Ferreiro i Teberosky (1999) que afirmen que el sistema alfabètic és una integració entre el llenguatge i la realitat, el que corrobora el mètode de Freire (1990), la qual cosa consisteix en l'ús d'allò quotidià com a font de coneixement en el procés d'alfabetització. Des del punt de vista formal, els arguments de Frutiger (2001), Heitlinger (2006) i Montesinos i Hurtuna (2007) sumen contribucions importants de la tipografia i el disseny. En conclusió, la investigació presenta recomanacions sobre els aspectes formals, per a possibles construccions de caràcters d'ús en el procés d'alfabetització d'adults a l'Amazònia brasilera.

\section{Paraules clau:}

Disseny gràfic, tipografia, alfabetització d'adults

\section{Línies de recerca:}

Disseny gràfic, escriptura manual, procés d'alfabetització d'adults 



\section{Resumo}

0 analfabetismo é um dos grandes problemas sociais que assola a humanidade, chegando a atingir quase $20 \%$ da população adulta no mundo e mais de 10 milhões de pessoas no Brasil. A Amazônia brasileira, por seus desafios logísticos e suas características geográficas, apresenta números significativamente altos com relação à falta de escolaridade, principalmente quanto à alfabetização de adultos. A presente tese, que tem como título: Estudo da construção dos elementos caligráficos no processo de alfabetização de adultos na Amazônia brasileira, visa somar esforços na luta para diminuir esses altos índices. A investigação analisa a questão do pouco material didático disponível e direcionado para o adulto iletrado, estudando, de forma específica, a morfologia das letras. 0 trabalho tem por objetivo estudar a construção dos elementos caligráficos e seu uso mais adequado no processo de alfabetização de adultos na Amazônia brasileira. O estudo apresenta uma abordagem metodológica qualitativa, valendo-se também de elementos quantitativos, com uma integração de trabalhos sobre a opinião de especialistas, bem como a utilização de aspectos técnicos, de áreas correlatas ao tema, através de um compêndio de publicações com base em referencial teórico e sistematizado através do design. É importante destacar também o uso da linha de pensamento pedagógico de Ferreiro e Teberosky (1999) que afirmam ser o sistema alfabético uma integração entre língua e realidade, corroborando com o método de Freire (1990) no qual consiste em utilizar o cotidiano como fonte de conhecimento no processo de alfabetização. Sob o ponto de vista formal, as argumentações de Frutiger (2001), Heitlinger (2006) e Montesinos \& Hurtuna (2007) trouxeram relevantes contribuições da tipografia e do design e como conclusão, o estudo apresenta uma série de recomendações sobre os aspetos formais dos caracteres a serem utilizados no processo de alfabetização de adultos.

\section{Palavras chave:}

Design Gráfico, Tipografia, Alfabetização de adultos

\section{Linhas de investigação:}

Design Gráfico, Escrita manual, Processo de alfabetização de adultos 



\section{Tesis por compendio de publicaciones}

La tesis se propone como un trabajo de creación inédita, de investigación rigurosa, y de producción científica, marco inicial de la especialidad de un investigador (Pujol, 1992). Se constituye como fuente de información que refleja el logro en su propio campo del saber, estando directamente relacionado con la búsqueda y la transmisión del conocimiento a través de la información documentada, donde la recopilación y al análisis de datos para el origen de la producción científica, son aspectos relevantes.

Con el ritmo actual de la transmisión del conocimiento, las Universidades y las Instituciones Profesionales y de Investigación de alto nivel han aceptado el papel de preparar a los futuros científicos y conceder el grado de Doctor a aquellos que demuestren ser capacitados para llevar a cabo investigaciones de alta calidad (Nascimento, 2000) y cuya producción científica sea una práctica habitual de la publicación de los resultados de las búsquedas que van surgiendo durante el desarrollo de las tesis doctorales, componiendo un trabajo original de investigación, que no siempre es totalmente inédito.

Con base en esta información, el Estudio de la construcción de los elementos caligráficos en el proceso de alfabetización de adultos en la Amazonia brasileña se presenta mediante un documento estructurado por compendio de artículos previamente publicados, aceptados y/o en evaluación para publicación, guardando relación entre sí. Los artículos poseen calidad contrastada, demostrada por el potencial atribuido al tema del estudio en revistas, congresos y eventos de naturaleza centrada en los aspectos de: diseño, enseñanza, gestión, pedagogía; así como, en base al prestigio de la publicación en que han sido insertados.

El documento, ha sido realizado de acuerdo con las normativas de estudio establecidas por el Programa de Doctorado en Diseño, Fabricación y Gestión de Proyectos Industriales de la Escuela Técnica Superior de Ingeniería de Diseño - ETSID perteneciente a la Universitat Politècnica de València - UPV; también sigue las líneas de investigación, mediante la oportuna tramitación ofrecida dentro de su organización funcional y aprobación de la propuesta del Proyecto de Tesis por la dirección y la Comisión de Doctorado de esta Universidad. 



\section{Autorización de la Directora de Tesis para su presentación}

Profa. Dra. María Begoña J ordá Albiñana y Profa. Dra. Jimena González del Rio Cogorno como Directoras de la Tesis Doctoral: Estudio de la construcción de los elementos caligráficos en el proceso de alfabetización de adultos en la Amazonia brasileña, realizada en el Programa de Doctorado en Diseño, Fabricación y Gestión de Proyectos Industriales del Departamento de Ingeniería Gráfica de la Escuela Técnica Superior de Ingeniería del Diseño ETSID de la Universitat Politècnica de València - UPV, Valencia/ España, por el Doctorando D. Almir de Souza Pacheco, AUTORIZAN la presentación de la citada Tesis Doctoral, desarrollada en la modalidad "Tesis por compendio de publicaciones", dado que el documento de investigación reúne las condiciones necesarias para su defensa.

En Valencia a 12 de Diciembre de 2012

LAS DIRECTORAS DE LA TESIS

Fdo:_ Dra. María Begoña J ordá Albiñana

Fdo:_ Dra. Jimena González del Rio Cogorno 
Estudio de la construcción de los elementos caligráficos en el proceso de alfabetización de adultos en la Amazonia brasileña

\section{Índice}

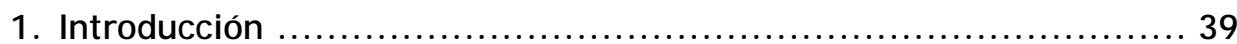

1.1. Motivación de la investigación ......................................... 39

1.2. Contextualización del tema....................................... 40

1.3. Problema identificado ............................................ 41

1.4. Objetivos de la investigación ...................................... 43

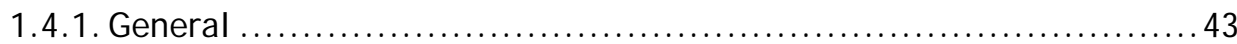

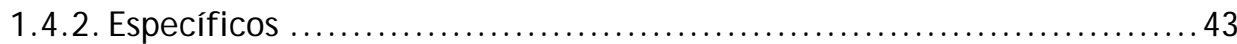

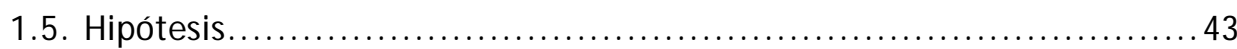

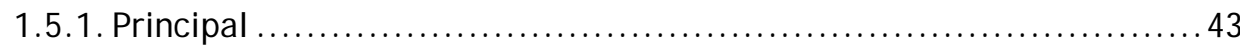

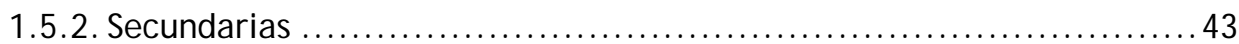

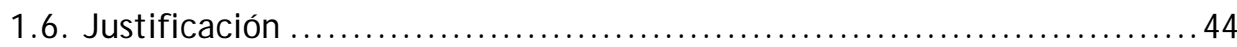

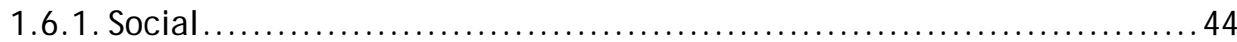

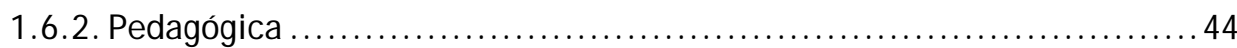

1.6.3. Económica....................................................... 44

1.6.4. Ambiental .................................................... 44

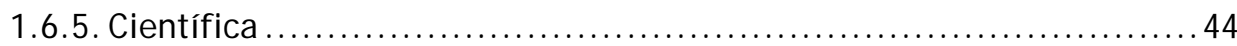

1.7. Delimitación de la investigación .................................... 45

1.8. Material y métodos ................................................ 45

1.8.1. Tipo de la investigación ....................................... 45

1.8.2. Tipo y diseño general del estudio ................................. 46

1.8.3. Procedimientos para la captación de datos, instrumentos a utilizar y métodos para el control y calidad de estos............................... 47

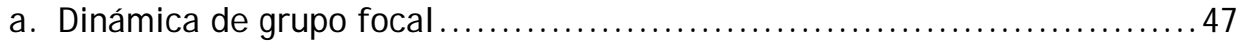

b. Entrevista en profundidad.......................................... 49

c. Procedimientos para garantizar los aspectos éticos de la investigación con

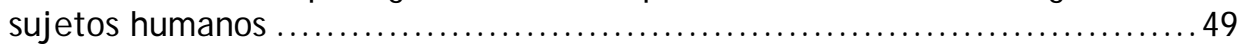

1.8.4. Sobre este contexto, se pretende en esta investigación: ...............50 
1.8.5. Estructura planeada del desarrollo de los artículos para la producción

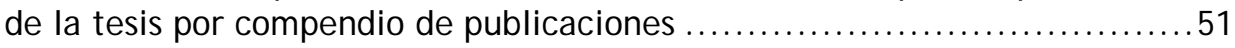

1.9. Estructura de la tesis............................................. 52

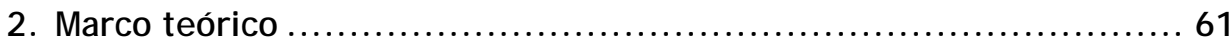

2.1. Enfoque de la alfabetización entre niños y adultos .....................61 61

2.1.1. Aspectos sociales e históricos de la alfabetización de adultos ...........62

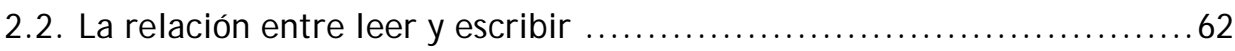

2.2.1. Grafía o caligrafía: una dicotomía más que etnológica..................63

2.3. La escritura escolar en Brasil .........................................6 64

2.3.1. Alfabetización de adultos y el formato de las letras ....................65 65

2.3.2. El diseño y la tipografía para la enseñanza ...........................66 66

2.4. La búsqueda de nuevas alternativas de escritura .......................69 69

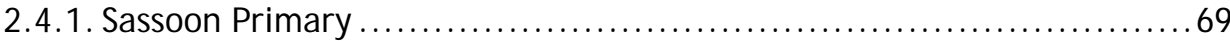

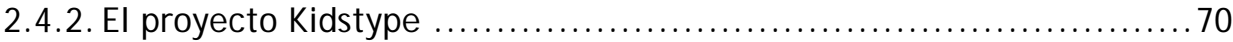

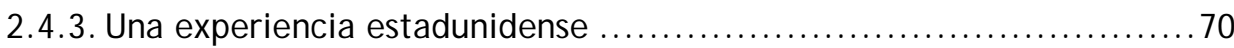

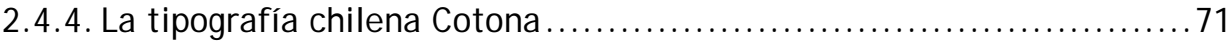

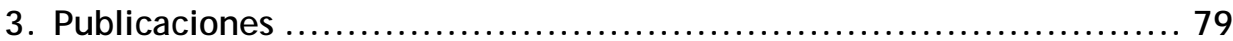

3.1. Artículo 1 - Caligrafia Cursiva: A única ou mais eficiente no processo de alfabetização? 79

3.2. Artículo 2 - Análise do posicionamento do design com relação ao estudo da construção dos elementos caligráficos para o processo de alfabetização de adultos na Amazônia brasileira. 93

3.3. Artículo 3 - Una mirada del diseño sobre la morfología de los caracteres caligráficos y sus implicaciones en el proceso de alfabetización de adultos. 107

3.4. Artículo 4 - A participação do design no ensino e na transição entre a escrita manual e as tendências da tipografia no ambiente tecnológico: Um convite à reflexão

3.5. Artículo 5 - Análise do posicionamento de especialistas em pedagogia, psicologia e design sobre a construção dos elementos caligráficos no processo de alfabetização de adultos na Amazônia brasileira 
Estudio de la construcción de los elementos caligráficos en el proceso de alfabetización de adultos en la Amazonia brasileña

3.6. Artículo 6 - Estudio comparativo de la morfología de las letras de cuadernos de caligrafía de algunos países y sus implicaciones para el proceso de alfabetización

3.7. Artículo 7 - Experimentaciones modulares para el diseño de caracteres tipográficos....

4. Discusión final

4.1. Resultados generales....

4.1.1. Comparativa sobre el grado de adecuación de la caligrafía enseñada en el proceso de alfabetización de adultos para el mundo contemporáneo.... 199

a. Caligrafía cursiva 199

b. Diseño en la transición de la escrita manual a las tendencias de la tipografía en el ambiente tecnológico....

4.1.2. Aspectos formales de los caracteres y sus implicaciones en el proceso de alfabetización de adultos 200

a. Morfología de caracteres caligráficos y sus implicaciones para el proceso de alfabetización de adultos 200

b. Posicionamiento del diseño con relación a la construcción de los elementos caligráficos en el proceso de alfabetización de adultos en la Amazonia brasileña 201

c. Estudio comparativo de la morfología de los caracteres de las cuartillas de caligrafía de algunos países y sus implicaciones en el proceso de alfabetización de adultos

4.1.3. Parámetros necesarios para el desarrollo de una caligrafía más adecuada al proceso de alfabetización de adultos basada en los estudios realizados

a. Posicionamiento de expertos en pedagogía, psicología y diseño con relación a la construcción de los elementos caligráficos en el proceso de alfabetización de adultos en la Amazonia brasileña. 203

4.2. Conclusiones generales 204

4.2.1. Resumen de los problemas detectados en las publicaciones e algunas recomendaciones: 208

4.3. Futuras líneas de investigación................................... 211

5. Anexos. 215 
5.1. Anexo I - Encuesta con expertos .................................. 215

5.2. Anexo II - Portada del Articulo 1 (publicado) .......................... 217

5.3. Anexo III - Aceptación del Artículo 2 en CIEPG2012 ..................... 218

5.4. Anexo IV - Carta aceptación para publicación del Artículo 3 ............ 219

5.5. Anexo V - Programa presentación del artículo 4 en II CIDAG ............. 221 
Estudio de la construcción de los elementos caligráficos en el proceso de alfabetización de adultos en la Amazonia brasileña

\section{Listado de Figuras}

\section{Introducción}

Figura 1 - mapa de la Amazonía brasileña y su cuenca hidrográfica. ........... 39

Figura 2 - Números de adultos analfabetas en el mundo (en millones). ....... 42

Figura 3 - Cuadro con los obj etivos de la tesis. ............................ 51

\section{Marco Teórico}

Figura 4 - Número de niños sin escolarizar (en millones). ....................61

Figura 5 - Logotipo de la Coca-Cola. ......................................... 65

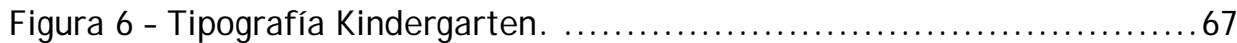

Figura 7 - Tipografía sturm blond de Herbert Bayer. ........................ 67

Figura 8- los alfabetos unicamerales árabe y hebreo. ......................6 68

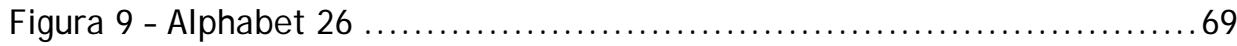

Figura 10 - tipografia Sassoon Primary ..................................... 69

Figura 11 - diferença entre caracteres. ................................. 70

Figura 12 - tipografía School Fonts for Beginning Writing. .................. 71

Figura 13 - tipografia Tcl Cotona. ........................................ 72

\section{Publicaciones}

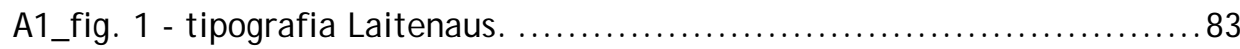

A1_fig. 2 - tipografia NormSchrift, letra normalizada alemã. ................. 84

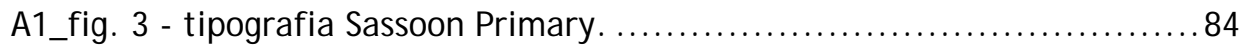

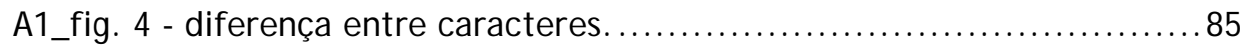

A1_fig. 5 - tipografia Americana School Fonts for Beginning Writing. ..........86 86

A1_fig. 6 - tipografia Tcl Cotona........................................ 87

A1_fig. 7 - folha informativa fornecida com um Palm Pilot (PDA)............. 88

A1_fig. 8 - comparação entre a cursiva em versal com outras tipografias. .... 90

A1_fig. 9 - diferença entre maiúsculas e minúsculas......................... 90 
A1_fig. 10 - letras com similaridade formal.

A2_Fig. 1 - Focus group realizado com os especialistas em design para a coleta de dados.

A2_Fig. 2 - Aspecto cognitivo evidenciado pelos participantes do Focus group 100

A2_Fig. 3 - Aspecto psicológico evidenciado pelos participantes do Focus group

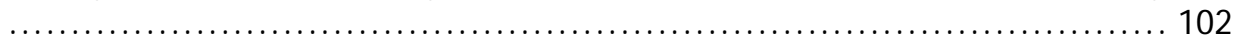

A3_Fig. 1 - Caracteres fenicios sin modulación (alrededor de 1600 a.C).... 110

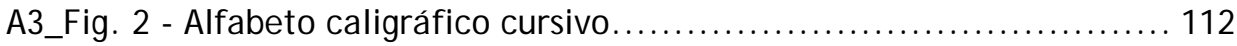

A3_Fig. 3 - Transformaciones formales en la transición de los caracteres mayúsculos a minúsculos. ............................................ 119

A4_Fig. 1 - Tipografia NormSchrift, letra normalizada alemã. .............. 130

A4_Fig. 2 - Tipografia sturm blond de Herbert Bayer. ...................... 131

A4_Fig. 3 - Alphabet 26, proj eto do designer Bradbury Thompson (1950). .. 132

A4_Fig. 4 - folha informativa fornecida com um Palm Pilot (PDA). .......... 132

A5_Fig. 1 - Números de adultos analfabetos no mundo (em milhões). ....... 138

Fonte: adaptado de (UNESCO, 2011; Villas-Boas, 1998) ................... 138

A5_Fig. 2 - Nível de apreciação do uso da caligráfica em função da dificuldade construtiva dos caracteres. ............................................ 141

A5_Fig. 3 - Nível de apreciação do uso da caligráfica cursiva para a alfabetização de adultos.

A5_Fig. 4 - Nível de apreciação da caligráfica para a alfabetização de pessoas destras e canhotas.

A5_Fig. 5 - Valoração da mudança da letra pelo uso da caligrafia cursiva (entre as etapas escolares de criança a adulto). .......................... 143

A5_Fig. 6 - Nível de apreciação do uso de material didático com características regionais para o aprendizado da escrita.................... 144

A5_Fig. 7 - Valoração o uso da letra romana (de forma) no processo de alfabetização de adultos. .............................................. 144

A5 Fig. 8 - Valoração o uso formas básicas para a construção dos elementos caligráficos. 145

A5_Fig. 9 - Valoração da velocidade da escrita pelos entrevistados. 146 
Estudio de la construcción de los elementos caligráficos en el proceso de alfabetización de adultos en la Amazonia brasileña

A5_Fig. 10 - Nível de preferencia da legibilidade em relação à velocidade da escrita. 146

A5_Fig. 11 - Nível de credibilidade da caligrafia cursiva para uma escrita ilegível devido sua complexidade construtiva. 147

A5_Fig. 12 - Nível de apreciação do material didático que valoriza a relação professor-aluno. 148

A5_Fig. 13 - Nível de credibilidade na existência de material didático direcionado à alfabetização de adultos. 148

A5_Fig. 14 - Nível de credibilidade do uso de material didático utilizado com crianças a ser aplicado com adultos.

A5_Fig. 15 - Valoração da adaptação dos recursos didáticos às características regionais. 149

A5_Fig. 16 - Valoração do uso de formas simples para o processo de alfābetização de adultos. 150

A6_Fig. 1 - Ejemplo del modelo caligráfico de Spencer y su aplicación en el logotipo de Coca-Cola. 157

A7_Fig. 1 - Adaptación de la estructura que describe el proceso de un SIV, Peón (2000). 180

A7_Fig. 2 - Diagrama adaptado de las etapas de un proyecto de identidad visual. 180

A7_Fig. 3 - Anatomía del tipo, adaptación de Montesinos y Hurtuna (2001). 181 A7 Fig. 4 - Diferentes formas de utilizar las letras en un logotipo, Strunck (2007)

A7_Fig. 5 - Representación gráfica del modelado, Hernandis (2003). ....... 184

A7_Fig. 6 - Diagrama de las fases del estudio. ............................ 185

A7_Fig. 7 - Referencia modular diagonal, Ghyka (1980)................... 189

A7_Fig. 8 - Esquema simbólico masónico, adaptación de Frutiger (2001) y Ghyka (1980). ................................................. 190

A7_Fig. 9 - análisis de la estructura para la construcción de un alfabeto,

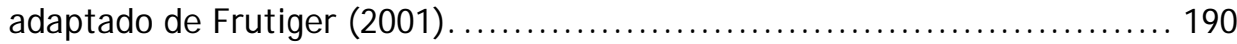

A7_Fig. 10 - Gráfico de derivación de los arquetipos - minúsculas, Buggy (2007). 
A7_Fig. 11 - Gráfico de derivación de los arquetipos - mayúsculas, Buggy

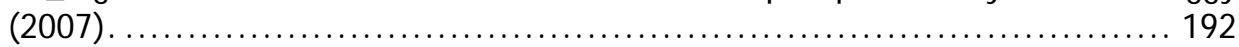

A7_Fig. 12 - Gráfico de derivación de los arquetipos - números, Buggy (2007).

A7_Fig. 13 - Logotipo desarrollado a partir de una estructura modular. ..... 193

A7_Fig. 14 - Logotipo desarrollado a partir de una estructura modular con referencia linear..................................................... 193

A7_Fig. 15 - alfabeto diseñado a través de una estructura modular con referencia linear...................................................... 194 



\section{Listado de tablas}

\section{Introducción}

Tabla 1. Grupo Focal - Estructura y Procedimiento .......................... 48

Tabla 2. Entrevista en profundidad - Expertos ............................ 49

\section{Publicaciones}

A2_Tab. 1 - Atributos relacionados pelos participantes para a atuação do design quanto 0 aspecto cognitivo..................................... 101

A2_Tab. 2 - Atributos formais considerados essenciais à atuação do design em relação ao aspecto psicológico ........................................ 103

A3_Fig. 4 - Tipografía Laitenaus usada por las escuelas primarias alemanas y austríacas.

A4_Tab. 1 - Exemplo de diferenças formais entre caracteres maiúsculos e minúsculos. 129

A5_Fig. 17 - Nível de apreciação do uso de letras com formas mais simples para a alfabetização de adultos. 151

A6_Tab. 1 - Tabla comparativa de aspectos formales de letras en libros de caligrafía de siete países. 167

A7_Tab. 1 - Metodologías de Diseño - Adaptado de Vieira (2007) 179

A7_Tab. 2 - Características formales de los principales grupos estilísticos. Adaptación de Montesinos y Hurtuna (2001). 186

A7_Tab. 3 - Matriz Comparativa. Adaptación de HERNANDIS y WESTERMEYER (2009) 188 



\section{Listado de cuadros}

\section{Publicaciones}

A3_Cua. 1 - Complejidad de lectura de las mayúsculas

A3_Cua. 2 - Diferenciación formal entre caracteres (mayúsculos y minúsculos)

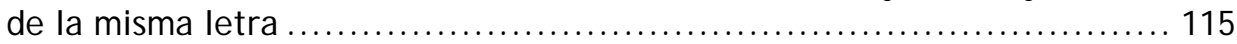

A3 Cua. 3 - Similaridad formal entre caracteres diferentes................. 116

A3_Cua. 4 - Deformación de caracteres ............................... 118

A3_Cua. 5 - Forma básica de los caracteres - mayúsculas .................. 120

A3_Cua. 6 - Formas básicas de los caracteres - minúsculas................. 121

A3_Cua. 7 - Cuadro Comparativo de las Formas Básicas de los Caracteres .. 122 



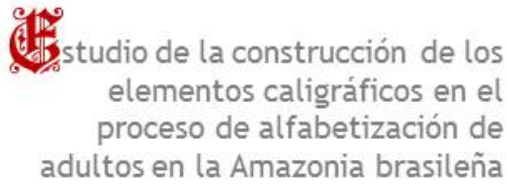
elementos caligráficos en el adultos en la Amazonia brasileña

\section{道apítulo 1}

\section{INTRODUCCIÓN}

1.1. Motivación de la investigación

1.2. Contextualización del tema

1.3. Problema identificado

1.4. Obj etivos de la investigación

1.5. Hipótesis

1.6. Justificación

1.7. Delimitación de la investigación

1.8. Material y método

1.9. Estructura de la tesis 



\section{Introducción}

\subsection{Motivación de la investigación}

El siglo XXI comenzó con una gran revolución mundial en los procesos de comunicación. Las distancias, en términos de capacidad de comunicación, están cada vez menores. La educación es un aspecto básico del desarrollo social, aunque a veces olvidado y relegado en comparación con el nivel de inversión en tecnología, especialmente en los países en desarrollo. Simples esfuerzos colectivos pueden hacer una diferencia, para poner la educación en el centro de los debates científicos con uno de sus temas más complejos: la alfabetización. Esta investigación tiene como foco la región norte de Brasil donde está ubicada la mayor floresta ecuatorial del mundo, la Amazonia que, por sus características, presenta grandes retos en torno a este tema.

La Amazonía se encuentra en el norte de América del Sur y llega a una parte del territorio de nueve países, entre ellos Brasil, Venezuela, Colombia, Perú, Bolivia, Ecuador, Surinam, Guyana y Guayana Francesa. La Amazonia brasileña abarca los estados de Pará, Amazonas, Maranhão, Goiás, Mato Grosso, Acre, Amapá, Rondônia y Roraima, que comprende una superficie de 5.033.072 $\mathrm{km} 2$, equivalente a un $61 \%$ del territorio brasileño. Sólo la Amazonia brasileña es siete veces más grande que Francia y el equivalente a 32 países de Europa occidental.

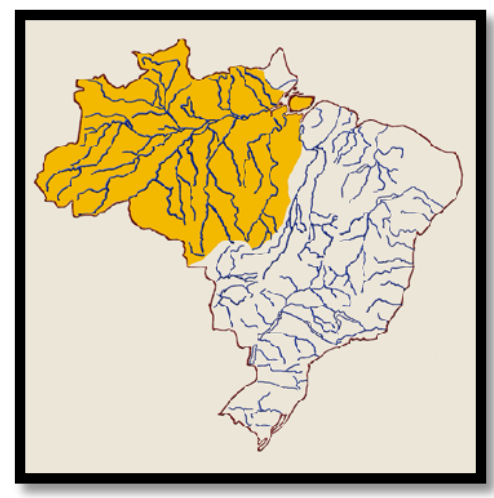

Figura 1 - mapa de la Amazonía brasileña y su cuenca hidrográfica.

Fuente: http:// educacao.uol.com. br/ geografia/ bacia-amazónica 
Estudio de la construcción de los elementos caligráficos en el proceso de alfabetización de adultos en la Amazonia brasileña

Esta vasta área de la Amazonía brasileña tiene un gran reto logístico causado por la estructura geográfica de la región, que es la falta de carreteras. La gran cuenca hidrográfica ubicada a lo largo del río Amazonas frustra los esfuerzos de la conexión terrestre en el norte de Brasil (Figura 1).

Las dificultades logísticas afectan el desarrollo de la región en todos los aspectos, la educación es uno de ellos. La llegada de las nuevas tecnologías que ayudan al proceso de educación, profesionales dispuestos a enfrentar los desafíos de trabajar en la Amazonia y el transporte de personal y material son obstáculos que enfrentan todos los días la población local.

Asimismo, presentando altos índices de analfabetismo, la educación brasileña aún necesita esfuerzos conjuntos para encontrar soluciones que minimicen este triste cuadro. Las peculiaridades regionales de un país del tamaño de Brasil obstaculizan el logro de resultados a través de acciones de carácter general, es decir, los proyectos deben adaptarse a las características de cada localidad. La Amazonía, que es el ámbito geográfico de este estudio, tiene una realidad muy diferente desde el sur, por lo que un mismo proyecto difícilmente alcanzaría los mismos resultados en comparación con las dos regiones, tampoco sería adecuado para estas.

\subsection{Contextualización del tema}

El análisis de los aspectos de la transcripción del lenguaje según Frutiger (2001), se estima que la escritura como expresión del pensamiento y del habla, se originó en el mismo instante en que dibujos o signos surgieran directamente relacionados con las sílabas, palabras o frases pronunciadas. Los primeros escribas han surgido 5.000 años antes de Cristo. La comunicación dio a través del diseño de objetos, fechas y acciones de los llamados pictogramas. La escritura, por sí misma, habría aparecido cuando el hombre comenzó a organizar y alinear las señales de lado a lado o uno sobre el otro correspondiente a una evolución lineal de su pensamiento.

La evolución y las adaptaciones de los escribas y los monjes en el método de escribir, conllevaron a la aparición del primer libro de la caligrafía en Italia en el año 1522 por Ludovico degli Arrighi Vicentino; fue el gran responsable de la popularización de la letra llamada cancilleresca o itálica y también por establecerla como la cursiva preferida de la tipografía. Arrighi era escribano papal y uno de los calígrafos / tipógrafos que participaron directamente en la creación de la cultura tipográfica occidental durante el renacimiento italiano. A partir de ahí, todo tipo de letra escrita a mano y del aspecto caligráfico pasó a llamarse cursiva (Briem, 1983). 
La popularización de la escritura cursiva fue tan grande que "invadió" el sistema educativo de Occidente y casi 500 años después, sigue siendo indiscutible en los libros de caligrafía usados en la alfabetización de niños y adultos, aunque el desarrollo tecnológico de la misma época hizo con que este tipo de escritura fuera cada vez menos habitual en los medios de comunicaciones modernas. Jury (2007) refuerza esta idea diciendo que a partir de la década de 1920, la máquina de escribir casi sustituyó la escrita a mano para la producción de la contabilidad y correspondencia comercial de las empresas este factor hizo con que la importancia de la enseñanza de la caligrafía en las escuelas disminuyera gradualmente.

Aprender a escribir es uno de los pasos más importantes en el proceso de aprendizaje, sin embargo, la mejora de este mecanismo requiere un poco de reflexión, especialmente en el elemento tipográfico que aún es utilizado en las escuelas: la tipografía cursiva. Otro factor es la poca variedad de alternativas caligráficas en el proceso de educación, hasta mismo como puntos de referencia en la comparación de los resultados. Para Heitlinger (2007), faltan tipos de letras adecuadas a las capacidades cognitivas y motoras de los niños en la edad de aprendizaje. No hay un consenso entre los profesores y educadores sobre el tipo que mejor se adapte al proceso de alfabetización. El consenso es menor cuando se trata de la alfabetización de adultos, casi olvidados en lo que respecta a estos estudios. La letra debe adaptarse a la evolución tecnológica y las necesidades del mundo moderno, así como a las variaciones en el perfil del estudiante, sea él, niño 0 adulto.

\subsection{Problema identificado}

En el Informe de Seguimiento de la Educación para Todos (UNESCO, 2011) señaló que en 2008 poco menos de 796 millones de adultos carecían de las habilidades básicas de alfabetización; esto equivale aproximadamente a un $17 \%$ de la población adulta en el mundo, la mayoría de estos adultos son habitantes de diez países, entre los que se encuentra Brasil (Figura 2). En síntesis, sobre indicadores de 2007 del IBGE el número de analfabetas en Brasil, en el año de 2005 superaba el 11\% este porcentaje representaba más de 14 millones, de los cuales un $36.4 \%$ pertenecían a la franja de edad de 40 a 59 años. A pesar de que los números son todavía muy altos, no existe un valor proporcional de acciones, por menores que sean para su reducción. Por más paradójico que parezca, la educación es un aspecto básico del desarrollo social de un país, aunque sea relegado $y$, a veces, olvidado cuando éste es comparado al grado de inversión en tecnología. Esfuerzos simples y colectivos pueden hacer la diferencia, mínimamente, para colocar la educación en el centro del debate científico que envuelvan una de sus más complejas 
Estudio de la construcción de los elementos caligráficos en el proceso de alfabetización de adultos en la Amazonia brasileña

cuestiones: la alfabetización, el diseño, como una actividad multidisciplinar, puede contribuir de forma significativa en ese contexto.

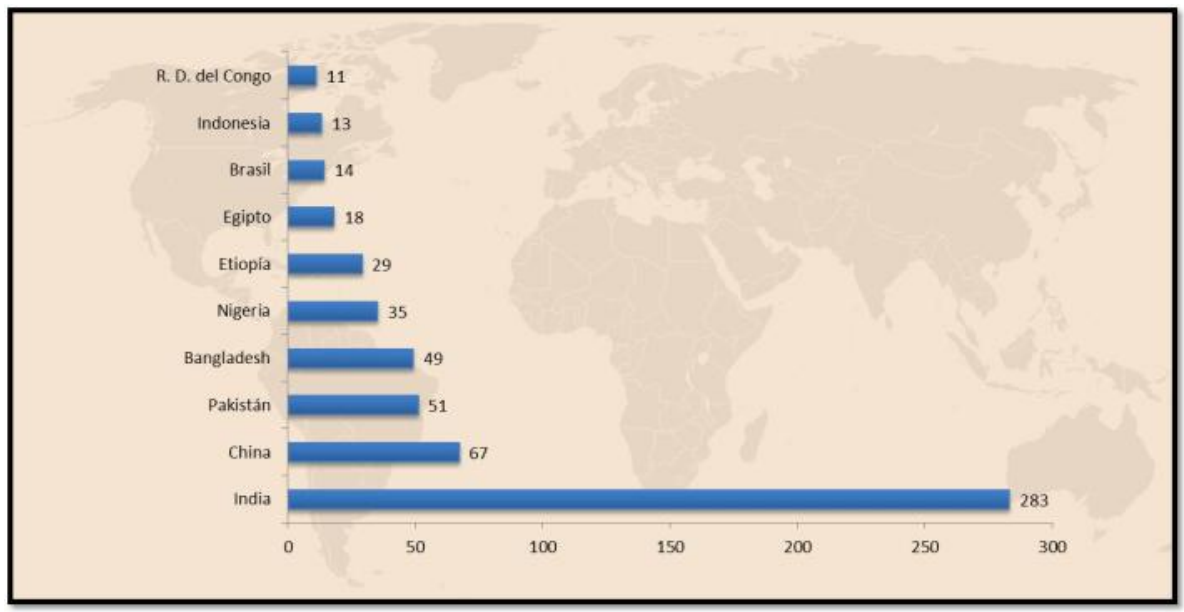

Figura 2 - Números de adultos analfabetas en el mundo (en millones).

Fuente: adaptado de (UNESCO, 2011).

Las características formales de las letras pueden ser una interesante herramienta de análisis por parte del diseñador, ellas presentan elementos en que estriba varios tipos de observaciones, tales como:

- ¿La caligrafía cursiva tiene el formato ideal para que los analfabetas adultos aprendan a escribir?

- ¿Por qué muchos adultos alfabetizados tienen una letra diferente de lo que aprendieron en la escuela?

- ¿En el mundo actual, tomado por la tecnología, donde la gente utiliza la escritura a mano cada vez menos, hay necesidad que el adulto analfabeta aprenda a escribir rápido y de forma cursiva?

- ¿Cuál es la ventaja de escribir rápido y de forma cursiva si la letra es ilegible?

- ¿Cuál sería la forma más apropiada de las letras para la alfabetización de los adultos?

La búsqueda de respuestas a preguntas como las anteriores son parte de la motivación para esta investigación, colocando el diseño en medio de los debates sobre los aspectos morfológicos de los caracteres caligráficos y las 
posibles contribuciones que pueden surgir en relación con ese tema en el campo de la alfabetización de adultos.

Sobre estos aspectos y teniendo en cuenta la falta de recursos didácticos e informaciones científicas suficientes para la alfabetización de adultos en la Amazonia brasileña, el estudio propone los siguientes objetivos:

\subsection{Objetivos de la investigación}

\subsubsection{General}

Estudiar los elementos caligráficos y su más adecuada construcción en el proceso de alfabetización de adultos en la Amazonía brasileña.

\subsubsection{Específicos}

a) Comparar el grado de adecuación de la caligrafía enseñada en el proceso de alfabetización de adultos para el mundo contemporáneo;

b) Estudiar los aspectos formales de los caracteres y sus implicaciones en el proceso de alfabetización de adultos;

c) Proponer los parámetros necesarios para el desarrollo de una caligrafía más adecuada al proceso de alfabetización de adultos basada en los estudios realizados.

\subsection{Hipótesis}

\subsubsection{Principal}

La información obtenida mediante de éste estudio, puede confirmar posibilidades de aplicación, reducir las incertidumbres, sistematizar los datos y facilitar el correcto dimensionamiento del uso de caracteres caligráficos en el proceso de alfabetización de adultos en la Amazonia brasileña.

\subsubsection{Secundarias}

H1 - El conocimiento sobre la morfología de los caracteres y sus perspectivas de cambio 0 aj ustes estructurales;

H2 - Información sobre aspectos técnicos de las letras y su utilización en los procesos de alfabetización;

H3 - Generación de información a partir de las opiniones y/ o posicionamiento de expertos en pedagogía, psicología y diseño sobre el tema de la caligrafía y sus implicaciones para la enseñanza de la escritura.; 
Estudio de la construcción de los elementos caligráficos en el proceso de alfabetización de adultos en la Amazonia brasileña

H4 - Conjunto de orientaciones técnicas, sistematizadas a través del diseño, para el desarrollo de un alfabeto más adecuado a alfabetización de adultos.

\subsection{J ustificación}

\subsubsection{Social}

La principal contribución de la investigación es sumar esfuerzos en la lucha constante contra el analfabetismo. Brasil presenta un alto índice de adultos iletrados y necesita de proyectos, viables y sencillos, que visen auxiliar el proceso de educación e inclusión social de esta gran parcela de su populación.

\subsubsection{Pedagógica}

La unión entre Diseño y Pedagogía puede generar resultados significativos en ambas áreas. Por una parte, enseñar la gran flexibilidad de interacción del Diseño en las más diversas áreas y por otra parte, comprobar que la Pedagogía, allende tener esta misma característica, es dinámica y está en constante evolución para adecuarse a las necesidades y retos sociales.

\subsubsection{Económica}

Con un alto índice de analfabetas, el gobierno brasileño hace una importante inversión (pero no eficiente) en material escolar, material didáctico, cursos, profesores, estructura física y todos los demás elementos que envuelven el proceso de educación básica; con la disminución de analfabetas, los gastos podrían ser orientados a otras áreas, también carentes, relacionadas con la educación brasileña; como por ejemplo, la creación de nuevas universidades, el incremento de la investigación y de la tecnología.

\subsubsection{Ambiental}

Cuanto más conocimiento mayor es la conciencia de su entorno. Esta es una premisa relacionada con el grado de educación que cada persona tiene. El acceso a la información puede ayudar a los pueblos de la Amazonía a entender mejor su papel en la preservación de la floresta y sobre las consecuencias que la deforestación puede causar en su futuro y en el de la comunidad.

\subsubsection{Científica}

Existe muy poca información sobre el tipo más adecuado de letra para alfabetizar. En el caso de los adultos analfabetas la referencia es mucho más escasa. En este contexto, el estudio puede contribuir para la construcción de 
un pensamiento sobre el tema y guiar las futuras líneas de investigación sobre la alfabetización de los adultos en relación con el uso correcto de la escritura.

\subsection{Delimitación de la investigación}

El trabajo se centra en la recolección y producción de datos en lo que se refiere al Estudio de la Construcción de los Elementos Caligráficos en el Proceso de Alfabetización de Adultos en la Amazonía Brasileña, de acuerdo con su comportamiento en cuanto a los siguientes aspectos:

- Material $\rightarrow$ tomando como base los libros, artículos, cartillas y las tipografías utilizadas en el proceso de alfabetización;

- Comparación $\rightarrow$ a través de un estudio comparativo entre la letra romana y la cursiva para verificar los posibles problemas técnicos existentes en cada una de ellas;

- Opinión $\rightarrow$ contraste de opiniones de expertos en pedagogía, psicología y diseño a través de una encuesta;

- Científico $\rightarrow$ generación de referencial científico sobre la caligrafía ideal para alfabetización de adultos;

- Recomendaciones $\rightarrow$ crear un listado de recomendaciones, basadas en los datos estudiados, direccionados al desarrollo de una caligrafía más adecuada para la alfabetización de adultos en la Amazonia brasileña;

\subsection{Material y métodos}

\subsubsection{Tipo de la investigación}

La investigación es cualitativa y cuantitativa, exploratoria, descriptiva y explicativa dentro de un marco teórico que proporciona un enfoque conceptual sobre el tema propuesto (Gil, 2002).

Los aspectos de la investigación cualitativa servirán para obtener las percepciones de la gente sobre los problemas sociales y hechos en relación al estado actual del fenómeno en estudio y/ o para describir la naturaleza de las condiciones existentes en una situación (Trochim, 2002).

Así, para examinar las cuestiones desde el punto de vista empírico y compararlo con un panorama teórico de los datos recogidos de la realidad, el estudio pretende presentar un modelo de funcionamiento - que muestra una recopilación de datos precedidos por una investigación bibliográfica y documental, entrevista de enfoque, entrevista en profundidad y análisis 
Estudio de la construcción de los elementos caligráficos en el proceso de alfabetización de adultos en la Amazonia brasileña

comparativo y de significación de las variables identificadas (Marconi \& Lakatos, 2006).

Los datos cuantitativos permiten examinar la información recogida de manera científica, o más específicamente en forma numérica y estudiar con ayuda de herramientas estadísticas, observando donde se inicia el problema, en qué dirección va y qué tipo de incidencia existe entre sus elementos. Son respuestas que podrán obtener y representar por medio de un modelo numérico lineal, exponencial o similar (Blaxter, Hughes, \& Tight, 2002).

El estudio estadístico podrá determinar la fuerza de asociación o correlación entre variables, la generalización y objetivación de los resultados a través de una muestra representativa para hacer inferencia a una población de la cual la muestra procede. El análisis al respecto de la asociación o correlación de estas variables, pretende hacer una inferencia causal que explique por qué las cosas suceden o no de una forma determinada.

\subsubsection{Tipo y diseño general del estudio}

El proceso de esta investigación científica involucra a una serie de actividades sucesivas y organizadas que deben ser consecuentes con los objetivos del tema propuesto y que constituyen los pasos y pruebas a efectuar así como las técnicas a utilizar para recolección y el análisis de datos. Se trabajará por tanto mediante la investigación bibliográfica y recopilación de datos en trabajos de campo.

El trabajo bibliográfico, recurre a las fuentes secundarias: libros, revistas, etc. Los trabajos de campo inciden en la realidad a los primeros aportados por los instrumentos que se han diseñado para su recolección, entre estos tenemos:

- Diseño de encuestas $\rightarrow$ siendo este un procedimiento exclusivo de las ciencias sociales, donde se parte de la premisa de que si queremos conocer algo sobre el comportamiento de las personas, lo mejor es preguntarlo directamente a ellas. Es importante en este diseño determinar la validez de muestreo.

- Diseño estadístico $\rightarrow$ que efectúa mediciones para determinar los valores de una variable 0 de un grupo de variables. Consiste en el estudio cuantitativo 0 evaluación numérica de hechos colectivos.

- Diseño de casos $\rightarrow$ realiza un estudio exhaustivo de uno o muy pocos objetos de investigación, lo cual permite conocer en forma amplia y detallada a los mismos. Este procedimiento consiste, por lo tanto, en estudiar cualquier 
unidad de un sistema, para estar en condiciones de conocer algunos problemas generales del mismo.

- Diseño experimental $\rightarrow$ cuando a través de un experimento se pretende llegar a la causa de un fenómeno. Su esencia es la de someter el objeto de estudio a la influencia de ciertas variables en condiciones controladas y conocidas por el investigador.

\subsubsection{Procedimientos para la captación de datos, instrumentos a utilizar y métodos para el control y calidad de estos.}

Los procedimientos que serán utilizados para la recolección de información contemplan: dinámica de grupo focal y entrevista en profundidad. Por lo tanto, los instrumentos elegidos para recopilar la información son: guía de moderador del grupo focal, guía de entrevista, cuestionario y guía de análisis de contenido. Cada una de las actividades tendrá un método específico para proceder con la recopilación de los datos, así como para controlar y validar la calidad de estos. A saber:

\section{a. Dinámica de grupo focal}

La dinámica de grupo focal es una herramienta de investigación cualitativa que consiste en la grabación de un grupo de discusión y la transcripción detallada de las respuestas y de las opiniones, tiene una duración de una 0 dos horas, y es dirigida por un moderador. La técnica proporciona un foro para recabar ideas y comentarios. La gran ventaja de la actividad es la producción de conocimientos (Krueger \& Casey, 2000).

Las discusiones suelen ser grabadas por audio y/o vídeo para garantizar un registro preciso de las interacciones y permitir la identificación de las respuestas. El tamaño de la muestra es pequeña, de 6 a 12 personas; no permite las pruebas o generalizaciones estadísticas, sino más bien una exploración de los temas seleccionados sin forzar las ideas preconcebidas de sus áreas de conocimiento (Clifton \& Handy, 2001).

Por tanto, la captación de opiniones e ideas al respecto del Estudio de la Construcción de los Elementos Caligráficos en el Proceso de Alfabetización de Adultos en la Amazonia Brasileña, será elaborada en una sesión de grupo focal (focus group) con 13 participantes expertos en diseño, se realiza en la Universitat Politècnica de València (UPV), en la sede de la ciudad de Valencia, España, con una duración de $01 \mathrm{~h} 30 \mathrm{~min}$, donde la información será grabada en cinta de audio tape, audio video y documentada por escrito.

Un moderador comandará la actividad, basándose en una guía con información sobre el tema de discusión, presentará la propuesta de estudio, los objetivos, 
Estudio de la construcción de los elementos caligráficos en el proceso de alfabetización de adultos en la Amazonia brasileña

las justificaciones y la estructura planeada para la sesión; igualmente, ilustrará el tema con varias citas y los posibles aspectos relacionados al contexto del objeto investigado.

Los expertos en diseño participan activamente del proceso de discusión, teniendo en cuenta las fortalezas y debilidades del objeto en estudio. Así, los pasos considerados esenciales para la estructuración de la investigación serán descritos por los miembros de la sesión. Al final de la actividad, toda la información será grabada y redactada para su posterior aprobación por los participantes. La Tabla 1 muestra la estructura y el procedimiento adoptados para la práctica de grupo focal aplicada para este estudio.

Tabla 1. Grupo Focal - Estructura y Procedimiento

\begin{tabular}{ll}
\hline Elementos & Dinámica de Grupo \\
\hline Formato & $\rightarrow$ Sesión de Grupo \\
\hline Tamaño & $\rightarrow 13$ participantes \\
\hline Duración & $\rightarrow$ 1h a 1:30h \\
Número de sesión & $\rightarrow 1$ sesión \\
\hline Participantes & $\rightarrow$ Especialistas en Diseño \\
\hline Forma de datos & $\rightarrow$ Conversación \\
\hline Recopilación de datos & $\rightarrow$ Audio tape; \\
& $\rightarrow$ Audio video; \\
& $\rightarrow$ Transcribir \\
\hline Moderador & $\rightarrow$ Profesional de Diseño \\
\hline Información producida & $\rightarrow$ Flexible, pero centrado en el tema \\
& $\rightarrow$ Usa guía de entrevista \\
\hline
\end{tabular}




\section{b. Entrevista en profundidad}

La entrevista en profundidad es también una técnica de investigación cualitativa que implica la realización entrevistas individuales intensivas, con un pequeño número de encuestados para explorar sus puntos de vista sobre una idea, programa o situación (Boyce $\&$ Neale, 2006). Es considerada como una fuente de información no estructurada y directa, que se realiza con cada persona (Malhotra, 2006).

Para este estudio, la entrevista ha sido estructurada con base en la información considerada pertinente por el grupo focal (focus group). Por lo tanto, es importante emplear tiempo y atención al planeamiento de la entrevista, a la selección de los participantes (profesionales relacionados con el tema para el debate) y la preparación de preguntas específicas.

La entrevista en profundidad se llevó a cabo mediante la participación de 31 expertos divididos en tres Grupos (Tabla 2) pertenecientes a las áreas: Pedagogía, Psicología y Diseño.

Tabla 2. Entrevista en profundidad - Expertos

\begin{tabular}{lcll}
\hline Expertos & Cuantidad & Formación & Actuación Profesional en: \\
\hline Grupo 1 & 16 & Pedagogía & Educación de jóvenes y adultos (EJ A) \\
Grupo 2 & 09 & Psicología & Educación de jóvenes y adultos (EJ A) \\
Grupo 3 & 07 & Diseño & Diseño y Docencia \\
\hline
\end{tabular}

Como se trata de una investigación direccionada al Estudio de la Construcción de los Elementos Caligráficos en el Proceso de Alfabetización de Adultos en la Amazonía Brasileña, y dado que el estudio se ha realizado en la Escuela Técnica Superior de Ingeniería del Diseño - ETSID de la Universitat Politècnica de València, en la sede de la ciudad de Valencia/España, se optó por elegir profesionales ubicados en Brasil, más precisamente en Amazonas - todos con experiencia en el tema abordado y la mayoría integrantes de la Secretaria de Educación. De esta manera, los cuestionarios y el consentimiento escrito se prepararon y enviaron a los entrevistados mediante correo electrónico.

c. Procedimientos para garantizar los aspectos éticos de la investigación con suj etos humanos

Los estudios de opinión y de mercado se apoyan en la colaboración voluntaria de las personas y en la confianza que son realizados con toda honestidad y objetividad, sin que las personas entrevistadas sean importunadas o sufran 
Estudio de la construcción de los elementos caligráficos en el proceso de alfabetización de adultos en la Amazonia brasileña

molestias de cualquier índole. Ambos, emplean la recolección y el análisis de la información a través de muestreo, de cuestionarios y otras técnicas apropiadas.

Los procedimientos para la investigación deben, igualmente, ser realizados conforme a los principios de la competencia leal, tal como son generalmente comprendidos y aceptados y según estándares técnicos de alto nivel. Los investigadores de mercado y de opinión deben estar dispuestos siempre a comunicar la información necesaria que permita comprobar la calidad de su trabajo y validez de los resultados.

El público en general, o cualquier otra parte interesada, tiene derecho a que se le garantice que todo estudio de mercado es realizado en estricta conformidad con las disposiciones del Código Internacional de la Asociación Europea de Estudios de Opinión y Mercado (ESOMAR9 de 1976), en cuanto a la protección de su privacidad, son respetados.

\subsubsection{Sobre este contexto, se pretende en esta investigación:}

- Trabajar mediante el anonimato de los entrevistados cumpliendo la norma del artículo 2 del Código de ética que enfatiza lo siguiente $\rightarrow$ Ninguna información que pueda servir para identificar a las personas entrevistadas, sea de forma directa o indirecta, no debe ser divulgada a nadie, a excepción del personal de investigación perteneciente a la organización del investigador que necesita de esta información para la realización y el control de las entrevistas, tratamiento de los datos, etc.

- Considerar los derechos de los entrevistados, conforme artículo $6 \rightarrow$ Todas las precauciones razonables deben ser tomadas a fin de asegurarse que la persona entrevistada y sus familiares no sufrirán ninguna incomodidad o molestia a consecuencia de la entrevista. La persona entrevistada debe estar informada del objeto de la encuesta cuando, por no estarlo, se arriesga a facilitar información que podrían perjudicarlo.

- Presentar los resultados de un estudio, de acuerdo con el artículo 33 $\rightarrow$ El investigador debe hacer una clara distinción entre los resultados propiamente dichos y la interpretación de los mismos, así como de sus recomendaciones - sea de manera escrita, de exposición oral, o de cualquier otra forma. 
1.8.5. Estructura planeada del desarrollo de los artículos para la producción de la tesis por compendio de publicaciones

La producción de los artículos que forman parte del documento de investigación desarrollado de acuerdo con la modalidad "Tesis por compendio de publicaciones" está basada en el siguiente cuadro de actividades abajo identificado (Figura 3).

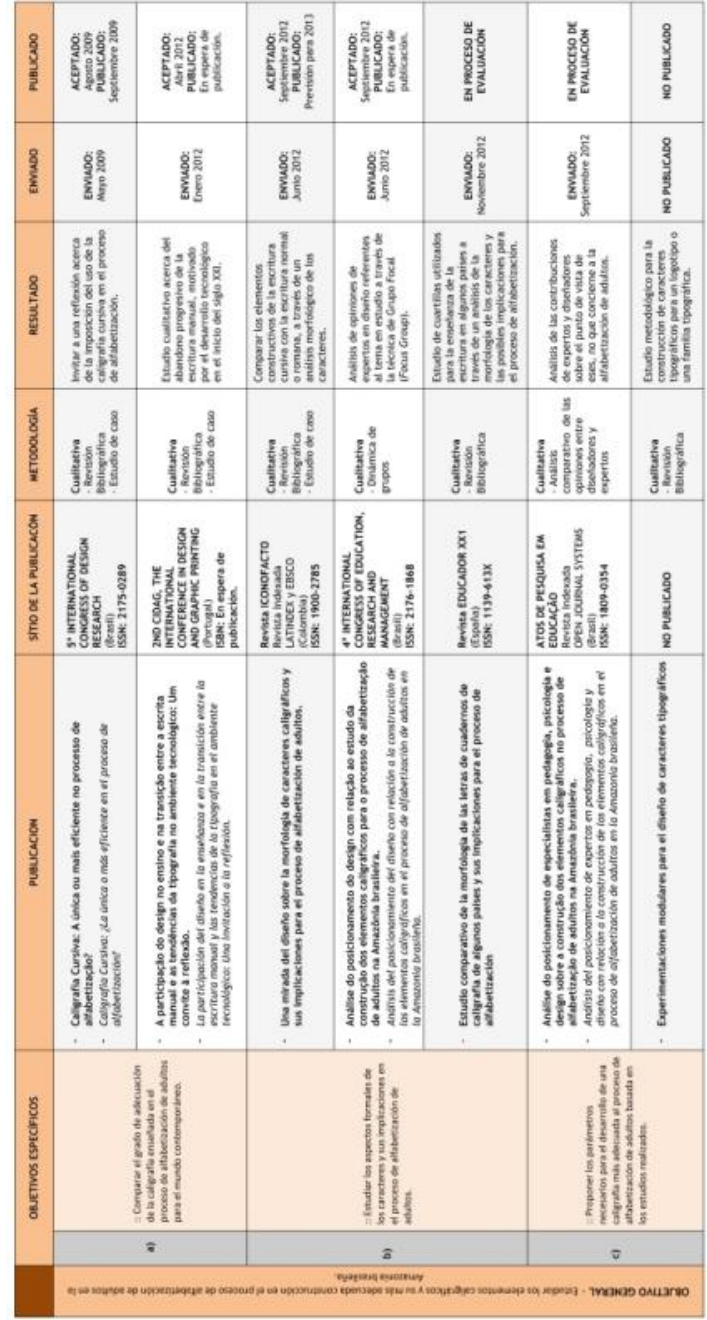

Figura 3 - Cuadro con los objetivos de la tesis.

(Disponible para consulta en los ANEXOS). 
Estudio de la construcción de los elementos caligráficos en el proceso de alfabetización de adultos en la Amazonia brasileña

\subsection{Estructura de la tesis}

El trabajo está dividido en 4 capítulos. El capítulo 1 presenta una introducción, donde son abordados los ítems relacionados: con la motivación del estudio; la contextualización del tema; la identificación del problema; los objetivos de la tesis; las hipótesis; la justificación - centrada en los factores social, pedagógico, económico, ambiental y científico; la delimitación del estudio - basada en los aspectos que involucran: la comparación morfológica entre las letras romanas y cursivas, la opinión de expertos, el registro científico (a partir de los objetivos alcanzados); los materiales y métodos utilizados para el alcance de los objetivos propuestos, los procedimientos adoptados, los instrumentos aplicados para la recolección de datos, los demostrativos y los análisis desarrollados para la obtención de los resultados esperados, las recomendaciones y; por último, la estructura de la tesis.

En el capítulo 2 el Marco Teórico, analiza el estado del arte y cuestiones fundamentales de las caligrafías y su uso en el proceso de alfabetización. Se discute también, acerca de las alternativas caligráficas que ya tuvieran espacio en las propuestas de letras para uso en la alfabetización. Luego, se hace un enfoque de la alfabetización brasileña en el contexto amazónico. El factor tecnológico también es estudiado, principalmente por hacer parte de las frecuentes discusiones sobre su uso en la enseñanza de la escritura. El capítulo finaliza con un análisis de las posibles contribuciones del diseño, no en el contexto pedagógico de las caligrafías, a través de una perspectiva de los estudios relacionados a las tipografías.

En el capítulo 3, se presentan de forma secuencial, los artículos previamente publicados, aceptados y en proceso de evaluación para su publicación y de relación entre sí. Estos fueron trabajados de acuerdo con los objetivos determinados para el desarrollo del estudio y en conformidad con la estructura establecida para la producción de los artículos.

Finalmente, el capítulo 4 presenta la discusión final con una síntesis de los resultados alcanzados en función de los objetivos propuestos, así como las respuestas obtenidas para suplir el problema identificado en el objeto de estudio, las conclusiones generadas y las recomendaciones que se consideran necesarias para el fortalecimiento de la investigación, lo que permite e incentiva la realización de nuevos estudios y futuras líneas de investigación. 


\section{Referencias}

Abramovitz, J., \& Rebello, L. H. (2002). Metodologia do Projeto. Rio de J aneiro - RJ / Brasil: UniverCidade / NPD.

Ackoff, R. (1987). Mission statements. Planning Review, 25 (4).

Aguayo, F. (2002). Metodología del diseño industrial: un enfoque desde la ingeniería concurrente. Madrid - España: Ed Ra-Ma.

Ajuriaguerra, J . (1985). Manual de Psiquiatria Infantil 2. ed. São Paulo: Masson.

Alexander, C. (1964). Notes on the Synthesis of Form. Cambridge: Massachusetts: Harvard University Press.

Ambrose, G., \& Harris, P. (2006). The fundamentals of typography. Laussane: AVA Publishing, SA.

Arenas, G. M., Carlosama, D. C., \& R., A. d. (2004). Importancia de una metodología de investigación y su relación con el diseño y elaboración de un proyecto investigativo de carácter social. Manizales - Colombia: Universidad Nacional de Colombia.

Asimov, M. (1962). Introduction to Design. New J ersey: Prentice-Hall. ASTM - Annual Book of Astm Standart. (1984). ASTM - Annual Book of Astm Standart. Pennsylvania: Wood.

Bailey, K. D. (1992). Methods of Social Research. Nova York, EEUU: McMillan.

Blaxter, L., Hughes, C., \& Tight, M. (2002). Cómo se hace una investigación. Barcelona: Gedisa.

Bomfim, G. A. (1995). Metodologia para o Desenvolvimento de Projetos. J oão Pessoa/ Brasil: Editora Universitária/ UFPB.

Bonsiepe, G. (1983). A Tecnologia da tecnologia. São Paulo - SP/ Brasil: Edgard Blucher.

Bonsiepe, G. (1984). Metodologia Experimental: Desenho Industrial. Brasília: CNPq / Coordenação Editorial.

Bortolanza, J. (1999). Uma contribuição ao planejamento municipal que propicie o desenvolvimento sustentável: 0 uso de indicadores de saúde da população. Florianópolis - SC: Universidade Federal de Santa Catarina - UFSC.

Boyce, C., \& Neale, P. (2006). http:// www. pathfind. org/ site/ DocServer/. Acesso em 05 de Octubre de 2010, disponível em Conducting In-Depth 
Estudio de la construcción de los elementos caligráficos en el proceso de alfabetización de adultos en la Amazonia brasileña

Interview: a guide for designing and conducting In-Depth Interviews for evaluation input. Pathfinder International Tool Series, monitoring and evaluation - 2. USA.

BRIEM, G. (1983). Special issue on calligraphy. Cleveland: Visible Language.

Buxton, B. (2007). Sketching user experience - Getting the design right and the right design. San Francisco: Morgan Kaufman.

Camargo, P. d. , \& Martinelli, S. d. (2006). Educação de adultos: percepções sobre o processo ensino-aprendizagem. Revista Semestral da Associação Brasileira de Psicologia Escolar e Educacional (ABRAPEE), 197-209.

Cardoso, R. (2004). Uma introdução à história do design. São Paulo - SP: Edgard Blücher.

Cinel, N. C. (2003). Disgrafia: Prováveis causas dos distúrbios e estratégias para a correção da escrita. Revista do professor, 19-25.

Clifton, K. J., \& Handy, S. L. (2001). Qualitative Methods in Travel Behaviour Research. . International Conference on Transport Survey Quality and Innovation. South Africa. : Kruger National Park.

Codato, L. A., \& Nakama, L. (2006). Pesquisa em saúde: metodologia quantitativa ou qualitativa? Revista Espaço para a Saúde, v. 8, n.1, p.34-35.

Costa, M. S., Palácio, P. P., \& Paulucci, G. (2005). O uso do computador como meio de inserção na cultura letrada e midiática do jovem ou adulto nos cursos de alfabetização. V Colóquio Internacional Paulo Freire, (pp. 19-22). Recife.

Desmet, P. (2006). Inspire \& Desire. Departamento de Diseño Industrial. Delft University of Technology.

Dincer, O. (2004). Strategy Management and Organization Policy. Istanbul: Beta Publication.

DUL, J ., \& WEERDMEESTER, B. (1993). Ergonomia Prática. São Paulo: Editora Edgard Blücher Ltda.

Dutra, R. M., Sperandio, M., \& Coelho, J . (2003). O Método Ward de Agrupamento de Dados e sua Aplicação em associação com os Mapas AutoOrganizáveis de Kohonen. Florianópolis - SC - Brasil: Universidade Federal de Santa Catarina (UFSC).

Fachin, O. (2001). Fundamentos de metodologia. São Paulo - SP/ Brasil: Saraiva.

Fachin, O. (2006). Fundamentos de Metodologia. 5. ed. São Paulo: Saraiva. 
Faria, J. H. (1992). Tecnologia e Processo de Trabalho. Curitiba - PR/ Brasil: UFPR.

Ferreiro, E. (1999). Psicogênese da Língua Escrita. Porto Alegre: Artes Médicas.

Freire, P. (1979). Coleção Educação e mudança Vol. 1. Rio de janeiro: Paz e Terra.

Freire, P. (1981). Ação cultural para a liberdade. Rio de J aneiro: Paz e Terra.

Freire, P. (1989). A importância do ato de ler: em três artigos que se completam 23 ed. São Paulo: Cortez.

Frutiger, A. (2001). Sinais e Símbolos: desenho, projeto e significado. São Paulo: Martin Fontes.

García-Vera, A. B. (2000). Tres temas tecnológicos para la formación del profesorado. Revista de Educación, 322, pp. 167-188.

Gerencia y Negocios en HispanoAmérica. (2011). Investigacion de mercado. Acesso em 16 de agosto de 2011, disponível em degerencia.com: http:// www. degerencia.com/tema/ investigacion_de_mercado\#articulos Ghiso, A. (2001). Sistematización de experiencias en Educación popular. Memorias Foro: Los contextos actuales de la educación popular. Medellín: Memorias Foro.

Gil, A. C. (1991). Como Elaborar Projetos de Pesquisa 3 ed. São Paulo: Atlas.

Gil, A. C. (2002). Como elaborar projetos de pesquisa. 4a ed. São Paulo: Atlas.

Heidegger, M. (1984). La pregunta por la técnica. Conferencias y artículos Ediciones del Serbal, pp. 9-37.

Heitlinger, P. (2006). Tipografia: origens, formas e uso das letras. Lisboa: Dinalivro.

Higounet, C. (2003). História Concisa da Escrita. São Paulo: Parábola Editorial.

IBGE. (2 de Fevereiro de 2007). IBGE - Instituto Brasileiro de Geografia e Estatística. Acesso em 10 de Maio de 2012, disponível em IBGE:

http:// www. ibge.gov. br/ home/ estatistica/ populacao/ condicaodevida/ indica doresminimos/ sinteseindicsociais2007/indic_sociais2007.pdf.

lida, I. (1992). Ergonomia, projetos e produção. São Paulo - SP/ Brasil: Edgar Blücher Ltda. 
Estudio de la construcción de los elementos caligráficos en el proceso de alfabetización de adultos en la Amazonia brasileña

J ury, D. (2007). O que é a Tipografia? 0 que é a Tipografia? Barcelona, Barcelona, Espanha: Gustavo Gili.

Krueger, R. A., \& Casey, M. A. (2000). Focus group: a practical guide for applied research. California: Sage Publications.

Krueger, R. A., \& Casey, M. A. (2000). Focus Groups. A Practical Guide for Applied Research. Thousand Oaks, CA: Sage Publications.

Krueger, R. A., \& Casey, M. A. (2000). Focus groups: A practical guide for applied research. . California: Thousand Oaks, Calif.: SAGE Publications.

Kuhn, R. L. (1993). Generating Creative and Innovation in large Bureaucracies. United States: Quorum Books.

Kurtgozu, A. (2003). From function to emotion: a critical essay on the History of design arguments. The Design J ournal, 6(2):45-49.

Lakatos, E. M., \& Marconi, M. d. (2001). Metodologia do trabalho científico: procedimentos básicos, pesquisa bibliográfica, projeto e relatório,

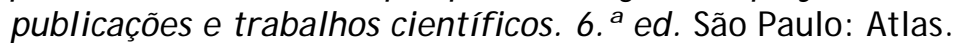

Lohr, S. (2000). Muestreo, diseño y análisis. México: Ed. Thomson.

Malhotra, N. K. (2006). Pesquisa de marketing. Porto Alegre - Brasil: Bookman.

Malhotra, N. K. (2006). Pesquisa de marketing. 4a ed. Porto Alegre: Bookman.

Marconi, M. A., \& Lakatos, E. M. (2006). Fundamentos de metodologia cientifica. . São Paulo: Atlas.

Martínez, J. A., \& Martínez, L. (2006). El Factor de Imprecisión sobre la Escala de Medida (FIEM) en la estimación de medias en un muestreo aleatorio simple. Investigación y Márketing, 92, 66-70.

Martins, R. F., \& Merino, E. (2008). A gestão de design como estratégia organi-zacional . Londrina - PR/ Brasil: Universidade Estadual de Londrina.

Mediavilla, C. (2001). Caligrafía: Del Signo Caligráfico a la Pintura Abstracta. Caligrafía: Del Signo Caligráfico a la Pintura Abstracta. Valencia, Valencia, España: Campgràfic.

Miguel Fernández, E. d. (2005). Introducción a la Gestión (Managment). Valencia: Editorial de la UPV.

Montesinos, J. L., \& Hurtuna, M. M. (2007). Manual de tipografía: del plomo a la era digital. Valencia: Campgràfic Editors. 
Moura, M. (2003). O Design de Hipermídia. Tese Doutorado não publicada em Comunicação e Semiótica. São Paulo - SP/ Brasil: Pontifícia Universidade Católica de São Paulo .

Olivier, F. S. (20 de Abril de 2009). Analfabetismo. Acesso em 25 de Marzo de 2012, disponível em Historia de los Medios:

http:// historiamedios1y2primavera2009. blogspot.com.es/2009/ 04/ analfabetis mo.html

Pacheco, A., Pacheco, K., \& Ortuño, B. (2009). Caligrafia Cursiva: A única ou mais eficiente no processo de alfabetização? 5. o Congresso Internacional de Pesquisa em Design - ISSN 2175-0289, (pp. 770-778). Bauru.

PROMEAPI. (2007). Programa Municipal de Escolarização do Adulto e da Pessoa Idosa - PROMEAPI. PROMEAPI. Manaus, Amazonas, Brasil.

Pujol, M. F. (1992). Documentação e informação científica: metodologia de intelectuais e científicas. Barcelona : PEIS-PPU .

Rocha, C. (2002). Projeto Tipográfico: Análise e produção de fontes digitais. São Paulo: Rosari.

Rumj anek, L. (2008). 8o Congresso Brasileiro de Pesquisa e Desenvolvimento em Design, 8 a 11 de outubro de 2008. São Paulo.

SME, S. M. (2010). Caderno de orientações didáticas para EJ A - Alfabetização: etapas. Manual EJ A. São Paulo, São Paulo, Brasil: Secretaria Municipal de Educação. Diretoria de Orientação.

Swann, C. (2002). Action Research and the Practice of Design. Design Issues, Vol.18, No.2, 49- 61.

Tripodi, T., Fellin, P., \& H., M. (1975). Análise da Pesquisa Social . Rio de J aneiro - RJ / Brasil: Francisco Alves Editora S.A.

Trochim, W. \& Donnelly, J. (2007). The Research Methods Knowledge Base. 3rd edition. Mason: Thomson Publishing.

Vasconcelos, F. C., \& Cyrino, A. B. (2000). Vantagem Competitiva: os modelos teóricos atuais e a convergência entre estratégia e teoria organizacional. RAE

- Revista de Administração de Empresas, v. 40, n. 4, p. 20-37. 



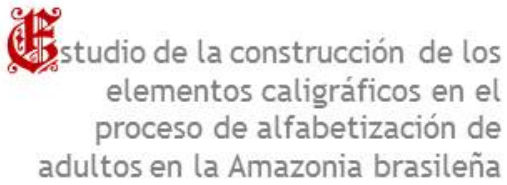
elementos caligráficos en el adultos en la Amazonia brasileña

\section{㷛apítulo 2}

\section{MARCO TEÓRICO}

2.1. Enfoque de la alfabetización entre niños y adultos

2.2. La relación entre leer y escribir

2.3. La escritura escolar en Brasil

2.4. La busca por nuevas alternativas de escritura 



\section{Marco teórico}

\subsection{Enfoque de la alfabetización entre niños y adultos}

El concepto de analfabetismo se define por la Organización para la Educación, la Ciencia y la Cultura de las Naciones Unidas (UNESCO) como "aquella que está incapacitada para leer y escribir una breve frase sobre su vida cotidiana". Algunos autores especulan que esta incapacidad, en un principio se dio debido a que no estaba permitido que el pueblo supiera leer o escribir; esta tarea era reservada a los monjes escribas, personas que dedicaban su vida a esto (Olivier, 2009). Las acciones gubernamentales de los países contra el analfabetismo, tienen como principal foco de actuación el grupo infantil; a pesar de esto, las cifras mundiales de niños sin escolarizar son muy altas. Actualmente, más de la mitad se concentran en un grupo de 15 países (Figura 4), en su gran mayoría, en Bangladesh, Etiopía y Níger las cuales se clasifican como naciones de bajos ingresos; no obstante, existen países de ingresos medios, como Brasil y Nigeria, que se destacan dentro de este grupo (UNESCO 2011).

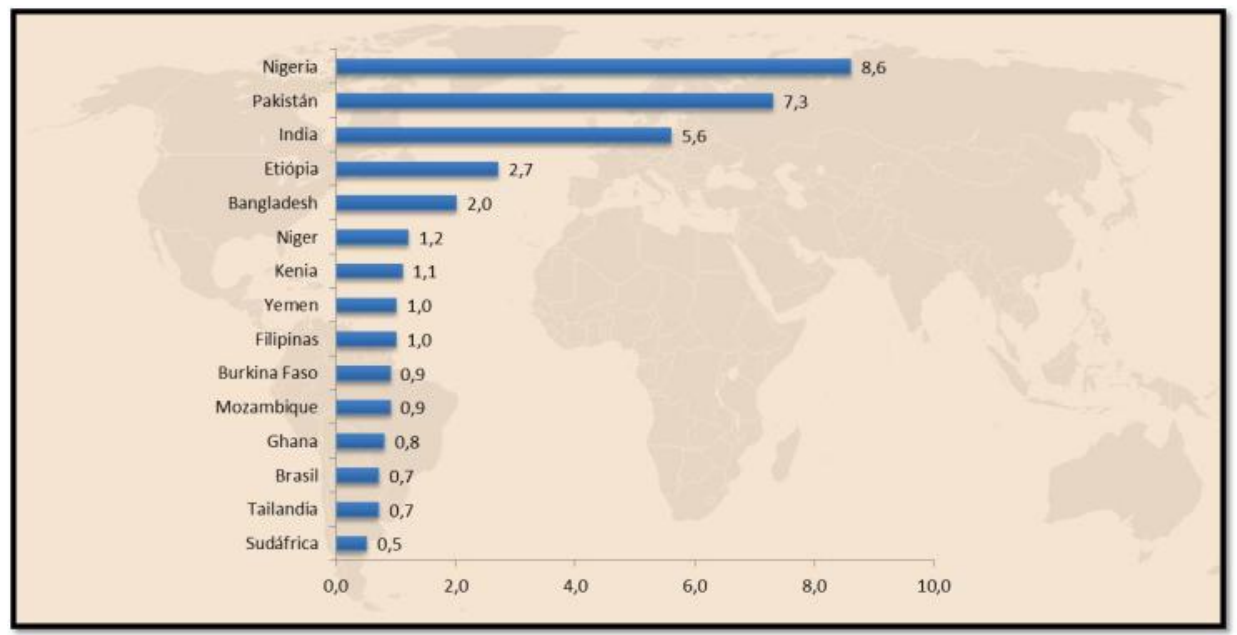

Figura 4 - Número de niños sin escolarizar (en millones).

Fuente: adaptado de (UNESCO, 2011).

En relación con los adultos, las cifras de analfabetismo son más altas. El Informe de Seguimiento de la Educación para Todos (UNESCO, 2011) señaló que en 2008 poco menos de 796 millones de adultos carecían de las habilidades básicas de alfabetización, esto equivale a aproximadamente un 
Estudio de la construcción de los elementos caligráficos en el proceso de alfabetización de adultos en la Amazonia brasileña

$17 \%$ de la población adulta en el mundo, la mayoría de estos adultos habitan en un grupo de diez países, entre los que se encuentra Brasil.

Las cifras presentadas son importantes para reflexionar sobre el punto de vista que la alfabetización representa para un niño y para un adulto ser analfabeta; un niño es llevado a la escuela para comenzar su integración social y recibir las enseñanzas necesarias para convertirse en un ciudadano. Por otro lado, el adulto analfabeta se encuentra en esta condición por varios factores sociales y, a menudo, tienen la necesidad de regresar a la escuela para mejorar su nivel funcional dentro de una empresa o conseguir un trabajo para mantener a su familia.

\subsubsection{Aspectos sociales e históricos de la alfabetización de adultos}

Un estudio de la UNESCO en Brasil sobre alfabetización discurre que las primeras políticas públicas brasileñas dirigidas a alfabetización de jóvenes y adultos se llevaron a cabo a partir de 1947, cuando fue estructurado el Servicio de Educación de Adultos del Ministerio de la Educación y comenzó a Campaña de Educación de Adolescentes y Adultos (CEAA). Durante este período, muchos países de América Latina, Asia y África, celebraron distintas campañas, siguiendo recomendaciones de la recién creada UNESCO que valorizó la alfabetización de adultos como medio de difusión de los valores democráticos y el desarrollo de los países atrasados, corroborando la idea de que la alfabetización produzca en el individuo su inserción en la vida cívica, capacitación laboral y aumento de la productividad, parámetros esenciales para el proyecto de desarrollo en el que muchos países estaban ocupados en ese momento posterior a la segunda guerra.

\subsection{La relación entre leer y escribir}

Según Teles (2012), la interrelación entre las actividades lingüísticas de la lectura y la escritura tiene un grado de dependencia mutua. Citando a Chomsky, la autora destaca que el lenguaje hablado es mucho más antiguo que la escritura, es decir, existe una en los seres humanos para el lenguaje oral, sin embargo, no todos los lenguajes orales tienen formas del lenguaje escrito.

Para Shaywitz (2003) la competencia del lenguaje escrito es muy reciente en la historia humana, es un producto de la evolución histórica y cultural, no forma parte del patrimonio genético de la humanidad; como consecuencia, no existe en el cerebro humano un módulo específico para la lectura. Desde el punto de vista ontogenético, el lenguaje hablado precede al lenguaje escrito, Bueno (2012) explica que un niño aprende a escribir cuando las letras dejan de tener el peso de las palabras que quieren significar y el tiempo para eso es 
del tamaño de la escuela primaria. Los niños aprenden las primeras palabras en torno a los doce meses de edad, y empiezan a aprender a leer, alrededor de cinco o seis años, cuando empiezan la escolarización (Castro, S.L. \& Gomes, I. 2000 citado por Teles 2012).

En la comparación del acto de hablar con el de escribir Teles (2012), destaca también que el lenguaje hablado es adquirido de forma natural, surge de una predisposición biológica del ser humano. El hablar se aprende casi que instintivamente, sin educación formal, explícito, mientras que la lengua escrita es una invención humana, no sigue un proceso biológicamente determinado, utiliza códigos específicos para representar lo que habla. Estos códigos no se aprenden naturalmente, deben ser explícitamente enseñadas de una manera formal.

\subsubsection{Grafía o caligrafía: una dicotomía más que etnológica}

Según la Real Academia Española (RAE), Grafía es el modo de escribir o representar los sonidos, y, en especial, empleo de tal letra o tal signo gráfico para representar un sonido dado. Caligrafía es conceptuado por la RAE como el arte de escribir con letra bella y correctamente formada, según diferentes estilos. Para Mediavilla (1996), una definición contemporánea de la práctica de la caligrafía es "el arte de escribir bello", según el autor, la caligrafía abarca desde creaciones completamente utilitarias hasta magníficas obras de arte donde la expresión abstracta puede (o no) adquirir más importancia que la legibilidad de las letras. Por estos conceptos, la caligrafía va un poco más allá que la grafía pero, en el área de la educación, ocurre mucha confusión y los significados de estas dos palabras son interpretados como sinónimos.

En países como Estados Unidos e Inglaterra, Calligraphy y Handwriting son campos distintos, pero interdisciplinarios. Mientras que Calligraphy está relacionada con la técnica de la escritura adornada, Handwriting es relacionada con el estudio de la escritura diaria humana (Fetter, 2010).

En la década de 1920 en Brasil, la escritura era comprendida a veces como un fin, otras veces como un medio de obtener una buena escritura escolar. Los significados como el arte o la técnica, de los términos "caligrafía y escritura", se encontraban superpuestos. El arte se relaciona con los valores estéticos de la ornamentación, esenciales para lograr la belleza, característica de la caligrafía y del arte de los calígrafos. Dado que la técnica estaba relacionada con la forma de escribir. Muy a menudo las defensas de determinados modelos caligráficos (vertical o inclinado) se utilizaban del término escritura en lugar de caligrafía. Además de la defensa de un modelo en particular, los discursos de la época defendían la metodología que se emplearía en la enseñanza de la 
Estudio de la construcción de los elementos caligráficos en el proceso de alfabetización de adultos en la Amazonia brasileña

escritura y la lectura en Brasil (Esteves, 2000). Hasta hoy no existe en Brasil un consenso acerca de esta nomenclatura.

\subsection{La escritura escolar en Brasil}

Según Gvirtz \& Vidal (1998), a principios del siglo XX los programas de enseñanza, en Brasil, adoptaban la caligrafía americana, o inclinada, como la más adecuada para el trabajo escolar. Años más tarde, la misma caligrafía se convirtió en tema de muchas críticas y fue señalado como una de las causas de los problemas de miopía y la escoliosis, que tenían los estudiantes (Vidal, 1998). Durante este período, la pedagogía comenzó a producir estudios que trataban de incorporar los avances en el campo de la salud y la higiene; reglas que comenzaban a ser adoptadas en la enseñanza, como por ejemplo: la posición correcta del papel del estudiante, cómo sostener el lápiz, el tamaño correcto de las carteras, etc.

Motivado por las críticas, el gobierno brasileño, según Vidal (2000), adoptó la fórmula de George Sand (papel derecho o vertical, el cuerpo derecho, la escritura derecha), los educadores eligieron la dicha caligrafía en defensa de la escritura vertical. El tipo caligráfico nuevo se presentaba como el más adaptado a los signos de la modernidad, así como rápido, económico e higiénico. Este nuevo tipo de letra, de característica vertical permite la correcta posición del alumno durante el acto de escribir, evitando deformaciones causadas al cuerpo por el uso de letras inclinadas u oblicuas (Gvirtz \& Vidal, 1998).

La escuela primaria en Brasil ya contaba con las condiciones para la difusión de la escritura, mientras que los actos de lectura y escritura comenzaron a ser enseñado de forma simultánea. En ese momento, la enseñanza de la escritura se basa en las teorías de la educación y la enseñanza de Europa y Estados Unidos, la escritura inclinada fue la más extendida en el país, con énfasis en dos subtipos principales: la letra Inglesa y la derivada del método Spencer Americano (Gvirtz \& Vidal, 1998). Para Vilella (2009), la escritura Spencer fue desarrollada, básicamente, en dos grandes grupos. En primer lugar, originando formas más adornados y elaborados, que se tornó conocido como el Ornamental Penmanship, destinado a explorar las capacidades artísticas de un calígrafo, utilizada normalmente en la producción de materiales de promoción. Esta escritura encarnaba la esencia del espíritu americano, que fue exportado a todo el mundo en el clásico logotipo de la Coca-Cola (Figura 5). El sistema de Spencer fue el principal sistema adoptado por las escuelas públicas en los Estados Unidos. Spencer es conocido hasta hoy por el título de "El hombre que enseñó a América a escribir" (Henning, 2002). 


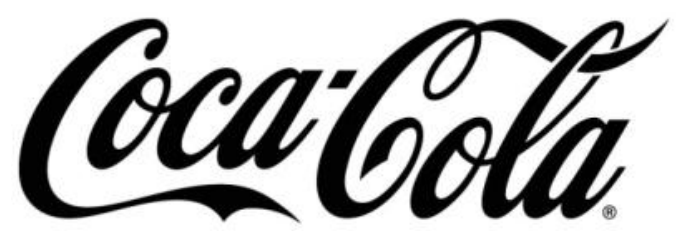

Figura 5 - Logotipo de la Coca-Cola.

Es importante destacar que el modelo de escritura vertical o redonda está estrechamente relacionado con una letra francesa conocida como "ronde" (redonda), que es, en su origen histórico, una letra formal vertical (o derecha). En este contexto, es comprensible que esa letra fuera considerada como una especie de "cura de los males", ya que se creía que los problemas de salud fueron causados por el uso de la letra inclinada, derivada de los modelos caligráficos angloamericanos. En poco tiempo, incluso en Gran Bretaña y Estados Unidos, la letra vertical fue adoptada y, sin embargo, fue desarrollado un modelo llamado "vertical writing".

El nuevo estilo caligráfico, que se presentaba como rápido, económico e higiénico, rescataba valores como la sencillez y la facilidad de lectura, además establecía un padrón entre la escritura de la escuela al texto producido por la máquina de escribir, proporcionando una regularización de la letra manual. El modelo de letra vertical era el único capaz de preparar a los estudiantes para la práctica de la escritura eficiente y fácil de leer, fundamentales al trabajo en el comercio y también en la industria (Faria Filho, 1998).

\subsubsection{Alfabetización de adultos y el formato de las letras}

El formato ideal de las letras a utilizar en el proceso de alfabetización de adultos tal vez pase por una simplificación de la forma, o sea, utilizar caracteres con aspectos lineales, sin modulación, resultado de la mezcla de líneas verticales, horizontales, diagonales, arcos y circunferencias como ya pudo observarse en líneas anteriores.

Un estudio de la forma de los caracteres mayúsculos centrado en los elementos de la ergonomía puede contener los ingredientes necesarios para identificar el camino a seguir en la búsqueda del formato ideal de las letras.

Los múltiples estudios centrados principalmente en medir la legibilidad, presentan varios parámetros tipográficos como: diseño de las letras, tamaño del cuerpo, espacio entre líneas, letras y palabras. La relación entre lo que el alumno escribe a mano y lo que lee en su entorno, es muy importante en 
Estudio de la construcción de los elementos caligráficos en el proceso de alfabetización de adultos en la Amazonia brasileña

cuanto al análisis de las letras, principalmente en lo que concierne a la legibilidad.

Los primeros estudios y discusiones sobre los factores que afectan a la facilidad y la velocidad de lectura son agrupados bajo el término legibilidad que se empleó (Rumjanek, 2008) y hace referencia al reconocimiento de los caracteres individuales que ocurren en la lectura. Sin embargo, según la autora, solamente a partir de 1940, algunos estudiosos en el tema pasaron a utilizar el término lecturabilidad (readability) pues parecía un término más amplio y más significativo.

Según Tracy (2003), la legibilidad se refiere a un asunto de percepción, y su medida es la velocidad con que se reconoce un caracter. Si el lector se confunde entonces el caracter está pobremente diseñado. La lecturabilidad se relaciona con la comprensión, y su medida es el lapso de tiempo en que el lector puede permanecer en un bloque de texto sin cansancio.

Legibilidad y lecturabilidad son dos aspectos funcionales de un diseño tipográfico, aunque la tipografía es más que función. Ciertas tipografías pueden resultar muy familiares, pero inoperantes en espacios de lectura con exigencias o limitaciones técnicas; Garamond en pantalla es un buen ejemplo. Junto al aspecto funcional se encuentra también el aspecto estético, y la responsabilidad del diseñador está en equilibrar ambas situaciones (Tracy 2003).

\subsubsection{El diseño y la tipografía para la enseñanza}

A diferencia de lo que ocurre en países como Inglaterra y Estados Unidos, donde los modelos de escritura escolar son analizados en un contexto multidisciplinar y creados por profesionales del diseño, de los campos de la caligrafía comercial, rotulación, tipografía y escritura manual, en Brasil son pocas las propuestas de modelos de escritura desarrollados por diseñadores.

Acerca de esto, Rumjanek (2009) señala el trabajo desarrollado en Brasil por el tipógrafo Tony de Marco, que creó la tipografía Kindergarten (Figura 6), respetando la tradición de los libros brasileños de enseñanza de la escritura. El objetivo del tipógrafo fue facilitar la producción de materiales de enseñanza, libros y folletos, llevadas a cabo por los editores y colegios del país. 


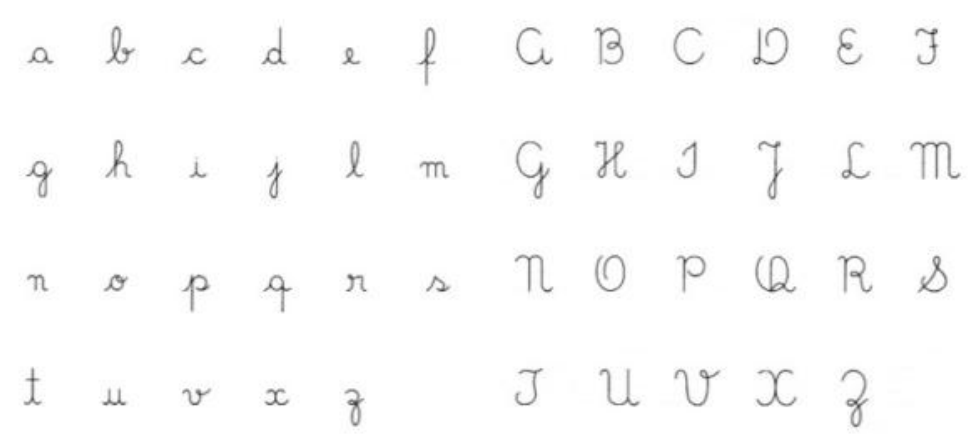

Figura 6 - Tipografía Kindergarten.

Como se ha señalado, la fuente sigue el modelo tradicional de la escritura cursiva vertical, muy popular y ampliamente utilizado en el país, desde la década de 1940, en folletos como "Caminho Suave", desarrollado por la educadora Branca Alves de Lima.

La búsqueda de soluciones de uso general para la tipografía con posibles usos en la enseñanza se remonta a la época de la Bauhaus. En 1925, Herbert Bayer presentó la sturm blond (Figura 5), también Ilamado Alfabeto Universal. Un conjunto de letras sin modulación y de palo seco, estructuradas solamente con el uso de formas geométricas simples para la construcción de todos los tipos (Montesinos y Hurtuna, 2007). Para Heitlinger (2007), la estrategia reduccionista de Bayer ignoraba el uso de mayúsculas, ya que la sturm blond tenía solamente minúsculas; el argumento fue que la palabra hablada no distingue entre mayúsculas y minúsculas y esta reducción podría facilitar el aprendizaje de la lectura en la escuela primaria además de ahorrar espacio de almacenamiento para los tipógrafos, ya que sólo usarían las cajas bajas.

\section{abcoefghi jklmnopqr sTUVwxyz}

Figura 7 - Tipografía sturm blond de Herbert Bayer. 
Estudio de la construcción de los elementos caligráficos en el proceso de alfabetización de adultos en la Amazonia brasileña

Otra iniciativa interesante discutida por Rocha (2003) es el trabajo del diseñador Bradbury Thompson. Mediante la observación de la dificultad de su hijo con la confusión de símbolos duplicados en la composición de las mismas palabras en un libro para niños, Thompson creó en 1950, el alfabeto 26 (Figura 3). La propuesta era hacer el alfabeto latino desde bicameral a unicameral, es decir, solamente un símbolo (constante) para representar las letras mayúsculas y minúsculas como en los alfabetos árabe y hebreo.

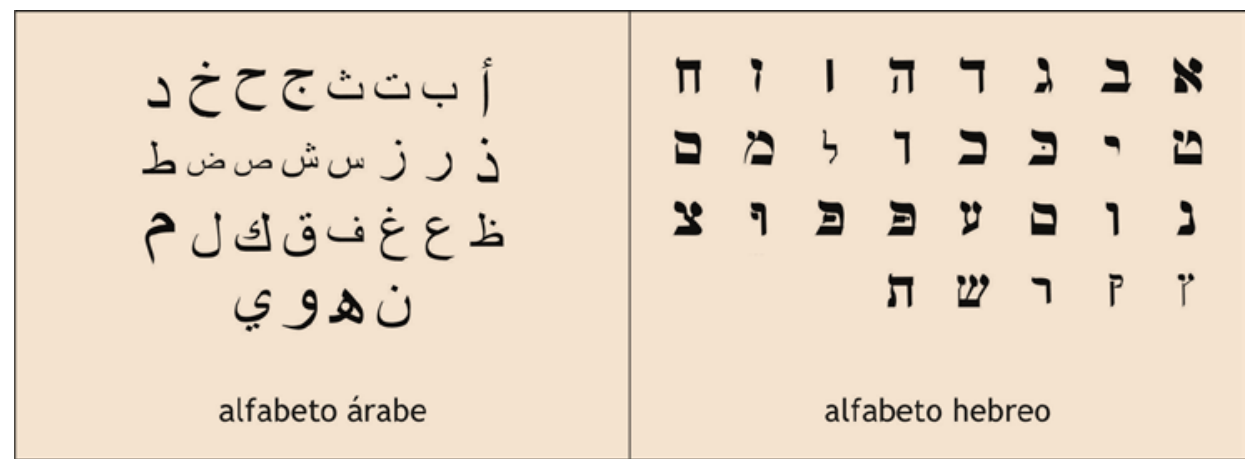

Figura 8- los alfabetos unicamerales árabe y hebreo.

Thompson imaginaba que, bajando a sólo 26 el número de caracteres del alfabeto para ser usado en la escritura, iba facilitar el proceso de la cognición de los niños, pero ello no consideraba otros aspectos que son importantes para la percepción del texto escrito y la velocidad de lectura, como es el caso de las astas ascendentes y las descendentes, la variación de las letras en cursiva (la letra "a" cambia en este formato para evitar cualquier deformación) y otros aspectos técnicos inherentes a la tipografía, su uso y la percepción. 


\section{aBCDe \\ FGHIJK \\ LmnOP \\ QRSTU \\ VWXY}

Figura 9 - Alphabet 26

\subsection{La búsqueda de nuevas alternativas de escritura}

\subsubsection{Sassoon Primary}

Rosemary Sassoon, diseñadora de la familia de fuentes Sassoon, investigó la forma en que los niños perciben las formas de las letras y consideró sus opiniones para desarrollar una familia tipográfica.

50 niños consultados sobre la legibilidad de 4 tipos de fuentes tipográficas: Times Roman, Times Itálica, Helvética y un tipo de fuente de palo seco.

El resultado de la búsqueda ha influido en algunas decisiones en el diseño de la fuente Sassoon Primary, como por ejemplo una pequeña inclinación para combinar legibilidad y, lo que calificó de "amistad" en el diseño de las letras, preferencia por el diseño de palo seco humanista mezclado con pequeños terminales en la línea de base como se fuera los terminales de unión típicos de las cursivas (Heitlinger, 2006), como se puede ver en la Figura 9.

\section{ABCDEFGGHIIJJKLMN OPQRSTUVWXYZÀÅÉĨ̃ $\varnothing U ̈ a b c d e f f g h i j k k l m n o p$ qqrstuvwxyzàåéîõøü\& $123445678990\left(\$ E_{.,}, ?\right)$}

Figura 10 - tipografia Sassoon Primary. 
Estudio de la construcción de los elementos caligráficos en el proceso de alfabetización de adultos en la Amazonia brasileña

\subsubsection{El proyecto Kidstype}

Sue Walker y Linda Reynolds, del Departamento de tipografía y Comunicación Gráfica de la Universidad de Reading, muestra en su trabajo, la necesidad de más investigación sobre la tipografía para los niños. Por ejemplo, no existen estudios que demuestren se las fuentes con remates o de palo seco son más legibles.

Según ellos, los maestros en general, tienden a preferir las fuentes de palo seco porque tienen formas más simples. Sin embargo, los niños encuentran una gran variedad de tipos en su vida cotidiana y que rara vez se preguntó a ellos acerca de lo que piensan en relación a las letras de los libros que leen.

En sus estudios, hicieron algunas pruebas que compararon el número de errores que los niños hacían en la lectura de textos compuestos con las tipografías Century (con remates) y Gill (palo seco). Llegaron a la conclusión de que la diferencia en el rendimiento de lectura entre estas fuentes es significantemente pequeña. Según los resultados de la investigación, es más importante elegir fuentes que tengan diferencias evidentes entre caracteres tales como 'o', 'a' y 'g' (Figura 10). La fuente de la Educación Gill tiene esta calidad, pero no ocurre lo mismo con las fuentes Avant Garde Gothic o Helvética.

\begin{tabular}{|l|c|}
\hline \multicolumn{2}{|c|}{ DIFERENÇA ENTRE CARACTERES } \\
\hline Gill Educational & Tipografia \\
\hline Avant Garde & Tipografia \\
\hline Helvética & Tipografia \\
\hline
\end{tabular}

Figura 11 - diferença entre caracteres.

\subsubsection{Una experiencia estadunidense}

School Fonts for Beginning Writing (fuentes escolar para empezar a escribir), esta fuente diseñada por Kim Voss (de la empresa norte-americana Ashley's Mom Inc.) y publicado por Mayer-J ohnson LLC, es una colección de 13 fuentes que se utilizarán en el material didáctico en los Estados Unidos (Heitlinger, 2006).

Las fuentes se venden en versiones para las plataformas Windows y Mac. Doce fuentes se ofrecen en versiones dashed (puntillada), aptos para que los niños 
aprendan a dibujar las letras. Este modelo también ofrece una variedad de tipografía fuera del contexto de escritura cursiva, huyendo del estándar habitual (figura 11).

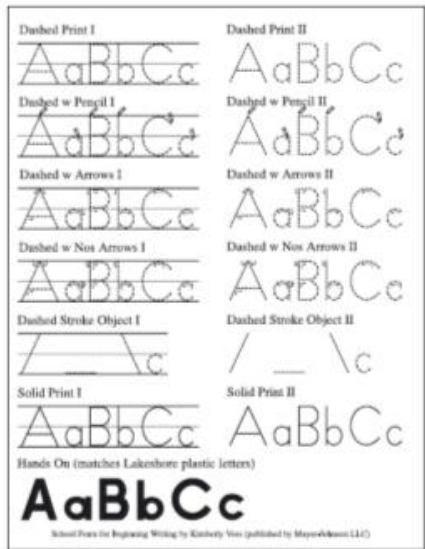

Figura 12 - tipografía School Fonts for Beginning Writing.

\subsubsection{La tipografía chilena Cotona}

Un ejemplo interesante de América del Sur es el caso chileno de los tipógrafos de la Tcl que, sobre la base de la experiencia adquirida con el desarrollo de Tcl fuente Lila, elaborado por Tono Rojas y Kote Soto para la Editora Marenostrum, en 2004, resolvieron hacer una revisión y optimización del diseño, mejorando diversos aspectos que añaden funcionalidad al tiempo que satisface las normas establecidas por el Ministerio de Educación de Chile. Aspectos de la inclinación, las proporciones y la lógica de conexión entre las letras, se optimizaron. Fueran desarrollados, por los expertos de Chile, nueve conjunto de fuentes, que fueron puesto en el mercado con el nombre Cotona Tcl. A pesar de que han cumplido con los requisitos del gobierno, la tipografía Tcl Cotona mantiene la estructura formal de la letra cursiva básica sin hacer ninguna contribución técnica además de que ya existe en el campo de la escritura escolar. Lo que parece es que el desarrollo de la fuente tiene una aplicación más direccionada para la industria gráfica de los libros escolares que una experimentación con objetivo de ayudar a encontrar el camino de una escritura más adecuada a la enseñanza de la escritura. La figura 12 presenta un ejemplo de la Tlc Cotona y sus rasgos más acerca de una escritura infantil que una alternativa caligráfica para el aprendizaje. 
Estudio de la construcción de los elementos caligráficos en el proceso de alfabetización de adultos en la Amazonia brasileña

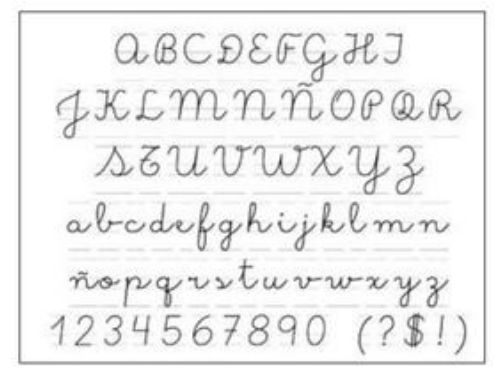

Figura 13 - tipografia Tcl Cotona.

Los ejemplos presentados son pruebas de la existencia de varios estudios y planteamientos desarrollados para la escritura de niños, sin embargo los adultos son olvidados en ese proceso. Muchas son las dudas que afligen los profesores que trabajan con la educación de adultos, principalmente en lo que concierne a la enseñanza de la escritura. En el próximo capítulo son presentadas varias publicaciones acerca de la relación del adulto iletrado e la enseñanza de la escritura, con el objetivo de fomentar la construcción de referencial teórico y plantear las posibles contribuciones del diseño en este contexto. 


\section{Referencia}

Ajuriaguerra, J . (1985). Manual de Psiquiatria Infantil 2. ed. São Paulo: Masson.

Asimov, M. (1962). Introduction to Design. New J ersey: Prentice-Hall. ASTM - Annual Book of Astm Standart. (1984). ASTM - Annual Book of Astm Standart. Pennsylvania: Wood.

Bailey, K. D. (1992). Methods of Social Research. Nova York, EEUU: McMillan. Blaxter, L., Hughes, C. \& \& Tight, M. (2002). Cómo se hace una investigación. Barcelona: Gedisa.

Bomfim, G. A. (1995). Metodologia para o Desenvolvimento de Projetos. J oão Pessoa/ Brasil: Editora Universitária/ UFPB.

Bonsiepe, G. (1983). A Tecnologia da tecnologia. São Paulo - SP/ Brasil: Edgard Blucher.

Bonsiepe, G. (1984). Metodologia Experimental: Desenho Industrial. Brasília: CNPq / Coordenação Editorial.

BRIEM, G. (1983). Special issue on calligraphy. Cleveland: Visible Language. Camargo, P. d., \& Martinelli, S. d. (2006). Educação de adultos: percepções sobre o processo ensino-aprendizagem. Revista Semestral da Associação Brasileira de Psicologia Escolar e Educacional (ABRAPEE), 197-209.

Cardoso, R. (2004). Uma introdução à história do design. São Paulo - SP: Edgard Blücher.

Cinel, N. C. (2003). Disgrafia: Prováveis causas dos distúrbios e estratégias para a correção da escrita. Revista do professor, 19-25.

Costa, M. S., Palácio, P. P., \& Paulucci, G. (2005). O uso do computador como meio de inserção na cultura letrada e midiática do jovem ou adulto nos cursos de alfabetização. V Colóquio Internacional Paulo Freire, (págs. 19-22). Recife.

DUL, J ., \& WEERDMEESTER, B. (1993). Ergonomia Prática. São Paulo: Editora Edgard Blücher Ltda.

Ferreiro, E. (1999). Psicogênese da Língua Escrita. Porto Alegre: Artes Médicas.

Fiell, C., \& Fiell, P. (2001). Design do século XX. Lisboa - Portugal: Taschen. 
Estudio de la construcción de los elementos caligráficos en el proceso de alfabetización de adultos en la Amazonia brasileña

Freire, P. (1979). Coleção Educação e mudança Vol. 1. Rio de janeiro: Paz e Terra.

Freire, P. (1981). Ação cultural para a liberdade. Rio de J aneiro: Paz e Terra.

Freire, P. (1989). A importância do ato de ler: em três artigos que se completam 23 ed. São Paulo: Cortez.

Frutiger, A. (2001). Sinais e Símbolos: desenho, projeto e significado. São Paulo: Martin Fontes.

García-Vera, A. B. (2000). Tres temas tecnológicos para la formación del profesorado. Revista de Educación, 322, pp. 167-188.

Gerencia y Negocios en HispanoAmérica. (2011). Investigacion de mercado. Recuperado el 16 de agosto de 2011, de degerencia.com:

http:// www.degerencia.com/ tema/ investigacion_de_mercado\#articulos

Ghiso, A. (2001). Sistematización de experiencias en Educación popular. Memorias Foro: Los contextos actuales de la educación popular. Medellín: Memorias Foro.

Heidegger, M. (1984). La pregunta por la técnica. Conferencias y artículos Ediciones del Serbal, pp. 9-37.

Heitlinger, P. (2006). Tipografia: origens, formas e uso das letras. Lisboa: Dinalivro.

Hernandis, B. (2003). Tesis Doctoral: Desarrollo de una metodología sistémica para el diseño de productos industriales. Valencia - España: Universidad Politécnica de Valencia - UPV.

Hernandis, B., \& Bonmatí, J . (16 de enero de 2008). El diseño coherente la correcta definición del producto - ler Encuentro Interinstitucional de Diseño Industrial. Recuperado el 26 de febrero de 2010, de objetual.com: http:/ / www. obj etual. com/ main. htm

Hernandis, B., \& Briede, J. C. (2009). An Educational Application for a Product Design and Engineering Systems using Integrated Conceptual Models. Ingeniare, v. 17, n. 3, pp. 432-442.

Hernandis, B. \& Iribarren, N. (2000). Diseño de nuevos productos: Una perspectiva sistémica. Valencia - España: Universidad Politécnica de Valencia.

Higounet, C. (2003). História Concisa da Escrita. São Paulo: Parábola Editorial.

IBGE. (2 de Fevereiro de 2007). IBGE - Instituto Brasileiro de Geografia e Estatística. Recuperado el 10 de Maio de 2012, de IBGE: 
http:// www.ibge.gov. br/ home/ estatistica/ populacao/ condicaodevida/ indica doresminimos/ sinteseindicsociais2007/indic_sociais2007.pdf.

lida, I. (1992). Ergonomia, projetos e produção. São Paulo - SP/ Brasil: Edgar Blücher Ltda.

Jury, D. (2007). O que é a Tipografia? 0 que é a Tipografia? Barcelona, Barcelona, Espanha: Gustavo Gili.

Kurtgozu, A. (2003). From function to emotion: a critical essay on the History of design arguments. The Design J ournal, 6(2):45-49.

Lohr, S. (2000). Muestreo, diseño y análisis. México: Ed. Thomson.

Martins, R. F., \& Merino, E. (2008). A gestão de design como estratégia organi-zacional . Londrina - PR/ Brasil: Universidade Estadual de Londrina.

Mediavilla, C. (2001). Caligrafía: Del Signo Caligráfico a la Pintura Abstracta. Caligrafía: Del Signo Caligráfico a la Pintura Abstracta. Valencia, Valencia, España: Campgràfic.

Montemayor, H., Velia, M., Treviño, M. C., \& Gorena, Y. G. (2002). Guía para la investigación documental. México: Trillas.

Montesinos, J. L., \& Hurtuna, M. M. (2007). Manual de tipografía: del plomo a la era digital. Valencia: Campgràfic Editors.

Moura, M. (2003). O Design de Hipermídia. Tese Doutorado não publicada em Comunicação e Semiótica. São Paulo - SP/ Brasil: Pontifícia Universidade Católica de São Paulo .

Munari, B. (1983). Das coisas nascem coisas. Apontamentos por uma metodologia proj etual. Barcelona - Espanha: Editorial Gustavo Gili.

Norman, D. A. (2002). The Design of everyday things. New York: New York: Basic Books.

Olivier, F. S. (20 de Abril de 2009). Analfabetismo. Recuperado el 25 de Marzo de 2012, de Historia de los Medios:

http:// historiamedios1y2primavera2009. blogspot.com.es/2009/ 04/ analfabetis mo.html

Pacheco, A., Pacheco, K. \& \& Ortuño, B. (2009). Caligrafia Cursiva: A única ou mais eficiente no processo de alfabetização? 5. Congresso Internacional de Pesquisa em Design - ISSN 2175-0289, (págs. 770-778). Bauru.

Pevsner, N. (2002). Os pioneiros do desenho moderno: de William Morris a Walter Gropius. São Paulo -SP: Martins Fontes. 
Estudio de la construcción de los elementos caligráficos en el proceso de alfabetización de adultos en la Amazonia brasileña

PROMEAPI. (2007). Programa Municipal de Escolarização do Adulto e da Pessoa Idosa - PROMEAPI. PROMEAPI. Manaus, Amazonas, Brasil.

Rocha, C. (2002). Projeto Tipográfico: Análise e produção de fontes digitais. São Paulo: Rosari.

Rumjanek, L. (2008). 8o Congresso Brasil eiro de Pesquisa e Desenvolvimento em Design, 8 a 11 de outubro de 2008. São Paulo.

SME, S. M. (2010). Caderno de orientações didáticas para EJ A - Alfabetização: etapas. Manual EJ A. São Paulo, São Paulo, Brasil: Secretaria Municipal de Educação. Diretoria de Orientação.

Swann, C. (2002). Action Research and the Practice of Design. Design Issues, Vol. 18, No.2, 49- 61.

Tripodi, T., Fellin, P., \& H., M. (1975). Anál ise da Pesquisa Social . Rio de J aneiro - RJ/ Brasil: Francisco Alves Editora S.A.

Trochim, W., \& Donnelly, J . (2007). The Research Methods Knowledge Base. 3rd edition. Mason: Thomson Publishing.

UNESCO. (2011). Informe de Seguimiento de Ia Educación Para Todos en el Mundo. París: Edições UNESCO.

UNESCO. (2011). Relatório de Monitoramento Global de Educação Para Todos. Paris: Edições UNESCO.

Villas-Boas, A. (1998). O Que é e o Que Nunca foi Design Gráfico. Rio de J aneiro - RJ/ Brasil: 2AB.

Wollner, A. (2002). Textos Recentes e Escritos Históricos. São Paulo - Brasil: Ed. Rosari.

Yin, R. K. (2001). Estudo de Caso: planejamento e métodos. Porto Alegre: Bookman Tradução: Daniel Grassi. 


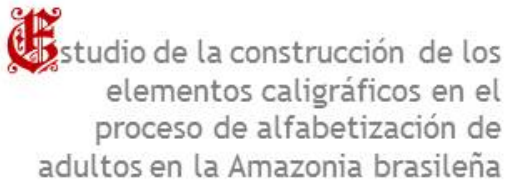
adultos en la Amazonia brasileña

\section{㷛apítulo 3}

\section{PUBLICACIONES}

3.1. Artículo 1

3.2. Artículo 2

3.3. Artículo 3

3.4. Artículo 4

3.5. Artículo 5

3.6. Artículo 6

3.7. Artículo 7 



\section{Publicaciones}

\subsection{Artículo 1 - Caligrafia Cursiva: A única ou mais eficiente no processo de alfabetização?}

Caligrafía Cursiva: ¿La única o más eficiente en el proceso de alfabetización?

Esta producción científica ha sido desarrollada con la intención de invitar a una reflexión acerca de la imposición del uso de la caligrafía cursiva en el proceso de alfabetización.

\section{Congreso: 50 INTERNATIONAL CONGRESS OF DESIGN RESEARCH (Brasil)}

ISSN: 2175-0289

Enviado: Mayo 2009 | Aceptado: Agosto 2009 | Publicado: Septiembre 2009

Caligrafia Cursiva: A única ou mais eficiente no processo de alfabetização? Cursive handwriting: The only or most efficient in the process of literacy?

\section{PACHECO, Almir de Souza}

Especialista em Design, Propaganda e Marketing - Universidade Federal do Amazonas UFAM

\section{PACHECO, Karla Mazarelo Maciel}

Mestre em Engenharia Florestal e Ambiental - Universidade Federal do Amazonas UFAM

\section{ORTUÑO, Bernabé Hernandis}

Doutor em Engenharia do Design - Universidade Politécnica de Valência/ Espanha - UPV

Palavras-chave: Design, Tipografia, Alfabetização.

Este artigo visa questionar a imposição da letra cursiva nas escolas como processo de alfabetização. A intenção não é questionar o sistema educacional nem tão pouco propor a eliminação desse tipo de escrita, mas provocar uma reflexão a respeito desse recurso pedagógico.

Key-words: Design, Typography, Literacy. 
Estudio de la construcción de los elementos caligráficos en el proceso de alfabetización de adultos en la Amazonia brasileña

This article aims to challenge the imposition of the letter cursive in schools as the literacy process. The intention is not to question the educational system or the proposed disposal of this type of writing but to cause a reflection about the use pedagogical recourse.

\section{Caligrafia Cursiva: A única ou mais eficiente no processo de alfabetização?}

\section{1 - Introdução}

Analisando aspectos da transcrição da linguagem segundo Frutiger (2001), estima-se que a escrita, como expressão do pensamento e da fala, teve origem no instante em que desenhos ou sinais surgiram relacionados diretamente com as sílabas, palavras ou frases pronunciadas.

Os primeiros escribas teriam surgido 5.000 anos antes de Cristo. A comunicação dava-se através da esquematização de objetos, datas e ações através dos chamados pictogramas. A escrita, propriamente dita, teria surgido no momento em que começaram a organizar e alinhar os sinais lado a lado ou um sobre o outro, correspondendo à evolução linear dos seus pensamentos. Frutiger (2001).

A evolução e adaptações de escribas e monges no método de escrever conduziram ao surgimento do primeiro caderno de caligrafia na Itália no ano de 1522 por Ludovico Vicentino degle Arrighi. Foi o grande responsável pela popularização da letra chamada chanceleresca ou itálica, e por estabelecê-la como a cursiva preferida pela tipografia. Arrighi era escriba papal e um dos calígrafos/tipógrafos que participaram diretamente na criação da cultura tipográfica ocidental durante o renascimento italiano. Convencionou-se então chamar de cursiva todo tipo de letra escrita à mão e de aspecto caligráfico.

A popularização da escrita cursiva foi tão grande que "invadiu" o sistema educacional do ocidente e, quase 500 anos depois, ainda permanece inconteste nos livros de caligrafia para alfabetização de crianças e adultos, embora o desenvolvimento tecnológico de igual período ter tornado esse tipo de escrita cada vez menos usual nos meios de comunicação modernos. J ury (2007) reforça esse pensamento afirmando que a partir da década de 1920, a máquina de escrever praticamente substituiu a escrita à mão para a produção da contabilidade e da correspondência das empresas e, portanto, a importância do ensino da caligrafia nas escolas diminuiu gradualmente.

Outro fator preponderante é a incipiente variedade de alternativas caligráficas no ensino, até como parâmetros de comparação de resultados. 
Para Heitlinger (2007), faltam fontes tipográficas adequadas às capacidades cognitivas e motoras das crianças na idade de aprendizagem. Não existe um consenso entre professores e educadores sobre qual o tipo mais adequado ao processo de alfabetização. O consenso é menor quando se trata da alfabetização de adultos (a qual não será abordada nesse artigo), quase esquecidos no que concerne a estudos dessa natureza. A caligrafia precisa se adaptar às evoluções tecnológicas e as necessidades do mundo moderno, bem como as variantes de perfil do aluno, seja ele criança ou adulto.

Diante disso, o referido trabalho busca fazer uma reflexão sobre o uso da tipografia cursiva no processo de alfabetização, razões pela qual a pesquisa encontra-se centralizada nos seguintes objetivos:

- Suscitar reflexão sobre o usa da tipografia cursiva no processo de alfabetização escrita;

- Conhecer as iniciativas de desenvolvimento de tipografias voltadas ao ensino da escrita;

- Analisar a tipografia cursiva usado no processo de alfabetização escrita;

- Comparar a adequabilidade da tipografia cursiva aprendida na escola com o mundo moderno.

\section{2 - Materiais e Métodos}

A eficiência do estudo depende da escolha e utilização dos materiais e métodos precisos para atingir resultados que sejam satisfatórios ao âmbito científico. Para isso, o trabalho deve determinar um objetivo a ser almejado, e dele traçar um planejamento do percurso para a construção do conhecimento sobre o objeto estudado. Sendo assim, Gil (2007) define a pesquisa como um "procedimento racional e sistemático que tem como objetivo proporcionar respostas aos problemas propostos." Quando não se dispõe de informações suficientes para responder ao problema, ou a informação não se encontra adequadamente em ordem, a pesquisa proporciona meios para que estas respostas sejam obtidas. A organização varia de acordo com as características da pesquisa. Serão utilizados neste projeto os procedimentos abaixo:

- Método: Indutivo

O Método Indutivo parte-se de fatos particulares, suficientemente aceitos e constatados e chega-se a uma conclusão geral não contida nos fatos examinados (FACHIN, 2006).

- Quanto à Natureza da Pesquisa: Científica 
Estudio de la construcción de los elementos caligráficos en el proceso de alfabetización de adultos en la Amazonia brasileña

Fachin (2006) relata que o Conhecimento Científico é resultante da investigação metódica e sistemática da realidade. Analisa os fatos a fim de descobrir suas causas e concluir as leis que os regem. Na Pesquisa Científica são relatados os resultados que podem ser utilizados para solucionar ou minimizar certos problemas.

- Quanto aos Objetivos: Pesquisa Exploratória

De acordo com Gil (2007), a pesquisa exploratória tem o objetivo de proporcionar maior familiaridade com o problema. Esta pesquisa será realizada através de levantamento bibliográfico e análise de exemplos para estimular a compreensão.

- Procedimentos Técnicos: Pesquisa bibliográfica

Segundo Gil (2007), "a pesquisa bibliográfica é desenvolvida a partir de material já elaborado, constituído principalmente de livros e artigos científicos". Serve como base para os estudos a serem realizados e proporciona a familiaridade do pesquisador com a área de estudo.

- Instrumento de Pesquisa: Observação, Experimento e Comparação Observar é utilizar os sentidos com intuito de obter dados e informações de determinados aspectos da realidade para formular a problematização. Consiste, além de ver e ouvir, em examinar os fatos e fenômenos que se desej a estudar (MARCONI e LAKATOS, 2001).

\section{3 - Desenvolvimento}

Na Síntese de Indicadores de 2007 do IBGE o número de analfabetos no Brasil no ano de 2005 superava a casa dos $11 \%$ e mesmo com uma redução para menos de $11 \%$ em 2006, esse percentual representava mais de 14 milhões, dos quais $36,4 \%$ pertenciam a faixa etária de 40 a 59 anos. Apesar dos números serem ainda muito altos, não existe um número proporcional de ações e esforços, por menores que sejam, para sua redução. Por mais paradoxal que seja, a educaçao é um aspecto básico do desenvolvimento social embora seja relegado e às vezes esquecido quando comparado ao grau de investimento em tecnologia. Esforços simples e coletivos podem fazer a diferença, no mínimo, para colocar a educação no cerne de debates científicos que envolvam uma de suas mais complexas questões: a alfabetização.

A aprendizagem da escrita constitui uma das mais importantes etapas no processo de alfabetização, no entanto, o aperfeiçoamento desse mecanismo didático requer um pouco de reflexão, principalmente quanto ao elemento tipográfico ainda utilizado nas escolas que é a tipografia cursiva. 


\section{1 - Algumas iniciativas de desenvolvimento de tipografias voltadas ao ensino da escrita pelo mundo.}

Buscando exemplos de outros países, durante a pesquisa sobre a tipografia cursiva aplicada ao ensino, foi observada a tentativa de desenvolver várias alternativas desse elemento caligráfico apresentados por Heitlinger (2007), contudo os estudos são direcionados apenas ao público infaltil em processo de alfabetização.

\subsection{1 - Alemanha}

O modelo alemão é um dos mais interessantes, baseia-se num desenho muito elementar e geométrico, para facilitar o desenho das formas; pertencem ao grupo que os alemães apelidam de Druckschriften, que significa letras de impressão. Esse tipo de alfabeto serviu como base para vários países como a Áustria que usa a tipografia Lateinaus para as crianças aprenderem a ler na escola primária. Vale ressaltar que a cursiva foi mantida com algumas poucas modificações em suas formas. 0 aspecto que mais chama a atenção nesse exemplo é a sua normatização.

\section{Lateinaus abcdefghijklmnapqnstumuseys$$
123 \text { ALEEHJKL MOL }
$$$$
\text { tipagnafia cursiva }
$$

\section{A1_fig. 1 - tipografia Laitenaus.}

Fonte: arquivo do autor.

A Alemanha possui uma tipografia chamada NormSchrift (letra normalizada) que é a fonte escolhida pelos grupos de trabalho que se ocupam da letra escolar na Alemanha. Depois de considerar os prós e os contras, chegou-se à conclusão que é melhor treinar a criança com uma letra muito próxima daquela que ela vê impressa na grande maioria dos livros escolares: uma fonte simples e direita, sem serifas e sem ornamentos. Nesse caso há uma mudança radical na estrutura formal dos caracteres, sendo adotado um modelo mais voltado ao uso cotidiano das expressões visuais. 


\section{ABCDEFGHIJKLMNO PQRTUVWXYZ12367890 abcdefghijktmnopqrsuv wxyzAÇOUßßàáâäèéêë•}

A1_fig. 2 - tipografia NormSchrift, letra normalizada alemã.

Fonte: Heitlinger (2007)

\subsection{2 - Reino Unido}

Rosemary Sassoon, designer da família de fontes Sassoon, pesquisou a maneira como as crianças percebem as formas das letras e considerou a opinião delas para desenvolver sua família tipográfica. Consultou 50 crianças sobre a legibilidade de 4 tipos: Times Roman, Times Italic, Helvetica e uma fonte sem serifa.

O resultado da pesquisa influenciou algumas decisões no desenho da fonte Sassoon Primary como uma pequena inclinação para aliar legibilidade e, aquilo que ela chamou de, 'amigabilidade' no desenho das letras, preferência pelo desenho sem serifa humanista temperado com pequenas serifas ou terminais na linha de base como se fossem as finalizações de ligação típicas de cursivas, como pode ser visto na figura 3.

\section{ABCDEFGGHIIJJKLMN OPQRSTUVWXYZÀÅÉÎ̃̃ ØÜabcdeffghijkklmnop qqrstuvwxyzàåéîõøü\&\& 123445678990 (\$E.,!?)}

\section{A1_fig. 3 - tipografia Sassoon Primary.}

Fonte: Heitlinger (2007) 


\subsubsection{O proj eto Kidstype}

Sue Walker e Linda Reynolds do Departamento de Tipografia e Comunicação gráfica da Universidade de Reading aponta, em seus trabalhos, a necessidade de mais pesquisas sobre a tipografia para crianças. Por exemplo, não existem estudos que comprovem se tipos serifados ou sem serifas são mais legíveis.

Segundo elas, geralmente professores tendem a preferir fontes sem serifas por terem formas mais simples. Porém as crianças encontram uma variedade grande de tipos no seu cotidiano e elas raramente são questionadas sobre 0 que pensam e os tipos dos livros que lêem.

Em seus estudos, fizeram alguns testes comparando a quantidade de erros que as crianças cometem lendo textos compostos com as tipografias Century (serifada) e Gill (sem serifa). Chegaram à conclusão que a diferença na performance da leitura entre estas fontes é insignificantemente pequena.

Eles chegaram à conclusão que é mais importante escolher fontes que a diferença entre os caracteres tais como ' $o$ ', ' $a$ ' e ' $g$ ' sejam bem evidentes (figura 4). A fonte Gill Educational tem esta qualidade, mas as fontes Avant Garde Gothic ou Helvética não.

\begin{tabular}{|l|c|}
\hline \multicolumn{2}{|c|}{ DIFERENÇA ENTRE CARACTERES } \\
\hline $\begin{array}{l}\text { Gill } \\
\text { Educational }\end{array}$ & Tipografia \\
\hline Avant Garde & Tipografia \\
\hline Helvética & Tipografia \\
\hline
\end{tabular}

\section{A1_fig. 4 - diferença entre caracteres.}

Fonte: arquivo do autor.

\subsection{3 - Estados Unidos}

School Fonts for Beginning Writing, desenhadas por Kim Voss (da empresa norte-americana Ashley's Mom Inc.) e publicadas por Mayer-J ohnson LLC, é uma colecção de 13 fontes para serem usadas em material educacional. 
Estudio de la construcción de los elementos caligráficos en el proceso de alfabetización de adultos en la Amazonia brasileña

As fontes são vendidas em versões para as plataformas Windows e Mac. Doze das fontes são oferecidas em versões dashed (pontilhadas), adequadas para as crianças aprenderem a traçar as letras. Como o tipo normatizado alemão, esse modelo também apresenta uma variedade tipográfica que foge do padrão usual cursivo.

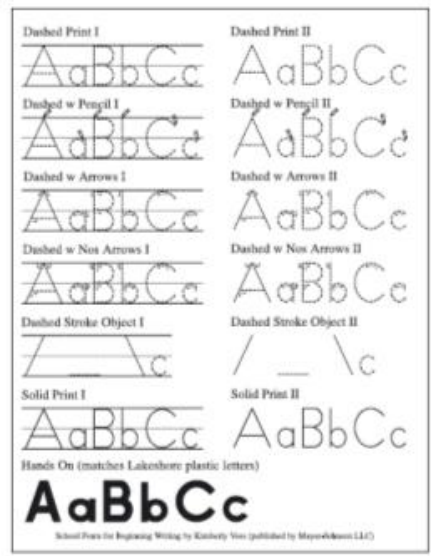

\section{A1_fig. 5 - tipografia Americana School Fonts for Beginning Writing.}

Fonte: Heitlinger (2007).

\subsection{4 - Chile}

Um exemplo interessante da América do Sul é o caso chileno dos tipógrafos da Tcl que, baseados na experiência que obtiveram com o desenvolvimento da fonte Tcl Lila, desenhada por Tono Rojas y Kote Soto para a Editora Marenostrum em 2004, decidiram fazer uma revisão e otimização do desenho alcançado, melhorando vários aspectos que aumentam a sua funcionalidade, ao mesmo tempo cumprindo os padrões estabelecidos pelo Ministério da Educação chileno. Aspectos da inclinação, das proporções e das lógicas de ligação entre letras, foram otimizados, desenvolvendo, os especialistas do Chile, nove conjunto de fontes, que foi posto no mercado com o nome Tcl Cotona. Embora tenham atendido às exigências governamentais, a tipografia Tcl Cotona mantém a estrutura formal básica da cursiva. 


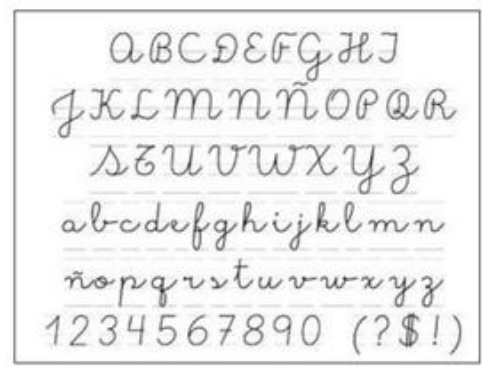

\section{A1_fig. 6 - tipografia Tcl Cotona.}

Fonte: Heitlinger (2007).

\section{2 - Análise da tipografia cursiva usado no processo de alfabetização escrita}

Vários são os aspecto a serem considerados na análise de uma tipografia no que concerne a sua aplicabilidade, esse análise vai além da dicotomia entre forma e função, inerente a qualquer projeto de design. Como o objetivo desse artigo é provocar reflexões acerca do tema, segue dois enfoques.

\subsection{1 - Sob o enfoque da Pedagogia}

Cinel (2003), em seu texto sobre Disgrafia, escreve que a gramática (normativa e, por isso, deficiente) e as cartilhas brasileiras, que ainda estão em uso, apesar dos estudos mais avançados a respeito da aprendizagem da escrita e da leitura, não explicam nem aos mestres nem aos aprendizes esta multivariedade de traçados ou de formas de representação gráfica, o porquê dessas diferenças e como ensiná-las, como aprendê-las.

Ainda na observação de Cinel (2003), é exigido um trabalho dobrado das crianças: primeiro, aprender a escrever em letra de forma. É mais fácil, mais compreensível, aparece nos textos, rótulos e no mundo escrito que nos cerca. Logo depois é exigido que a criança passe a escrever em letra cursiva, mais complicada, de mais difícil leitura e de caráter individual e idiossincrático: cada usuário adota seu próprio traçado, coloca suas nuances, mostra sua personalidade. Mas a sociedade e a cultura consideram importantíssimo, fundamental mesmo, saber "escrever emendado".

Vale ressaltar que nem todos os adultos mantém o estilo caligráfico aprendido na infância e uma outra grande parcela que o mantém, sofre para se fazer compreendido quando sua escrita é exigida em um exame seletivo de emprego ou concurso público, por exemplo. Um dos maiores complicadores dessa 
Estudio de la construcción de los elementos caligráficos en el proceso de alfabetización de adultos en la Amazonia brasileña

problemática é a falta de prática diária da escrita manual em função da disponibilidade tecnógica moderna do uso da escrita digital, já em estado de evolução e apresentando-se como uma tendência cada vez maior para a convergência da escrita direto na tela dos dispositivos eletrônicos (touch screen) como celulares, palm tops, video-games, etc. (figura 7)
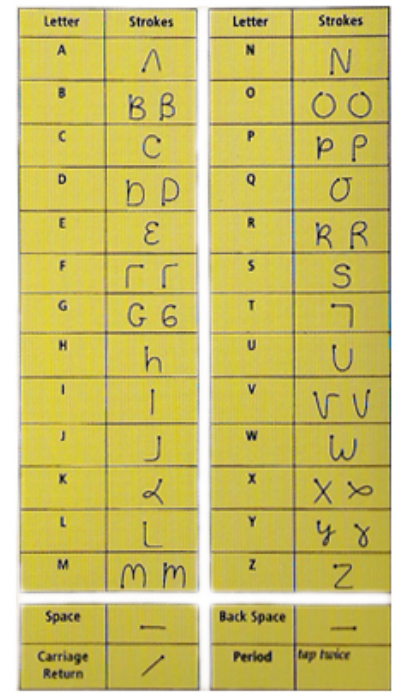

\section{A1_fig. 7 - folha informativa fornecida com um Palm Pilot (PDA).}

Fonte: J ury (2007).

A legibilidade da escrita é uma qualidade complexa que se constitui na soma de vários aspectos, dentre outros considerados relevantes estudados por Cinel (2003) com observações importantes de caráter pedagógico e, por vezes dentro de aspectos ergonômicos, descritos a seguir.

\subsubsection{2 - Forma das letras}

Cada letra tem uma forma característica. A clareza de traçado então reside em escrever cada letra na sua forma exata. A letra cursiva deformada pode ser a causa mais poderosa de ilegibilidade. Por exemplo:

a) se o aluno não fecha o círculo do "a", pode-se lê-lo como "u" ou "ce";

b) quando não fecha o círculo do "d", pode-se lê-lo como "cl" ou "el";

c) outros escrevem " $n$ " como " $u$ "; 
d) alguns alunos podem adquirir o hábito de escrever " $\mathrm{m}$ " como " $\mathrm{u}$ " ou como " $n$ ", etc.

Estes exemplos são suficientes para demonstrar a importância do formato da letra para a legibilidade da escrita. Muitas vezes, as formas inadequadas das letras são consequência da falta de orientação docente, do mau uso ou do abuso das cópias e dos ditados ou da rapidez descabida da escrita para fazer apontamentos em aula, dentre outras.

\subsubsection{3 - Uniformidade}

A letra cursiva, em nosso alfabeto, apresenta quatro características no traçado em relação à linha:

- só há uma letra cujo traçado sobe a desce - f;

- há seis letras com haste ascendente - b, d,h, k. , l,t;

- há seis letras com haste descendente - g j,p ,q, y, z

- há treze letras citadas como pequenas - a, c, e.i., m, n, o, r, s, u, v,w, x.

Outro aspecto a ser observado é a passagem de um sistema de escrita (letra de forma) para outro (letra cursiva), por exemplo. É preciso realizar um trabalho bem planejado, de comum acordo com os alunos, de modo sistemático e cuidadoso. A letra cursiva exige maior esforço mental e físico da criança porque apresenta complexidade de movimentos.

O uso da caligrafia, considerada obsoleta e antipedagógica pelos desavisados e indicada pelos mais modernos autores, ocupa papel relevante, hoje em dia. Visa atender às atuais exigências de clareza, legibilidade e rapidez, justificando-se, portanto, sua presença em sala de aula, nas atividades escolares.

\subsection{2 - Sob o enfoque do Design}

A Ergonomia é o principal caminho para análise tipográfica por parte do designer em função dos muitos estudos de referência na área. Os muitos estudos, focados principalmente em medir a legibilidade, apresentam vários parâmetros tipográficos como: desenho de letras, tamanho do corpo e espaçamento entre linhas, letras e palavras. 
Estudio de la construcción de los elementos caligráficos en el proceso de alfabetización de adultos en la Amazonia brasileña

Segundo Rumjanek (1999) os primeiros estudos e discussões sobre fatores que afetam a facilidade e a velocidade de leitura, o termo legibilidade foi empregado. No entanto, a partir de 1940, alguns autores passaram a utilizar 0 termo leiturabilidade (readability), pois parecia ser um termo mais amplo e mais significativo.

No que concerne a tipografia cursiva e sua percepção, além dos aspectos da ergonomia, foram destacados alguns outros para exemplificar suas restrições técnicas:

- A legibilidade da tipografia cursiva em detrimento das demais é complexa com palavras em versal (maiúscula ou caixa alta) como mostra a figura 8.

\begin{tabular}{|c|c|c|c|}
\hline & \multicolumn{3}{|c|}{ COMPLEXIDADE DE LEITURA EM CAIXA ALTA } \\
\hline fonte & cursiva & arial & times new roman \\
\hline exemplo & JJPOGRCJJG & TIPOGRAFIA & TIPOGRAFIA \\
\hline
\end{tabular}

A1_fig. 8 - comparação entre a cursiva em versal com outras tipografias.

Fonte: arquivo do autor.

- 0 desenho das letras maiúsculas e minúsculas é diferente entre si e das existentes nas mais variadas formas de aplicações em cartazes, revistas, jornais etc.

\begin{tabular}{|c|c|c|c|}
\hline & \multicolumn{3}{|c|}{ DIFERENÇAS ENTRE MAIÚSCULA E MINÚSCULA } \\
\hline fonte & cursiva & calibri & garamond \\
\hline exemplo & G a f f & A a F f & A a F f \\
\hline
\end{tabular}

A1_fig. 9 - diferença entre maiúsculas e minúsculas.

Fonte: arquivo do autor.

- Confusão formal ou similaridade entre letras. Pela forma do desenho, há confusão entre letras como " $k$ " e "I" e as maiúsculas " $U$ " e "V" e "F" e "T". 


\begin{tabular}{|c|c|c|c|}
\hline & \multicolumn{3}{|c|}{ SIMILARIDADE FORMAL ENTRE LETRAS } \\
\hline fonte & cursiva & rockwell & helvetica It std \\
\hline exemplo & $k \ell U U$ I J & kl UV FT & kIUVFT \\
\hline
\end{tabular}

\section{A1_fig. 10 - letras com similaridade formal.}

Fonte: arquivo do autor.

\section{5 - Considerações Finais}

Como citado anteriormente, esse artigo não tem a pretensão de ir contra preceitos educativos ou condenar o uso da cursiva, mas sim provocar reflexões sobre seu uso quase que único no processo educacional. Também não pretende ser conclusivo, muito pelo contrário, o objetivo é levantar algumas questões que precisam ser discutida em várias áreas, como o Design e a Pedagogia, a respeito desse recurso caligráfico, como por exemplo: Porque as pessoas tem que ter a letra cursiva? Seria a cursiva ideal para alfabetização de crianças e adultos? Vivendo numa era tecnológica em que a letra cursiva está mais próxima de "estilo artístico" que do funcional, em se tratando de aplicabilidade nas mais varia formas de expressões visuais, quais as vantagens de sua manutenção no processo educativo que alguma outra letra não se equipare? Não seria mais interessante pensar num formato de letra mais adequada também ao uso em equipamentos eletrônicos modernos?

Alguns países fizeram e fazem estudos e experimentações tipográficas buscando alternativas para a educação escrita de crianças, como mostrado no artigo, embora em alguns casos permaneça a letra cursiva com pequenos ajustes estruturais e mesmo nos casos onde existe uma investigação um pouco mais apurada, não é abordada a alfabetização de adultos, mas isso é tema para outra pesquisa.

Mesmo que na busca de respostas para os questionamentos supracitados o resultado seja discordante de tudo aqui exposto, o presente artigo atingiu seus objetivos. 
Estudio de la construcción de los elementos caligráficos en el proceso de alfabetización de adultos en la Amazonia brasileña

\section{6 - Referências}

BRINGHURST, Robert. Cadernos de Tipografia, nr 3 - Legibilidade. Disponível em: বhttp:// www.tipografos. net/ cadernos>Acesso em: fev. 2009.

BRINGHURST, Robert. Elementos do Estilo Tipográfico: versão 3.0. São Paulo: Cosac Naify, 2005.

CINEL, Nora Cecília Bocaccio. Disgrafia: Prováveis causas dos distúrbios e estratégias para a correção da escrita. Porto Alegre: Revista do Professor, abr./ jun. 2003. p. $19-25$

FACHIN, O. Fundamentos de Metodologia. 5. ed. São Paulo: Saraiva, 2006.

FRUTIGER, Adrian. Sinais e Símbolos: desenho, projeto e significado. São Paulo: Martins Fontes, 1999.

GIL, Antônio Carlos. Como Elaborar Projetos de Pesquisa. 3 ed. São Paulo: Atlas, 1991.

IBGE 2007. Síntese de indicadores sociais: uma análise das condições de vida da população brasileira. Disponível em: http:/ / www.ibge.gov.br/ home/ estatistica/ populacao/ condicaodevida/ indica doresminimos/ sinteseindicsociais2007/indic_sociais2007.pdf. Acesso em 2 fev. 2008.

J URY, David. O que é a Tipografia? Barcelona: Editora Gustavo Gili, 2007.

LAKATOS, E.M.; MARCONI, M. de A. Fundamentos de metodologia científica. 3a ed. São Paulo: Atlas, 1991.

RUMJ ANEK, Letícia. Tipografia para crianças: estudos de legibilidade. 8o Congresso Brasileiro de Pesquisa e Desenvolvimento em Design, 8 a 11 de outubro de 2008, São Paulo. Anais... São Paulo, 2008.

Almir de Souza Pacheco e-mail: almirdesigner@gmail.com

Karla Mazarelo Maciel Pacheco e-mail: karlamazarelo@hotmail.com

Bernabé Hernandis Ortuño e-mail: bhernand@degi.upv.es 


\subsection{Artículo 2 - Análise do posicionamento do design com relação ao estudo da construção dos elementos caligráficos para 0 processo de alfabetização de adultos na Amazônia brasileira}

Análisis del posicionamiento del diseño con relación a la construcción de los elementos caligráficos en el proceso de alfabetización de adultos en la Amazonia brasileña.

Esta producción científica ha sido desarrollada con la intención de hacer un análisis de opiniones de expertos en diseño referentes al tema en estudio a través de la técnica de Grupo Focal (Focus Group).

\section{Congreso: 4 INTERNATIONAL CONGRESS OF EDUCATION, RESEARCH AND MANAGEMENT (Brasil)}

ISSN: 2176-1868

Enviado: J unio 2012 | Aceptado: Septiembre 2012 | Publicado: En espera de publicación.

\section{Análise do posicionamento do design com relação ao estudo da construção dos elementos caligráficos para o processo de alfabetização de adultos na Amazônia brasileira}

Almir de Souza Pacheco (Universitat Politècnica de València - UPV) almirdesigner@gmail.com

María Begoña J ordá Albiñana (Universitat Politècnica de València - UPV) bego@mag.upv.es

Jimena Gonzáles del Rio Cogorno (Universitat Politècnica de València - UPV) jimena@mag.upv.es

Karla Mazarelo Maciel Pacheco (Universidade Federal do Amazonas - UFAM) karlamazarelo@hotmail.com

Maria Daise Cunha Matos (Secretaria Municipal de Educação - SEMED) daisematos_matos@hotmail.com

\section{Resumo:}

Este artigo apresenta uma análise sobre o estudo da construção dos elementos caligráficos para o processo de alfabetização de adultos na Amazônia brasileira. 0 documento descreve as opiniões de 15 especialistas do 
Estudio de la construcción de los elementos caligráficos en el proceso de alfabetización de adultos en la Amazonia brasileña

design, referentes às ações necessárias à atuação desta atividade para o tema abordado. O método utilizado possui caráter qualitativo, exploratório e descritivo, apresentando como ferramenta de apoio para a coleta de dados a técnica Focus Group. Como resultado, os participantes consideraram importante planificar 0 estudo com base nos princípios cognitivos e psicológicos aplicados à alfabetização de adultos, tendo no design um apoio estratégico para proporcionar uma melhor forma de aprendizado da escrita. 0 grupo ressaltou que a ergonomia deve ser o principal atributo do design a ser relacionado ao fator cognitivo, estabelecendo parâmetros tipográficos; verificando a necessidade de facilitar a velocidade de leitura e legibilidade dos caracteres construída em caixa alta e caixa baixa (letras maiúsculas e minúsculas) e; trabalhando a representatividade desses aspectos em função da melhoria do processo didático. A afetividade e a interatividade - entre professor e aluno, foram apontadas como aspectos essenciais à atuação do fator psicológico, que apoiadas pelo design (enquanto atributo formal conceitualmente projetado em materiais didáticos), podem beneficiar 0 processo de aprendizado da escrita para o alfabetizando adulto. 0 trabalho reuniu informações valiosas que determinam os aspectos mais rel evantes para a procedência do estudo, mas que necessitam ser comparadas à opinião de pedagogos, de modo a auxiliar o desempenho do design em prol de uma forma mais eficaz da escrita manual, que possa também respeitar as especificidades do adulto iletrado.

Palavras chave: Alfabetização de adultos, Design tipográfico, Caligrafia

\title{
Analysis of design positioning about study of the construction of calligraphic elements to the process of adult literacy in the Brazilian Amazon
}

\begin{abstract}
This article presents an analysis of construction study of calligraphic elements to the process of adult literacy in the Brazilian Amazon. The document describes the opinions by 15 design experts about actions necessary to performance's design in this theme. The method used has a qualitative, exploratory and descriptive, presenting the Focus Group technique as a support tool for data collection. As a result, participants considered it important to plan the study with based on cognitive and psychological principles applied to adult literacy, and design a strategic support to provide a better way of learning to write. The group stressed that ergonomics should
\end{abstract}


be the main attribute of the design to be related to cognitive factor, typographical setting parameters, verifying the need to facilitate the reading speed and legibility of the characters built in uppercase and lowercase letters, and; working the representativeness of these aspects on the basis of improving the learning process. The affection and interactivity - between teacher and student, have been identified as essential for action of psychological factor, that with supported the design (as a formal attribute conceptually designed in textbooks), can benefit the learning process of writing for adult literacy. The study gathered valuable information that determine the aspects most relevant to the merits of the study, but need to be compared to the opinions of educators in order to assist the performance of the design in favor of a more efficient way of handwriting and also meet the specifics of the adult illiterate.

Key-words: Adult literacy, typographic design, calligraphy

\section{Introdução}

A alfabetização é a habilidade de identificar, compreender, interpretar, criar, comunicar e assimilar, utilizando materiais impressos e escritos associados a diversos contextos, conforme definido pela UNESCO (2008). Trata-se de um processo complexo que envolve a leitura de mundo atrelada à leitura da palavra, ao aprender a ler e escrever, à reflexão e à ação sobre a realidade na qual os sujeitos encontram-se inseridos. É entender o que se lê e escrever 0 que se entende, é comunicar-se graficamente, é incorporação e auto formação, ou seja, é resultar uma postura atuante do homem sobre seu contexto (FREIRE, 1979).

0 processo de alfabetização melhora as habilidades de comunicação do individuo, garantindo o seu acesso ao conhecimento, construindo a sua autoconfiança e autoestima necessárias para a tomada de decisões. Sobre esses aspectos, vemos que a decodificação da informação escrita, seja por meio da leitura ou da escrita, tem se tornado uma peça fundamental no que diz respeito à qualificação de mão-de-obra para o mundo do trabalho e uma das ferramentas mais preciosas para se obter poder e riqueza (CAMARGO \& MARTINELLI, 2006).

No que se refere à alfabetização de adultos, torna-se necessário implicar esforços para uma correta compreensão do que é a palavra escrita, a linguagem, a relação com o contexto de quem fala, de quem lê e escreve, compreensão, portanto da relação entre "leitura" do mundo e leitura da palavra, como cita Freire (1989). De acordo com Ferreiro (1989), as pessoas 
Estudio de la construcción de los elementos caligráficos en el proceso de alfabetización de adultos en la Amazonia brasileña

em processo de alfabetização precisam resolver problemas de natureza lógica até chegarem a compreender de que forma a escrita alfabética representa a linguagem, para que possam escrever e ler por si mesmas. Assim, a aprendizagem da língua escrita passou a ser concebida como:

- A compreensão de um sistema de representação, e não como um código que transcreve a fala;

- Um aprendizado que coloca diversas questões de ordem conceitual e não somente perceptivo- motoras para 0 a suj eito;

- Um processo de construção de conhecimento pelo sujeito, através de práticas que têm, como ponto de partida e de chegada, o uso da linguagem e o livre trânsito pelas práticas sociais da escrita.

Freire (1981) afirma que a primeira exigência prática que a concepção crítica da alfabetização se impõe, sobretudo para o aprendizado de adultos, é que as palavras geradoras com as quais os alunos começam sua alfabetização (como sujeitos do processo), sejam buscadas em seu "universo vocabular mínimo" e que envolve sua temática significativa.

É papel do alfabetizador, descobrir em que fase o alfabetizando adulto se encontra no processo de aquisição da base alfabética e considerar que, na maioria das vezes, esse diagnóstico fica comprometido pela ilegibilidade decorrente do traçado errado ou do mal traçado das letras que o aluno evidencia, conforme citam Costa, Palácio e Paulucci (2005), ocorre que, em muitos casos, os problemas estão interligados às questões motoras ou, simplesmente, a momentos do processo de aprender; o que não devem ser confundidos como dificuldades de aprendizagem, pois isso pode ocasionar consequências graves, limitando a possibilidade de realização de um diagnóstico mais preciso acerca do nível real de desenvolvimento cognitivo do aluno. A interação mútua entre o alfabetizador e alfabetizando, é um fator primordial ao processo de alfabetização do adulto que consequentemente, beneficia a aquisição da leitura e da escrita.

Portanto, a apropriação de novos conceitos e métodos em prol da eficácia no ensino e aprendizado do sistema alfabético por adultos requer um estudo direcionado às formas de construção dos elementos caligráficos, de forma a analisar os elementos individuais da escrita para uma melhor representação e entendimento.

Neste contexto, o design pode apresentar uma significativa contribuição ao universo científico e pedagógico, principalmente por ser uma atividade multidisciplinar com capacidade de reunir conceitos formais, funcionais e ergonômicos em projetos de comunicação visual, 0 que implica 0 
desenvolvimento de padrões tipográficos apropriados ao processo de alfabetização, diferenciando entre os mais indicados para as crianças daqueles que mais se adequam aos adultos iletrados, razão pela qual se encontra centralizado nos seguintes objetivos:

- Analisar a opinião de profissionais do design sobre a atuação desta atividade no estudo da construção dos elementos caligráficos para o processo de alfabetização de adultos na Amazônia brasileira; e

- Identificar os aspectos considerados mais relevantes para a procedência do estudo.

\section{A alfabetização de adultos na Amazônia brasileira}

A Amazônia brasileira abrange mais de cinco milhões de quilômetros quadrados, correspondendo a mais da metade do território nacional. Esta vasta área apresenta um grande desafio logístico causado pela estrutura geográfica da região, pois sua grande bacia hidrográfica, com rios caudalosos, impede a construção de estradas e a conexão terrestre no norte do Brasil.

As dificuldades logísticas afetam o desenvolvimento dos estados nortistas em vários aspectos, a educação é um deles. Mesmo com o surgimento de novas tecnologias que contribuem para 0 processo de educação, encontrar profissionais qualificados dispostos a enfrentar os desafios de trabalhar na Amazônia, o transporte de pessoal (principalmente alunos e professores) e material são obstáculos que corroboram de forma negativa para 0 desenvolvimento educacional da região. Como consequência dessa união de fatores, um número alto de adultos e crianças nunca estiveram em um banco de escola.

Na Síntese de Indicadores de 2007 do IBGE (Instituto Brasileiro de Geografia e Estatística) o número de analfabetos no Brasil no ano de 2005 superava a casa dos $11 \%$ e mesmo com uma redução para menos de $11 \%$ em 2006, esse percentual representava mais de 14 milhões, dos quais $36,4 \%$ pertenciam à faixa etária de 40 a 59 anos. Apesar dos números serem ainda muito altos, não existe um número proporcional de ações, por menores que sejam para sua redução. Por mais paradoxal que seja, a educação é um aspecto básico do desenvolvimento social de um país, que, no caso do Brasil, é relegado e, às vezes, esquecido quando comparado ao grau de investimento em tecnologia. Esforços simples e coletivos podem fazer a diferença, no mínimo, para colocar a educação no cerne de debates científicos que envolvam uma de suas mais complexas questões: a alfabetização. 
Estudio de la construcción de los elementos caligráficos en el proceso de alfabetización de adultos en la Amazonia brasileña

\subsection{A escrita e a construção dos elementos caligráficos para o processo de alfabetização}

0 processo de transmitir informações de forma escrita sofreu uma grande evolução, principalmente a partir da invenção da imprensa e dos processos de impressão, contudo a escrita manual não acompanhou de forma proporcional tal desenvolvimento. 0 surgimento dos tipos metálicos e o desenvolvimento da indústria de impressos contribuíram para o afastamento cada vez maior dos formatos de letra derivados da escrita à mão, como citam Montesinos y Hurtuna (2007).

A grande variedade de tipos surgidos nos últimos cinco séculos e adotados pelos diversos tipos de manifestações visuais apresenta formas individuais de caracteres que se diferenciam bastante daqueles ensinados até os dias atuais. Considerando a facilidade moderna de acesso aos meios de comunicação, a variedade de aparatos eletrônicos e o número de horas que uma criança passa em frente a uma televisão antes que inicie sua vida escolar, é perfeitamente justificável uma possível confusão formal entre os caracteres que aprende a escrever com o que the é apresentado, de forma impressa e/ ou digital, pelo mundo que a cerca (ROCHA, 2002).

Embora mais adaptado ao ambiente comunicativo, em função da idade, 0 adulto iletrado também sofre o mesmo problema quanto ao desenho das letras, principalmente em determinados caracteres que apresentam variedades formais, bem como naqueles que possuem estruturas construtivas distintas nas versões maiúsculas e minúsculas.

A baixa qualidade da grafia apresentada pela maioria das pessoas faz com que 0 uso de uma máquina para realizar quase todas as atividades, que exijam 0 uso da letra grafada a mão, torne-se bastante justificável, além do forte apelo ecológico e econômico que essa atitude provoca, pois haveria uma consequente diminuição do uso de papel e também dos mais variados materiais utilizados no processo da escrita. Outro fator preponderante é a incipiente variedade de alternativas caligráficas no ensino, até como parâmetros de comparação de resultados.

Para Heitlinger (2006), faltam fontes tipográficas adequadas às capacidades cognitivas e motoras das crianças na idade de aprendizagem. Não existe um consenso entre professores e educadores sobre qual o tipo mais adequado ao processo de alfabetização. 0 consenso é menor quando se trata da alfabetização de adultos, quase esquecidos no que concerne a estudos dessa natureza, prova disso é a escassez de material didático para alfabetização dessa categoria de aluno. A caligrafia precisa se adaptar às evoluções 
tecnológicas e as necessidades do mundo moderno, bem como as variantes de perfil do aluno, seja ele criança ou adulto.

\section{Material e Métodos}

O estudo apresenta uma abordagem qualitativa, com objetivos de caráter exploratório e descritivo, conforme Gil (2002). A estrutura do conteúdo contempla uma pesquisa do tipo bibliográfica e documental, ratificada a um estudo específico - correlacionado aos processos de inovação e de estratégia (YIN, 2001).

Para o presente artigo, que é parte de um estudo maior, os dados foram obtidos a partir de referências bibliográficas que discutem a temática e através da aplicação da técnica qualitativa Focus Group, com o intuito de obter as percepções de um grupo de pessoas sobre questões, fatos sociais e status atual do objeto de estudo, gerando ideias, comentários e a produção de insights (KRUEGER \& CASEY, 2000).

Considerando o caráter do estudo e seus objetivos, foram selecionados, de forma intencional, 15 profissionais do design, para a realização da dinâmica (Focus Group) na sede da Universidade Politécnica de Valência UPV/ Espanha, com duração de 01h30min.

A sessão contou com um moderador que se baseou numa guia com informações, apresentando os objetivos, a justificativa, algumas citações e os possíveis aspectos contextuais interligados ao assunto. Tais informações serviram como pontos iniciais à atividade do grupo (Figura 1), que participou ativamente do processo de discussão.
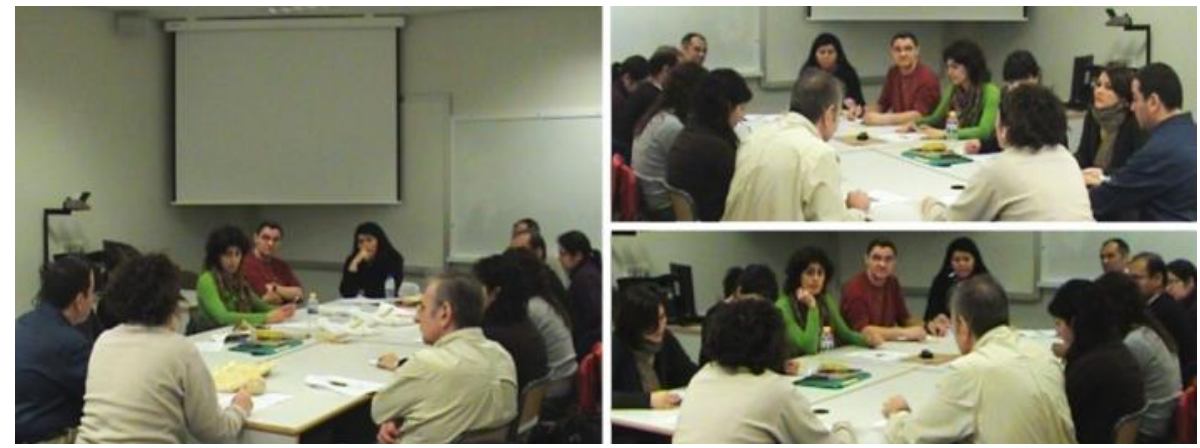

A2_Fig. 1 - Focus group realizado com os especialistas em design para a coleta de dados 
Estudio de la construcción de los elementos caligráficos en el proceso de alfabetización de adultos en la Amazonia brasileña

As etapas consideradas essenciais à realização da pesquisa foram delimitadas pelos integrantes da sessão e todas as informações foram registradas e relatadas para posterior aprovação dos participantes.

\section{Resultados}

Mediante as informações apresentadas pelo moderador à atividade Focus group, os participantes observaram que a cisão entre a razão e a emoção é predominante nos estudos e pesquisas sobre o comportamento e aprendizado humano. Assim sendo, o grupo considerou necessário planificar o estudo mediante o apoio de dois fatores: cognitivo e psicológico, onde o primeiro deverá ressaltar aspectos relevantes ao processo de aprendizado da escrita e ter no design um apoio estratégico para proporcionar uma forma de facilitar a construção, compreensão e representação dos caracteres caligráficos (letras), tendo em vista favorecer a legibilidade, leitura, comunicação e expressão do alfabetizando adulto. A figura 3 apresenta o esquema de percurso, com as variáveis principais, a serem consideradas sobre 0 aspecto cognitivo evidenciado pelos especialistas.

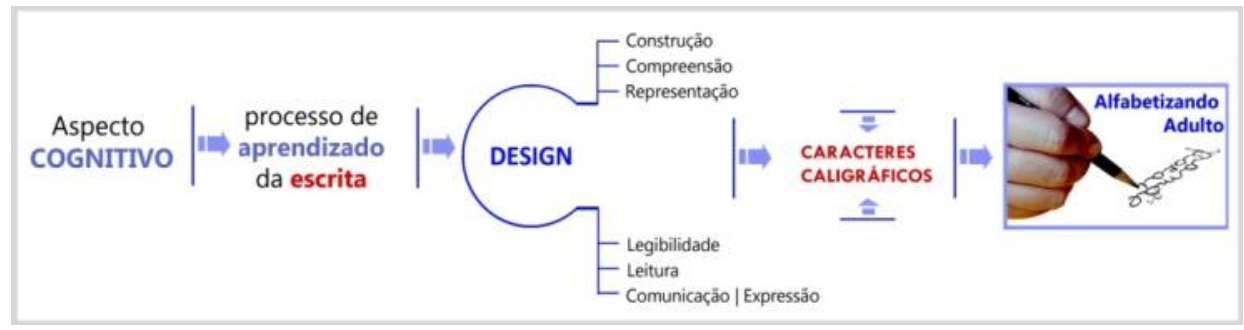

\section{A2_Fig. 2 - Aspecto cognitivo evidenciado pelos participantes do Focus group}

Sobre a atuação do design, para o referido tópico, o grupo assinalou alguns atributos relacionados à: forma, função e ergonomia. Na tabela 1, podemos observar os aspectos principais considerados pelos especialistas. As informações identificadas em $(+)$ representam as mais relevantes para o estudo, e as representadas em (-) as de menor importância. 


\section{A2_Tab. 1 - Atributos relacionados pelos participantes para a atuação do design quanto $o$ aspecto cognitivo}

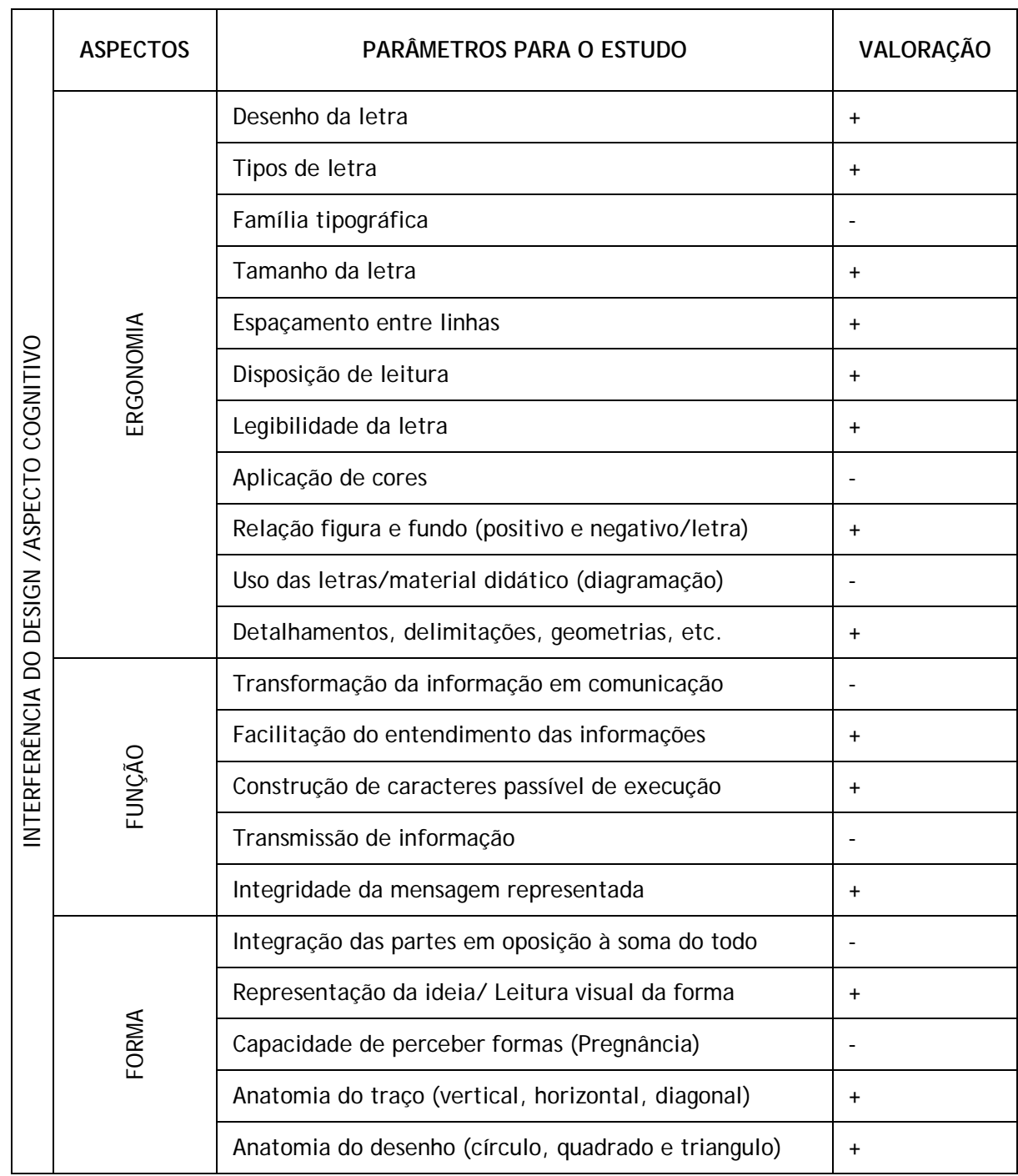

De acordo com os atributos do design relacionados pelos especialistas, a ergonomia apresentou-se com maior relevância por compreender o uso de parâmetros tipográficos (detalhamentos, delimitações, definições, geometrias e regras básicas do desenho de letras, tipos de letras, tamanhos de letras, 
Estudio de la construcción de los elementos caligráficos en el proceso de alfabetización de adultos en la Amazonia brasileña

família tipográfica, espaçamento entre linhas, disposição de leitura e legibilidade, aplicação de cores, relação figura e fundo, ângulo de visão, recursos para construção dos caracteres, diagramação, representação visual e etc.).

Com relação ao fator psicológico, o grupo acredita que toda aprendizagem está impregnada à afetividade, já que ocorre a partir das influências mútuas e sociais em um processo interativo: docente/ discente. Ainda que se identifique ou crie um instrumento metodológico facilitador - através a interferência do design, para por em prática o que se propõe ao aspecto cognitivo direcionado ao aprendizado da escrita, torna-se importante ressaltar que o aluno adulto só irá aceitar a aprender com quem outorga confiança, conferindo o direito de ensiná-lo. Neste caso, cabe ao professor saber trabalhar a construção dos elementos caligráficos para o processo de alfabetização desse adulto, de modo a criar um vínculo afetivo positivo entre ambos, bem como no ambiente de ensino, aumentando as chances de existir motivação para retornar todos os dias e verificar uma melhora significativa na qualidade do aprendizado. A figura 4 apresente um esquema resumido sobre as variáveis a serem consideradas para 0 aspecto psicológico ressaltado pelos especialistas quanto ao tema.

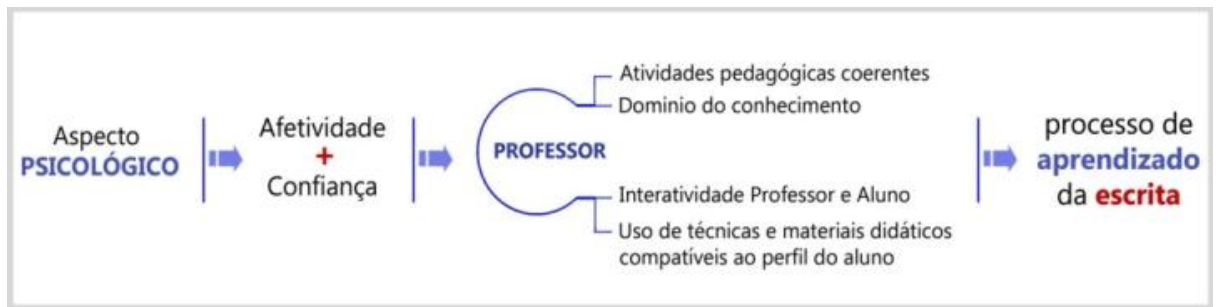

\section{A2_Fig. 3 - Aspecto psicológico evidenciado pelos participantes do Focus group}

Conforme o ponto de vista dos participantes do Focus group, retratado na figura 4, a oferta de atividades pedagógicas coerentes, bem planejadas, um bom domínio do conhecimento, a interatividade por parte do professor e o uso de técnicas e materiais didáticos compatíveis ao "universo vocabular" e ao perfil do aluno podem contribuir para o bom nível de envolvimento do alfabetizando adulto no aprendizado da escrita.

Especificamente sobre esse aspecto, o grupo acredita que 0 design pode colaborar através da projetação de materiais didáticos que auxiliem o aluno a compreender e desenhar os caracteres caligráficos e ao professor para estabelecer suas estratégias, tendo como base 0 uso dos elementos da 
linguagem visual e os princípios básicos da Gestalt (método de leitura visual da forma), ou seja, considerando a "forma" como atributo fundamental para este processo.

$\mathrm{Na}$ tabela 2 podemos ver as variáveis formais assinaladas pelos especialistas como essenciais ao fator psicológico. Mais uma vez, as informações identificadas em $(+)$ representam as mais relevantes para o estudo enquanto que as representadas em (-) demonstram ter menor importância.

\section{A2_Tab. 2 - Atributos formais considerados essenciais à atuação do design em relação ao aspecto psicológico}

\begin{tabular}{|c|c|c|c|}
\hline \multirow{12}{*}{ 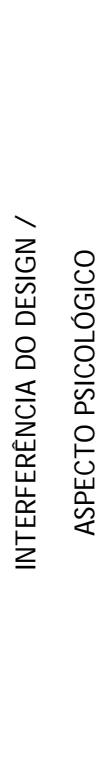 } & ASPECTOS & PARÂMETROS PARA O ESTUDO & VALORAÇÃO \\
\hline & \multirow{11}{*}{ 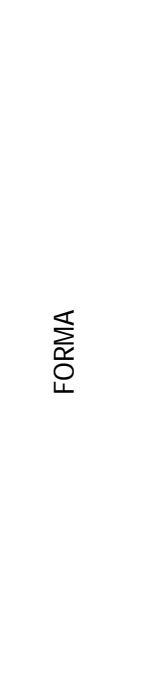 } & Inter-relação dos aspectos simbólicos e semióticos & - \\
\hline & & Inter-relação dos aspectos ergonômicos & - \\
\hline & & Inter-relação dos valores culturais/ perfil aluno & + \\
\hline & & Inter-relação dos códigos visuais tipográficos & + \\
\hline & & Inter-relação dos códigos visuais cromáticos & - \\
\hline & & Inter-relação dos códigos visuais morfológicos & - \\
\hline & & Inter-relação dos códigos visuais tecnológicos & - \\
\hline & & Uso da tríade do design (circulo quadrado e triangulo) & + \\
\hline & & $\begin{array}{l}\text { Uso de elementos básicos (ponto, linha, plano, } \\
\text { volume) }\end{array}$ & + \\
\hline & & Uso de configurações reais e esquemáticas & + \\
\hline & & Uso dos conceitos da Gestalt & + \\
\hline
\end{tabular}

De acordo com os atributos formais do design destacados pelo grupo, os valores culturais (compreendidos mediante o perfil do alfabetizando adulto), a inter-relação dos códigos visuais tipográficos e os usos: da tríade do design, dos elementos básicos, das configurações reais e esquemáticas e dos conceitos da Gestalt devem ser aplicados, impreterivelmente, em materiais didáticos que possibilitem a eficiente atuação do fator psicológico no processo de aprendizado da escrita. 
Estudio de la construcción de los elementos caligráficos en el proceso de alfabetización de adultos en la Amazonia brasileña

A aplicação desses conceitos (como parte de um todo) compreende a projeção de imagens como instrumentos de comunicação, de informação, de conhecimento, fator de motivação, de discurso, de ensino, meio de ilustração da aula, utensílio de memorização e de observação das reais informações e mensagens a serem representadas e compreendidas pelo alfabetizando adulto, de modo a orientá-lo para o processo de assimilação e construção dos caracteres caligráficos (desenho das letras/ escrita).

Sendo assim e com o intuito de validar todas as informações obtidas, através da atividade Focus group, sobretudo a atuação do design como fator estratégico e de apoio para o uso dos fatores cognitivos e psicológicos - como base à estruturação do estudo, os profissionais de design consultados também aconselharam à aplicação de uma entrevista em profundidade com pedagogos, principalmente com aqueles que estão diretamente relacionados com o ensino e a Educação de Jovens e Adultos (EJ A), verificando os possíveis caminhos para tomada de ações que atinjam os obj etivos proposto por esse estudo.

\section{Considerações finais}

A educação brasileira ainda apresenta números altos no que concerne ao analfabetismo e, pelas dificuldades estruturais e logísticas, na Amazônia os índices são maiores. Contribuições científicas de outras áreas podem constituir um importante somatório de ações pedagógicas que, juntas e coordenadas, auxiliem a minimizar a estatística negativa com relação à educação básica, principalmente no que se refere à alfabetização de adultos.

0 trabalho reuniu informações que determinam aspectos relevantes para a procedência do estudo, mas que necessitam passar pelo crivo de especialistas em educação, principalmente a opinião e contribuição de pedagogos, de modo a corroborar os estudos dos designers em prol de uma forma mais eficaz da escrita manual, que possa também respeitar as especificidades do adulto iletrado.

\section{Referências}

CAMARGO, P. d., \& MARTINELLI, S. d. Educação de adultos: percepções sobre 0 processo ensino-aprendizagem. Revista Semestral da Associação Brasileira de Psicologia Escolar e Educacional (ABRAPEE), v. 10, n. 2, p. 197-209, jul./ dez. 2006.

COSTA, M. S., PALÁCIO, P. P., \& PAULUCCI, G. O uso do computador como meio de inserção na cultura letrada e midiática do jovem ou adulto nos cursos de alfabetização. V Colóquio Internacional Paulo Freire, (págs. 19-22). Recife, 2005. 
FERREIRO, E. Psicogênese da Língua Escrita. Porto Alegre: Artes Médicas, 1999.

FREIRE, P. Coleção Educação e mudança Vol. 1. Rio de janeiro: Paz e Terra, 1979. . Ação cultural para a liberdade. Rio de J aneiro: Paz e Terra, 1981. A importância do ato de ler: em três artigos que se completam 23 ed. São Paulo: Cortez, 1989.

GIL, A. C. Como Elaborar Projetos de Pesquisa 3 ed. São Paulo: Atlas, 1991.

HEITLINGER, P. Tipografia: origens, formas e uso das letras. Lisboa: Dinalivro, 2006.

IBGE 2007. Síntese de indicadores sociais: uma análise das condições de vida da população brasileira. Disponível em: http:// www.ibge.gov. br/ home/ estatistica/ populacao/ condicaodevida/ indica doresminimos/ sinteseindicsociais2007/indic_sociais2007.pdf. Acesso em: 10 mar. 2012.

KRUEGER, R. A., \& CASEY, M. A. Focus group: a practical guide for applied research. California: Sage Publications, 2000.

MONTESINOS, J. L., \& HURTUNA, M. M. Manual de tipografía: del plomo a la era digital. Valencia: Campgràfic Editors, 2007.

ROCHA, C. Projeto Tipográfico: Análise e produção de fontes digitais. São Paulo: Rosari, 2002.

UNESCO. The Global Literacy Challenge, as we move into the second half of the United Nations Literacy. Decade (2003-2012). Paris, 2008.

YIN, R. K. Estudo de Caso: planejamento e métodos. Porto Alegre: Bookman, 2001. Tradução: Daniel Grassi. 



\subsection{Artículo 3 - Una mirada del diseño sobre la morfología de los caracteres caligráficos y sus implicaciones en el proceso de alfabetización de adultos.}

Una mirada del diseño sobre la morfología de los caracteres caligráficos y sus implicaciones en el proceso de alfabetización de adultos.

Esta producción científica ha sido desarrollada con la intención de comparar los elementos constructivos de la escritura cursiva con la escritura normal 0 romana, a través de un análisis morfológico de los caracteres.

Revista Icono Facto - Revista de la Escuela de Arquitectura y Diseño (Colombia)

Indexada: LATINDEX y EBSCO

ISSN: 1900-2785

Enviado: Junio 2012 | Aceptado: Septiembre 2012 | Publicado: Previsión para 2013

Una mirada del diseño sobre la morfología de los caracteres caligráficos y sus implicaciones en el proceso de alfabetización de adultos

Almir de Souza Pacheco. Doctorado en Diseño, Fabricación y Gestión de Proyectos Industriales por la Universidad Politécnica de Valencia (UPV) España. Especialista en Diseño, Publicidad y Marketing - Universidade Federal do Amazonas (UFAM) - Brasil. Diseñador Gráfico y Docente. Correo electrónico: almirdesigner@gmail.com

María Begoña Jordá Albiñana. Doctora en Bellas Artes, directora académica del Master Universitaria en Ingeniería del Diseño, profesora titular e 
Estudio de la construcción de los elementos caligráficos en el proceso de alfabetización de adultos en la Amazonia brasileña

investigadora de la Universidad Politécnica de Valencia (UPV) España. Editora de la revista Anales de Ingeniería Gráfica. Correo electrónico: bego@mag.upv.es

Jimena González del Río Cogorno. Doctora en Bellas Artes, diseñadora gráfica, profesora del Master Universitario en Ingeniería del Diseño y del Grado en Ingeniería en Diseño Industrial y Desarrollo de Productos. Coordinadora del Master en Artes Gráficas de la Universidad Politécnica de Valencia (UPV) España. Correo electrónico: jimena@mag.upv.es

Karla Mazarelo Maciel Pacheco. Master en Ciencias Forestales y Ambientales - Universidade Federal do Amazonas (UFAM) - Brasil. Diseñadora Industrial y Docente Titular de la Universidade Federal do Amazonas, Brasil. Actualmente cursa el Doctorado en Diseño, Fabricación y Gestión de Proyetos Industriales de la Universidad Politécnica de Valencia (UPV) España. Correo electrónico: karlamazarelo@hotmail.com

\section{Resumen}

A través de un tratamiento metodológico cualitativo, el presente estudio tiene por objetivo comparar los elementos constructivos de la escritura cursiva con la escritura normal o romana, a través de un análisis morfológico de los caracteres (mayúsculos y minúsculos) y sus implicaciones en términos de uso y facilidad de ejecución en el proceso de alfabetización de adultos. La relación entre aspectos históricos, ergonomía y facilidad de uso, suscita una discusión sobre la forma en que el diseño de las letras puede constituir un elemento complicado para el adulto analfabeto. De igual manera se plantea cómo el diseño puede contribuir a minimizar los impactos negativos de la relación del estudiante con el universo de las letras.

Palabras clave: Diseño, Tipografía, Alfabetización de adultos.

\section{Introducción}

Casi siempre escribir a mano constituye un acto de gran dificultad para quienes se inician en el universo de las letras, sean niños 0 adultos, hecho que se prolonga durante toda la vida escolar. La facilidad de acceso a los recursos tecnológicos agrava aún más este panorama, pues es un hecho que las personas se alejan cada vez más de la escritura a mano.

El proceso de transmitir informaciones de forma escrita sufrió una gran evolución, principalmente a partir de la invención de la imprenta y de los 
procesos de impresión, sin embrago, la escritura manual no acompañó de forma proporcional este desarrollo. El surgimiento de los tipos metálicos y el desarrollo de la industria gráfica contribuirán al alejamiento cada vez mayor de los formatos derivados de la escritura a mano (Montesinos \& Hurtuna, 2007). La gran variedad de tipos surgidos en los últimos cinco siglos y de adaptaciones a los diversos tipos de manifestaciones visuales presenta formas individuales de caracteres que se diferencian bastante de aquellos enseñados hasta nuestros días.

Considerando la actual facilidad de acceso a los medios de comunicación, la variedad de aparatos electrónicos y el número de horas que un niño pasa frente a un televisor antes de iniciar su vida escolar, es perfectamente justificable una posible confusión formal entre los caracteres que aprende a escribir y aquellos que se le están presentando de forma impresa y/o digital en el mundo que lo rodea (Rocha, 2002). Aunque más adaptado al medio ambiente comunicativo, en función de la edad, el adulto analfabeto también sufre el mismo problema en cuanto al diseño de las letras, principalmente en determinados caracteres que presentan variedades formales, así como también en aquellos que poseen estructuras constructivas distintas en las versiones minúsculas y mayúsculas.

La baja calidad de la grafía presentada por la mayoría de las personas hace que el uso de una máquina para realizar casi todas las actividades que exigen el uso de la letra escrita a mano, se torne bastante justificable. Detrás de esto hay un fuerte reclamo ecológico y económico, pues habría una consecuente disminución del uso de papel y también de los más variados materiales utilizados en el proceso de la escritura.

Otro factor preponderante es la incipiente variedad de alternativas caligráficas en la enseñanza y de los parámetros de comparación de sus resultados. Para Heitlinger (2006), faltan fuentes tipográficas adecuadas a las capacidades cognitivas y motoras de los niños en la época de aprendizaje. El consenso es menor cuando se trata de la alfabetización de adultos casi olvidados en lo que concierne a estudios de esa naturaleza, prueba de esto es la escasez de material didáctico para alfabetización de esa categoría de alumno. La caligrafía necesita adaptarse a las evoluciones tecnológicas y a las necesidades del mundo moderno, así como a las variantes de perfil del alumno, no importa si se trata de un niño o un adulto.

Expuesto lo anterior, este trabajo busca hacer una reflexión sobre la morfología de los caracteres caligráficos y de sus implicaciones para el proceso de alfabetización de adultos, razón por la cual la investigación se encuentra centralizada en los siguientes objetivos: 
Estudio de la construcción de los elementos caligráficos en el proceso de alfabetización de adultos en la Amazonia brasileña

- Comparar la conveniencia del uso de los caracteres cursivo y romano en la enseñanza de la escritura a adultos.

- Analizar la morfología de los caracteres caligráficos

- Identificar qué forma de caracteres caligráficos es más adecuada para la enseñanza de la caligrafía destinada a los adultos analfabetos.

\section{Aspectos Históricos}

Para Frutiger (2001) la evolución de las señales y de la escritura sufrió varias transformaciones y simplificaciones, cambiando según los medios de expresión y la localización geográfica. Las primeras manifestaciones de la escritura estaban intrínsecamente relacionadas con el tipo de herramienta y el soporte adoptado por el hombre para efectuar sus manifestaciones gráficas. Los más antiguos registros fueron hechos por medio de surcos y cortes rústicos en piedra y madera. Ese tipo de incisión profunda permitía que la señal fuera percibida de forma óptica y táctil (Frutiger, 2001). Ante la necesidad de hallar un medio de expresión permanente, el hombre primitivo recurrió a ingeniosos adornos de objetos simbólicos 0 a señales materiales en los tallados y los diseños (Higounet, 2003).

Como los instrumentos de escribir o tallar, inicialmente se trataban de elementos rudimentarios y naturales (un pedazo de madera o piedra), las "letras" no poseían modulación, o sea, tenían un trazo uniforme. Así, la caligrafía permaneció invariable durante muchos siglos. Lo mismo que sucedió con la evolución de las herramientas y soportes, las formas de los elementos constituyentes de los caracteres tenían uniformidad de trazo derivado de la facilidad de ejecución y del reducido número de movimientos para su diseño, como los del alfabeto Fenicio (Figura 1) que dio origen a los alfabetos árabe, hebraico, griego y latín (Ambrose \& Harris, 2006).
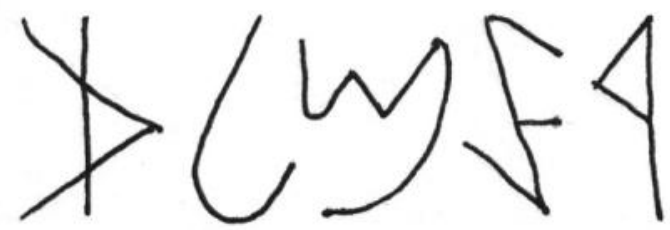

A3_Fig. 1 - Caracteres fenicios sin modulación (alrededor de 1600 a.C).

Fuente: autores 
La simplicidad en el trazo de los caracteres de la figura 1 probablemente son consecuencia del material utilizado para escribir y del uso de la superficie en que tales caracteres fueron escritos. Son líneas rectas y angulares del mismo espesor y con limitados elementos curvos, lo que denota la intención de diseñar formas simples y más fáciles de ej ecutar para el hombre.

El interés por mejorar la forma de escribir las letras surgió a partir de la evolución y adaptación del método de escribir que hicieron los escribas y monjes. Como resultado, surgió en Italia el primer cuaderno de caligrafía en el año 1522. (Heitlinger, 2006). Ludovico Vicentino degle Arrighi fue el gran responsable de la popularización de la letra llamada cancilleresca o itálica y de establecer la cursiva como la letra preferida en la tipografía. Arrighi era escribano papal y uno de los calígrafos/tipógrafos que participaron directamente en la creación de la cultura tipográfica occidental durante el Renacimiento Italiano. Se acordó convencionalmente llamar cursiva a todo tipo de letra escrita a mano y de aspecto caligráfico (Heitlinger, 2006).

La popularización de la escritura cursiva en Europa tuvo una gran influencia en la cultura occidental y permaneció viva en el proceso de iniciación de la escritura hasta nuestros días (Mediavilla, 2001). La fuerte influencia europea en la cultura occidental y el establecimiento de las colonias implantadas en todo el continente americano, causó una "invasión" de la escritura cursiva en el sistema educacional. Hoy, después de 500 años, esa influencia es perceptible y, aunque permanezca sin respuesta en los libros de caligrafía, es tema relevante en lo que concierne a la alfabetización de niños y adultos en un mundo en el que este tipo de escritura es cada vez menos usual en unos medios de comunicación promovidos por el desarrollo tecnológico. Jury (2007) refuerza ese pensamiento afirmando que a partir de la década de 1920, la máquina de escribir prácticamente sustituyó la escritura a mano para la producción de la contabilidad y de la correspondencia de las empresas y, por tanto, la importancia de la enseñanza de la caligrafía en las escuelas disminuyó gradualmente.

La evolución tecnológica de la escritura es incomparable con los instrumentos de uso propios de la escritura manual. Aun cuando las características formales del producto escrito sean las mismas hay una brecha entre la forma de escritura de la antigüedad y la que usamos en nuestros días. La escritura cursiva enseñada en las escuelas en el proceso de alfabetización (Figura 2), presenta una gran complejidad de ejecución que, según opinión de la mayoría de especialistas, tiene como uno de los objetivos principales, auxiliar en el desarrollo de la cordinación motora fina de los niños. No se puede afirmar que tal justificación sea tan relevante en la alfabetización de adultos, una vez que el adulto ya posee cierto grado de desarrollo psicomotor, además del hecho 
Estudio de la construcción de los elementos caligráficos en el proceso de alfabetización de adultos en la Amazonia brasileña

de que la coordinación motora fina se refiere a la destreza a la hora de realizar movimientos precisos y suaves, principalmente con las manos y los dedos, como escribir, pintar, diseñar, recortar, montar, o sea envuelve aspectos visomotores (Ajuriaguerra, 1985).

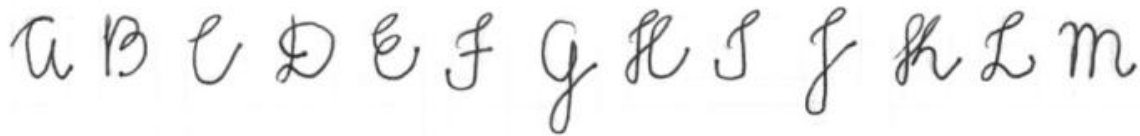 $n \in p \in R \& J u v w x y z$ $a b c d e f g h i j k l m$

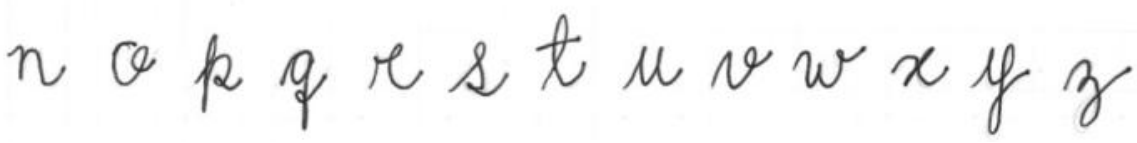

\section{A3_Fig. 2 - Alfabeto caligráfico cursivo.}

Fuente: autores

Las características formales de las letras cursivas pueden constituir un interesante instrumento de análisis por parte del diseñador, pues presentan elementos que remiten a varios tipos de observaciones, como por ej emplo:

- ¿Tendría la letra cursiva el formato ideal para que el adulto analfabeto aprenda a escribir?

- ¿Por qué muchos adultos alfabetizados poseen la letra diferente de la que aprenden en la escuela?

- ¿En el mundo actual, regido por la tecnología, donde cada vez menos personas escriben a mano, existe la necesidad de que un adulto analfabeto aprenda a escribir rápido y de forma cursiva?

- ¿Cuál es la ventaja de escribir rápido y de forma cursiva si la letra es ilegible?

La búsqueda de respuestas para cuestiones como las expuestas anteriormente, constituye parte de la motivación presente en la investigación, colocando el diseño en el centro de las discusiones sobre los aspectos morfológicos de los 
caracteres caligráficos o las posibles contribuciones que puedan surgir al respecto de la referida temática en el campo de la alfabetización de adultos.

\section{Metodología}

El tratamiento cualitativo adoptado para el presente estudio busca comprender y discutir los fundamentos teóricos que relacionan al adulto mayor analfabeto con la morfología de las letras adoptadas en el proceso de alfabetización, entendiendo que las formas de las mismas constituyen, fundamentalmente, elementos complicados que aparecen en la ejecución manual. La siguiente descripción de la metodología presenta la forma en que fue pensada la investigación, pues la eficiencia del estudio depende de la elección y utilización de los materiales y métodos precisos para comprender resultados que sean satisfactorios al ámbito científico. Para eso, el trabajo debe determinar un objetivo a alcanzar, y a partir de él, trazar una planificación del recorrido para la construcción del conocimiento sobre el objeto estudiado. Siendo así Gil (2002) define la investigación como un "procedimiento racional y sistemático que tiene por objetivo proporcionar respuestas a los objetivos propuestos". Cuando no se dispone de informaciones suficientes para responder al problema o la información no se encuentra adecuadamente en orden, la investigación proporciona medios para que se obtengan estas respuestas. La organización varía de acuerdo con las características de la investigación. Se utilizarán en este proyecto los procedimientos expuestos a continuación:

- Método inductivo

El método inductivo parte de los hechos particulares, suficientemente aceptados y constatados para llegar a una conclusión general no contenida en los hechos examinados.

- En cuanto a la naturaleza de la investigación: Científica

Fachin (2006) relata que el Conocimiento Científico es el resultado de la investigación metódica y sistemática de la realidad. Analiza los hechos a fin de descubrir sus causas y concluir las leyes que los rigen. En la investigación científica se exponen los resultados que pueden utilizarse para solucionar 0 minimizar ciertos problemas.

- En cuanto a los objetivos: investigación exploratoria.

De acuerdo con Gil (2002), la investigación exploratoria tiene el objetivo de proporcionar mayor familiaridad con el problema. Esta investigación será 
Estudio de la construcción de los elementos caligráficos en el proceso de alfabetización de adultos en la Amazonia brasileña

realizada a través del análisis bibliográfico y del análisis de ejemplos que ayuden a estimular la comprensión.

- Procedimientos técnicos: investigación bibliográfica.

Según Gil (2002), la investigación bibliográfica se desarrolla a partir de material ya elaborado constituido principalmente por libros y artículos científicos. Sirve como base para los estudios a realizar y proporciona la familiaridad del investigador con el área de estudio.

Instrumento de investigación: observación, experimentación y comparación.

\section{Resultados}

\section{Comparación entre la gráfica cursiva y la romana para el uso en la alfabetización de adultos}

El formato ideal de las letras a utilizar en el proceso de alfabetización de adultos tal vez pase por una simplificación de la forma, o sea, utilizar caracteres con aspectos lineales, sin modulación, resultado de la mezcla de líneas verticales, horizontales, diagonales, arcos y circunferencias como ya pudo observarse en líneas anteriores.

Un estudio de la forma de los caracteres mayúsculos centrado en los elementos de la ergonomía puede contener los ingredientes necesarios para identificar el camino a seguir en la búsqueda del formato ideal de las letras. Los múltiples estudios centrados principalmente en medir la legibilidad, presentan varios parámetros tipográficos como: diseño de las letras, tamaño del cuerpo, espacio entre líneas, letras y palabras. La relación entre lo que el alumno escribe a mano y lo que lee en su entorno, es muy importante en cuanto al análisis de las letras, principalmente en lo que concierne a la legibilidad.

Los primeros estudios y discusiones sobre los factores que afectan a la facilidad y la velocidad de lectura son agrupados bajo el término legibilidad que se empleó (Rumjanek, 2008) y hace referencia al reconocimiento de los caracteres individuales que ocurren en la lectura. Sin embargo, para la autora, solamente a partir de 1940, algunos estudiosos en el tema pasarán a utilizar el término lecturabilidad (readability) pues parecía un término más amplio y más significativo. 
En lo que concierne a la grafía cursiva y su percepción, además de los aspectos de la ergonomía, se destacaron algunos otros para demostrar sus restricciones técnicas:

La legibilidad de la grafía cursiva, en detrimento de las demás, es compleja con palabras en mayúscula (o caja alta) como se muestra en el cuadro 1.

\section{A3_Cua. 1 - Complejidad de lectura de las mayúsculas}

\begin{tabular}{|l|c|c|c|}
\hline \multirow{2}{*}{ fuente } & \multicolumn{3}{|c|}{ COMPLEJ IDAD DE LECTURA EN CAJ A ALTA } \\
\hline cursiva & arial & $\begin{array}{c}\text { times new } \\
\text { roman }\end{array}$ \\
\hline $\begin{array}{l}\text { ejempl } \\
0\end{array}$ & s p p grafsa & TIPOGRAFIA & TIPOGRAFIA \\
\hline
\end{tabular}

Los diseños de las letras mayúsculas y minúsculas cursivas son diferentes entre sí y respecto a las otras letras existentes en las distintas formas de aplicación en libros, revistas, periódicos, carteles, etc. (Cuadro 2).

A3_Cua. 2 - Diferenciación formal entre caracteres (mayúsculos y minúsculos) de la misma letra

\begin{tabular}{|c|c|c|c|}
\hline & \multicolumn{3}{|c|}{ DIFERENCIAS ENTRE MAYÚSCULA Y MINÚSCULA } \\
\hline fuente & cursiva & calibri & garamond \\
\hline ejemplo & Ua f f & A a Ff & A a F f \\
\hline
\end{tabular}


Estudio de la construcción de los elementos caligráficos en el proceso de alfabetización de adultos en la Amazonia brasileña

Confusión formal o similaridad entre letras cursivas, lo que no ocurre con las demás letras. Por ej emplo, por la forma del diseño, hay confusión entre letras como " $R$ " $y$ " $k$ ", entre las mayúsculas " $U$ " y " $V$ " y entre " $F$, "I" $y$ " $T$ ". Cuadro 3.

A3_Cua. 3 - Similaridad formal entre caracteres diferentes

\begin{tabular}{|c|c|c|c|}
\hline & \multicolumn{3}{|c|}{ SIMILARIDAD FORMAL ENTRE LETRAS } \\
\hline fuente & cursiva & rockwell & calibri \\
\hline ejemplo & $\Re k u v$ f JJ & Rk UV FIT & Rk UV FIT \\
& & & \\
\hline
\end{tabular}

Cinel (2003), en su texto sobre Digrafía ${ }^{1}$, expone que, a pesar de los estudios avanzados al respecto del aprendizaje de la escritura, la lectura y la gramática (normativa y, por eso, deficiente) de las cartillas brasileñas, que todavía están en uso, no explican nunca a los maestros ni a los alumnos esta multivariedad de trazos o de formas de representación gráfica, o el porqué de esas diferencias y como las enseñan, las aprenden.

Todavía en la observación de Cinel (2003), se exige un trabajo doble a los niños: primero, aprender a escribir en letra de molde. Es más fácil, más comprensible, aparece en los textos, rótulos y en el mundo escrito que nos rodea. Después se exige que el niño escriba en letra cursiva, más complicada, de más difícil lectura y de carácter individual e idiosincrático pues cada usuario adopta su propio trazado, coloca sus énfasis y, a través de ellos, muestra su personalidad.

Es de destacar que no todos los adultos alfabetizados mantienen el estilo caligráfico aprendido en la infancia y aquellos que lo mantienen sufren para ser comprendidos en cuanto se exige su escritura en exámenes selectivos de empleo o concursos públicos, por ejemplo. Uno de los mayores agravantes de esta problemática es la falta de práctica diaria de la escritura a mano en

\footnotetext{
${ }^{1}$ Según la autora, digrafía y perturbación de la escritura se refieren al trazado de las letras y las disposiciones de los conjuntos gráficos en el espacio utilizado. Se relacionan, por tanto, dificultades motoras y espaciales.
} 
función de la disponibilidad tecnológica moderna del uso de la escritura digital, ya en estado de evolución y presentándose como una tendencia cada vez mayor para la convergencia de la escritura directa en la pantalla de los dispositivos electrónicos (touchscreen) como teléfonos celulares, tabletas, palms, videojuegos, etc.

\section{Legibilidad de la escritura cursiva}

La legibilidad de la escritura es una cualidad compleja que se construye con la suma de varios aspectos, además de otras consideraciones relevantes estudiadas por Cinel (2003) con observaciones importantes de carácter pedagógico $\mathrm{y}$, a veces, dentro de aspectos ergonómicos, descritos a continuación:

- Forma de las letras

Por cuestiones históricas, cada letra tiene una forma característica. La claridad y la legibilidad del trazado inciden a la hora de escribir las letras en su forma exacta. La especificidad de la letra cursiva presenta, algunas veces deformaciones (Cuadro 4) que pueden causar dificultad de lectura o confusión de interpretación y lectura (Cinel, 2003). Por ejemplo:

a) si el alumno no cierra el círculo de la "a" puede leerse como "u" o como "ce";

b) cuando no cierra el círculo de la "d" puede leerse como " $\mathrm{cl}$ " o "el";

c) Otros escriben " $n$ " como " $u$ ";

d) algunos alumnos pueden adquirir el hábito de escribir " $m$ " como " $u$ " 0 como " $n$ ", etc. 
Estudio de la construcción de los elementos caligráficos en el proceso de alfabetización de adultos en la Amazonia brasileña

\section{A3_Cua. 4 - Deformación de caracteres}

\begin{tabular}{|c|c|c|}
\hline & \multicolumn{2}{|c|}{$\begin{array}{c}\text { FORMATO E DEFORMACIÓN DE } \\
\text { CARÁCTER CURSIVO }\end{array}$} \\
\hline & $\begin{array}{c}\text { Formato } \\
\text { normal }\end{array}$ & Deformación \\
\hline a) & & \\
\hline b) & & \\
\hline C) & & \\
\hline d) & & \\
\hline
\end{tabular}

Estos son algunos ejemplos presentados para demostrar la importancia que la letra tiene para la legibilidad de la escritura. Según Cinel (2003) muchas veces, las formas inadecuadas de las letras son consecuencia de la falta de orientación docente, del mal uso o del abuso de las copias y de los dictados 0 de la rapidez desmedida para tomar apuntes dentro del aula, entre otras.

Otro aspecto a ser observado es el traslado de un sistema de escritura (letras de molde) a otro (letra cursiva), por ejemplo. Es preciso realizar un trabajo bien planificado, de común acuerdo con los alumnos, de modo sistemático y cuidadoso. La letra cursiva exige mayor esfuerzo mental y físico del alumno porque presenta movimientos complejos. 


\section{Análisis morfológico de la "letra de molde" (Romanas)}

Después de analizar los aspectos relevantes de la caligrafía cursiva tradicional, para así establecer un referente comparativo, se analizaron los caracteres romanos $^{2}$ en versiones mayúsculas y minúsculas. El objetivo del análisis es entender la complejidad de las formas de las letras romanas, en versiones mayúsculas y minúsculas en relación a la letra cursiva.

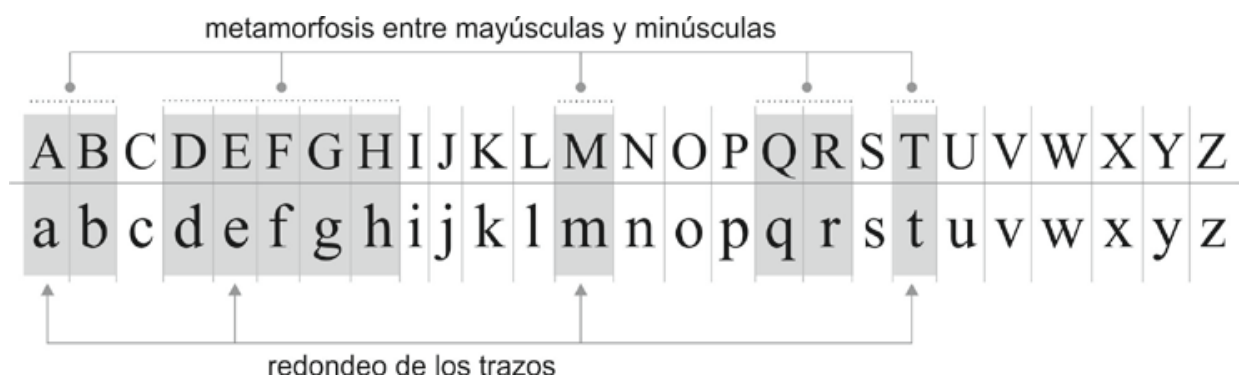

\section{A3_Fig. 3 - Transformaciones formales en la transición de los caracteres mayúsculos a minúsculos.}

Fuente: autores (adaptado de Frutiger, 2001).

La figura 3 también muestra, comparando los aspectos formales, la gran alteración que el mismo carácter presenta en sus versiones mayúsculas y minúsculas (destacado en gris), llegando, en algunos casos, a ser radical como en el caso de las letras A, D, G y Q. Es natural que un iniciado en el proceso de alfabetización confunda esas letras puesto que existen otras en las que ocurre diametralmente lo contrario, o sea, el formato de la minúscula es idéntico al de la mayúscula, como en el caso de las letras $C, K, O, S, W, X$ y Z.

Además de las transformaciones formales que sufren los caracteres es importante hacer hincapié en otros factores presentes en los caracteres mayúsculos y minúsculos ${ }^{3}$ que deben analizarse de forma separada.

2 El patrón tipográfico del alfabeto utilizado en la comparación tuvo como base un formato similar a las populares "letras de molde", o sea, una letra hecha a mano, con trazos simples y más próximos a aquellas utilizadas en las distintas formas de comunicación visual, como por ejemplo: libros, revistas, carteles etc.

3 Para realizar el estudio, se adoptaron los 26 caracteres del alfabeto occidental (que hoy sirve de base para las lenguas occidentales) conforme describe Frutiger (2001). 
Estudio de la construcción de los elementos caligráficos en el proceso de alfabetización de adultos en la Amazonia brasileña

Inicialmente se estudiaron los caracteres mayúsculos. A través de sus formas básicas se consideraron sus elementos constructivos y el grado de dificultad constructiva, conforme se ilustra en el Cuadro 5.

\section{A3_Cua. 5 - Forma básica de los caracteres - mayúsculas}

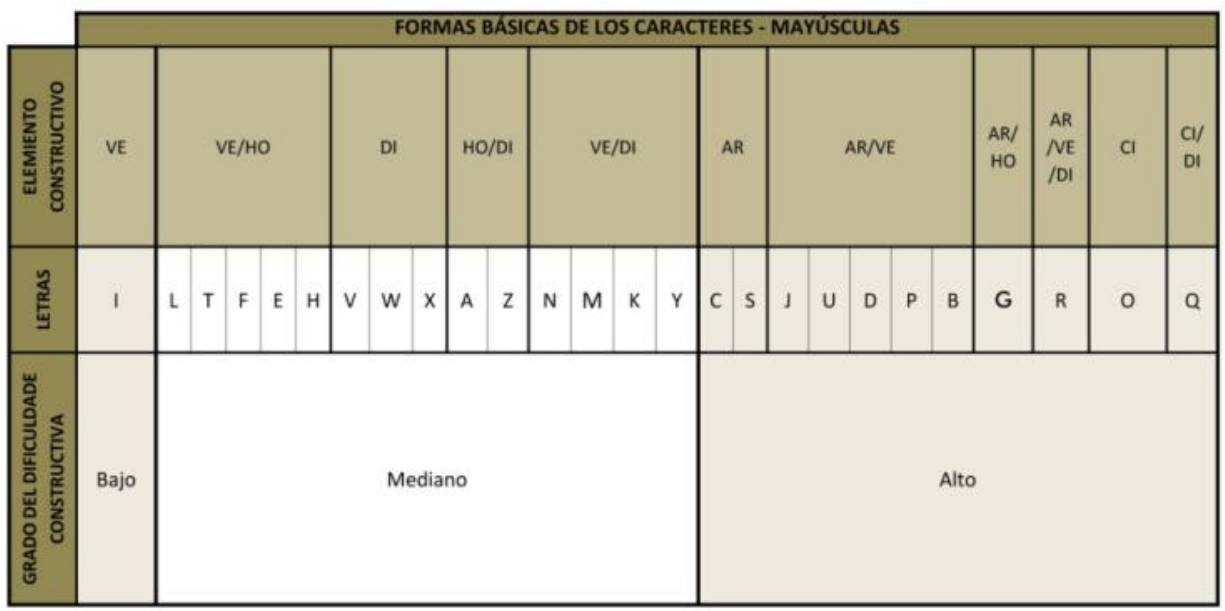

Subtítulo: VE (vertical); HO (horizontal); DI (diagonal); AR (arco); $\mathrm{Cl}$ (circunferencia).

Basándonos en la forma de los caracteres mayúsculos, cantidad y características de los trazos, además de la observación de los principales problemas presentes en la manera en que el adulto analfabeto ejecuta los trazos de las letras, se establecieron tres niveles de dificultad: Bajo, Medio y Alto. Solamente la letra "I" está presente en el primer grupo (Bajo) y fue considerada así por contener apenas la forma vertical. En el segundo grupo (Medio) se concentran la mayor parte de los caracteres (14), compuestos por uno o dos elementos, distribuidos así: solo con diagonales (03); con elementos verticales y horizontales (05); con horizontales y diagonales (02); y con verticalidad constructiva, clasificados así por contener elementos curvos (arco y circunferencia), divididas de la siguiente forma: solo con arcos (02), arco y vertical (05); arco y horizontal (01); circunferencia y diagonal (01); solo circunferencia (01) y la letra "R", única mayúscula compuesta por tres elementos (arco, vertical y diagonal).

Para el análisis de las letras minúsculas, se utilizaron los mismos criterios, principalmente para facilitar una comparación posterior con el estudio hecho con las mayúsculas. (Cuadro 6). 
A3_Cua. 6 - Formas básicas de los caracteres - minúsculas

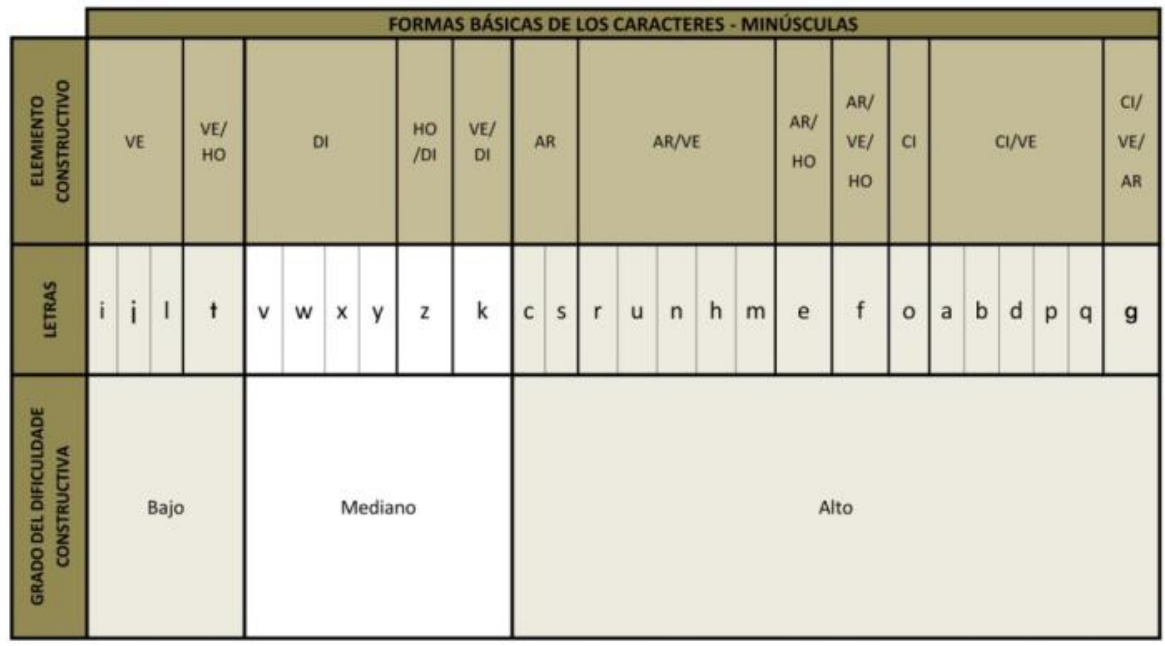

En el grado de Dificultad Constructiva identificado como Bajo, las minúsculas presentan un número mayor de letras (04), de las cuales una presenta elementos verticales y horizontales y las demás (03) solamente verticales. Las letras de grado Medio (06) se dividen en los siguientes grupos: solo con elementos diagonales (04); con elementos diagonales y horizontales (01) y con elementos diagonales y verticales (01). La concentración mayor de las letras está en el Grado de Dificultad Constructiva Alto (16), divididas de la siguiente forma: solo con $\operatorname{arcos}^{4}(02)$; con arcos y verticales (05); con arco y horizontal (01); con arco, vertical y horizontal (01), solo con circunferencia (01); con circunferencia y elementos verticales (05) y con circunferencia, elementos verticales y arco (01).

Para un mejor análisis conjunto y comparativo entre los caracteres Romanos mayúsculos y minúsculos, se elaboró el Cuadro 7, que representa la unión de los Cuadros 5 y 6 y que tiene como objetivo proponer una mejor visualización de las letras que presentan mayores y menores grados de dificultad constructiva. Se trata de un resumen de los elementos constructivos de cada letra que permite identificar qué caracteres poseen los mismos elementos compositivos, cuáles presentan la combinación de más de dos elementos y qué

4 Para efectos de análisis y para que no haya confusión entre las características formales, las letras consideradas con arco presentan la forma abierta y las letras con circunferencia tienen la forma circular cerrada. 
Estudio de la construcción de los elementos caligráficos en el proceso de alfabetización de adultos en la Amazonia brasileña

mayúsculas no poseen correspondencia de elementos con las minúsculas y viceversa.

A3_Cua. 7 - Cuadro Comparativo de las Formas Básicas de los Caracteres

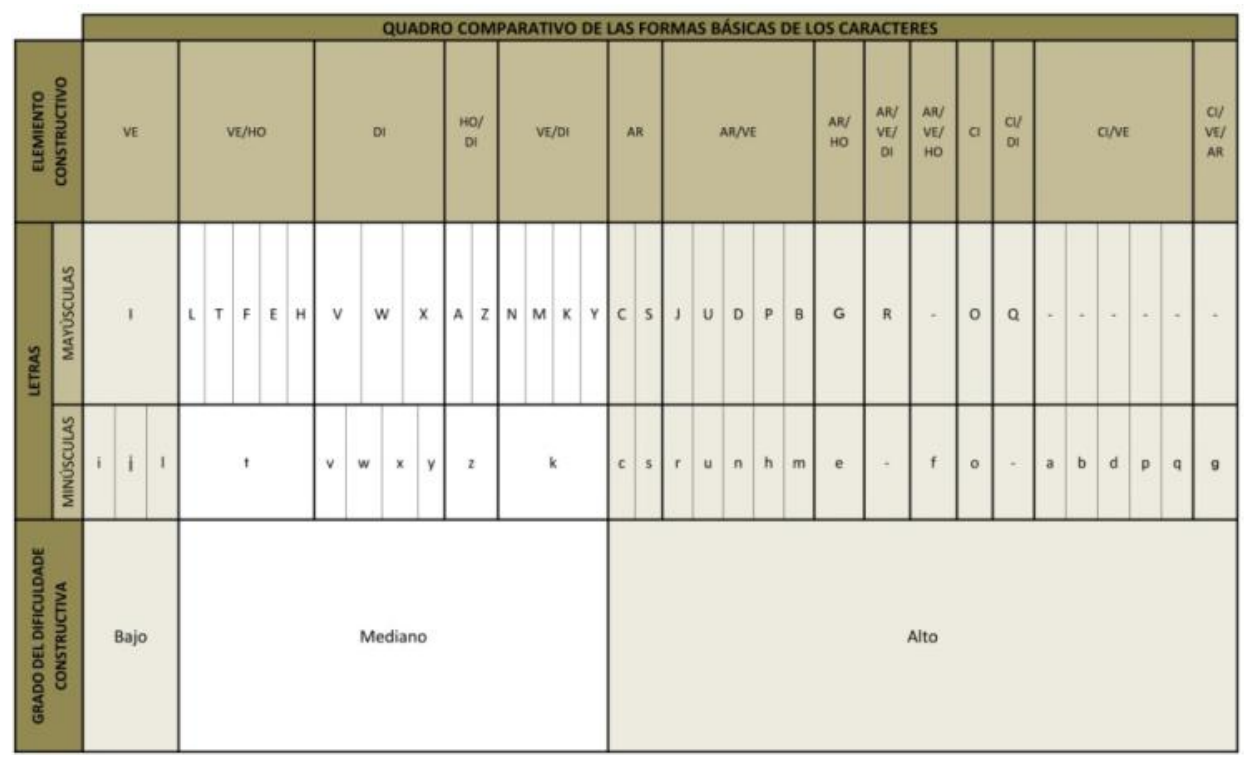

Se observa en el Cuadro 7 que en lo referente a las mayúsculas, éstas poseen apenas una letra en el Grado de Dificultad Constructiva Bajo, mientras que las minúsculas presentan tres. La concentración mayor de mayúsculas se encuentra en el grado medio (14) en tanto que las minúsculas representan apenas la mitad (07). 16 letras minúsculas están concentradas en Grado Alto frente a 11 minúsculas.

De las 52 letras (26 mayúsculas y 26 minúsculas) solamente 03 presentan más de dos elementos constructivos: la letra mayúscula " $R$ " y las minúsculas " $f$ " y " $g$ ".

El mayor número de letras con similitudes formales entre mayúsculas y minúsculas están en el Grado Medio de Dificultad Constructiva, representadas por las letras que poseen solo trazos diagonales ( $\mathrm{Vv}, \mathrm{Ww}$ y $\mathrm{Xx})$. 


\section{Discusión}

Respecto al análisis morfológico de los caracteres cursivos y romanos aplicados a la alfabetización explicados en el presente estudio, es importante observar algunos aspectos:

a) Ia caligrafía cursiva utilizada en el proceso de alfabetización de adultos presenta varios elementos que dificultan su ejecución, complican la legibilidad y la cualidad de la escritura.

b) la caligrafía romana, aunque también contenga elementos complicados en su escritura, se muestra más simple de ejecutar y está dentro del contexto comunicativo del entorno del alumno.

c) Ambas caligrafías son enseñadas en el proceso de alfabetización de adultos, pero la cursiva prevalece como la indicada para el uso corriente; el ideal sería la búsqueda de un término medio, o sea, una simplificación de las cursivas y una tentativa de aproximación formal con las letras romanas.

d) El docente carece de material de enseñanza de la escritura para adultos, así como no existe un patrón de la forma de los caracteres usados en el proceso de alfabetización; los autores consideran que eso debería recibir una atención especial de los órganos involucrados con la educación

e) A partir de los cuadros de análisis formal estudiados en el artículo, los autores sugieren su uso, por parte de los docentes para intentar la enseñanza de las letras a partir del grado de dificultad constructiva de los caracteres pudiendo ser asociado a la enseñanza de las formas básicas (triángulo, círculo, cuadrado);

f) Como los elementos constructivos de la forma de las letras son los mismos de los números, el estudio de éstos no fue abordado en el artículo. Los autores observan que los números solo pueden ser escritos de forma individual y no vinculados, como las letras romanas, o sea, los números no pueden ser escritos en forma cursiva;

g) Por limitación de material didáctico direccionado, la mayoría de las estrategias y libros usados por adultos analfabetos fueron elaborados para niños, por tanto el profesor debe tener especial atención en el proceso de adaptación didáctica de los recursos disponibles. 
Estudio de la construcción de los elementos caligráficos en el proceso de alfabetización de adultos en la Amazonia brasileña

El análisis del proceso constructivo de las letras en la búsqueda de la forma más simple y eficiente de escribir los caracteres caligráficos abordado en este trabajo, tiene como objetivo contribuir con más de un recurso para que los profesores tengan una mayor variedad de opciones didácticas a la hora de establecer estrategias, en ese caso, a través de la mirada del diseñador y de sus conocimientos específicos sobre la morfología, Gestalt, semiótica y los detalles que permean el universo de la forma.

\section{Conclusiones}

El artículo presentó un análisis morfológico sobre los caracteres caligráficos que se utilizan en el proceso de alfabetización. Las letras cursivas y las romanas presentan particularidades formales que deben ser observadas por los educadores en cuanto a la determinación de las estrategias de enseñanza. Por una serie de cuestiones de naturaleza cultural y social, pocas naciones utilizan los veintiséis caracteres del alfabeto occidental de la escritura ni dan una atención especial a las letras en la educación, prueba de eso es que no existe un patrón de manera específico de la forma de los caracteres en los cuadernos de caligrafía.

Según Heitlinger (2006) el modelo alemán es uno de los más interesantes y se basa en un diseño elemental y geométrico para facilitar el diseño de las formas; pertenecen al grupo que los alemanes apellidan Druckschriften, que significa letras de impresión. Ese tipo de alfabeto sirvió como base para varios países como Austria que usa la tipografía Lateinaus (Figura 4) para que los niños aprendan a leer en la escuela primaria. Es de resaltar que la cursiva se mantuvo con algunas pocas modificaciones en su forma. El aspecto que más llama la atención en ese ejemplo es su normalización:

$$
\begin{aligned}
& \text { Lateinaus } \\
& \text { abcdefghijklmnaponstumuseys } \\
& 123 \text { AlEEH JKL MOI } \\
& \text { tipagnafia cunsiva }
\end{aligned}
$$

\section{A3_Fig. 4 - Tipografía Laitenaus usada por las escuelas primarias alemanas y austríacas.}


Fuente: autores

El aprendizaje de la escritura constituye una de las etapas más importantes en el proceso de alfabetización, por lo tanto, el perfeccionamiento de este mecanismo didáctico requiere un poco de reflexión, principalmente en lo relacionado con el elemento tipográfico utilizado en las escuelas que es la tipografía cursiva.

De acuerdo con la investigación, aunque la escritura cursiva tenga relevancia en lo que concierne a la velocidad de la escritura y a las contribuciones relativas al desarrollo de la coordinación motora fina, representa un nivel mayor de complejidad constructiva del que representa la escritura romana, lo que influye sobremanera en la legibilidad de la escritura, unido al hecho de que esta letra no es utilizada comúnmente en las manifestaciones visuales presentes en el entorno comunicativo de las personas. Como el público objetivo del estudio es el adulto, esos factores solo dificultan el proceso de aprendizaje de la escritura.

En el compendio de indicadores de 2007 del IBGE, el número de analfabetos en Brasil en el año de 2005 superaba el $11 \%$ ese porcentaje representaba más de 14 millones, de los cuales $36.4 \%$ pertenecían a la franja de edad de 40 a 59 años. A pesar de que los números son todavía muy altos, no existe un número proporcional de acciones, por menores que sean, para su reducción. Por más paradójico que parezca, la educación es un aspecto básico del desarrollo social de un país, aunque sea relegado y, a veces, olvidado cuando éste es comparado con el grado de inversión en tecnología. Esfuerzos simples y colectivos pueden hacer la diferencia, mínimamente, para colocar la educación en el centro del debate científico que envuelva una de sus más complejas cuestiones: la alfabetización, el diseño, como una actividad multidisciplinar, puede contribuir de forma significativa en ese contexto.

\section{REFERENCIAS}

Ajuriaguerra, J. (1985). Manual de Psiquiatria Infantil 2. ed. São Paulo: Masson.

Ambrose, G., \& Harris, P. (2006). The fundamentals of typography. Laussane: AVA Publishing, SA.

Buggy, L. A. (2007). O Mecotipo: método de ensino de desenho coletivo de caracteres tipográficos. Recife: Buggy.

Cinel, N. C. (2003). Disgrafia: Prováveis causas dos distúrbios e estratégias para a correção da escrita. Revista do professor, 19-25. 
Estudio de la construcción de los elementos caligráficos en el proceso de alfabetización de adultos en la Amazonia brasileña

DUL, J., \& WEERDMEESTER, B. (1993). Ergonomia Prática. São Paulo: Editora Edgard Blücher Ltda.

Fachin, O. (2006). Fundamentos de Metodologia. 5. ed. São Paulo: Saraiva.

Frutiger, A. (2001). Sinais e Símbolos: desenho, projeto e significado. São Paulo: Martin Fontes.

Gil, A. C. (2002). Como elaborar projetos de pesquisa. 4ạ ed. São Paulo: Atlas.

Heitlinger, P. (2006). Tipografia: origens, formas e uso das letras. Lisboa: Dinalivro.

Higounet, C. (2003). História Concisa da Escrita. São Paulo: Parábola Editorial.

IBGE. (2 de Fevereiro de 2007). IBGE - Instituto Brasileiro de Geografia e Estatística. Recuperado el 10 de Maio de 2012, de IBGE: http:// www.ibge.gov. br/ home/ estatistica/ populacao/ condicaodevida/ indica doresminimos/ sinteseindicsociais2007/ indic_sociais2007.pdf.

Jury, D. (2007). O que é a Tipografia? 0 que é a Tipografia? Barcelona, Barcelona, Espanha: Gustavo Gili.

Lakatos, E. M., \& Marconi, M. d. (2001). Metodologia do trabalho científico: procedimentos básicos, pesquisa bibliográfica, projeto e relatório, publicações e trabalhos científicos. 6. a ed. São Paulo: Atlas.

Mediavilla, C. (2001). Caligrafía: Del Signo Caligráfico a la Pintura Abstracta. Caligrafía: Del Signo Caligráfico a la Pintura Abstracta. Valencia, Valencia, España: Campgràfic.

Montesinos, J. L., \& Hurtuna, M. M. (2007). Manual de tipografía: del plomo a la era digital. Valencia: Campgràfic Editors.

Rocha, C. (2002). Projeto Tipográfico: Análise e produção de fontes digitais. São Paulo: Rosari.

Rumjanek, L. (2008). 8o Congresso Brasileiro de Pesquisa e Desenvolvimento em Design, 8 a 11 de outubro de 2008. São Paulo. 


\title{
3.4. Artículo 4 - A participação do design no ensino e na transição entre a escrita manual e as tendências da tipografia no ambiente tecnológico: Um convite à reflexão
}

La participación del diseño en la enseñanza e en la transición entre la escritura manual y las tendencias de la tipografía en el ambiente tecnológico: Una invitación a la reflexión.

Esta producción científica ha sido desarrollada con la intención de hacer un estudio cualitativo acerca del abandono progresivo de la escritura manual, motivado por el desarrollo tecnológico en el inicio del siglo XXI.

Congreso: 2ND CIDAG, THE INTERNATIONAL CONFERENCE IN DESIGN AND GRAPHIC PRINTING (Portugal)

ISBN: En espera de publicación.

Enviado: Enero 2012 | Aceptado: Abril 2012 | Publicado: En espera de publicación.

\section{A PARTICIPAÇÃO DO DESIGN NO ENSINO E NA TRANSIÇÃO ENTRE A ESCRITA MANUAL E AS TENDÊNCIAS DA TIPOGRAFIA NO AMBIENTE TECNOLÓGICO: Um convite à reflexão}

\author{
Almir Pachecoํ․ Begoña J ordá1, Jimena González ${ }^{1}$, Karla Pacheco ${ }^{2}$ \\ 1 Universitat Politècnica de València - UPV - Espanha \\ 2 Universidade Federal do Amazonas - UFAM - Brasil
}

almirdesigner@gmail.com; bego@mag.upv.es; jigondel@degi.upv.es;

karlamazarelo@hotmail.com 
Estudio de la construcción de los elementos caligráficos en el proceso de alfabetización de adultos en la Amazonia brasileña

\section{Resumo}

O presente artigo realiza, de forma elementar, um estudo qualitativo (levantamento e análise bibliográfica e documental) sobre 0 abandono progressivo da escrita manual pelos alunos, motivado pelo desenvolvimento tecnológico no início deste século. Tal renúncia merece especial atenção dos designers, principalmente no momento em que o estudo da tipografia ganha um espaço cada vez maior no ambiente acadêmico. Fora os aspectos técnicos da tipografia aplicada aos projetos gráficos, o designer também pode fazer parte de uma discussão que envolva questões inerentes a essa temática, tais como: Qual seria a melhor forma do design contribuir para minimizar os impactos dessa transição? Seria possível, através do design, encontrar um meio termo entre o uso da escrita tradicional a mão e o ambiente digital cada vez mais presente no cotidiano das pessoas? Os resultados alcançados com esta discussão poderão auxiliar na busca por respostas aos questionamentos supracitados através de um debate coletivo e multidisciplinar sobre uma maior participação do designer no impacto que o futuro da tipografia pode sofrer em função dos avanços tecnológicos e a forma como a comunicação vai afetar o dia-a-dia das pessoas.

\section{Abstract}

This article presents, in elemental form, a qualitative study (survey and literature review and documentary) about the progressive abandonment of handwriting by the students, motivated by the technological development in this century. Such waiver deserves special attention of the designers principally at the time the study of typography win a growing space in the academic environment. Aside from the technical aspects of typography applied to graphic designs, the designer can also be part of a discussion involving issues inherent in this theme, such as: What would be the best design's form to help minimize the impacts of this transition? Would it be possible, by design, find a middle ground between: the traditional hand writing use and the digital environment? Increasingly present in daily life. The results achieved with this discussion, may aid in the search for answers to the questions above, through a collective debate and greater participation on a multidisciplinary of the designer in the impact that the future of typography may suffer because of technology advances and how communication will affect the day-to-day lives. 


\section{Palavras-chave}

Design, Tipografia, Caligrafia

\section{Keywords}

Design, Typography, Calligraphy

\section{Introdução}

Com mais de uma década transcorrida do século XXI é importante refletir sobre 0 entorno tecnológico que acompanha 0 mundo atual e suas consequências para os mais variados segmentos. 0 presente artigo visa analisar as influências digitais no ensino, mais particularmente na forma como os alunos lidam com a escrita manual num cotidiano dominado pelo uso do computador e como o design pode interferir nesse contexto.

Contribuir nessa questão através da busca do equilíbrio formal entre os caracteres elaborados para a leitura e uma hipotética aproximação caligráfica manual que constitua um instrumento de transição paulatina e mais suave entre o meio físico e o digital talvez seja o grande desafio para os designers.

\section{História, forma e norma}

Embora o processo de transmitir informações de forma escrita tenha sofrido uma grande evolução, principalmente a partir da invenção da imprensa e dos processos de impressão, a escrita manual não acompanhou de forma proporcional tal desenvolvimento (Mediavilla, 2001). O surgimento dos tipos metálicos e 0 desenvolvimento da indústria de impressos corroboraram para 0 afastamento cada vez maior dos formatos de letra derivados da escrita à mão (Montesinos \& Hurtuna, 2007). A grande variedade de tipos surgidos nos últimos cinco séculos e adotados pelos diversos tipos de manifestações visuais apresenta formas individuais de caracteres que se diferenciam bastante daqueles ensinados até os dias atuais (Tabela 1).

\section{A4_Tab. 1 - Exemplo de diferenças formais entre caracteres maiúsculos e minúsculos.}

\begin{tabular}{|c|c|c|c|}
\hline & \multicolumn{4}{|c|}{ DIFERENÇAS FORMAIS ENTRE CARACTERES } \\
\hline Grafia/ Tipografia & cursiva & calibri & garamond \\
\hline exemplo & G a I f & A a F f & A a F f \\
\hline
\end{tabular}


Estudio de la construcción de los elementos caligráficos en el proceso de alfabetización de adultos en la Amazonia brasileña

Como pode ser observado no exemplo apresentada na Tabela $1^{5}$, o desenho das letras maiúsculas e minúsculas (em alguns casos) na grafia cursiva apresenta diferenças individuas entre si (letras " $A$ " e " $F$ ") e em relação à maioria dos tipos de letras aplicadas em cartazes, livros, revistas, mídias eletrônicas, etc.

Já existem países onde a normatização da escrita não se restringe a um determinado grupo, ela é ensinada na escola. A Alemanha possui uma letra normalizada, NormSchirift (Figura 1), escolhida pelos grupos de trabalhos que estudam a letra escolar no país. Depois de analisar vários aspectos positivos e negativos houve um consenso que é mais interessante treinar as crianças com uma letra próxima daquela que é vista impressa na maioria dos livros escolares (HEITLINGER, 2007).

\section{ABCDEFGHIJKLMNO PQRTUVWXYZ12367890 abcdefghijktmnopqrsuv wxyzẠÇOUßàáâäèéêë•}

\section{A4_Fig. 1 - Tipografia NormSchrift, letra normalizada alemã.}

A estrutura formal de características eminentemente geométrica demonstra a preocupação dos alemães em facilitar o processo de aprendizagem das letras através do uso das formas elementares básicas (círculo, quadrado e triângulo).

\section{0 design e a tipografia para o ensino}

A busca por soluções de uso geral para a tipografia com possibilidades de uso na área educacional remonta desde os tempos da Bauhaus. Em 1925 Herbert Bayer apresentou a sturm blond (Figura 2), chamado também de Alfabeto Universal. Um conjunto de letras desprovidas de modulação e serifas, sendo moldadas apenas com o uso de formas simples geométricas para a construção de todos os tipos (Montesinos \& Hurtuna, 2007). Para Heitlinger (2007), a

\footnotetext{
${ }^{5}$ É importante ressaltar que a Tabela 1 tem por objetivo somente exemplificar uma relevante questão quando se compara a grafia à mão com tipografias de uso comercial, e essas últimas foram tomadas de maneira aleatória e apenas para a visualização da diferença formal entre a letra escrita, como é ensinada na escola, e os tipos de letras de uso geral.
} 
estratégia reducionista de Bayer ignorava o uso das maiúsculas, uma vez que a sturm blond não as possuía; o argumento era que a palavra falada não distingue as maiúsculas das minúsculas e essa redução facilitava a aprendizagem da leitura na escola primária além de economizar espaço de armazenamento para os tipógrafos, já que só usariam as caixas baixas.

\section{abcoefghi jklmnopqr sTUVwxyz}

A4_Fig. 2 - Tipografia sturm blond de Herbert Bayer.

Outra interessante iniciativa abordada por Rocha (2003) é o trabalho do designer Bradbury Thompson. Ao observar a dificuldade do filho com a confusão da duplicidade de símbolos na composição das mesmas palavras em um livro infantil, criou em 1950 o Alphabet 26 (Figura 3). A proposta era tornar o alfabeto latino de bicameral a unicameral, ou seja, um único símbolo (constante) para representar as maiúsculas e as minúsculas como ocorre com 0 alfabeto árabe e o hebraico.

Thompson imaginava que, diminuindo para apenas 26 o número de caracteres do alfabeto a ser usado na escrita, facilitaria o processo de cognição das crianças, mas desconsiderava outros aspectos que são importantes para a percepção do texto escrito e a velocidade da leitura, como é o caso das ascendentes e descendentes, a variação das letras em itálico (a letra "a" muda nessa forma de aplicação para evitar que haja deformação) e outros aspectos técnicos inerentes à tipografia, seu uso e percepção. 


\section{aBCDe \\ FGHIJK \\ LmnOP \\ QRSTU \\ VWXYZ}

A4_Fig. 3 - Alphabet 26, projeto do designer Bradbury Thompson (1950).

\section{Tendências tipográficas para 0 ambiente tecnológico}

Alguns dos modernos aparatos tecnológicos portáteis e de uso diário como laptop, palmtop, tablet e telefone celular dispõem da tecnologia sensível ao toque (touchscreen), que permite escrever diretamente na tela, seja com uma caneta especial ou até mesmo com o próprio dedo. Alguns desses referidos equipamentos possuem um alfabeto particular para tornar ágil a escrita na tela (J ury, 2007), como mostra a Figura 4. Pensar que 0 touchscreen seria a tendência tecnológica da tipografia no ambiente digital pode ser precipitado, pois a evolução digital é rápida e constante e já existe a tecnologia de reconhecimento de gestos que promete aposentar o toque na tela. Estudos ainda precisam ser feitos para buscar o formato ideal dos caracteres em consonância com a melhor tecnologia.

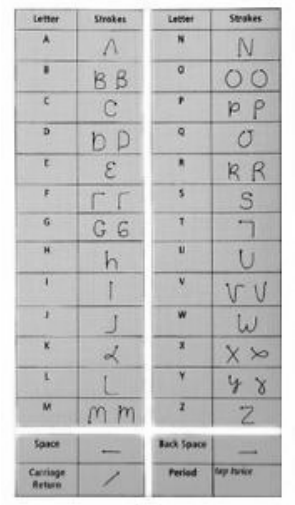

A4_Fig. 4 - folha informativa fornecida com um Palm Pilot (PDA). 


\section{Resultados e discussões}

0 presente artigo não tem a pretensão de ser conclusivo uma vez que a temática é muito ampla. 0 objetivo principal e fomentar uma discussão multidisciplinar sobre a tipografia usada no ensino e as tendências futuras no ambiente tecnológico em que vivemos.

Os exemplos mostrados no estudo mostram que ainda não se tem uma solução ideal quando se compara a escrita ensinada na escola com as tipografias aplicadas na comunicação visual e se nessa relação for acrescido o fato da escrita manual tender cada vez mais para a forma digital, os designers tem um grande desafio pela frente na busca da melhor forma de contribuir para essa transição. Não se pode esquecer também da diversidade de usuários e os aspectos socioculturais a eles relacionados, fato que torna as dificuldades ainda maiores.

Os designers devem procurar ampliar e compartilhar os conceitos técnicos envoltos no seu meio e que envolvam outras áreas do conhecimento. 0 constructo resultante pode ser muito mais proveitoso do que apenas uma solução paliativa para uma questão de projeto, convertendo-se numa proposta mais ampla e mais significativa.

\section{Referências}

Heitlinger, P. (2006). Tipografia: origens, formas e uso das letras. Lisboa: Dinalivro.

Jury, D. (2007). O que é a Tipografia? O que é a Tipografia? Barcelona, Barcelona, Espanha: Gustavo Gili.

Mediavilla, C. (2001). Caligrafía: Del Signo Caligráfico a la Pintura Abstracta. Caligrafía: Del Signo Caligráfico a la Pintura Abstracta. Valencia, Valencia, España: Campgràfic.

Montesinos, J. L., \& Hurtuna, M. M. (2007). Manual de tipografía: del plomo a la era digital. Valencia: Campgràfic Editors.

Rocha, C. (2002). Projeto Tipográfico: Análise e produção de fontes digitais. São Paulo: Rosari.

Reconhecimentos: Trabalho desenvolvido no programa de doutorado em Diseño, Fabricación y Gestión de Proyectos Industriales da Universitat Politècnica de València - UPV - Espanha. 

3.5. Artículo 5 - Análise do posicionamento de especialistas em pedagogia, psicologia e design sobre a construcão dos elementos caligráficos no processo de alfabetização de adultos na Amazônia brasileira

Análisis del posicionamiento de expertos en pedagogía, psicología y diseño con relación a la construcción de los elementos caligráficos en el proceso de alfabetización de adultos en la Amazonia brasileña.

Esta producción científica ha sido realizada con la intención de hacer un análisis de las contribuciones de expertos y diseñadores sobre el punto de vista de eses, no que concierne a la alfabetización de adultos.

Revista: ATOS DE PESQUISA EM EDUCAÇÃO (Brasil)

Indexada en: Open J ournal System

ISSN: 1809-0354

Enviado: Septiembre 2012 | Aceptado: EN PROCESO DE EVALUACIÓN | Publicado: EN PROCESO DE EVALUACIÓN

ANÁLISE DO POSICIONAMENTO DE ESPECIALISTAS EM PEDAGOGIA, PSICOLOGIA E DESIGN SOBRE A CONSTRUÇÃO DOS ELEMENTOS CALIGRÁFICOS NO PROCESSO DE ALFABETIZAÇÃO DE ADULTOS NA AMAZÔNIA BRASILEIRA

POSITIONING ANALYSIS OF SPECIALISTS IN PEDAGOGY, PSYCHOLOGY AND DESIGN ABOUT CONSTRUCTION OF THE HANDWRITING ELEMENTS IN THE ADULT LITERACY PROCESS IN THE BRAZILIAN AMAZON 
Estudio de la construcción de los elementos caligráficos en el proceso de alfabetización de adultos en la Amazonia brasileña

PACHECO, Almir de Souza

Universitat Politècnica de València - UPV/ Espanha

almirdesigner@gmail.com

ALBIÑANA, María Begoña J ordá

Universitat Politècnica de València - UPV/Espanha

bego@mag.upv.es

COGORNO, J imena Gonzáles del Rio

Universitat Politècnica de València - UPV/ Espanha

jimena@mag.upv.es

PACHECO, Karla Mazarelo Maciel

Universidade Federal do Amazonas - UFAM/ Brasil

karlamazarelo@hotmail.com

GAMA, Adênis Lêda Ferreira

Secretaria Estadual de Educação - SEDUC-AM/ Brasil

adenisgama@hotmail.com

RESUMO 0 presente artigo é parte integrante de uma tese de doutorado que versa sobre 0 estudo da construção dos elementos caligráficos no processo de alfabetização de adultos na Amazônia brasileira. 0 critério de escolha entre especialistas nas áreas de pedagogia, psicologia e design está pautado na tentativa de buscar contribuições multidisciplinares sobre a visão e experimentação, acadêmica e profissional desses, no que concerne à alfabetização de adultos, levando-se em consideração a problemática que envolve a caligrafia ideal para uso com o adulto iletrado e o pouco referencial bibliográfico existente sobre o tema. Nesse contexto, a pesquisa objetiva comparar a opinião de pedagogos, psicólogos e designers, sobre a temática 
abordada, com 0 intuito de identificar aspectos técnicos comuns, sistematizados através de uma metodologia qualitativa, e que possam nortear as ações sob o ponto de vista científico. Os especialistas assinalaram, como resultado, alguns pontos principais a serem considerados, como: a simplificação dos caracteres, através de formas elementares (círculo, quadrado e triângulo); uso de recursos didáticos que fortaleçam a relação professor/aluno e façam parte do entorno regional do mesmo, além do direcionamento do material didático ao perfil do alfabetizando adulto.

Palavras-chave: alfabetização de adultos, caligrafia, estudo de opinião.

ABSTRACT This article is part of a doctoral dissertation about the study of the construction of handwriting elements in the process of adult literacy in the Brazilian Amazon. The criterion of choice between specialists in the areas of pedagogy, psychology and design is guided in an attempt to seek multidisciplinary contributions, visions and experimentation of these academics and professionals in regard to adult literacy, taking into account the problems involved about an ideal handwriting to use with illiterate adults, and the few bibliographic references existing on the subject. In this context, the research aims to compare the views of educators, psychologists and designers on the theme discussed, in order to of identifying the technical aspects in common, systematized through a qualitative methodology that it can guide the actions under the scientific point of view. The experts pointed, as a result, some key points to consider, such as the simplification of characters through elementary shapes (circle, square and triangle), use of teaching resources that strengthen the teacher / student relationship and that it's part of the regional environment the same, besides directing the educational material to profile of the literacy adult .

Keywords: adult literacy, handwriting, opinion study.

\section{INT RODUÇÃO}

O século XXI já conta com mais de uma década e o analfabetismo ainda é um problema de amplitude global. Apesar dos avanços tecnológicos, científicos e dos métodos empregados no processo de ensino, a alfabetização ainda constitui um desafio para muitos países. Segundo dados da UNESCO (United Nations Educational. Scientific and Cultural Organization), através do Relatório de Monitoramento Global de Educação Para Todos (2011), o Brasil está entre os quinze países que concentram a metade do quantitativo mundial 
Estudio de la construcción de los elementos caligráficos en el proceso de alfabetización de adultos en la Amazonia brasileña

de crianças que se encontram fora da escola. Os números que envolvem a quantidade de adultos iletrados, que fazem parte do foco do presente artigo, são bem piores, uma vez que somam mais de quatorze milhões, posicionando o país entre os dez maiores índices de analfabetismo no mundo como podem ser observado na Figura 1.

A5_Fig. 1 - Números de adultos analfabetos no mundo (em milhões).

Fonte: adaptado de (UNESCO, 2011; Villas-Boas, 1998)

Os programas de educação de jovens e adultos surgidos no Brasil a partir da década de 1930 contribuíram significativamente na redução do número de analfabetos no país (SME, 2010), no entanto a questão a ser abordada na atualidade envolve 0 material didático empregado com 0 alfabetizando adulto. Durante muito tempo o analfabetismo era concebido como causa e não efeito da situação econômica, social e cultural do país. Essa concepção legitimava a visão do adulto analfabeto como incapaz e marginal, identificando psicológica e socialmente com a criança (PROMEAPI, 2007), talvez por isso exista uma lacuna teórico-pedagógica com relação aos livros usados para alfabetizar ou, até mesmo, a falta desses.

Em qualquer livraria, é muito fácil encontrar uma infinidade de cadernos de caligrafia direcionados para as crianças, mas para o adulto é muito raro. Raras também são as referências bibliográficas de cunho científico sobre aspetos técnicos do ensino da escrita para adultos e qual o tipo de letra a ser usada. Outro fator preponderante é a incipiente variedade de alternativas caligráficas empregadas para ensinar a escrever, até como parâmetros de 
comparação de resultados. Para Heitlinger (2007), faltam fontes tipográficas adequadas às capacidades cognitivas e motoras das crianças na idade de aprendizagem. Não existe um consenso entre professores e educadores sobre qual o tipo mais adequado ao processo de alfabetização. 0 consenso é menor quando se trata da alfabetização de adultos, quase esquecidos no que concerne a estudos dessa natureza. A caligrafia precisa se adaptar às evoluções tecnológicas e as necessidades do mundo moderno, bem como as variantes de perfil do aluno, seja ele criança ou adulto (Pacheco, Pacheco, \& Ortuño, 2009). Profissionais de pedagogia e psicologia, que trabalham com a alfabetização de adultos, e designers, que estudam os meandros morfológicos das letras, foram convidados a responder algumas questões que envolvem aspectos construtivos dos caracteres usados no processo de alfabetização de adultos e suas opiniões foram analisadas e comparadas com o objetivo de construir um pensamento científico sobre o tema.

\section{MATERIAIS E MÉTODOS}

A pesquisa é de caráter descritivo-exploratório e com o uso de técnicas quantitativas e qualitativas, ambas baseadas em um marco teórico que possibilita uma aproximação conceitual sobre o tema abordado (Gil, 2002). 0 procedimento qualitativo foi adequado à obtenção das percepções dos participantes consultados sobre questões e fatos sociais relativos ao status atual do fenômeno observado e para descrever a natureza das condições existentes sobre a situação do tema abordado (Trochim, Donnelly, 2007).

A coleta de dados foi feita por pesquisa bibliográfica e documental, acrescentando-se a esta uma entrevista em profundidade realizada com 31 especialistas de áreas correlacionadas à pesquisa (16 Pedagogos; 9 Psicólogos e 7 Designers). A técnica foi aplicada com 0 objetivo de explorar 0 posicionamento e as perspectivas desses profissionais sobre a proposta do estudo, e por ser considerada como um método não estruturado, mas direto na forma de obter informações, sendo realizado com cada pessoa de forma individual (Malhotra, 2006).

0 procedimento foi realizado num prazo de um mês, considerando o tempo para aplicação da entrevista e para a análise dos resultados, sendo iniciado ao final do mês de julho de 2012 e concluído ao final do mês de agosto do mesmo ano, através de um formulário preparado e enviado aos informantes, por correio eletrônico juntamente com uma nota explicando a natureza da pesquisa. 0 documento apresentou 24 questões, elaborado a partir de temas 
Estudio de la construcción de los elementos caligráficos en el proceso de alfabetización de adultos en la Amazonia brasileña

relevantes apontados na literatura e conforme os problemas identificados com relação à realidade do tema.

Para a presente publicação, que é parte de um estudo maior (tese de doutorado), foram explorados os resultados de algumas questões do roteiro, em consonância com os objetivos do artigo, focalizando os seguintes aspectos:

a) O uso da caligráfica em função da dificuldade construtiva dos caracteres;

b) Principais razões para a mudança da letra entre as etapas escolares de criança a adulto;

c) 0 uso de material didático com características regionais como influencia de forma positiva no processo de aprendizagem da escrita;

d) Valoração do uso da letra romana (de forma) em versões maiúsculas e minúsculas no processo de alfabetização de adultos;

e) Avaliação sobre 0 uso de formas básicas (quadrado, círculo e triângulo) como base para a construção dos elementos caligráficos (letras);

f) Aspectos da caligrafia e avaliação da velocidade da escrita;

g) Caligrafia cursiva: uma escrita ilegível em função de sua complexidade construtiva;

h) Valoração da interatividade professor-aluno no processo pedagógico;

i) Adaptação dos recursos didáticos, utilizados no processo de alfabetização de adultos, às características regionais;

j) O uso de letras com formas mais simples para a alfabetização de adultos.

Para este estudo, os dados obtidos através de métodos quantitativos, foram organizados e analisados a partir da distribuição de frequência.

\section{RESULT ADOS}

A maior parte dos entrevistados vive no Brasil $(n=30 ; 97 \%)$, sendo Manaus a cidade com o maior número de participantes na entrevista $(n=26 ; 84 \%$ ) a cidade foi escolhida por ser a capital do estado do Amazonas, onde se concentra a maior parte da Amazônia brasileira. Dos campos de atuação escolhidos para esse estudo, a área de maior destaque pertence à pedagogia 
$(n=16 ; 52 \%)$, seguida pelos atuantes em psicologia $(n=9 ; 29 \%)$ e, por último, pelos profissionais de design $(n=7 ; 19 \%)$. Dos especialistas consultados, $94 \%$ $(n=29)$ desenvolvem trabalhos em Institutos de Educação ou em Escolas. A maioria trabalha em sistema público $(n=19 ; 61 \%)$, enquanto outros atuam em órgão privados $(n=11 ; 35 \%)$ ou atuam somente através de pesquisas $(n=3 ; 4 \%$. Grande parte dos entrevistados possui de 5 a 10 anos de profissão $(n=13$; $42 \%$ ), seguida por profissionais com mais de 10 anos de atuação $(n=11 ; 35 \%)$ e por outros que apresentam somente de 1 a 5 anos de conhecimento na área $(n=7 ; 23 \%$ ). Quando questionados sobre o tema e linha de pesquisa abordada, $67 \%$ dos especialistas ( $n=20$ ) afirmaram não ter experiência alguma, o que comprova o baixo nível de produção científica sobre o tema.

De acordo com os aspectos observados e com base nas 24 perguntas formuladas a partir de temas relevantes apontados na literatura e de acordo com os problemas identificados em relação à realidade do assunto, os especialistas apresentaram o seguinte posicionamento:

1. O uso da caligráfica em função da dificuldade construtiva dos caracteres:

A maioria dos profissionais $(n=27 ; 87 \%)$ não acredita que a caligrafia é ensinada considerando o nível de dificuldade construtiva dos caracteres (Figura 2).

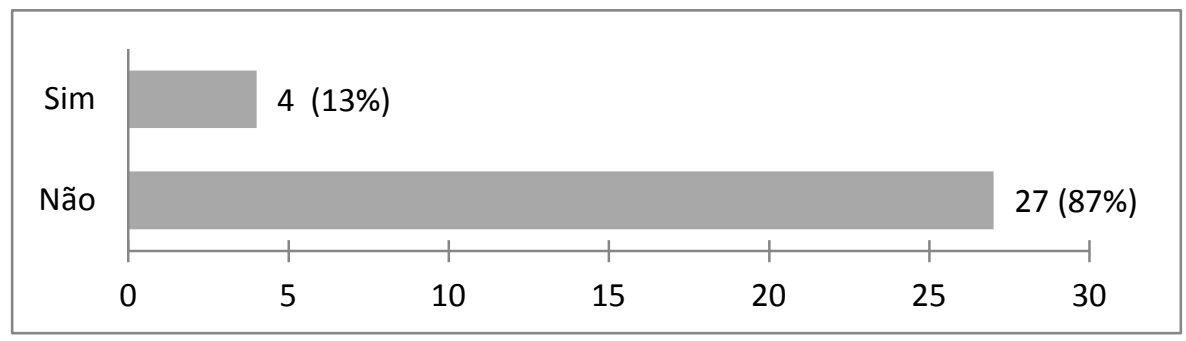

\section{A5_Fig. 2 - Nível de apreciação do uso da caligráfica em função da dificuldade construtiva dos caracteres.}

De acordo com os especialistas consultados, para saber escrever, é necessário além de conhecer e compreender as letras, saber coordenar as ideias, coordenar a mão, a mente e os olhos, compreender que é preciso prestar atenção na parte sonora e na escrita como um todo. No entanto, para alcançar o domínio dessas informações, o alfabetizando necessita do apoio do professor, do suporte de materiais didáticos e do incentivo do sistema 
Estudio de la construcción de los elementos caligráficos en el proceso de alfabetización de adultos en la Amazonia brasileña

educacional, de modo a auxiliá-lo a suprir as dificuldades existentes no processo de construção dos caracteres que geralmente é um reflexo da falta de domínio e conhecimento (por parte do aluno) sobre os aspectos, anteriormente, mencionados.

2. Para grande parte dos entrevistados $(n=23 ; 74 \%)$, a caligrafia cursiva não é a mais indicada para a alfabetização de adultos (Figura 3).

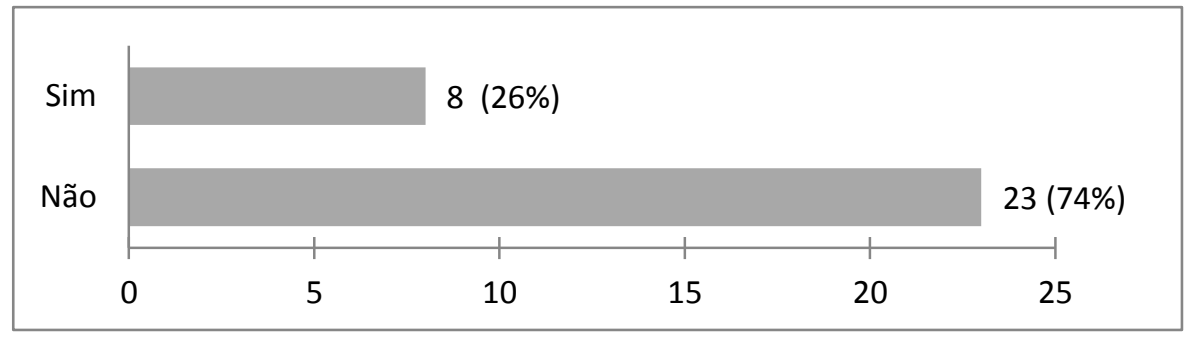

\section{A5_Fig. 3 - Nível de apreciação do uso da caligráfica cursiva para a alfabetização de adultos.}

A justificativa parte por considerar que a letra cursiva é mais rápida de ser traçada, exigir uma coordenação motora mais definida e representa um uso exclusivamente pessoal. É algo que dificulta para o ensino e alfabetização de pessoas adultas, uma vez que estas não possuem o domínio de segurar um lápis ou caneta pelo fato de não terem desenvolvido esta habilidade na idade propícia.

3. Outro fator considerado negativo pela maioria dos especialistas ( $n=24$; $77 \%$ é que a caligrafia ensinada hoje, nas escolas ou em institutos de educação, não contempla as pessoas destras e as canhotas (Figura 4).

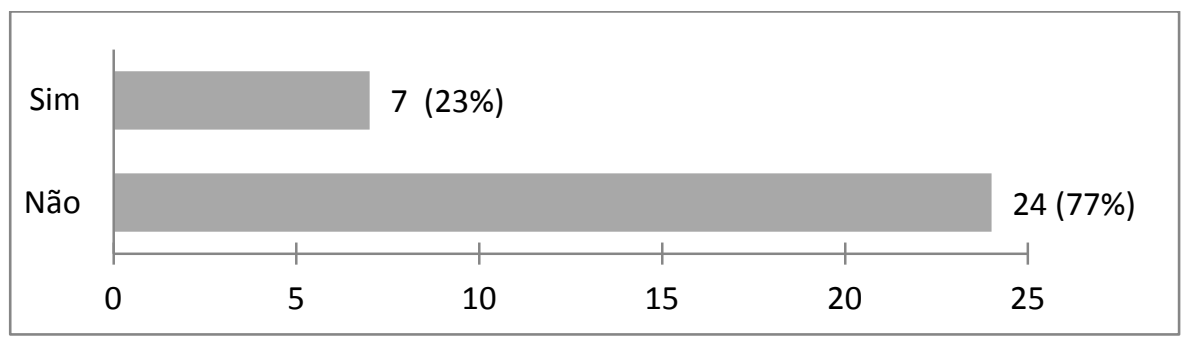

\section{A5_Fig. 4 - Nível de apreciação da caligráfica para a alfabetização de pessoas destras e canhotas.}


Segundo os entrevistados, o ensino da caligráfica ainda não está adaptado à alfabetização de alunos destros e, muito menos, de canhotos por fato do sistema de ensino não oferecer condições básicas relacionadas à forma de escrever desses alfabetizandos. A postura deve ser o fator principal a ser considerado para essa prática, uma vez que as pessoas canhotas tem uma preferência mais manual e muitas das vezes escrevem de modo "invertido", enquanto que as destras por mais que a sua prioridade nem sempre seja pela forma cursiva, geralmente apresentam dificuldades em função de certos arranjos nos ambientes físicos educacionais.

4. A maioria dos participantes $(n=13 ; 42 \%$ ) valorou como bastante importante à mudança da letra, entre as etapas escolares: de criança a adulto, devido à dificuldade construtiva da caligrafia cursiva (Figura 5).

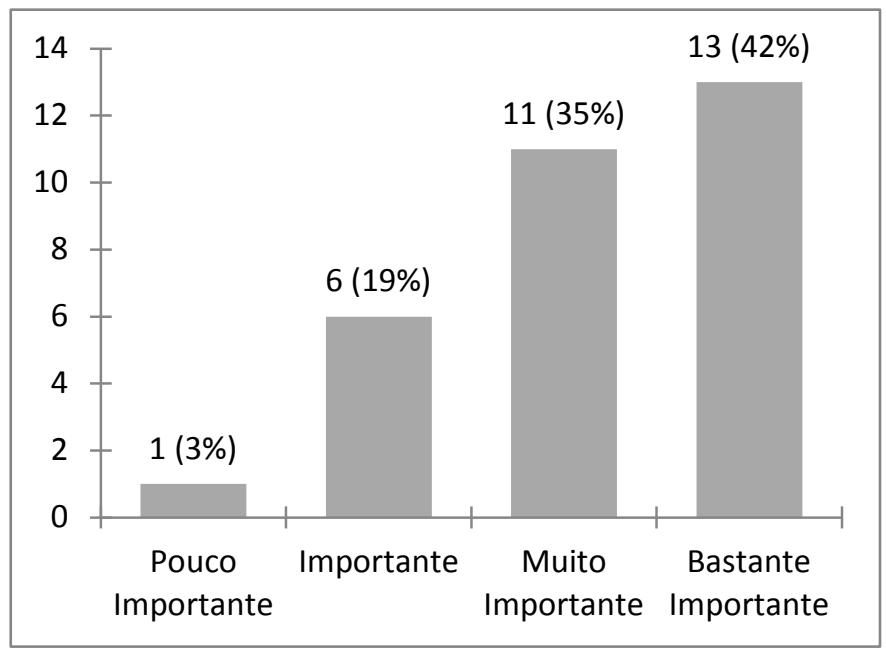

\section{A5_Fig. 5 - Valoração da mudança da letra pelo uso da caligrafia cursiva (entre as etapas escolares de criança a adulto).}

Conforme a avaliação feita pelos especialistas, a mudança da letra (nos dias de hoje) torna-se inevitável, ainda mais porque disponibilizamos de muitas tecnologias que se apresentam como eficientes para atingir os mais diversos campos da ciência e educação. No entanto, 0 acesso a esses meios tecnológicos, muitas vezes, não contemplam a realidade de muitos alunos e mesmo que isso seja possível, torna-se importante pensar nos efeitos colaterais que isso pode causa com o passar dos tempos, principalmente no que se refere entre as etapas escolares de criança a adulto, e na formação da escrita dessas pessoas. 
Estudio de la construcción de los elementos caligráficos en el proceso de alfabetización de adultos en la Amazonia brasileña

5. $81 \%(n=25)$ dos entrevistados acreditam que o material didático com características regionais pode influenciar de forma positiva no processo de aprendizagem da escrita (Figura 6).

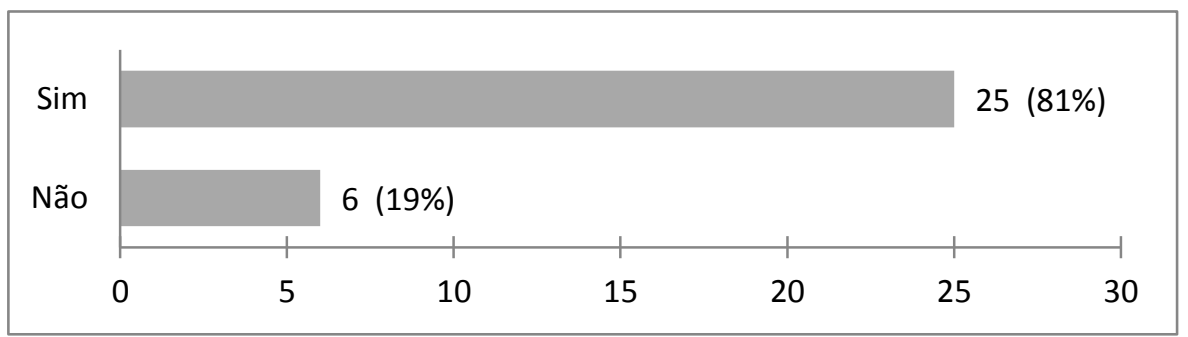

A5_Fig. 6 - Nível de apreciação do uso de material didático com características regionais para o aprendizado da escrita.

De acordo com as opiniões apresentadas quanto ao tema de adotar características regionais com um fator estratégico para influenciar positivamente no processo de aprendizagem dos adultos, os especialistas justificaram que tal ideia poderá não só facilitar a assimilação das informações (construção de letras associadas às formas e estruturas de elementos regionais) por parte dos alfabetizando, como também familiarizar 0 aluno com a sua realidade cultural e de identidade local.

6. O maior número de especialistas $(n=13 ; 42 \%)$ valorou como muito importante o uso da letra romana (de forma) em versões maiúsculas e minúsculas no processo de alfabetização de adultos (Figura 7).

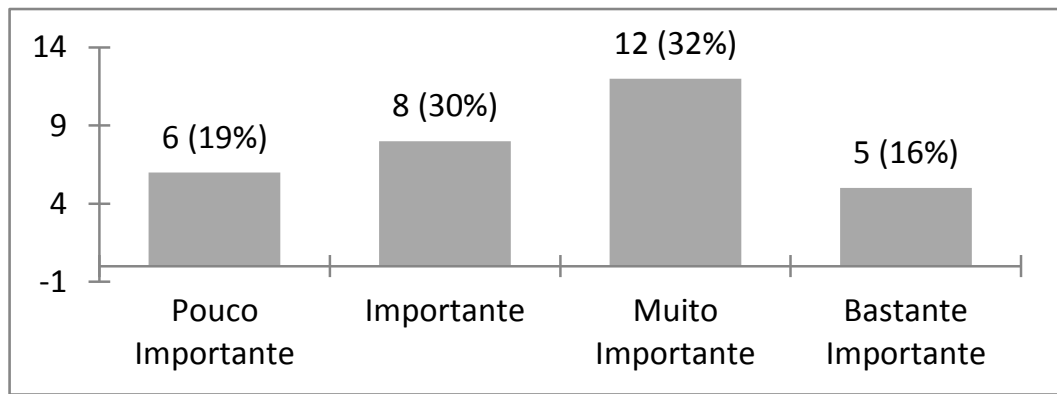

A5_Fig. 7 - Valoração o uso da letra romana (de forma) no processo de alfabetização de adultos. 
Para os entrevistados, o uso da letra romana facilita o entendimento da representatividade dos caracteres durante o processo de alfabetização, contribuindo também para que 0 alfabetizando adulto comece a treinar e a dominar os traços e movimentos simples apresentados por esse tipo de letra, auxiliando assim na sua coordenação motora.

7. Grande parte dos participantes da entrevista $(n=14 ; 45 \%)$ avaliou como muito importante o uso de formas básicas (quadrado, círculo e triângulo) como base para a construção dos elementos caligráficos (Figura 8).

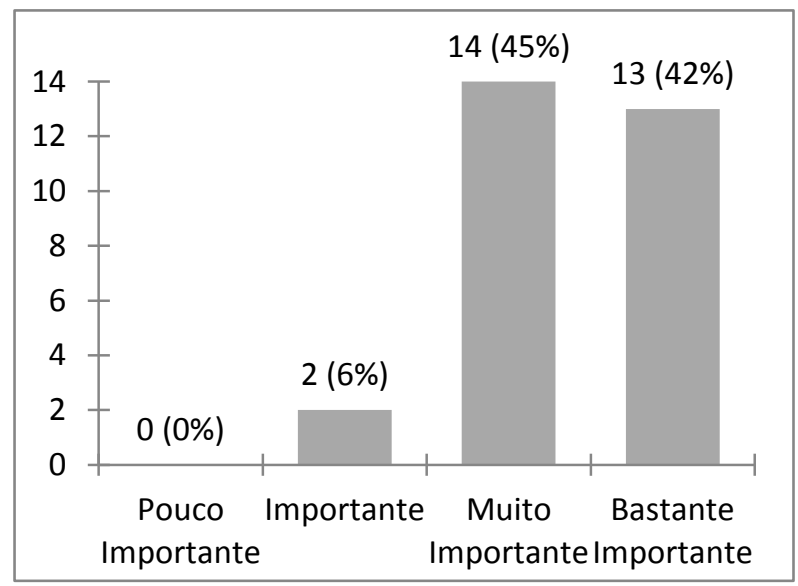

\section{A5_Fig. 8 - Valoração o uso formas básicas para a construção dos elementos caligráficos.}

Segundo o posicionamento dos profissionais consultados, o quadrado, o círculo e o triângulo são elementos simples e de fácil assimilação, além de serem componentes geométricas capazes de auxiliar e "emprestar" partes de sua forma estrutural para a construção de letras. Associar as formas básicas à parte da formação dos caracteres caligráficos poderá beneficiar e agilizar o processo de aprendizado dos alunos.

8. A maioria dos profissionais consultados $(n=13 ; 42 \%)$ avaliou como muito importante a velocidade da escrita (Figura 9). 
Estudio de la construcción de los elementos caligráficos en el proceso de alfabetización de adultos en la Amazonia brasileña

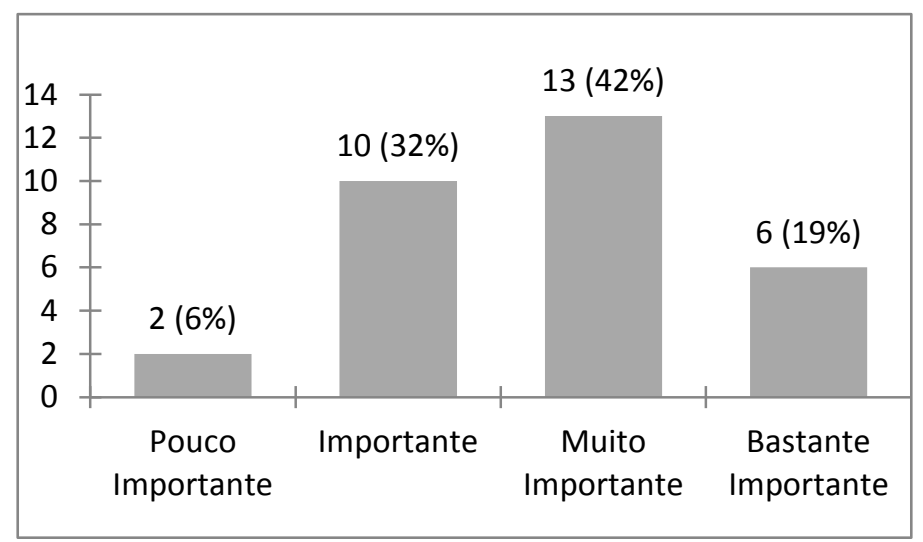

\section{A5_Fig. 9 - Valoração da velocidade da escrita pelos entrevistados.}

Para os pedagogos, psicólogos e designers entrevistados os mesmos sinais gráficos de uma escrita rápida ou lenta assumem significados diferentes. No entanto, a escrita pode espelhar a personalidade do indivíduo e a velocidade com que é feita ajuda a determinar o grau de atividade e a rapidez de raciocínio do escrevente. Assim sendo, o adulto que consegue escrever de forma rápida é aquele que possui como características positivas: agilidade mental, criatividade, originalidade e dinamismo.

9. Maior parte dos entrevistados $(n=29 ; 97 \%)$ considerou que a legibilidade é um fator mais importante que a velocidade da escrita (Figura 10).

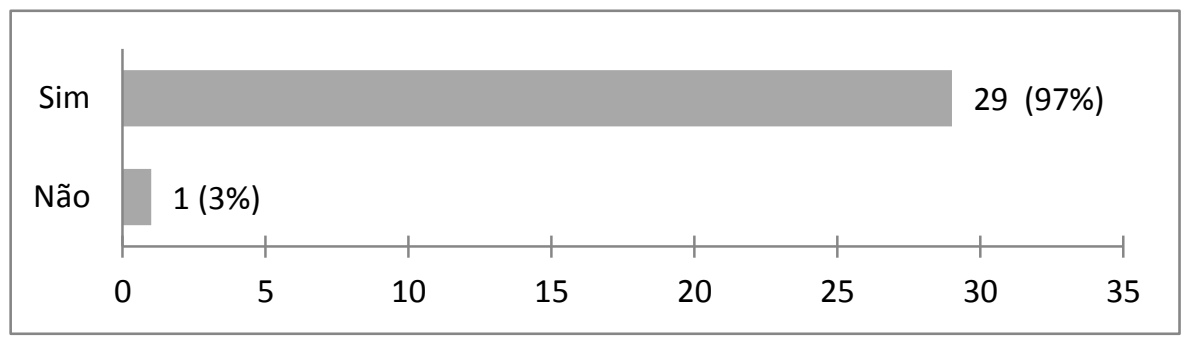

A5_Fig. 10 - Nível de preferencia da legibilidade em relação à velocidade da escrita. 
De acordo com a opinião dos especialistas, escrever com legibilidade e rapidez são aspectos essenciais aos alunos por registrar as informações adquiridas na escola, expressar o que sabe e compartilhar ideias e conhecimentos. No entanto, é através da legibilidade que observamos qualidade da escrita, da construção e representação dos caracteres e a facilidade de leitura.

10. $52 \%$ dos entrevistados $(n=16)$ acredita que a caligrafia cursiva contribui para o aluno ter uma escrita ilegível em função de sua complexidade construtiva (Figura 11).

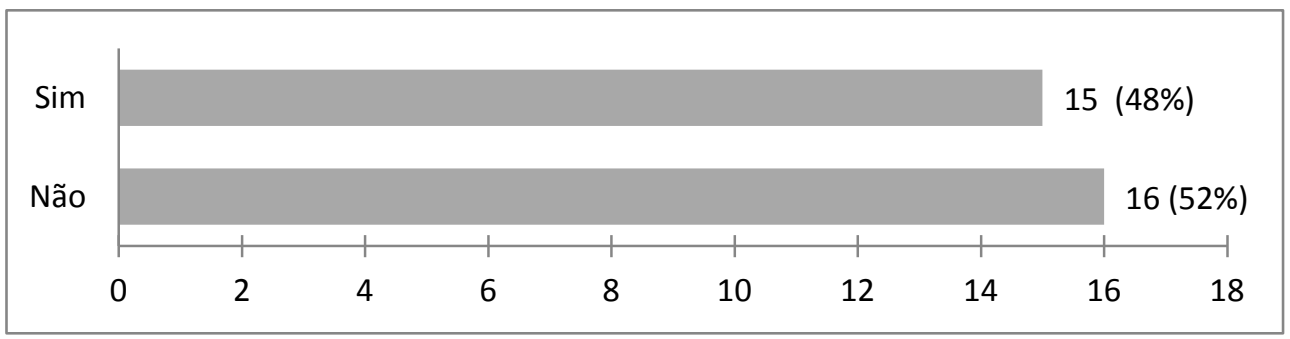

\section{A5_Fig. 11 - Nível de credibilidade da caligrafia cursiva para uma escrita ilegível devido sua complexidade construtiva.}

Para os profissionais consultados, nada adianta saber escrever com letras cursivas, se ninguém entende o que você escreve. Escrever de forma legível é tão importante quanto aprender a escrever de forma correta e a letra cursiva por apresentar em sua estrutura a formação de letras ligadas umas nas outras de modo que a palavra é escrita num único bloco, muitas vezes causa dificuldades para 0 aluno construir as letras através dessa representação ementada, até mesmo pelo fato de alguns alunos ainda não dominarem por completo a forma de construção desse tipo de caracteres (letras).

11. A maioria dos entrevistados $(n=22 ; 71 \%$ avaliou como bastante importante o material didático que valoriza a relação professor-aluno (Figura 12). 
Estudio de la construcción de los elementos caligráficos en el proceso de alfabetización de adultos en la Amazonia brasileña

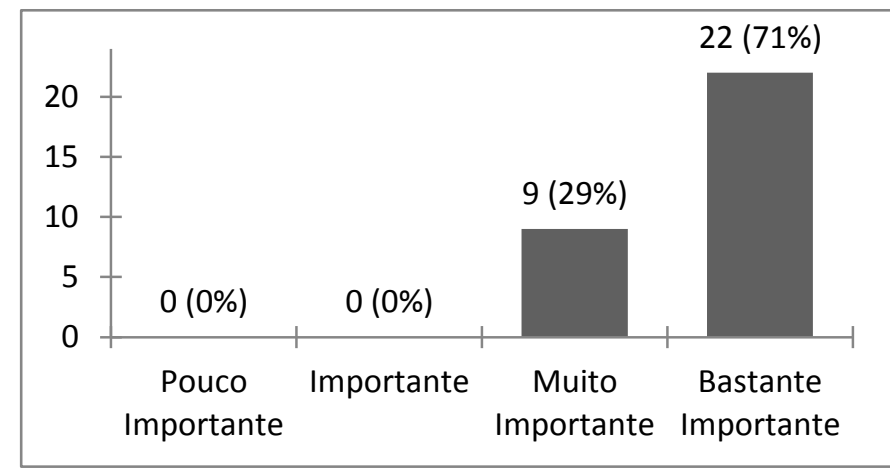

\section{A5_Fig. 12 - Nível de apreciação do material didático que valoriza a relação professor-aluno.}

Segundo os especialistas, a relação entre o professor e o aluno depende muito do clima estabelecido pelo professor, da relação empática com seus alunos, de sua capacidade de ouvir, refletir e discutir no nível de compreensão dos alunos e da criação das pontes entre o seu conhecimento e o deles, para isso - material didático torna-se um forte aliado, sobretudo para facilitar a aprendizagem do aluno e estimulá-lo para a aquisição do conhecimento.

12. $97 \%$ dos profissionais consultados $(n=29)$ não acredita que exista uma variedade suficiente de material didático direcionado para a alfabetização de adultos (Figura 13).

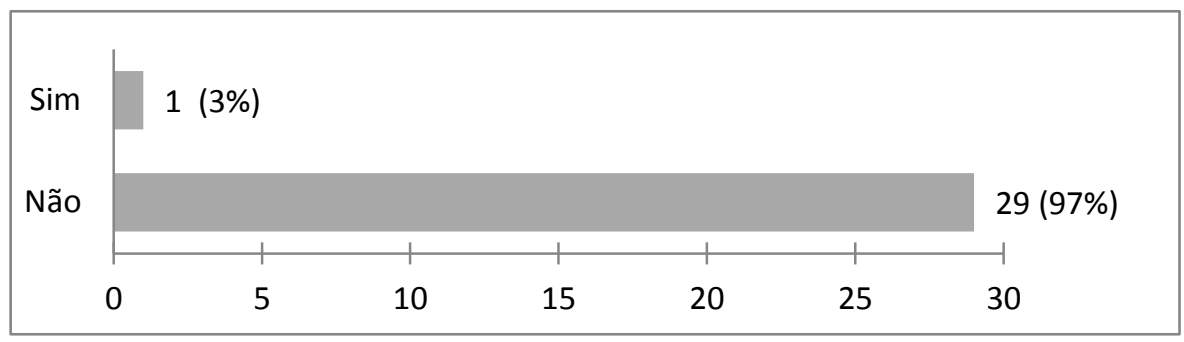

\section{A5_Fig. 13 - Nível de credibilidade na existência de material didático direcionado à alfabetização de adultos.}

Conforme opinião manifestada pelos entrevistados, a existência de material didático para a alfabetização de adultos ainda é muito pouca e necessita de maior elaboração, considerando a realidade dos alunos e o seu grau de dificuldade no momento da construção dos caracteres, assim como 
assimilação de elementos que não fazem parte da sua cultura ou identidade que são utilizados para associação de informações necearias à representação da escrita.

13. Grande parte dos entrevistados $(n=19 ; 61 \%$ ) não acredita que 0 material didático utilizado para a alfabetização de crianças pode ser utilizado com adultos iletrados (Figura 14).

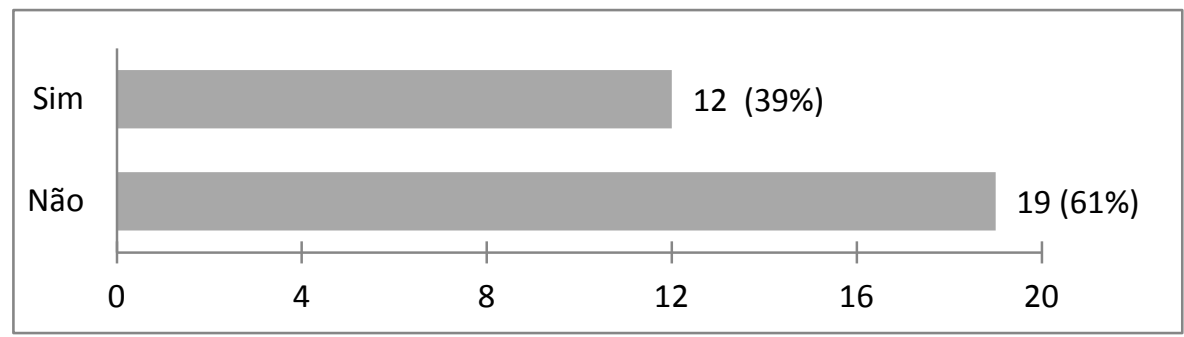

\section{A5_Fig. 14 - Nível de credibilidade do uso de material didático utilizado com crianças a ser aplicado com adultos.}

Os especialistas acreditam que o material didático para a alfabetização de adultos deve ter um direcionamento mais apropriado à realidade desse tipo de aluno, a base dessa ferramenta deve relacionar o conteúdo ministrado com 0 cotidiano e a condição social do educando, suas crenças, valores, gostos artísticos, jargões etc.

14. $58 \%$ dos entrevistados valoraram como bastante importante à adaptação dos recursos didáticos, utilizados no processo de alfabetização de adultos, às características regionais (Figura 15).

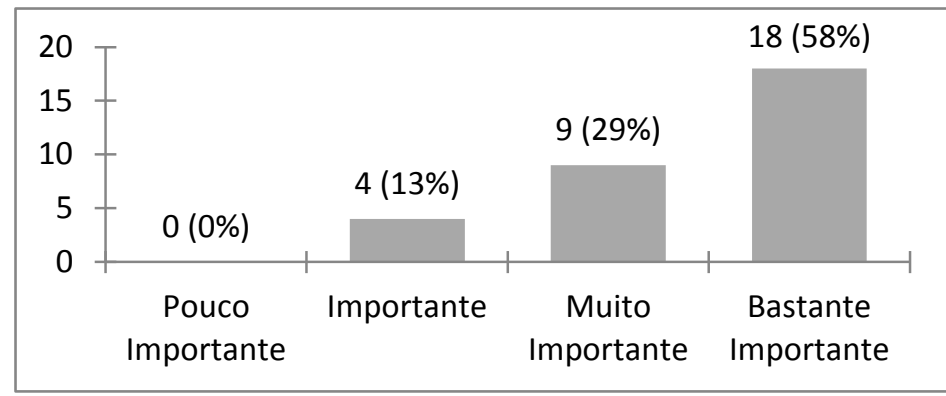

A5_Fig. 15 - Valoração da adaptação dos recursos didáticos às características regionais. 
Estudio de la construcción de los elementos caligráficos en el proceso de alfabetización de adultos en la Amazonia brasileña

Conforme a avaliação feita pelos especialistas, o uso de recursos didáticos adaptado às características regionais compatíveis ao "universo vocabular" e ao perfil do aluno, e ainda, unificado às atividades pedagógicas coerentes, bem planejadas, um bom domínio do conhecimento, a interatividade por parte do professor podem contribuir para o bom nível de envolvimento do alfabetizando adulto e, sobretudo, favorecer o seu aprendizado da escrita.

15. Quando questionados sobre a simplificação da forma dos caracteres utilizados para a alfabetização de adultos, mais uma vez $58 \%(n=18)$ dos entrevistados valoraram como bastante importante 0 uso de formas simples no processo de ensino e aprendizagem da escrita para pessoas adultas (Figura 16).

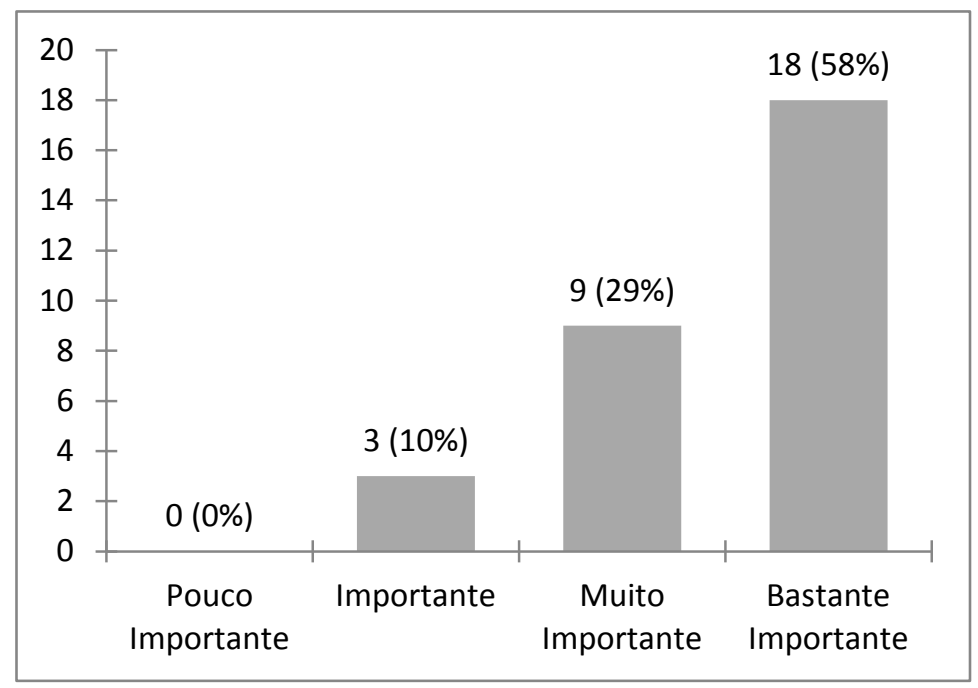

\section{A5_Fig. 16 - Valoração do uso de formas simples para o processo de alfabetização de adultos.}

A resposta dada pelos especialistas ressaltou que trabalhar com elementos simples é uma forma de possibilitar um melhor entendimento a respeito do que se lê e escrever 0 que se entende, além disso, o aluno de maneira clara e objetiva a comunicar-se graficamente, garantindo a assimilação dos caracteres e das suas formas de representação. 
16. Por fim, a maioria dos profissionais consultados $(n=16 ; 52 \%)$ afirmou ser bastante importante 0 uso de letras com formas mais simples para a alfabetização de adultos (Figura 17).

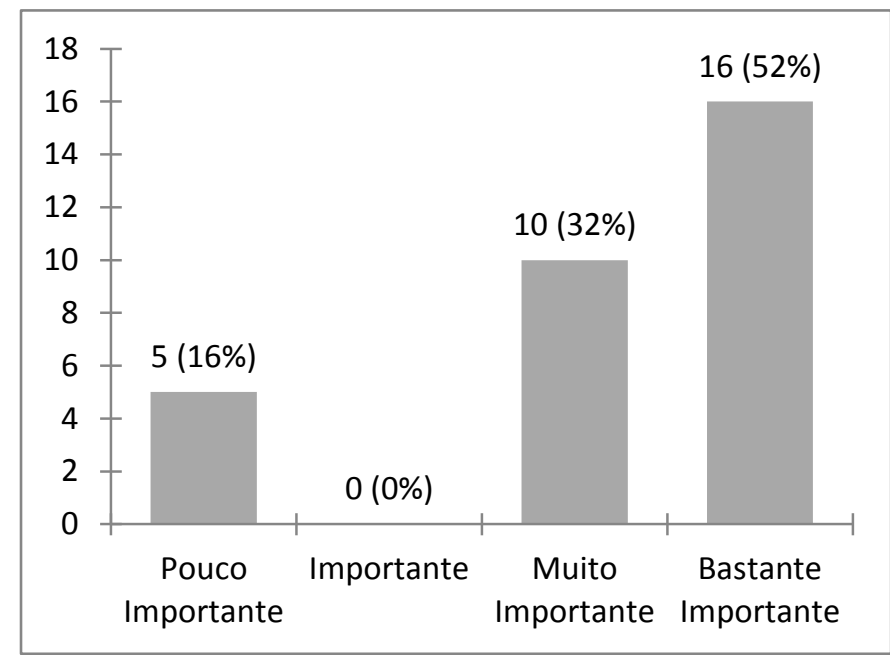

\section{A5_Fig. 17 - Nível de apreciação do uso de letras com formas mais simples para a alfabetização de adultos.}

Tal afirmação está relacionada à compreensão e desenho dos caracteres caligráficos. Para os pedagogos, psicólogos e designer, utilizar letras com formas mais simples no processo de alfabetização de adultos oferece maior facilidade no traçado desse perfil de aluno, que ainda não desenvolveu ou apresenta alguma coordenação motora fina para a escrita, além do que, as formas simples auxiliam para que 0 aluno não sinta dificuldades em reconhecer 0 alfabeto, facilitando assim com que o mesmo domine melhor os movimentos da escrita.

\section{CONSIDERAÇÕES FINAIS}

0 trabalho reuniu informações sobre o posicionamento de 31 especialistas (16 Pedagogos; 9 Psicólogos e 7 Designers) a respeito do aprendizado da escrita na alfabetização de adultos. Conforme os dados apurados, os profissionais sinalizaram como importante à simplificação da forma dos caracteres tem como auxilio o uso das formas básicas, para facilitar o aprendizado e garantir 
Estudio de la construcción de los elementos caligráficos en el proceso de alfabetización de adultos en la Amazonia brasileña

uma melhor legibilidade da escrita. Outro aspecto a ser considerado é a necessidade de se criar, planejar e usar recursos e materiais didáticos que possam estar mais identificados com o alfabetizando adulto, de modo a caracterizá-los com a realidade social do educando, relacionando suas crenças, valores, gostos artísticos, cotidiano, etc, além de promover melhor a interatividade entre professor-aluno, para que unificados possam beneficiar a aquisição da leitura e da escrita pelo adulto iletrado.

\section{REFERÊNCIAS}

GIL, A. C. Como elaborar projetos de pesquisa. 4a ed. São Paulo: Atlas, 2002.

HEITLINGER, P. Tipografia: origens, formas e uso das letras. Lisboa: Dinalivro, 2006.

MALHOTRA, N. K. Pesquisa de marketing. 4a ed. Porto Alegre: Bookman, 2006.

PACHECO, A., Pacheco, K., \& Ortuño, B. Caligrafia Cursiva: A única ou mais eficiente no processo de alfabetização? 5. - Congresso Internacional de Pesquisa em Design - ISSN 2175-0289, (págs. 770-778). Bauru, 2009.

PROMEAPI. Programa Municipal de Escolarização do Adulto e da Pessoa Idosa PROMEAPI. PROMEAPI. Manaus, Amazonas, Brasil, 2007.

SME, S. M. Caderno de orientações didáticas para EJ A - Alfabetização: etapas. Manual EJ A. São Paulo, São Paulo, Brasil: Secretaria Municipal de Educação. Diretoria de Orientação, 2010.

TROCHIM, W., \& Donnelly, J. The Research Methods Knowledge Base. 3rd edition. Mason: Thomson Publishing, 2007.

UNESCO. Relatório de Monitoramento Global de Educação Para Todos. Paris: Edições UNESCO, 2011. 
3.6. Artículo 6 - Estudio comparativo de la morfología de las letras de cuadernos de caligrafía de algunos países y sus implicaciones para el proceso de alfabetización

Esta producción científica ha sido realizada con la intención de hacer un estudio de libros escolares utilizados para la enseñanza de la escritura en algunos países a través de un análisis de la morfología de los caracteres y las posibles implicaciones para el proceso de alfabetización.

Revista: EDUCACIÓN XX1 (España)

Indexada en: DIALNET, EBSCO, CCHS, ERA, ERIH, HEDBIB, IBEDOCS, ISOC, IRESIE, LATINDEX, PSICODOC, REDALYC, REDINED, SCOPUS, SOCIAL SCIENCES CITACION INDEX, ULRICH'S y A 360\%: PLATAFORMA DE REVISTAS, SUMÁRIOS Y EDITORIALES

ISSN: $1139-613 X$

Enviado: Noviembre 2012 | Aceptado: EN PROCESO DE EVALUACIÓN | Publicado: EN PROCESO DE EVALUACIÓN

ESTUDIO COMPARATIVO DE LA MORFOLOGÍA DE LAS LETRAS DE CUADERNOS DE CALIGRAFía DE ALGUNOS PAÍSES Y SUS IMPLICACIONES PARA EL PROCESO DE ALFABETIZACIÓN

(COMPARATIVE STUDY OF THE MORPHOLOGY OF THE LETTERS OF CALLIGRAPHY BOOKS SOME COUNTRIES AND ITS IMPLICATIONS FOR THE PROCESS OF LITERACY)

\author{
Almir de Souza Pacheco \\ Universitat Politècnica de València (UPV) - España \\ María Begoña J ordá Albiñana \\ Universitat Politècnica de València (UPV) - España
}


Estudio de la construcción de los elementos caligráficos en el proceso de alfabetización de adultos en la Amazonia brasileña

J imena Gonzáles del Rio Cogorno

Universitat Politècnica de València (UPV) - España

\section{RESUMEN}

El artículo presenta un estudio de la morfología de las letras utilizadas en los libros para el aprendizaje de la escritura en siete países (Brasil, España, Portugal, Colombia, Venezuela, Francia y Alemania). A través de un enfoque metodológico cualitativo y basado en los estudios de Frutiger (2001), Cinel (2003), las observaciones de Heitlinger (2006), las letras caligráficas utilizados en la iniciación se analizan con el fin de detectar las divergencias y convergencias formales entre sus componentes y las posibles implicaciones para el proceso de alfabetización. Como resultado, se observó la falta de uniformidad de los caracteres utilizados en el material de enseñanza dentro de cada nación y cuando comparado los libros entre los países involucrados en el estudio, la diferencia parece bien mayor. En conclusión, la investigación apunta a la necesidad del establecimiento de una norma internacional, desarrollado por un estudio multidisciplinario que incluye áreas como la pedagogía, la psicología y el diseño, que pueda estandarizar un alfabeto modelo y más adecuado para la enseñanza de la escritura.

\section{ABSTRACT}

The article presents a study of the morphology of the letters used in books for learning to write in seven countries (Brazil, Spain, Portugal, Colombia, Venezuela, France and Germany). Through a qualitative methodological approach, based on studies of Frutiger (2001), Cinel (2003), Heitlinger observations (2006), calligraphic letters used in initiation are analyzed in order to detect formal divergences and convergences between its components and the possible implications for the literacy process. As a result, there was lack of uniformity of the characters used in the teaching material within each nation, and when compared to the books among the countries involved in the study, the difference seems greater good. In conclusion, the research points to the need to establish an international standard developed by a multidisciplinary study which includes areas such as education, psychology and design, you can standardize an alphabet and most appropriate model for teaching writing. 


\section{INTRODUCCIÓN}

El trabajo continuo de los escribas y monjes en el método de escritura tuvieron como consecuencia la aparición del primer libro de caligrafía en Italia en el siglo XVI, desarrollado por Ludovico Arrighi Vicentino degle Arrighi. Este calígrafo fue en gran parte responsable de popularizar la letra llamada cancilleresca o cursiva, y establecerla como la tipografía cursiva preferida, principalmente por la "influencia política" disfrutado por esto, ya que era escriba del Papa (Heitlinger, 2006). Desde entonces, todos los tipos de letra cursiva y de aspecto caligráfico se acordaron Ilamar de cursiva. Mientras se extendía por toda la cultura occidental, la escritura cursiva ha sufrido variaciones formales de los caracteres y ganando versiones no estandarizadas de alfabetos. Los procesos de publicación electrónica de libros a través del ordenador y la disponibilidad y el acceso, cada vez más facilitados las fuentes tipográficas, contribuyó en gran medida a la profusión de letras de diferentes formas presentes en los materiales educativos que se ofrecen en el proceso de alfabetización.

Es muy raro que un país o grupo de países tengan una normalización nacional o internacional en el formato de los alfabetos presentes en los libros de escritura escolar, debido a que pocos cuentan con una legislación específica sobre la materia. Otra observación importante que debe ser llevada en cuenta, cerca de la falta de estandarización de los aspectos formales de las letras entre las naciones, son las posibles dificultades que un alumno en proceso de alfabetización pueda tener (sea ello adulto o niño) al cambiar de país, sea por el trabajo de los familiares (como actualmente se produce en Europa en crisis económica), por razones políticas, guerras, u otro tipo de acontecimiento que lleva las personas a emigrar. Las dificultades serán mayores de que normalmente tendría un estudiante usando libros de alfabetización de su país con las letras que ya estaba acostumbrado.

\subsection{La caligrafía y la escuela}

Discurriendo acerca de los aspectos de la caligrafía y su uso en la escuela, Cinel (2003) afirma que cada persona expresa su trazo a través de matices propios y de su personalidad. Mismo en la ausencia de estudios científicos y de convergencia pedagógica que indican una elección fundamental por el uso de la letra cursiva, la sociedad y la cultura consideramos importante saber escribir con este tipo de caligrafía (Cinel, 2003). 
Estudio de la construcción de los elementos caligráficos en el proceso de alfabetización de adultos en la Amazonia brasileña

Otro factor considerado importante para el estudio es la poca variedad de modelos caligráficos distintos de lo cursivo en los procesos de alfabetización, por lo menos como parámetros para comparar los resultados. Para Heitlinger (2007), el mercado del material educativo está muy falto de variantes formales dirigidas al público iletrado; faltan tipografías adecuadas a las capacidades cognitivas y motoras de los niños en edad de aprendizaje. No existe un consenso entre los profesores y los educadores sobre el tipo más adecuado para el proceso de alfabetización.

\section{MATERIALES Y MÉTODOS}

El estudio presenta un enfoque metodológico cualitativo, con objetivos de carácter exploratorio y descriptivo, según lo que plantea Gil (2002). La estructura de contenido incluye una investigación bibliográfica y documental, ratificada a un estudio específico, correlacionada con los procesos de innovación y estrategia (Yin, 2001).

\subsection{Procedimientos}

Para el presente artículo, que forma parte de un estudio de una tesis de doctorado, los datos se obtuvieron a partir de las referencias bibliográficas que discuten el tema y mediante el análisis de libros, para la enseñanza de la escritura a mano, usado actualmente en siete países (Brasil, España, Portugal, Colombia, Venezuela, Francia y Alemania).

Para el estudio, se seleccionó de forma aleatoria una muestra de libro de enseñanza de la escritura de cada uno de los siete países. A Cada libro fue seleccionado el alfabeto utilizado para el ejercicio de la escritura a mano y construida una tabla con columnas referentes a cada país y con las letras en la secuencia de "A" a la "Z" (mayúsculas y minúsculas) y cada línea con referencia a un caracter. La forma en que se estructuró la tabla proporciona una comparación morfológica de cada letra en los siete países involucrados en el estudio. El objetivo del análisis fue demostrar la falta de estandarización entre la morfología de las letras presentes en los libros de caligrafía y como esto puede perjudicar el proceso didáctico de enseñanza de la escritura. 


\section{BRASIL Y LA CALIGRAFÍA ESCOLAR}

Según Vidal y Gvirtz (1998) A mediados del siglo XIX, la escuela primaria en Brasil ya contaba con las condiciones para la difusión de la escritura, mientras que los actos de lectura y escritura empezaron a ser enseñados de forma simultánea. En ese momento, la enseñanza de la escritura se basa en las teorías de la educación y la enseñanza de Europa y Estados Unidos, y por lo menos hasta 1890, la escritura inclinada era la más extendida en el país, con énfasis en dos subtipos principales: la letra inglesa y el método americano de Spencer. El estilo caligráfico de Spencer se ha hecho conocido en todo el mundo a través del logotipo de Coca-Cola (Figura 1).

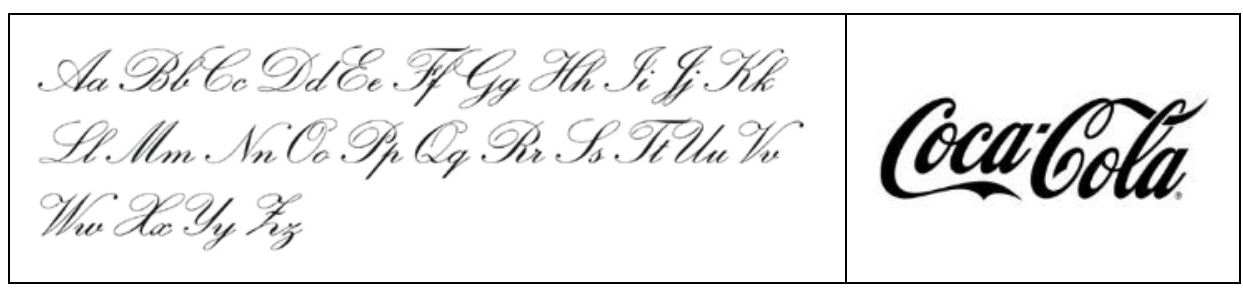
A6_Fig. 1 - Ejemplo del modelo caligráfico de Spencer y su aplicación en el
logotipo de Coca-Cola.

La diferencia de lo que ocurre en países como Inglaterra y Estados Unidos, donde los modelos de escritura escolar son analizados en un contexto multidisciplinar y creados por profesionales del diseño, de los campos de la caligrafía comercial, rotulación, tipografía y escritura manual, en Brasil son pocas las propuestas de modelos de escritura desarrollados por diseñadores.

Acerca de esto, Rumjanek (2009) señala el trabajo desarrollado por el tipógrafo Tony de Marco, que creó la tipografía Kindergarten, respetando la tradición de los libros brasileños de enseñanza de la escritura. La tipografía de Tony de Marco sigue el modelo tradicional de la escritura cursiva vertical, muy popular y ampliamente utilizado en Brasil, desde la década de 1940, en folletos como "Caminho Suave", desarrollado por la educadora Branca Alves de Lima. El libro que hace parte de esta investigación utiliza la fuente Kindergarten pues ella se encuentra presente en muchos libros e es adoptada por muchas editoras en Brasil. 
Estudio de la construcción de los elementos caligráficos en el proceso de alfabetización de adultos en la Amazonia brasileña

\subsection{El idioma portugués de Brasil}

De acuerdo con datos del gobierno brasileño, el idioma portugués llego a Brasil junto con las carabelas portuguesas, a principios del siglo XVI, a unirse a la familia lingüística tupí-guaraní, especialmente el tupinambá, un dialecto del tupí. El tupinambá fue la lengua general de Brasil en el siglo XVII, usado principalmente por los misioneros religiosos en el proceso de la catequesis con los indígenas.

La profusión de idiomas se ha convertido en más grande con la llegada de los esclavos africanos y los nuevos colonos, fato que llevó a la Corte portuguesa a obligar, en el norte de Brasil, la enseñanza de la lengua portuguesa a los indios y, más tarde, prohibir la enseñanza de cualquier otro lenguaje. El mundo tiene hoy más de 200 millones de personas que hablan portugués. Se trata de la octava lengua más hablada en el mundo y el tercer lugar entre las lenguas occidentales, después de inglés y español. Además de Portugal, es el idioma oficial de siete países, todos ellos ex colonias portuguesas: Angola, Brasil, Cabo Verde, Guinea Bissau, Mozambique y Santo Tomé y Príncipe.

Recientemente el portugués ha sufrido algunos cambios a través de un acuerdo ortográfico entre los siete países que hablan el idioma. El Acuerdo Ortográfico de la Lengua Portuguesa, que entró en vigor el 1 de enero de 2009. El periodo de transición para poner en práctica el acuerdo es de 1 de enero 2009 hasta el 31 diciembre de 2012. Durante este período, las normas viejas y las nuevas coexisten, hasta que el país se adapta a las normas establecidas en el acuerdo y los incluyen en los libros escolares, libros de texto y otras publicaciones en portugués.

Bajo las nuevas normas, el alfabeto portugués se compone de 26 letras: $a, b$, $c, d, e, f, g, h, i, j, k, l, m, n, o, p, q, r, s, t, u, v, w, x, y, z$. Se incorpora, por lo que el alfabeto oficial, las letras "k", "w" y "y".

\section{EL LIBRO ESCOLAR EN ESPAÑA}

En España, la investigación sobre los libros escolares tuvo su inicio a principios de la década de 1990 y se ha convertido desde entonces en un campo de investigación muy prolífico. Los libros escolares han sido históricamente unos productos culturales sujetos a regulaciones políticas o religiosas, a través de la obligación de responder a procesos de autorización y censura, el estudio de 
la legislación y las disposiciones oficiales que han regulado la edición y uso de los textos escolares ha sido otro tema de estudio necesario para conocer los mecanismos mediante los cuales los distintos poderes han pretendido controlar los procesos de aculturación y socialización de las sociedades (Ossenbach, 2010). A pesar de las investigaciones realizadas con los libros escolares, no hay una propuesta de estandarización de las letras usadas para la enseñanza de la escritura. Por la falta de una norma u orientaciones gubernamentales, no es difícil encontrar variantes de la forma de la misma letra en libros escolares diferentes y, en algunos casos, las diferencias se presentan en las páginas de un mismo libro. Al igual que ocurre en muchos países, España también tiene una variedad muy grande de libros de enseñanza de la escritura, acompañados de una también gran variedad de alfabetos y letras.

\subsection{El alfabeto español}

Como las demás lenguas románicas, el español se sirvió básicamente desde sus orígenes de la serie alfabética latina, que fue adaptada y completada a lo largo de los siglos. Así, el abecedario español está hoy formado, según la Real Academia Española de la Lengua, por las veintinueve letras siguientes:

$a, b, c, c h, d, e, f, g, h, i, j, k, I, I I, m, n, \tilde{n}, 0, p, q, r, s, t, u, v, w, x, y, z$.

Esta variante española del alfabeto latino universal ha sido utilizada por la Academia desde 1803 en la confección de todas sus listas alfabéticas. Desde esa fecha, la ch y la II, que en realidad son dígrafos, es decir, signos gráficos compuestos de dos letras, pasaron a considerarse convencionalmente letras del abecedario por el hecho de representar, cada uno de ellos, un solo sonido. No obstante, en el X Congreso de la Asociación de Academias de la Lengua Española, celebrado en 1994, se acordó adoptar, a petición de varios organismos internacionales, el orden alfabético latino universal, en el que la ch y la II no se consideran letras independientes. Esta reforma afecta únicamente al proceso de ordenación alfabética de las palabras, no a la composición del abecedario, del que los dígrafos ch y II siguen formando parte.

En sentido estricto el alfabeto está formado sólo por veintisiete letras

$(a, b, c, d, e, f, g, h, i, j, k, l, m, n, \tilde{n}, 0, p, q, r, s, t, u, v, w, x, y, z)$ algunas de los cuales pueden combinarse en dígrafos (ch, II, rr, qu y gu). 
Estudio de la construcción de los elementos caligráficos en el proceso de alfabetización de adultos en la Amazonia brasileña

\section{EL MANUAL ESCOLAR EN PORTUGAL}

Para Justino (2006) as cartilhas portuguesas e manuais escolares foram produzidos por instituições de cunho religioso, monárquicas ou pertencentes ao Estado e desde o século XVIII que há fatores de natureza corporativa e de controle que exercem determinado tipo de pressão sobre a produção, aprovação e circulação dos referidos livros. No que se refere ao ensino de Primeiras Letras e à Instrução Elementar, é possível contabilizar, até 1974, mais de três centenas de manuais de leitura e escrita, cerca de metade dos quais são manuais apenas de leitura, porque o ensino da escrita junto com a leitura só foi consolidado no século XX.

Em se tratando especificamente de ensino da escrita, Heitlinger (2009) afirma que na escola portuguesa, aos finais do século XIX, já havia uma divisão entre caligrafia e escrita com o surgimento dos Cadernos Caligráficos e Cadernos de Escrita. O referido autor também observa que durante os últimos 30 anos, Portugal sofre com o total abandono de qualquer consideração de qualidade caligráfica, racionalidade da escrita infantil ou qualquer outro tema relacionado com uma pedagogia coerente no ensino da escrita.

\subsection{La escritura portuguesa}

El lenguaje portugués ha surgido en la Península Ibérica (donde se formaron los países de Portugal y España) a partir de la lengua de los conquistadores romanos y de su imposición cultural (el primer aterrizaje romano en la región ocurrió en 219 a.C.). Éste idioma sufrió influencia de las lenguas habladas por los pueblos que habitaban la región antes de la llegada de los romanos y por los que vinieron después de la caída del imperio y con las invasiones bárbaras. Utiliza el alfabeto latino y es derivado del latín, una lengua nacida en Italia por vuelta del siglo $\mathrm{V}$ antes de Cristo, tornándose así un dialecto que dio, literalmente, muchas vueltas por el mundo, desde su origen hasta llegar a otros países donde es hablado como: Brasil, en las Américas; Angola, Mozambique, Guiñé Bissau, Cabo Verde, y San Tomé y Príncipe, en África, más allá de Azores y Madera (islas atlánticas próximas a la espalda africana); Macao, Goa, Damián, y Diu, en Asia; y Timor Leste, en Oceanía.

Así siendo, tanto en Portugal como en los demás países de lengua portuguesa, el alfabeto portugués se compone de 26 letras, donde todas son del género masculino. Por lo tanto, las letras son: 
$A(a), B$ (bê), C (cê), D(dê), E(é), F(efe), G(gê), H(agá), I(i), J(jota), L(ele), $M($ eme), $\mathrm{N}$ (ene), O (ó), P(pê), Q(quê), R(erre), S(esse), T(tê), U(u), V(vê), $\mathrm{X}$ (xis), Z(zê) y las letras " $\mathrm{K}$ ", " $\mathrm{W}$ " $\mathrm{y}$ " $\mathrm{Y}$ ", incorporadas a través del nuevo acuerdo ortográfico de la lengua portuguesa.

\section{LA CARTILLA COLOMBIANA}

Las dificultades en el aprendizaje de la lectura y la escritura aparecen como el tema más comprometedor de los pedagogos y la polémica crece dando lugar a experimentos muy variados y a toda clase de argumentaciones. Los métodos de marcha analítica (o métodos globales) promueven una enseñanza de la lectura y la escritura correspondiente al primer estadio del desarrollo del alfabeto en el hombre, antes de que la imprenta hubiese inventado un significado concreto para el alfabeto (Posada, 1993).

El proceso de alfabetización implica una comprensión y un desarrollo holísticos del lenguaje como totalidad, en sus cuatro funciones básicas e inter-relacionadas: hablar, escuchar, leer y escribir. Leer implica comprender lo que se lee; escribir es una actividad eminentemente creativa, que compromete y promueve la expresión y la comunicación de las propias ideas.

En la historia y en el contexto latinoamericano, la alfabetización de adultos ha sido reconocida en su potencial para la emancipación humana y la transformación política. Paulo Freire y el movimiento de Educación Popular son parte de esta tradición regional. Los enfoques constructivistas en torno a la adquisición de la lectura y la escritura, ampliamente diseminados en la región en las dos últimas décadas, agregan una dimensión epistemológica y cognitiva que reconoce la alfabetización como un proceso de conocimiento (y no de mero adiestramiento en una técnica de cifrado y descifrado) y a quienes aprenden como personas inteligentes, que merecen respeto, son capaces de aprender, poseen y construyen activamente conocimiento si se les permite hacerlo y si éste es de su interés (Ferreiro,2007).

En uno de los libros más populares de enseñanza de la caligrafía en Colombia, se observa un enfoque principal en la enseñanza de la lectura y la escritura y no se presentan ejercicios en letra cursiva, en cambio si se proponen ejercicios de curvas en diferentes direcciones y proporciones (Granada, 2009). Con relación a los aspectos formales e estructurales de los caracteres, Granada (2009) resalta que se tiene en cuenta un espacio e un orden de inicio de cada letra, para lo cual se manejan cuadrículas. El tipo de letra empleado en la cartilla son básicamente fuentes digitales, y para la enseñanza de cada 
Estudio de la construcción de los elementos caligráficos en el proceso de alfabetización de adultos en la Amazonia brasileña

letra se emplean ilustraciones, frases y oraciones que contengan la letra en cuestión. Es importante observar que en la dicha cartilla el enfoque mayor estriba en las minúsculas, ni todas las letras son presentadas y no hay ejercicios con las mayúsculas.

\subsection{El alfabeto español en Colombia}

El alfabeto utilizado en Colombia se basa a partir de la Ortografía del español, aplicando una variante modificada del alfabeto latino que consta de 27 letras: $\mathrm{Aa}, \mathrm{Bb}, \mathrm{Cc}, \mathrm{Dd}, \mathrm{Ee}, \mathrm{Ff}, \mathrm{Gg}, \mathrm{Hh}, \mathrm{li}, \mathrm{Jj}, \mathrm{Kk}, \mathrm{Ll}, \mathrm{Mm}, \mathrm{Nn}, \tilde{\mathrm{N}} \tilde{\mathrm{n}}, \mathrm{Oo}, \mathrm{Pp}, \mathrm{Qq}, \mathrm{Rr}, \mathrm{Ss}$, Tt, Uu, Vv, Ww, Xx, Yy y Zz. Los dígrafos Ch y LI tienen valores fonéticos específicos, y durante los siglos XIX y XX se ordenaron separadamente de C y $\mathrm{L}$, aunque la práctica se abandonó en 1994 para homogeneizar el sistema con otras lenguas. Las vocales ( $A, E, I, 0$ y U) aceptan, además, el acento agudo 0 tilde (' , como en áéíoú), para indicar la sílaba acentuada y la diéresis o crema (" ), que modifica a la $U$ en las sílabas güe, güi para indicar su sonoridad. Sin embargo, La divergencia de la fonología de la lengua entre sus diversos dialectos hace hoy imposible la elaboración de una grafía puramente fonética que refleje adecuadamente la variedad de la lengua; la mayoría de las propuestas actuales se limitan a la simplificación de los símbolos homófonos, que se conservan por razones etimológicas. Las variaciones de nomenclaturas implican la existencia de varios de los grafemas con más de un nombre. La "b" se conoce como "be a secas", "be alta" (en Cataluña), "be grande" (en México, Colombia, Venezuela y Perú) o "be larga" (en Argentina, Chile, Paraguay, República Dominicana y Uruguay); por haber representado en latín el fonema consonante bilabial sonoro (que tiene como alófonos la consonante Oclusiva bilabial sonora [b] y la fricativa bilabial sonora [B]), se la Ilama a veces b labial en Colombia, aunque la pronunciación de la v es en la inmensa mayoría de los dialectos también labial e idéntica. A su vez, esta última se conoce como uve (en España), ve, ve baja, ve chica (en Perú), ve pequeña (en Colombia) o ve corta (en Argentina, Chile, República Dominicana y Uruguay); por el mismo afán de precisión histórica en algunos manuales se designa como $v$ dental, aunque la pronunciación dental desapareció hace siglos del sistema de la lengua.

La i se llama a veces i latina para distinguirla de la "y", "y griega" (o i griega). En algunos lugares, se prefiere el nombre de ye para esta última. 


\section{VENEZUELA Y LA ESCRITURA ESCOLAR}

Las experiencias para el desarrollo del lenguaje escrito en Venezuela han permitido comprobar que el alfabetizando construye la lengua escrita en un proceso largo y de interacción con diversos tipos de materiales escritos, como por ejemplo: carteles, etiquetas, actos de lectura y escritura en el hogar, entre otros (Álvarez, 2002).

Sin embargo, el nivel de comprensión que presentan en general los alumnos es claramente bajo, pues no poseen dominio plausible ni en la expresión oral ni en la escrita, una vez que las debilidades presentadas por el sistema educativo venezolano han sido guiadas de acuerdo con las diferentes conductas y distintos puntos de vista, principalmente, en la enseñanza del lenguaje. O sea, el problema de la escritura está limitado en las prácticas metodológicas que el docente recurrir para promover el aprendizaje de la letra, y por otro lado, los entornos tanto psíquicas como motores del educando (Reyes, 1997).

En el caso concreto de la escritura, esta situación tiene entre otros resultados, en el paso de la letra Script a la letra cursiva no se da de forma apropiada, por lo que el alfabetizando ha de confrontar serios problemas que lo confunden generándole inseguridad y confusión hasta el extremo de dificultarle la adopción de un estilo particular de letra. Así siendo, las principales características de las fallas caligráficas identificadas son: deficiencias en la reproducción de los signos escritos, falta de uniformidad en los signos gráficos que se reproducen, confusión de grafemas e inversión de los mismos (Ferreiro, 1998).

\subsection{El alfabeto español en Venezuela}

El alfabeto utilizado en Venezuela es, en esencia, el mismo romano, con el agregado de otras letras y convenciones necesarias para representar los sonidos del español. Constan de veintinueve letras:

$A$ a, B b, C c, Ch ch, Dd, E e, F f, G g, H h, I i, J j, K k, LI, LI II, M m, N n, N n, O o, P p, Q q, R r, S s, T t, U u, V v, W w, Xx, Y y, Z z

Dónde Ch y $\mathrm{LI}$ son, en realidad "dígrafos", es decir convenciones ortográficas compuestas de dos letras para representar un solo sonido, pero desde el siglo XIX vienen considerándose letras. A pesar de ello, en 1994 la Asociación de 
Estudio de la construcción de los elementos caligráficos en el proceso de alfabetización de adultos en la Amazonia brasileña

Academias de la Lengua Española acordó no tratarlas como letras independientes en los diccionarios. Por esa razón, las palabras que comienzan por " $\mathrm{ch}$ " se incluyen ahora en la parte correspondiente a la letra " $\mathrm{c}$ ", y las que comienzan con "II" se colocan en la parte correspondiente a la letra "I".

\section{EL CUARDERNO ESCOLAR EN FRANCIA}

De acuerdo a los estudios de J ean Hébrard sobre la educación escolar, desde mediados del siglo XIX, la escuela en Francia no limita su proceso de alfabetización sólo al acto de leer o escribir, sino crear las condiciones necesarias para que los estudiantes desarrollen su razonamiento personal, es decir, desarrollen su "saber cómo" (savoir-faire). La escuela se presenta con una gama de enfoques distintos acerca del conocimiento, donde la escritura tiene una función educativa importante. El cuaderno escolar, que sustituí la simple hoja de papel, es el espacio de la escritura en la que todos estos aprendizajes suceden. El uso del cuaderno en la escuela primaria en el siglo $X I X$, es sin duda un acontecimiento importante en la evolución de la alfabetización escolar. Su presencia en las escuelas existe desde 1833 y las grandes exposiciones internacionales fueron los principales instrumentos difusores de su uso, ya que representaban uno de los principales medios de innovaciones educativas.

Las prácticas pedagógicas unificaran el uso del cuaderno escolar, además ello representa un conjunto de documentos propios de un período importante de la historia educacional de Francia, que se encuentra entre los años 1860 y 1960. El cuaderno escolar es, en este período, el soporte de una práctica de escritura que podría ser la matriz de una alfabetización escolar específica que ha conducido a Francia rural para adentrar en el universo cultural de la escritura moderna.

\subsection{La escritura francesa}

El idioma francés se escribe con el alfabeto latino. Utiliza cinco diacríticos: (acento agudo, acento circunflejo, acento grave, cedilla y diéresis), así como dos ligaduras (æ y œ).

La escritura tiene poco que ver con la pronunciación real pero es fácil predecir la pronunciación a partir de la escritura lo cual no es cierto a la 
inversa pues esta no es predecible a partir de la audición. Una de sus características es el uso de dos o tres letras para indicar un fonema, si bien muchas veces estos fonemas franceses reúnen el carácter de dos fonemas predominando uno de ellos, por ejemplo el dígrafo o en el francés parisino suena prácticamente como una [u] española aunque mantiene casi átono algo del fonema [0].

En general, la forma escrita es más conservadora que la forma hablada. La pronunciación típica del francés normativo hace recaer casi siempre el acento prosódico en la última sílaba (agudísimo). La frecuente poca correspondencia entre el francés escrito y el hablado es un fenómeno que se debe a los fuertes cambios fonéticos que se han presentado desde el período del francés antiguo, y que no se correspondieron con cambios en la escritura.

\section{LA CALIGRAFÍA DEL LIBRO PARA ENSEÑANZA DE LA ESCRITURA EN ALEMANIA}

Alemania tiene una rica historia de libros dedicados a la alfabetización de los niños y las fuentes utilizadas en los mismos. La preocupación por la forma de los caracteres se remonta a las primeras décadas del siglo XX, como escribe Heitlinger (2006) sobre el gráfico y educador Ludwig Sütterlin que en 1914 desarrolló un estilo de letra para ayudar a los niños encontrar su propio estilo de la caligrafía, la Ilamada Sütterlin-Schrift. Es importante tener en cuenta las características de la Sütterlin-Schrift, que tenía la forma de la escritura derecha, con letras más anchas, menos adornos y con ascendente y descendente más corto. Este patrón se puso a experimentar en algunas sítios, hasta que se introdujo en todas las escuelas de Prusia en 1915. A partir de 1935 fue parte del plan de estudios de todas las escuelas en Alemania, antes de ser prohibido en 1941 por el gobierno nazi. Después de la Segunda Guerra Mundial, fue utilizado todavía, hasta ser sustituida por la Lateinische Schrift, que sigue en vigor hasta hoy (Heitlinger, 2006).

\subsection{Escrita Alemana}

La escrita alemana está estructurada a partir del alfabeto latino que, además de las 26 letras patronadas, dispone aún de tres vocales más con Umlaut (ä, ö e ü), así como también la consonante eszett o scharfes es (" $ß$ "). Siendo ésta 
Estudio de la construcción de los elementos caligráficos en el proceso de alfabetización de adultos en la Amazonia brasileña

bastante parecida con la letra beta del alfabeto griego, sin embargo su pronuncia es la misma que "ss", la cual tiene su sonido escrito tanto con ésa letra como con "ss": Straße y essen. De acuerdo con la nueva ortografía alemana, la " $\beta$ " es utilizada después de una vocal extendida ("Straße") y el "ss", después de una vocal curta ("essen").

Por otro lado, también existe la escrita alemana gótica que se trata de un alfabeto que empezó a declinar en la Primera Guerra Mundial, cayendo por definitivo al final de la Segunda Guerra Mundial se tornando muy raro, en los días de hoy, encontrar personas que sepan leer o escribir este tipo de letra pues en general, los pocos conocedores sobre esta escrita fueron alfabetizados hasta la entre guerras.

\section{RESULTADOS}

Después de conocer algo de la historia de la caligrafía y libros destinados a la enseñanza de la escritura en siete países, así como el funcionamiento de sus alfabetos, se construyó una tabla comparativa de los aspectos formales de los caracteres que se encuentran en los libros de enseñanza de la escritura de los siete países. Es importante tener en cuenta que los criterios de selección de los países se hicieron de forma aleatoria, ya que el único propósito del estudio es comprobar la existencia de convergencias o divergencias formales de las letras de los alfabetos presentes en los libros escolares.

Aunque existan caracteres especiales en los alfabetos de algunos países del estudio, como en el alemán (la consonante eszett o scharfes " $\$$ "), en el castellano (la "ñ") y en portugués (la consonante "ç") el análisis comparativo se limita a los 26 caracteres comunes a todos los alfabetos estudiados.

A continuación se muestra una colección de alfabetos de los siete países estudiados (Tabla 1) para entender mejor el análisis de la morfología de los caracteres. 
A6_Tab. 1 - Tabla comparativa de aspectos formales de letras en libros de caligrafía de siete países.

\begin{tabular}{|c|c|c|c|c|c|c|c|c|c|c|c|c|c|c|c|}
\hline & & \multicolumn{14}{|c|}{ Paises } \\
\hline \multicolumn{2}{|c|}{ LETRAS } & \multicolumn{2}{|c|}{ BRASIL } & \multicolumn{2}{|c|}{ ESPANA } & \multicolumn{2}{|c|}{ PORTUGA } & \multicolumn{2}{|c|}{ COLOMEAA } & \multicolumn{2}{|c|}{ VENEZUELA } & \multicolumn{2}{|c|}{ Francia } & \multicolumn{2}{|c|}{ ALEmaNAA } \\
\hline A & . & $a$ & a & A & & A & $a$ & A & a & $A$ & $a$ & A & $a$ & $A$ & $a$ \\
\hline B & D & $B$ & $b$ & B & & $\mathcal{B}$ & b & B & $b$ & $B$ & b & B & b & B & b \\
\hline c & . & C & $c$ & C & & C & $c$ & C & C & e & c & $\varphi$ & c & $c$ & $c$ \\
\hline D & a & $D$ & $d$ & D & & $D$ & $d$ & D & $d$ & 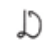 & $d$ & D & d & $D$ & $d$ \\
\hline E & . & $\varepsilon$ & e & & & $\varepsilon$ & e & $\mathrm{E}$ & e & $\varepsilon$ & $\ell$ & $\varepsilon$ & e & $\varepsilon$ & $e$ \\
\hline$F$ & . & $\mathcal{F}$ & f & & & $\mathcal{F}$ & f & F & r & $\mathscr{F}$ & 1 & $g$ & f & $F$ & f \\
\hline - & . & G & $g$ & $\sqrt{7}$ & & G & $g$ & G & 9 & \& & $g$ & $\xi$ & $g$ & G & $g$ \\
\hline H & n & $x$ & h & $H$ & & $\mathcal{H}$ & $h$ & 11 & $h$ & $\mathcal{H}$ & $h$ & H & $h$ & H & h \\
\hline 1 & 1 & 1 & $i$ & 1 & & J & $i$ & I & i & ป & $i$ & g & $i$ & J & i \\
\hline$J$ & 1 & j & $j$ & J & & $\gamma$ & $j$ & $\mathrm{~J}$ & j & $\gamma$ & $j$ & $g$ & $j$ & $\gamma$ & $\dot{\gamma}$ \\
\hline$\kappa$ & $k$ & $k$ & $k$ & K & 8 & K & $k$ & K & k & $\mathcal{K}$ & $k$ & $\pi$ & $k$ & $K$ & $k$ \\
\hline L & 1 & $\mathcal{L}$ & $\ell$ & I & & $\mathscr{L}$ & $\ell$ & L & 1 & $\mathcal{L}$ & $l$ & $\mathscr{L}$ & $l$ & $L$ & $e$ \\
\hline m & $\mathrm{m}$ & $m$ & $m$ & M & & $m$ & $m$ & $M$ & $m$ & $M$ & $m$ & $M$ & $m$ & $M$ & m \\
\hline N & $n$ & $n$ & $n$ & v & & $n$ & $n$ & $\mathrm{~N}$ & $n$ & $N$ & $n$ & $\mathbb{N}$ & $\pi$ & $N$ & $n$ \\
\hline 。 & . & 0 & $\theta$ & 0 & & $\theta$ & a & 0 & c & $\sigma$ & $\sigma$ & O & 0 & 0 & $\sigma$ \\
\hline$p$ & $p$ & $p$ & $p$ & $P$ & & $\mathcal{S}$ & $\uparrow$ & P & $p$ & $P$ & $n$ & 9 & 0 & $D$ & p \\
\hline a & 9 & $Q$ & 9 & Q & 9 & $Q$ & 9 & $Q$ & 9 & $Q$ & $q$ & 2 & $q$ & $Q$ & $q$ \\
\hline$R$ &. & $R$ & 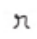 & $R$ & 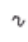 & $R$ & $n$ & $P$ & $r$ & $R$ & 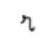 & $R$ & 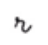 & $R$ & $r$ \\
\hline s &. & $s$ & 1. & S & & 8 & $s$ & $S$ & $s$ & $\&$ & 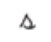 & $\varphi$ & 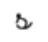 & $S$ & $\gamma$ \\
\hline$T$ & . & $J$ & $t$ & $T$ & $\mathrm{t}$ & $\mathcal{T}$ & $t$ & $\mathrm{~T}$ & 1 & 8 & 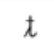 & $q$ & 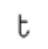 & $T$ & 1 \\
\hline u & u & u & $\mu$ & U & & $u$ & $u$ & U & $u$ & U & $u$ & น & $u$ & $u$ & $w$ \\
\hline v &. & $v$ & $v$ & V & & $v$ & $v$ & V & $\vee$ & V & $v$ & $q$ & $v$ & $V$ & $v$ \\
\hline w & $w$ & $w$ & $\omega$ & W & & $\omega$ & $w$ & W & $W$ & W & $w$ & ש & $w$ & $w$ & $\omega$ \\
\hline $\mathrm{x}$ & $x$ & $x$ & $x$ & $x$ & ${ }^{2}$ & $x$ & $x$ & $X$ & $x$ & $x$ & $x$ & $\mathscr{C}$ & $\propto$ & $x$ & $x$ \\
\hline$r$ & $y$ & y & y & $Y$ & $y$ & $y$ & $y$ & $Y$ & y & Y & $y$ & y & $y$ & $y$ & $y$ \\
\hline$z$ & 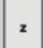 & $z$ & z & $z$ & & $Z$ & $z$ & 2 & $z$ & $z$ & $z$ & $q$ & $z$ & $Z$ & z \\
\hline
\end{tabular}


Estudio de la construcción de los elementos caligráficos en el proceso de alfabetización de adultos en la Amazonia brasileña

A través de la observación de la Tabla se puede observar los siguientes aspectos:

- En cuanto a las características generales de los alfabetos presentes en los libros escolares de los siete países

1) En Brasil muchos libros de enseñanza de la escritura, como el usado para este estudio, usan la tipografía Kindergarten del tipógrafo brasileño Tony de Marco. El objetivo del tipógrafo fue facilitar la producción de materiales de enseñanza, libros y folletos, llevadas a cabo por los editores y colegios del país, es decir, no fue un trabajo resultante de una investigación científica desarrollada con expertos en educación;

2) En el libro español elegido para el presente estudio, presentase una tipografía caligráfica con las mayúsculas de tipo palo, sin enlazar con las minúsculas, la Escolar SD Regular (Figura 3), diseñada por Antonio Herrera Infantes. Es curioso observar que, diferente de la mayoría de los alfabetos presentes en los libros escolares de enseñanza de la escritura en los siete países estudiados, en esta tipografía solamente las minúsculas son cursivas;

3) El libro portugués utiliza la tipografía Escolar Portugal, diseñada por el tipógrafo Paulo Heitlinger. Según Heitlinger, la tipografía fue proyectada para ser el primer alfabeto usado por niños de 4 a 8 años, además, la fuente Escolar Portugal es un alfabeto didáctico, en el sentido primario del término. Enseña a escribir y ayuda a los educadores a enseñar a escribir. Su función es la de proporcionar a los niños en la primera fase de aprendizaje a leer y escribir el idioma portugués, una experiencia tan satisfactoria como sea posible, omitiendo las dificultades y frustraciones innecesarias con énfasis en las relaciones estéticas entre las letras;

4) El alfabeto usado en el libro de Colombia tiene una proximidad formal con la tipografía Script-École diseñada por Henri Rogelet. Es uno de los raros casos en este estudio donde las letras no tienen ninguna característica cursiva, aunque la tipografía diseñada por Rogelet tenga su aplicación destinada a libros escolares. Otro dato interesante es que en el libro colombiano no hay ejercicios con la letra "x" ni con las mayúsculas;

5) En uno de los libros más populares de enseñanza de la escritura de Venezuela se encuentra un alfabeto compuesto por letras minúsculas en formato cursivo y con aproximación formal igual a la mayoría de los alfabetos caligráficos. Las mayúsculas presentan una combinación de formas cursivas y romanas sin una estandarización formal como se puede ver en las minúsculas; 
6) En el libro escolar de Francia fue encontrada la tipografía GinoSchoolScript, diseñada por J ean-Claude Gineau. Esta cursiva escolar cuenta con muchos movimientos curvos y decorativos, sobre todo en letras mayúsculas, presentando un alto nivel de dificultad constructiva de los caracteres;

7) Por la simplicidad de los caracteres en mayúsculas y minúsculas, el alfabeto en el libro alemán es uno de los más interesantes de todos los modelos estudiados en la investigación. Hay una clara preocupación por la simplificación de la forma, por eso la tipografía tiene el nombre Vereinfachte Ausgangsschrift (fuente simplificada). Esta simplificación es el resultado de un proceso que comenzó con Ludwig Sütterlin en las primeras décadas del siglo $X X$.

- En cuanto a las características formales de los caracteres de los alfabetos presentes en los libros escolares de los siete países

1) La letra "a" (minúscula) tiene al menos cinco formatos diferentes, aunque con una aproximación formal. La mayor variación se da en la versión en mayúsculas ("A"), destacando los formatos de Portugal y Francia que son muy similares, pero se diferencian de los demás;

2) Por sus características formales, las letras "Cc", "Dd" y "Ee" no tiene muchas divergencias formales. La única excepción es la letra "C" mayúscula del alfabeto francés que, cuando se aplica solo, puede presentar dificultades de interpretación;

3) La letra "f" minúscula tiene pequeñas diferencias entre los alfabetos, sólo en el libro de Colombia, la letra tiene un formato diferente. El mismo no se produce con la letra "F" mayúscula porque las diferencias formales están presentes en todos los países;

4) La letra "G" mayúscula presenta una gran variedad de formato, con énfasis en el carácter del libro de Venezuela que tiene un formato Sui Generis y difícil de identificar cuando se aplica solo. La variación formal de las minúsculas es muy pequeña, sólo en el libro de Colombia que hay una diferencia en la forma de la letra;

5) La "h" es una de las letras que casi no tiene variaciones formales. La versión en mayúsculas de "H" es una de las letras más difíciles de diseñar (principalmente en el libro francés), en función del doble lazo invertido que conecta las dos partes verticales del caracter. Sólo en los libros procedentes de España, Colombia y Alemania, se encontró una simplificación de la forma; 
Estudio de la construcción de los elementos caligráficos en el proceso de alfabetización de adultos en la Amazonia brasileña

6) Las letras "i" y "j" minúsculas no presentan muchas variaciones formales. Las versiones de estos caracteres en mayúscula no poseen características cursivas en los libros de España y Colombia, estos son los países que tienen los cambios en el formato;

7) La "k" minúscula (de difícil complejidad constructiva y con similitud formal con la "R" mayúscula) sigue el mismo patrón formal en los libros de Brasil, Portugal, Francia y Alemania. La versión mayúscula tiene aproximación formal sólo en los libros de Portugal, Venezuela y Francia. En el caso francés, la letra se parece mucho a la mayúscula "H" del mismo alfabeto;

8) El grupo está formado por las letras LI, Mn, $\mathrm{Nn}$ y Oo tienen pocas variaciones formales en los caracteres mayúsculas y minúsculas. Sólo la "L" mayúscula del libro de Portugal y las letras "L", "M" y "N" mayúsculas del alfabeto francés presentan un estilo decorativo que añade un grado de dificultad constructivo mayor en los caracteres;

9) La 'p' minúsculo de los libros procedentes de España, Portugal, Francia y Alemania tienen una peculiar similitud a la letra " $n$ " minúscula, lo que las diferencia es sólo la descendiente de la "p". Las mayúsculas no tienen muchas diferencias formales, excepto el carácter de libros portugueses que tienen el arco superior mucho distante de la hasta vertical en la parte posterior;

10) La letra "q" minúscula no tiene variaciones formales en ningún de los libros de los siete países. La versión en mayúsculas también tiene poca variación formal, excepto por el carácter del alfabeto francés que tiene un formato Sui Generis y similar con el número 2 (dos).

11) La "r" minúscula solo presenta variación formal en los libros de Colombia y Alemania. La versión en mayúsculas tiene poca variación formal.

12) Las variaciones formales de la "s" minúscula son muy pequeñas, en las versiones en mayúsculas hay aproximaciones formales en los libros de Brasil, Portugal y Venezuela, diferenciando del formato presentado por el grupo de España, Colombia y Alemania. La versión de la mayúscula "S" de los libros franceses presenta un aspecto Sui Generis y difíciles de identificar cuando se utiliza solo.

13) La letra "t" minúscula cuenta con cuatro variaciones formales, con destaque para el formato Sui Generis en el libro alemán; el caracter es muy similar a la forma del número 1 (uno), porque el trazo transversal está muy cerca del extremo inferior de la hasta vertical. Los caracteres en mayúsculas presentan cinco variaciones formales. La letra del libro brasileño se asemeja mucho con la mayúscula "I" del mismo alfabeto; los caracteres que aparecen 
en los libros de Venezuela y Francia tienen características Sui Generis y difíciles de interpretar cuando aplicados de forma aislada.

14) Debido a sus características, el conjunto de caracteres formado por las letras "Uu", "Vv", "Ww", "Xx", "Yy" y "Zz" no tiene muchas variaciones formales, sobre todo porque la forma de las minúsculas es muy similar al formato de las minúsculas.

\section{CONCLUSIONES}

El estudio demuestra la falta de uniformidad de las letras presentes en los libros de enseñanza de la escritura. El problema no está relacionado con el nivel educacional o económico de los países presentes en el estudio, ello estriba en el hueco pedagógico de presentar alternativas de la caligrafía que permitan una transición menos abrupta entre la escritura manual y la escritura en los ordenadores y/ u a través de dispositivos electrónicos.

Hay un sinnúmero de daños causados por la falta de una normalización de la escritura escolar, especialmente en continentes como Europa, donde la libre circulación de las familias pertenecientes a la comunidad, permite un constante cambio de país, sea por trabajo, estudio, factores económicos, etc. Los niños de estas familias podrán tener grandes dificultades al encontrar, en las nuevas escuelas, caracteres diferentes de los que estaban acostumbrados en su país.

Países como Brasil (antigua colonia de Portugal), Venezuela y Colombia (antiguas colonias de España) que comparten el mismo idioma de los colonizadores, y donde se produce un gran flujo de la inmigración, tienen grandes diferencias formales entre los caracteres presentes en sus libros de texto, como se comprobó en esto estudio.

La creación de una norma internacional para estandarizar alfabetos presentes en los libros escolares podría ayudar a minimizar los impactos negativos sobre la educación y la enseñanza de la escritura. Un análisis multidisciplinaria entre profesionales de la educación, la psicología y los desarrolladores de tipografías, como diseñadores, podría ser el primer paso para crear un estándar de la escritura en las escuelas.

Muchos alfabetos han sido diseñados con el propósito de ayudar a la enseñanza de la escritura. Un debate internacional con profesionales relacionados con el tema, para elegir un alfabeto existente o desarrollar un patrón de letras, a través de sus aspectos y convergencias formales, podría 
Estudio de la construcción de los elementos caligráficos en el proceso de alfabetización de adultos en la Amazonia brasileña

convertirse en un importante avance educativo para introducir la enseñanza de la escritura de manera más adecuada en el universo tecnológico del mundo moderno.

\section{REFERENCIAS BIBLIOGRÁFICAS}

Álvarez, G. (2002). Legibilidad de la Escritura en Alumnos de la Primera Etapa de Educación Básica. Maracay, Venezuela.

Cinel, N. C. (2003). Disgrafia: Prováveis causas dos distúrbios e estratégias para a correção da escrita. Revista do professor, 19 (74), 19-25.

Ferreiro, E. (1998). La construcción de la escritura en los niños. Caracas: Mimeo.

Frutiger, A. (2001). Sinais e Símbolos: desenho, projeto e significado. São Paulo: Martin Fontes.

Gil, A. C. (2010). Como elaborar projetos de pesquisa. 5ạ ed. São Paulo: Atlas.

Granada, I. K. (2009). Didactica de la Enseñanza de la Caligrafia Expresiva en niños de primaria. Pereira, Colombia.

Heitlinger, P. (2006). Tipografia: origens, formas e uso das letras. Lisboa: Dinalivro.

Justino, M. (2006). O Manual Escolar no Quadro da História Cultural. Sísifo. Revista de Ciências da Educação, 1, 5-14.

Ossenbach, G. (2010). Manuales escolares y patrimonio histórico-educativo. Educatio Siglo XXI, 28 (2), 115-132.

Posada, E. G. (1993). La lengua escrita en la escuela primaria. Contexto y vigencia histórica de la querella de los métodos en la enseñanza de la lectura y la escritura. Revista Educación y Pedagogía, 10 y 11, 119-143.

Reyes, L. (1997). Estrategias para el aprendizaje eficaz de la escritura. Maracay, Venezuela.

Rumjanek, L. (2008). 8o P\&D Design. Disponible en: http:// www1.sp.senac. br/ hotsites/ arquivos_materias/ ped2008/20081022_pe d_05_Caderno_Resumos.pdf [consulta: 2012, 12 de marzo]. 
Vidal, D. G., \& Gvirtz, S. (1998). O ensino da escrita e aconformação da modernidade escolar: Brasil e Argentina (1880-1940). Revista Brasileira de Educação, 8, 13-30.

Yin, R. K. (2010). Estudo de Caso - Planejamento e Métodos. Porto Alegre: Bookman Tradução: Daniel Grassi.

\section{Palabras clave:}

Alfabetización, Escritura, Morfología

\section{Keywords:}

Literacy, Writing, Morphology

Almir de Souza Pacheco. Doctorando en Diseño, Fabricación y Gestión de Proyectos Industriales por la Universitad Politècnica de València (UPV) España. Especialista en Diseño, Publicidad y Marketing - Universidade Federal do Amazonas (UFAM) - Brasil. Diseñador Gráfico y Docente.

María Begoña J ordá Albiñana. Doctora en Bellas Artes, directora académica del Master Universitaria en Ingeniería del Diseño, profesora titular e investigadora de la Universitad Politècnica de València (UPV) España. Editora de la revista Anales de Ingeniería Gráfica.

Jimena González del Río Cogorno. Doctora en Bellas Artes, diseñadora gráfica, profesora del Master Universitario en Ingeniería del Diseño y del Grado en Ingeniería en Diseño Industrial y Desarrollo de Productos. Coordinadora del Master en Artes Gráficas de la Universitad Politècnica de València (UPV) España. 
Estudio de la construcción de los elementos caligráficos en el proceso de alfabetización de adultos en la Amazonia brasileña

Dirección de los autores:

Universitat Politècnica de València

Camino de Vera s/ $\mathrm{n}$

46022 - Valencia

Telf. +34 963877064

E-mail:

almirdesigner@gmail.com

bego@mag.upv.es

jimena@mag.upv.es 


\title{
3.7. Artículo 7 - Experimentaciones modulares para el diseño de caracteres tipográficos
}

Esta producción científica ha sido realizada con la intención de hacer un estudio metodológico de la construcción modular de caracteres para un logotipo o un alfabeto tipográfico.

\section{Artículo no Publicado}

\section{Experimentaciones modulares para el diseño de caracteres tipográficos}

\author{
Almir de Souza Pacheco ${ }^{1}$ \\ María Begoña J ordá Albiñana ${ }^{1}$ \\ J imena Gonzáles del Río Cogorno ${ }^{1}$ \\ ${ }^{1}$ Universidad Politécnica de Valencia - Valencia, España
}

\section{Resumen}

La construcción modular de las formas ha sido utilizada por la humanidad durante miles de años y aún se aplica en la mayoría de los proyectos de diseño, como también en muchas otras áreas. No se puede pensar en construir un edificio sin su plano correspondiente, un producto de diseño industrial sin dibujo técnico o un libro sin diagramación, sobre todo cuando se tienen en cuenta los aspectos técnicos, materiales y de producción. El objetivo de este trabajo es presentar recomendaciones elementales para la construcción 
Estudio de la construcción de los elementos caligráficos en el proceso de alfabetización de adultos en la Amazonia brasileña

modular de caracteres, sea para el uso de un logotipo o como base para el desarrollo de una tipografía. Como resultado de la investigación se propone una estructura modular flexible para el desarrollo de caracteres adaptables a los propósitos y características del proyecto gráfico.

Palabras claves - Diseño Gráfico, Tipografía, Estructura Modular

Abstract

The modular design of the forms has been used by mankind for thousands of years and still applies in most design projects, as well as in many other areas. Can't think of a building without its corresponding plane, a product of industrial design without technical drawing or a book without layout, especially when taking into account the technical, material and production. The aim of this paper is to present recommendations for elementary modular character, is to use a logo, or as a basis for development of a typeface. As a result of research proposes a flexible modular character development adaptable to the purposes and characteristics of graphic design.

Keywords - Graphic Design, Typography, Modular Structure

Relevancia para la práctica en diseño - La principal contribución de esta investigación radica en la aplicación de un método que sirve como referencia auxiliar en la generación de parámetros de diseño en proyectos gráficos para el desarrollo de logotipos, y como base para la construcción de los caracteres de una familia tipográfica a través de una estructura modular.

\section{Introducción}

La necesidad de comunicación induce a la sociedad a una constante búsqueda de información, y mediante la percepción visual las personas la pueden absorber de forma inmediata. A principios del siglo pasado, William Ivins identificó como países atrasados a aquellos que no comprendían el potencial de la comunicación visual;el argumentó, que muchas de las ideas de la civilización occidental se corresponden con las características de expresión y creación de diversas formas de comunicación gráfica.

Con frecuencia la actividad del diseñador gráfico es confundida e interpretada como algo instintivo y carente de técnica, esto a pesar de ser 
uno de los principales agentes de comunicación en las empresas, productos y servicios con el mercado.

Incluso, si el universo del diseño se enmarcara en la inspiración artística y la creatividad fuera la fuerza impulsora detrás de los proyectos, el diseñador no puede pasar por alto el uso de un método y convertir la inspiración en el núcleo de su actividad; el uso de la metodología proporciona una forma objetiva de observación, permite el desarrollo coherente del proyecto y es un elemento importante de las acciones para su control y seguimiento, a partir de la fijación de todo el proceso de información, del enfoque del problema y de cómo se plantea la mejor manera de resolver la necesidad del cliente y/ 0 público (Olson, 2000). Elegir el método ideal puede significar ahorro de tiempo y facilidad de control en las etapas de desarrollo del proyecto.

Una forma específica del diseño gráfico es el Sistema de Identidad Visual Corporativo (SIV), que exige un largo período de preparación, comenzando con el desarrollo de los elementos primarios (logotipo y/o símbolo), en este sistema el método puede ser el diferencial en el proceso creativo. Muchas marcas se componen únicamente de letras, asumiendo la tipografía un papel importante, aunque en general la opción más fácil es elegir un alfabeto existente, recayendo en el problema de la falta de originalidad; el diseñador puede resolver esto, creando él mismo las letras del logotipo de SIV, siendo el momento de elección del método, el factor primordial en el proceso creativo y en la sistematización de la solución.

Con esta premisa, la investigación tiene como objetivo contribuir con una alternativa para sistematizar el desarrollo del proyecto tipográfico, y así, ayudar al diseñador gráfico en la validación de su proceso creativo de una manera coherente, creando una referencia técnica para la elaboración y uso de los caracteres generados; por tanto, se proponen los siguientes objetivos:

- Analizar las metodologías del diseño que puedan ser adaptadas para el proceso de construcción de caracteres tipográficos;

- Estudiar la relación de la tipografía con los Sistemas de Identidad Visual;

- Estudiar los tipos de estructuras para la construcción de caracteres tipográficos;

- Proponer un procedimiento metodológico para el diseño de caracteres que ayude en la construcción de un logotipo y/ o de una familia tipográfica.

\section{La importancia del método}

2.1 Métodos y metodologías 
Estudio de la construcción de los elementos caligráficos en el proceso de alfabetización de adultos en la Amazonia brasileña

Para la interpretación correcta de un proyecto es necesario entender que el método está directamente relacionado con los pasos que hay que seguir para llegar a un resultado; Leopardi (1999) afirma que el método es la forma en que hacemos algo con el fin de alcanzar una meta, es la base mental para el ejercicio de una actividad eficiente $y$, requiere la organización de conocimientos y experiencias anteriores. La metodología no es más que el estudio de métodos o la disciplina que se ocupa de estudiar y ordenar (en la medida de lo posible) muchos métodos, sus orígenes históricos, sus fundamentos y paradigmas, junto con sus relaciones teóricas, sus características estructurales y las especificidades de sus objetivos (Turati, 2003).

Algunos profesionales creen que la experiencia de diseño gráfico y la creatividad son suficientes para resolver cualquier problema de diseño, en este sentido es importante reflexionar sobre las palabras de Nigel Cross (2004), quién afirma que el conocimiento del proyecto no es simplemente una cuestión de tener "talento", sino que es el resultado de una aplicación dedicada a un campo específico del diseño, donde se ha desarrollado la capacidad mental para retomar ejemplos concretos de lo que se ha acumulado, para formar nuevos conceptos y un resumen pertinente de su área de especialización.

La dinámica del mercado determina la necesidad de normalizar las tareas de forma ordenada para llegar a una solución en la cual, cada paso tiene inicio y final muy bien definidos. En diseño gráfico donde los plazos son cada vez más cortos, el uso de metodologías más que una necesidad, es una obligación.

\subsection{La metodología en el diseño gráfico}

Muchos autores han desarrollado estudios buscando reducir la complejidad de los métodos para el desarrollo de proyectos de diseño, entre ellos están: Back (1983), Munari (1983), Bonsiepe (1984), Baxter (1998), Löbach (2000), Abramovitz (2002). Se observa en un análisis más detallado de los diversos métodos adoptados, que estos se enfocan principalmente en el diseño industrial, es decir que, aunque el término utilizado es el producto, el énfasis es el producto tridimensional, como se muestra en la Tabla 1, que contiene una adaptación esquemática de dos de los métodos citados. 
A7_Tab. 1 - Metodologías de Diseño - Adaptado de Vieira (2007)

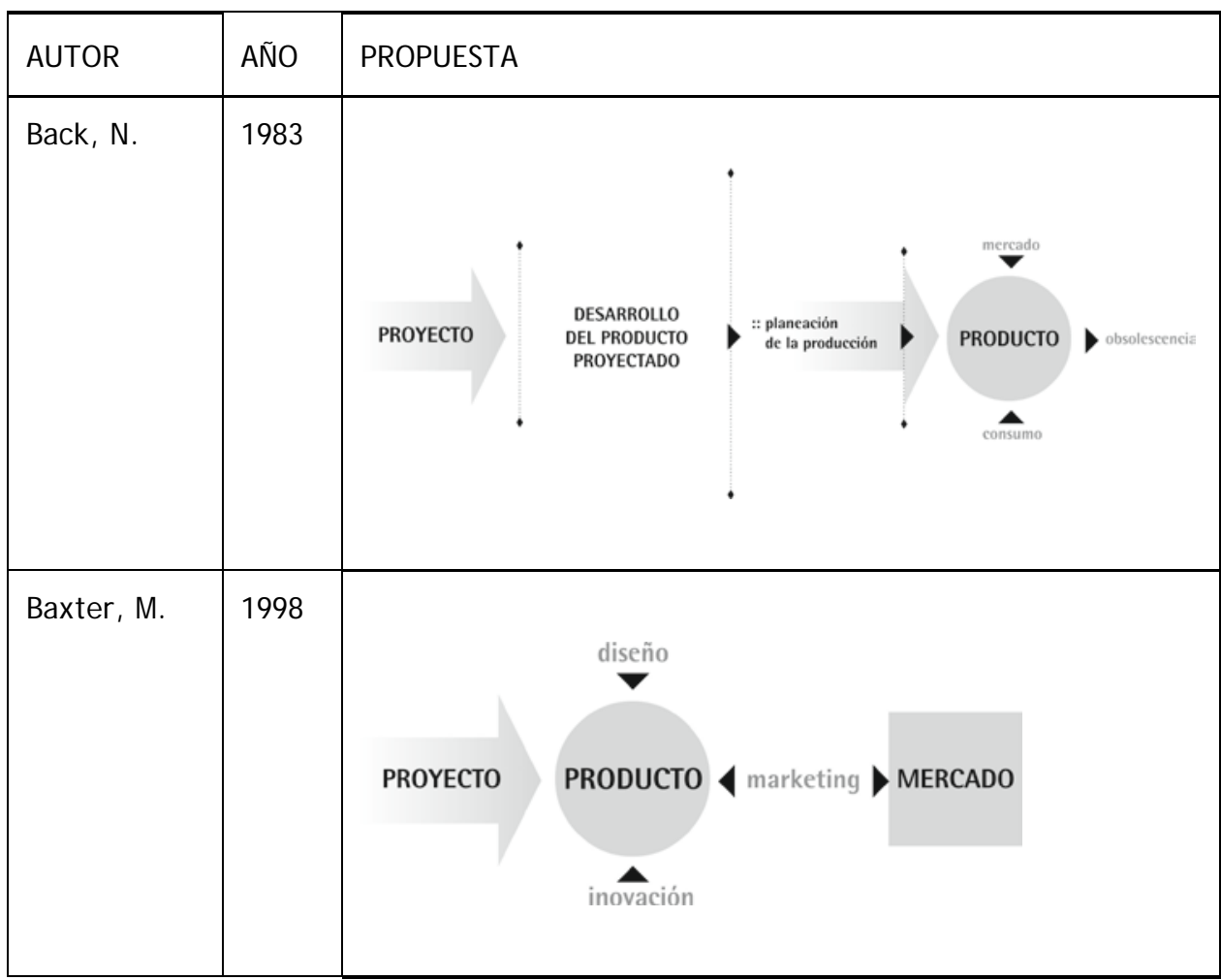

El diseño gráfico necesita más referencias proyectuales y metodológicas que apoyen el proceso creativo, y que ayuden al diseñador gráfico a desarrollar un enfoque más coherente de sus proyectos; además permiten justificar a los clientes que los resultados presentados han sido obtenidos con base en procedimientos técnicos de diseño.

Cabe señalar que esta necesidad va más allá del aspecto representativo, por ejemplo, en un sistema de identidad visual corporativa, hay un gran número de aplicaciones en cuanto a materiales, formas y tamaños, dependientes de las especificaciones técnicas de producción.

La esencia de la comunicación de una empresa con el mercado, se produce a través de su identidad visual. Según Villafañe (1999), la identidad visual es algo que está por encima de una señal tangible para distinguir productos o negocios de sus competidores, es un conjunto de ideas y valores que hacen una empresa única y expresen su particular forma de estar en el mercado. Un 
Estudio de la construcción de los elementos caligráficos en el proceso de alfabetización de adultos en la Amazonia brasileña

ejemplo de método aplicado al diseño es la metodología de los Sistemas de Identidad Visual (SIV) de María Luisa Peón (2000), que utiliza la estrategia de dividir el proyecto en fases y etapas ordenadas cronologicamente, así cada paso se inicia desde la conclusión de la fase anterior, como se describe en la figura 1.

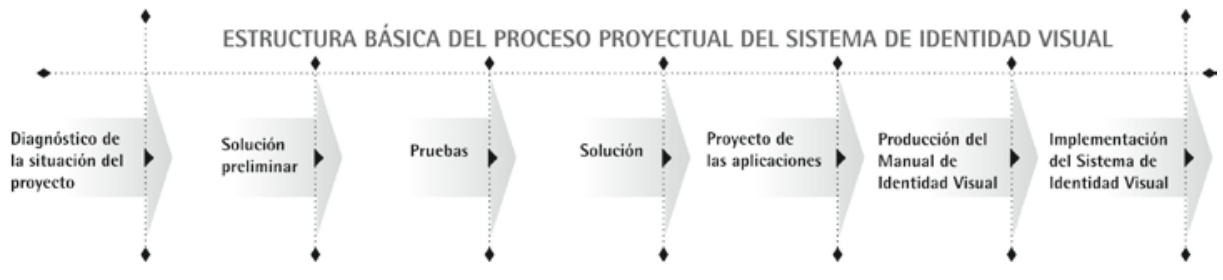

A7_Fig. 1 - Adaptación de la estructura que describe el proceso de un SIV, Peón (2000).

Analizado en un sentido más amplio, según Peón (2000), el diseño de un sistema de identidad visual se compone de tres fases principales en que los elementos fijos de cada paso varían según el tamaño o tipo de empresa y las características de su producto o servicio (figura 2).

FASES DEL PROYECTO

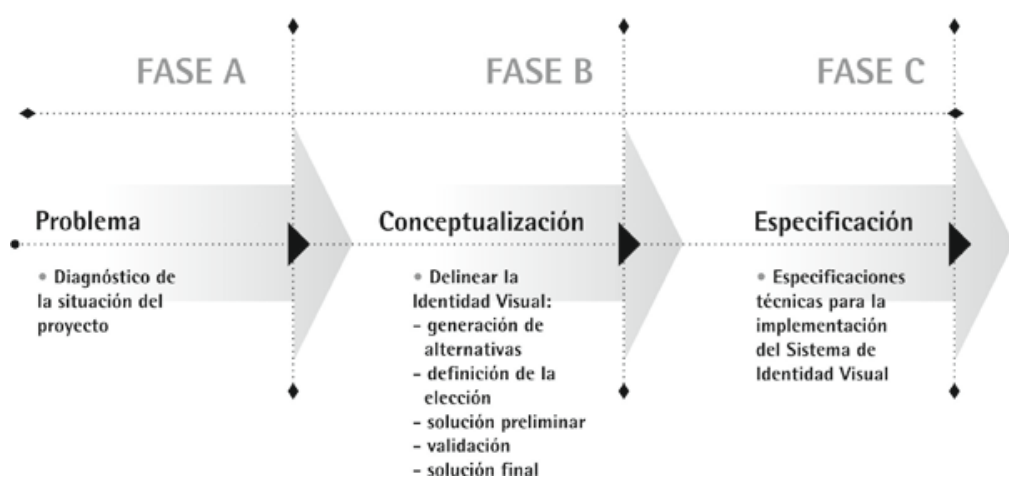

A7_Fig. 2 - Diagrama adaptado de las etapas de un proyecto de identidad visual.

De las fases de diseño gráfico que se observan en la Figura 2, el presente estudio se centra en la fase B (Conceptualización), buscando específicamente 
contribuir en el respeto que debe haber entre la tipografía con el elemento fundamental de un sistema de identidad visual: el logotipo.

\section{Comprendiendo la tipografía}

Al hablar de la tipografía, Niemeyer (2003) la clasifica como la práctica que se ocupa de los atributos visuales de la lengua escrita, la participación de los tipos de selección y aplicación, la elección del formato y la composición de la página con las letras de un texto con el fin de transmitir el mensaje. Farías (2001) complementa este pensamiento, expresando que la tipografía también implica un conjunto de prácticas y procedimientos para la creación y el uso de símbolos visibles relacionados con tipos de letra, es decir, las letras y también los signos de ortografía (números, puntuación, etc.) con fines de reproducción. Esto incluye tanto el diseño del tipo, como el diseño con el tipo.

En general, el objetivo principal de la tipografía es facilitar la comunicación, por lo que exige un poco de cuidado y requiere que los criterios técnicos deban ser respetados a la hora de su desarrollo.

\section{1 Anatomía tipográfica}

Para una correcta interpretación de la forma de los tipos es importante entender sus elementos como componentes individuales del diseño y los aspectos técnicos relativos a su unidad constructiva.

Durante la evolución de la tipografía, los caracteres han sufrido una serie de cambios y atributos formales, algunos innecesarios y algunos indispensables. Los elementos de la anatomía tipográfica cambian la nomenclatura en función de su idioma o fuente de origen. Hay algunos accesorios que son esenciales para la identificación y el reconocimiento de caracteres, sobre todo cuando se trata de una familia tipográfica, según Montesinos y Hurtuna (2001). La figura 3, muestra una adaptación de los elementos principales de la anatomía tipográfica.

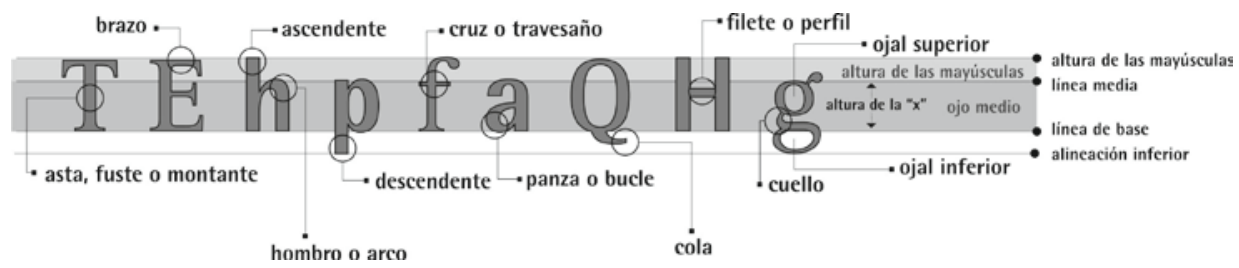

A7_Fig. 3 - Anatomía del tipo, adaptación de Montesinos y Hurtuna (2001). 
Estudio de la construcción de los elementos caligráficos en el proceso de alfabetización de adultos en la Amazonia brasileña

\subsection{Características formales de los principales grupos estilísticos}

Además de los conocimientos de la anatomía de los tipos, es importante conocer las características formales de los grupos estilísticos, es decir, las variables de la forma que cada familia tenga. Existen muchas clasificaciones de las familias tipográficas, como también hay muchas tipografías difíciles de encajar en las tipologías de los grupos tipográficos, incluso basándose en las clasificaciones del tipógrafo francés Maximilien Vox y los adoptados por la Asociación Tipográfica Internacional (ATypl).

Como referencia para este estudio, se adoptó la clasificación propuesta por Montesinos y Hurtuna (2001); según estos autores, aunque no hay una clasificación basada en las formas de los caracteres, es muy difícil encontrar una tipografía que tenga las características descritas en grupos puros en su estilo. La clasificación aumenta en complejidad cuando se estudia la aplicación de la tipografía aislada como en los logotipos, por ejemplo.

\section{3 La relación de la tipografía con el logotipo}

De los elementos primarios que componen una identidad visual la tipografía tiene una importancia fundamental. Es de suma importancia para una empresa, producto o servicio tener un nombre que lo identifique y diferencie de los demás, por eso muchas marcas se hacen sólo para logotipos o simplemente letras. Strunk (2000) define un logotipo como la particularización de escribir un nombre y siempre que se utilice un nombre representado por el mismo tipo de letra (especialmente diseñado o no), se tratará de un logotipo (Figura 4). 


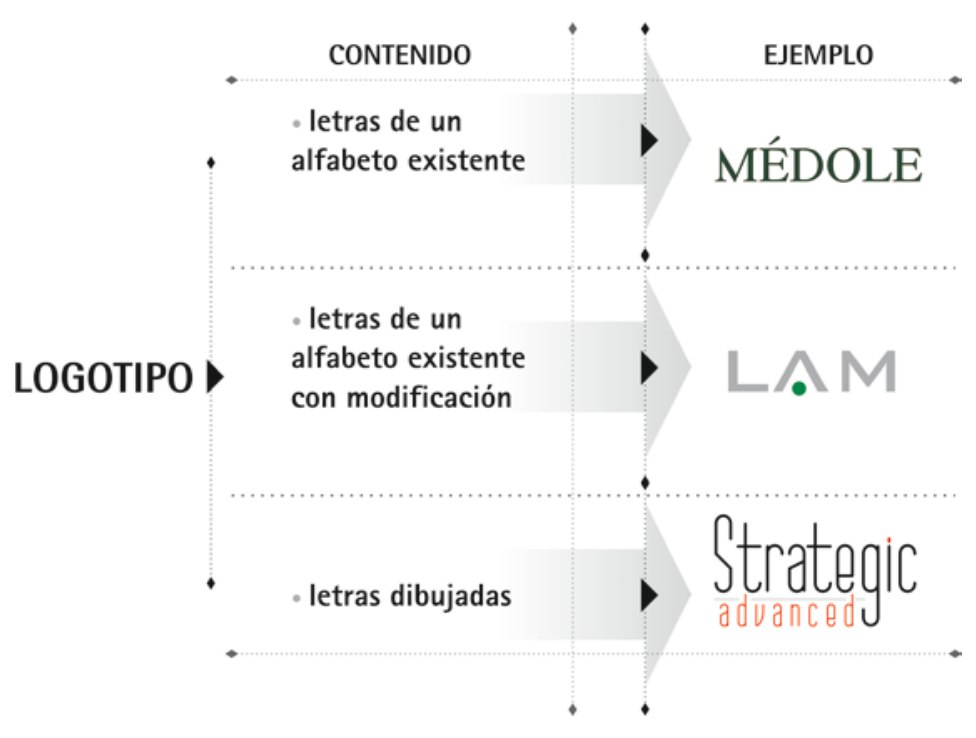

A7_Fig. 4 - Diferentes formas de utilizar las letras en un logotipo, Strunck (2007).

Algunas marcas tienen tradicionalmente sólo letras, ya que el propio nombre es lo suficientemente fuerte como para diferenciarse de las demás, y tal vez por esto se optó por utilizar un alfabeto existente, como por ejemplo en las marcas Dior, Sony, JVC y otras. En este caso la elección de la tipografía tiene que ser muy cuidadosa, de lo contrario la marca puede ser confundida con otra que utiliza la misma tipografía y ha escrito un nombre similar. La deformación de las letras es un poco irrespetuosa con el creador de la tipografía original y no siempre tiene un buen resultado, eso sin tener en cuenta los efectos jurídicos que esta práctica puede causar. Una forma original de personalizar el logo es dibujar las letras que lo componen, aunque laborioso tiene muchas ventajas, ya que un logotipo no tiene todas las letras del alfabeto y en algunos casos hay letras que se repiten, siendo un gran aspecto de venta de marca, una opción creativa y una excelente herramienta para la diferenciación, además de evitar los problemas antes mencionados, Coca-Cola es un buen ejemplo de esto. Si el diseñador elige dibujar las letras, se enfrenta al siguiente dilema:

- ¿Diseñar las letras de un logotipo es lo mismo que diseñar las de una tipografía?

- ¿Cómo definir la forma de los caracteres? 
Estudio de la construcción de los elementos caligráficos en el proceso de alfabetización de adultos en la Amazonia brasileña

- ¿Cuáles ventajas y desventaj as pueden tener los caracteres?

- ¿Por dónde empiezo? ¿Cuál letra debe ser diseñada primero?

- ¿Cuál es tamaño de las letras?

Pocas opciones están disponibles para responder a todas estas y muchas otras preguntas relacionadas con el diseño de tipografías. El presente estudio intenta visualizar un camino metodológico para responder a estas preguntas mediante la elección de un procedimiento que ayude en el dibujo de los caracteres.

\section{Modelización de Sistemas}

El modelado de sistemas se basa en el modelo de Ashby y se desarrolló en la Escuela de Investigación Operativa de Valencia (España). Hay varios modelos basados en el desarrollo de Ashby, pero el elegido por esa escuela fue el modelo español para la formulación de objetivos (Hernandis, 2003).

El modelo de diseño concurrente es una variante del sistema de modelado utilizada para el desarrollo de productos industriales (Hernandis, 2003). El uso de este modelo se justifica por la posibilidad de examinar las variables necesarias para el diseño, a través del análisis de los aspectos formales, funcionales y ergonómicos del objeto en estudio, y a partir de esta información, obtener los parámetros de referencia para la construcción de una estructura modular dirigida al diseño de tipos de letra. La figura 5 muestra una representación gráfica del modelo.

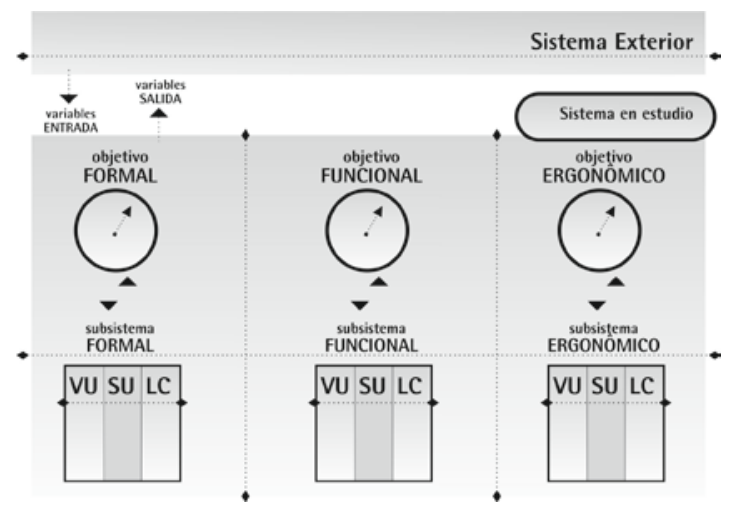

A7_Fig. 5 - Representación gráfica del modelado, Hernandis (2003). 


\section{Material y métodos}

\section{1 Clasificación de la investigación}

Este estudio de investigación tiene una dirección y enfoque cualitativo, se clasifica como exploratorio, descriptivo y basado en un marco teórico que permite una aproximación conceptual sobre el tema (Gil, 2002). El principal objetivo del carácter cualitativo es la aprehensión y la interpretación de la relación de los significados de los fenómenos para el individuo y para la sociedad (Turato, 2003).

Para analizar los hechos, desde el punto de vista empírico y compararlos con una visión teórica de los datos recogidos de la realidad, el documento expone un modelo de funcionamiento - para esta primera etapa de la investigación presentando una colección de datos precedido por la investigación bibliográfica y documental (Marconi, MA, y Lakatos, NY, 2006).

El uso del modelo Concurrente (Hernandis, 2003) sirve como referencia para la determinación y el análisis de las variables utilizadas en la construcción de una estructura modular y flexible, para el diseño de elementos tipográficos para su uso en logotipos y/ o construcción de una familia tipográfica.

\section{2 Procedimientos técnicos utilizados}

La idea general del estudio es desarrollar una metodología para la construcción de caracteres que se pueda utilizar para personalizar un logo, o servir de base para el diseño de una familia tipográfica. El procedimiento metodológico del estudio se dividió en cinco etapas de acuerdo con la figura 6.

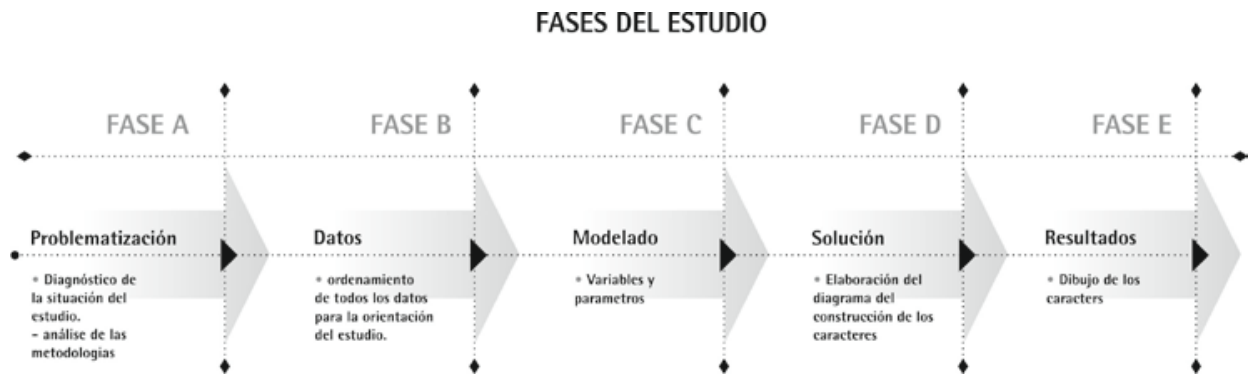

A7_Fig. 6 - Diagrama de las fases del estudio. 
Estudio de la construcción de los elementos caligráficos en el proceso de alfabetización de adultos en la Amazonia brasileña

Inicialmente, en la fase $A$, se realiza una investigación y análisis de las metodologías de diseño para determinar cuáles tienen más proximidad con el diseño gráfico.

Se verifica que la mayoría de los métodos tienden al diseño de productos industriales (tres dimensiones), aunque algunos tratan de adaptarse al diseño gráfico, cabe destacar que esta observación se hace teniendo en cuenta que el resultado de un diseño gráfico también es un producto (dos dimensiones), ya que en la mayoría de los casos se produce a escala industrial; se utiliza este planteamiento para el desarrollo de un sistemas de identidad visual (Peón, 2000), puesto que contempla aspectos de interés de la investigación: el diseño de la tipografía para proyectos de logotipos, aunque no describe cómo esta tipografía puede ser desarrollada.

La FASE B resume los datos recopilados que están relacionados con el enfoque del estudio, ordenados en una secuencia cronológica, usados para obtener el resultado deseado. Como el objetivo principal del estudio es ser un referente para la construcción una familia tipográfica, los aspectos técnicos de las formas de los tipos de letra sirven como referencia inicial para la construcción de una tabla basada en la clasificación propuesta por Montesinos y Hurtuna, que se refiere a las características formales de los grupos estilísticos principales, como se muestra en el tabla 2.

\section{A7_Tab. 2 - Características formales de los principales grupos estilísticos. Adaptación de Montesinos y Hurtuna (2001)}

\begin{tabular}{|c|c|c|c|c|}
\hline GRUPO & $\begin{array}{l}\text { CARACTERÍSTICAS } \\
\text { FORMALES }\end{array}$ & SUBGRUPO & $\begin{array}{c}\text { CARACTERÍSTICAS } \\
\text { FORMALES }\end{array}$ & EJ EMPLOS \\
\hline \multirow[t]{3}{*}{ ROMANAS } & \multirow[t]{3}{*}{$\begin{array}{l}\text { - Modulación visible } \\
\text { de los trazos } \\
\text { - Trazos acabados en } \\
\text { remates }\end{array}$} & Antiguas & $\begin{array}{l}\text { - Modulación } \\
\text { inclinada de trazo } \\
\text { quebrado } \\
\text { (plumilla). } \\
\text { - Remates } \\
\text { ligeramente } \\
\text { desproporcionados } \\
\text {. }\end{array}$ & $\begin{array}{l}\text { - Bembo } \\
\text { - Sabon } \\
\text { - Minion }\end{array}$ \\
\hline & & De transición & $\begin{array}{l}\text { - Modulación } \\
\text { inclinada de trazo } \\
\text { redondeado } \\
\text { - Remates } \\
\text { proporcionados }\end{array}$ & $\begin{array}{l}\text { - Garamond } \\
\text { - Times New } \\
\text { Roman } \\
\text { - Century Old } \\
\text { Style }\end{array}$ \\
\hline & & Modernas & $\begin{array}{l}\text { - Modulación axial } \\
\text { y de acentuado }\end{array}$ & $\begin{array}{l}\text { - Didot } \\
\text { - Bodoni }\end{array}$ \\
\hline
\end{tabular}




\begin{tabular}{|c|c|c|c|c|}
\hline & & & $\begin{array}{l}\text { contraste entre } \\
\text { los trazos finos y } \\
\text { los gruesos. }\end{array}$ & $\begin{array}{l}\text { - New } \\
\text { Baskerville }\end{array}$ \\
\hline & & De lectura & $\begin{array}{l}\text { - Ligero aumento } \\
\text { del ojo medio con } \\
\text { contrapunzones } \\
\text { abiertos. }\end{array}$ & $\begin{array}{l}\text { - Bookman } \\
\text { - Impressum } \\
\text { - New Century } \\
\text { Schoolbook }\end{array}$ \\
\hline & & Atípicas & $\begin{array}{l}\text { - Cualquier } \\
\text { romana con una } \\
\text { interpretación } \\
\text { muy libre de los } \\
\text { elementos fijos y } \\
\text { variables. Prima } \\
\text { su aspecto visual. }\end{array}$ & $\begin{array}{l}\text { - Tifanny } \\
\text { - Benguiat } \\
\text { - Belwe }\end{array}$ \\
\hline \multirow[t]{2}{*}{ EGIPCIAS } & \multirow{2}{*}{$\begin{array}{l}\text { - Modulación } \\
\text { tendente a la } \\
\text { uniformidad } \\
\text { - Engrosamiento del } \\
\text { trazo } \\
\text { - Visible aumento del } \\
\text { tamaño de los } \\
\text { remates }\end{array}$} & Suaves & $\begin{array}{l}\text { - Modulación } \\
\text { visible } \\
\text { - Punto de enlace } \\
\text { suave. }\end{array}$ & $\begin{array}{l}\text { - Clarendon } \\
\text { - Egyptienne } \\
\text { - Lino Letter }\end{array}$ \\
\hline & & Duras & $\begin{array}{l}\text { - Tendencia a la } \\
\text { uniformidad del } \\
\text { trazo. } \\
\text { - Punto de enlace } \\
\text { duro. }\end{array}$ & $\begin{array}{l}\text { - Memphis } \\
\text { - Rockwell } \\
\text { - Calvert }\end{array}$ \\
\hline \multirow[t]{2}{*}{ INCISAS } & \multirow[t]{2}{*}{$\begin{array}{l}\text { - Trazo modulado } \\
\text { - Remates insinuados }\end{array}$} & Híbridas & $\begin{array}{l}\text { - Ausencia de } \\
\text { modulación. } \\
\text { - Utilización de } \\
\text { remates. }\end{array}$ & $\begin{array}{l}\text { - Cantoria } \\
\text { - Copperplate } \\
\text { Ghotic } \\
\text { - Serif Gothic }\end{array}$ \\
\hline & & Incisas & $\begin{array}{l}\text { - Trazo modulado. } \\
\text { - Remates } \\
\text { insinuados. }\end{array}$ & $\begin{array}{l}\text { - Optima } \\
\text { - Eras } \\
\text { - Formata }\end{array}$ \\
\hline \multirow[t]{4}{*}{ PALO SECO } & \multirow[t]{4}{*}{$\begin{array}{l}\text { - Ausencia de } \\
\text { modulación } \\
\text { - Ausencia de remates }\end{array}$} & Grotescas & $\begin{array}{l}\text { - Persistencia de } \\
\text { la modulación del } \\
\text { trazo. } \\
\text { - Ausencia de } \\
\text { remates. }\end{array}$ & $\begin{array}{l}\text { - Akzidenz } \\
\text { Grotesk }\end{array}$ \\
\hline & & Humanistas & $\begin{array}{l}\text { - Persistencia de } \\
\text { la modulación del } \\
\text { trazo. } \\
\text { - Ausencia de } \\
\text { remates. }\end{array}$ & - Gill Sans \\
\hline & & Neogrotescas & $\begin{array}{l}\text { - Ausencia de } \\
\text { modulación y de } \\
\text { remates. } \\
\text { - Estructura } \\
\text { humanística del } \\
\text { carácter. } \\
\end{array}$ & $\begin{array}{l}\text { - Helvética } \\
\text { - Frutiger } \\
\text { - Univers }\end{array}$ \\
\hline & & Geométricas & - Ausencia de & - Avant Garde \\
\hline
\end{tabular}


Estudio de la construcción de los elementos caligráficos en el proceso de alfabetización de adultos en la Amazonia brasileña

\begin{tabular}{|c|c|c|c|c|}
\hline & & & $\begin{array}{l}\text { modulación y de } \\
\text { remates. } \\
\text { - Estructura } \\
\text { geométrica del } \\
\text { carácter. }\end{array}$ & - Futura \\
\hline \multirow[t]{2}{*}{ ESCRITURA } & \multirow[t]{2}{*}{$\begin{array}{l}\text { - Imitación del } \\
\text { trazado manual } \\
\text { - Pueden tener los } \\
\text { caracteres enlazados } \\
\text { o sueltos }\end{array}$} & Caligráficas & $\begin{array}{l}\text { - Imitan los } \\
\text { estilos surgidos de } \\
\text { este tipo de } \\
\text { técnicas de } \\
\text { escritura. }\end{array}$ & - Mistral \\
\hline & & Manuales & $\begin{array}{l}\text { - De trazado } \\
\text { libre. }\end{array}$ & $\begin{array}{l}\text { - One Stroke } \\
\text { Script }\end{array}$ \\
\hline \multirow[t]{2}{*}{ FANTASIA } & \multirow{2}{*}{$\begin{array}{l}\text { - Reinterpretaciones, } \\
\text { fuera de toda norma, } \\
\text { de los elementos fij os } \\
\text { e incorporación de } \\
\text { elementos variables } \\
\text { de diversas } \\
\text { naturalezas }\end{array}$} & De diseño & $\begin{array}{l}\text { - Realizadas a } \\
\text { partir de } \\
\text { cualquier pretexto } \\
\text { gráfico. }\end{array}$ & \\
\hline & & Ornamentales & $\begin{array}{l}\text { - Por repetición } \\
\text { de elementos } \\
\text { adicionales de } \\
\text { tipo decorativo. }\end{array}$ & \\
\hline
\end{tabular}

Después de establecer el grupo, y en consecuencia los aspectos formales a las que presuntamente pertenecerán los caracteres, aún en la fase $B$, tres familias de fuentes fueron elegidas, y se analizaron sus ventajas y desventajas sobre los aspectos formales, funcionales y ergonómicos por medio de una matriz de comparación, obteniendo un abordaje preliminar y algunas variables que alimentaron el modelo concurrente, posibilitando una visión sistémica, tal como lo sugieren Hernandis y Westermeyer (2009) y se describe en la Tabla 3.

\section{A7_Tab. 3 - Matriz Comparativa. Adaptación de HERNANDIS y WESTERMEYER (2009)}

\begin{tabular}{l|l|l|l|l|l|l}
\hline & \multicolumn{2}{l|}{ FORMA } & \multicolumn{2}{l}{ FUNCIÓN } & \multicolumn{2}{l}{ ERGONOMÍA } \\
\hline TIPOGRAFIA & V & I & V & I & V & I \\
\hline 1 & $\ldots$ & $\ldots$ & $\ldots$ & $\ldots$ & $\ldots$ & $\ldots$ \\
\hline 2 & $\ldots$ & $\ldots$ & $\ldots$ & $\ldots$ & $\ldots$ & $\ldots$ \\
\hline 3 & $\ldots$ & $\ldots$ & $\ldots$ & $\ldots$ & $\ldots$ & $\ldots$ \\
\hline
\end{tabular}


Todos los datos recopilados fueron utilizados para alimentar el sistema del Modelo Concurrente en la "fase C". El desarrollo del Modelado genera los requisitos y parámetros necesarios para la construcción de los caracteres.

En la "fase D", el estudio mostró la necesidad del uso de una estructura modular para facilitar la construcción de los caracteres y para que puedan ser utilizados en aplicaciones de software para la creación de tipografías digitales. Inicialmente fueron estudiados algunos ejemplos de estructuras utilizadas para el diseño de caracteres, pero las referencias no son muchas. Ghyka (1980) dejó un gran legado sobre estudios de geometría y proporción áurea, así como una serie de ejemplos sobre algunos tipos de diagramas de las formas de construcción. La figura 7 muestra un ejemplo de estructura modular con referencias diagonales.

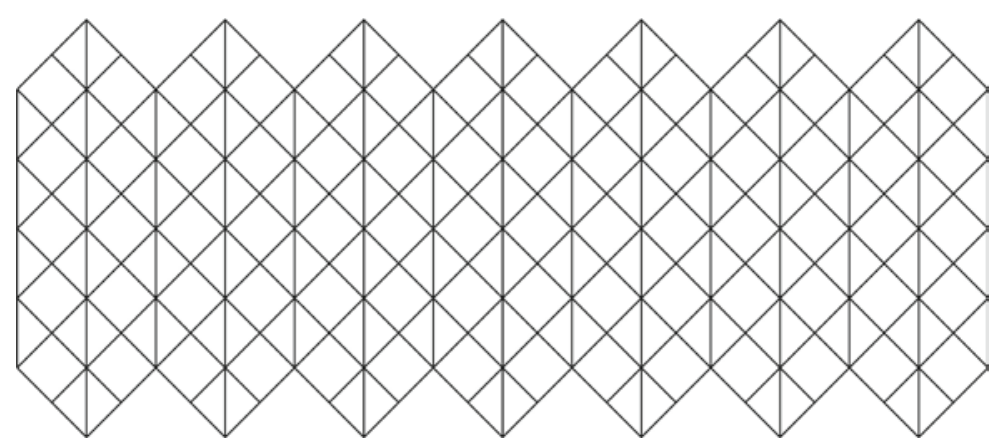

A7_Fig. 7 - Referencia modular diagonal, Ghyka (1980).

Otras interesantes estructuras citadas por Ghika (1980), que también fueron observadas por Frutiger (2001), son las construcciones simbólicas de la masonería, estudiadas en la tesis del Rziha. Estos símbolos han traído una variante interesante para la investigación porque indican una estructura circular, con referencia linear para la construcción de las formas (Figura 8). 
Estudio de la construcción de los elementos caligráficos en el proceso de alfabetización de adultos en la Amazonia brasileña
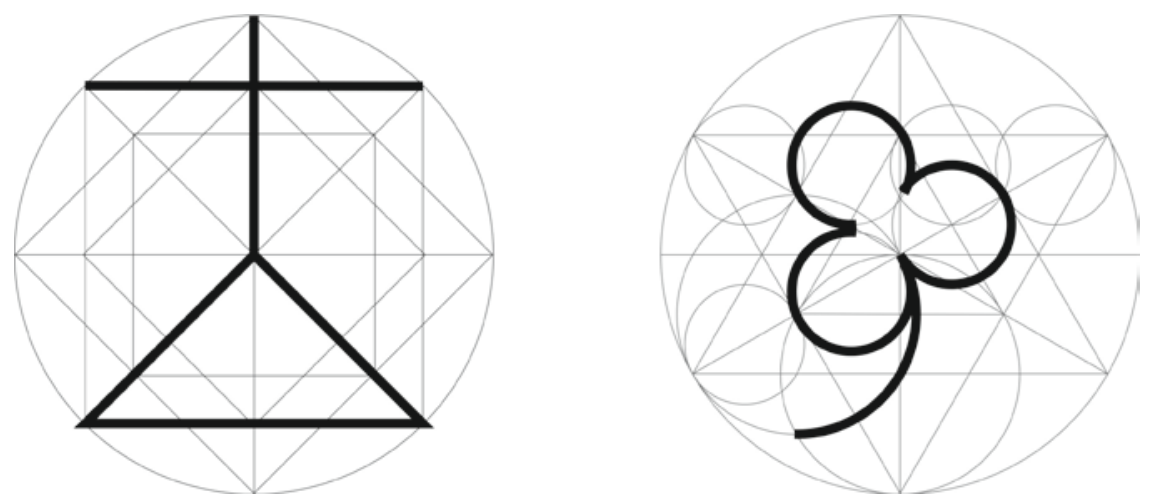

A7_Fig. 8 - Esquema simbólico masónico, adaptación de Frutiger (2001) y Ghyka (1980).

Otra estructura modular utilizada en el diseño de caracteres es de la autoría de Adrian Frutiger (2001), pero no resuelve el diseño de los caracteres que tienen diagonales $(\mathrm{V}, \mathrm{y}, \mathrm{w}, \mathrm{X}, \mathrm{Z}, \mathrm{k}, \mathrm{V}, \mathrm{A}, \mathrm{Y}, \mathrm{W}, \mathrm{X}, \mathrm{Z}, \mathrm{K})$, ni tampoco la descripción de la variación establecida por el contraste entre las astas, de acuerdo con lo que recomienda Buggy (2007).

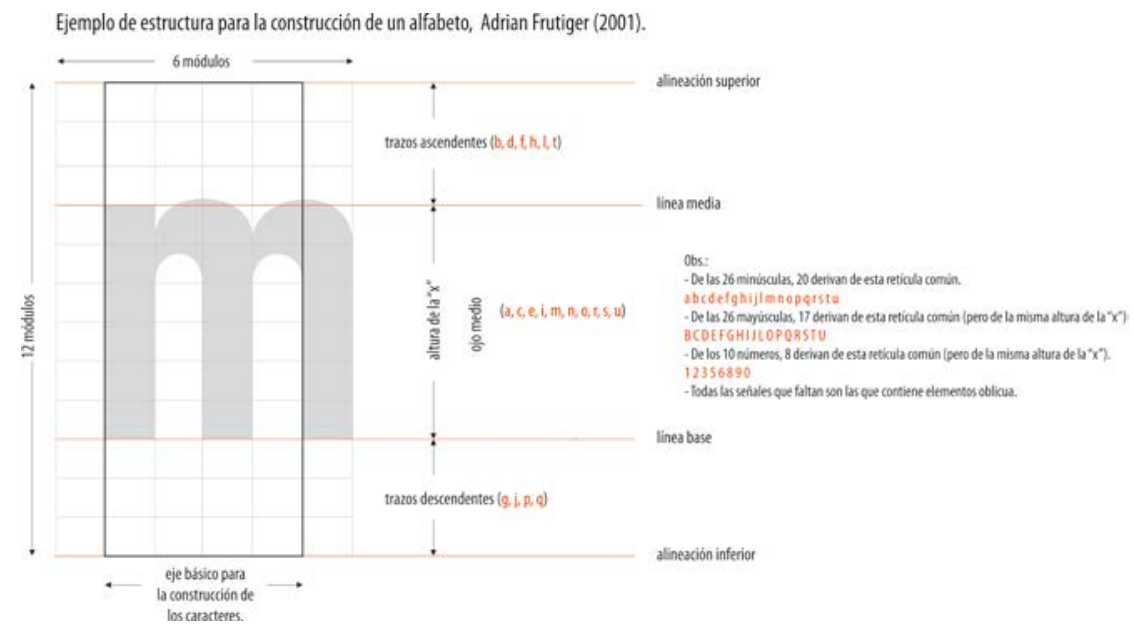

A7_Fig. 9 - análisis de la estructura para la construcción de un alfabeto, adaptado de Frutiger (2001). 
Buggy (2007) afirma que la construcción de una retícula como base para el dibujo del carácter facilita la ejecución del proyecto, y puede ayudar a definir la longitud de las astas descendentes y ascendentes, la altura de la $\mathrm{x}$, la relación entre anchura y altura, la relación del grosor de las astas con el ancho del carácter y los contrastes, detalles de suma importancia antes de comenzar el diseño de las letras.

La definición de los módulos de la retícula se puede lograr por múltiples vías, que van desde las características del proyecto, la información del cliente, el análisis de la población objetivo, entre otros. El diseño cuenta con una serie de elementos que le pueden ayudar en la construcción de una estructura modular para el dibujo de caracteres, incluyendo la posibilidad de ser reutilizado en proyectos futuros.

En la conclusión de la "fase D", se buscó una referencia en el ordenamiento de dibujo de los caracteres. Buggy (2007) cita la recomendación de la escuela suiza de la tipografía para comenzar con los dibujos de los caracteres "O", "H", "n" y "o" que proporcionan datos, tales como el grosor de la línea, ancho de las letras rectangulares, ancho de letras redondas, la altura de mayúsculas y de las minúsculas, uniones de las curvas con las rectas y acabado de las astas verticales. A continuación el autor sugiere el dibujo de los caracteres " $\mathrm{p}$ " y "h" para obtener las referencias de las astas ascendentes y las astas descendentes, y por fin los caracteres con diagonales y los más delgados.

A través de la adaptación del sistema diseñado por Debra Anne Adams, teniendo en cuenta la similitud de formas, Buggy (2007) propuso un gráfico de derivación de los arquetipos para facilitar el diseño de los caracteres (figuras 10, 11 y 12).

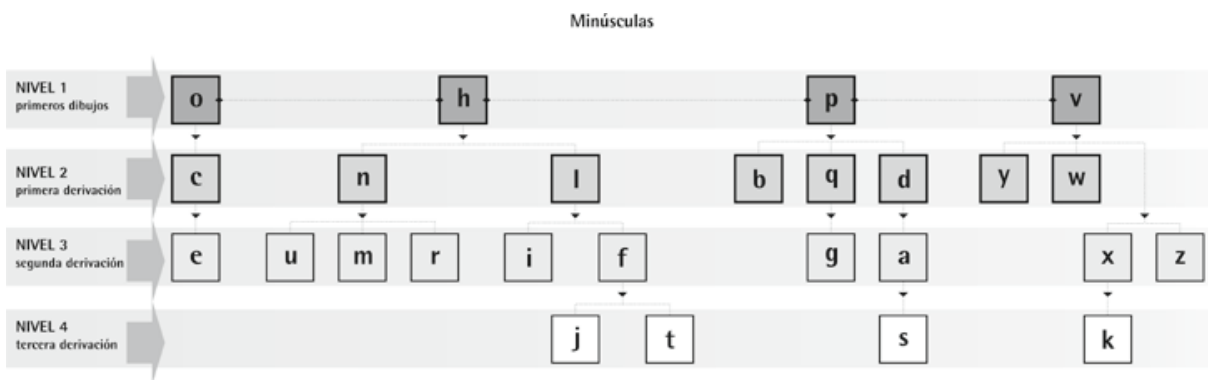

A7_Fig. 10 - Gráfico de derivación de los arquetipos - minúsculas, Buggy (2007). 


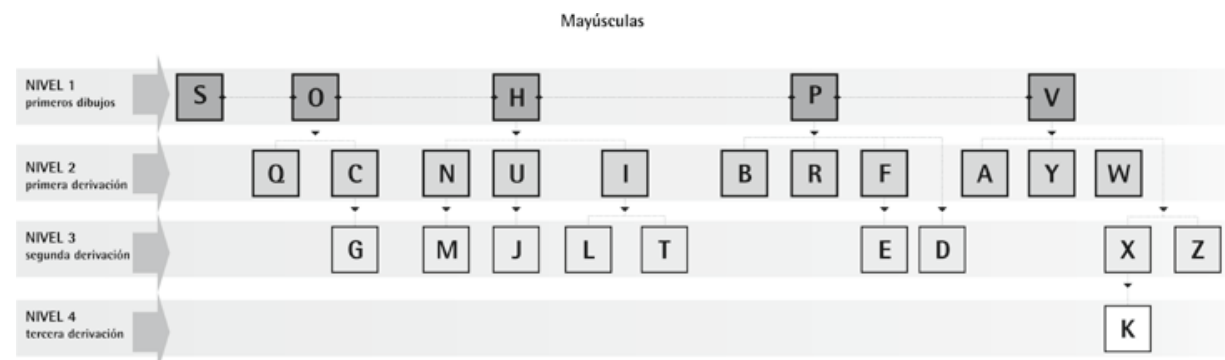

A7_Fig. 11 - Gráfico de derivación de los arquetipos - mayúsculas, Buggy (2007).

Números

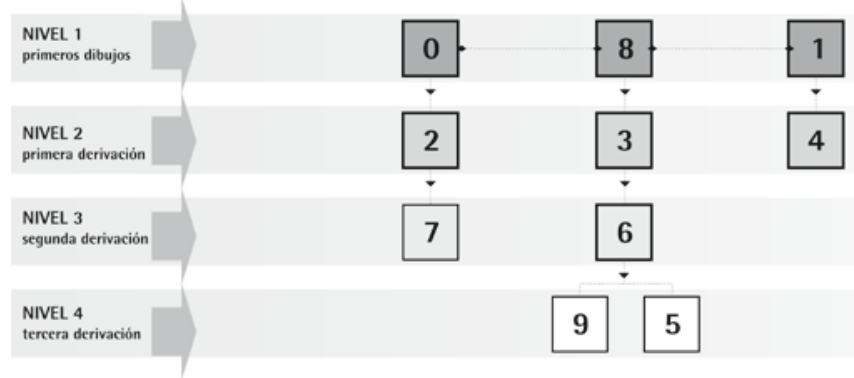

A7_Fig. 12 - Gráfico de derivación de los arquetipos - números, Buggy (2007).

En la "fase E" el diseñador dibuja los caracteres basado de toda la información recolectada en las etapas anteriores, buscando resolver el problema que originó el proyecto. Como ejemplo la figura 13 muestra un logotipo diseñado a partir de un triángulo de oro y basado en una estructura modular. 

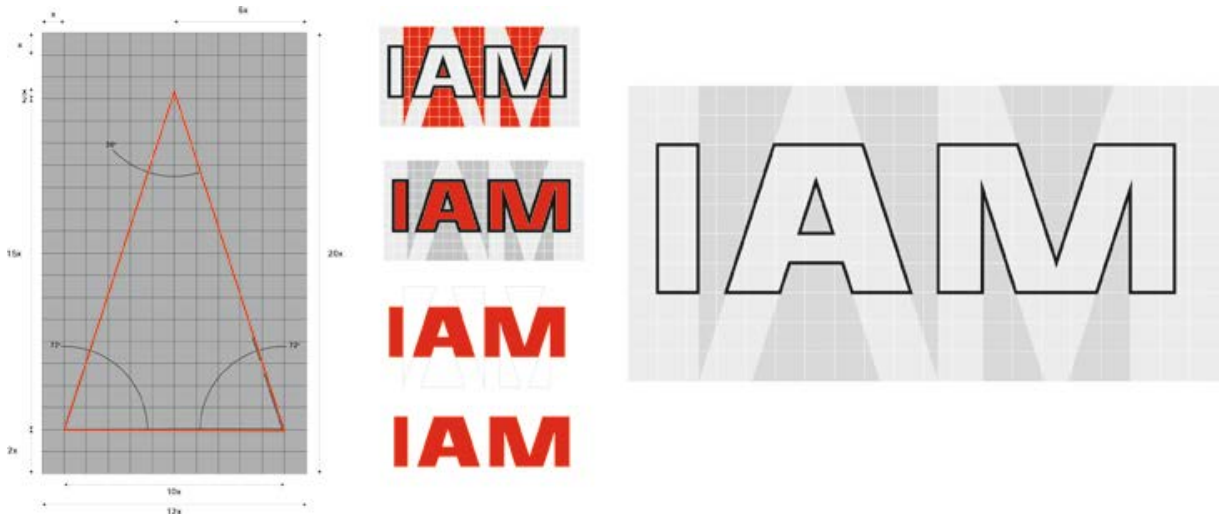

A7_Fig. 13 - Logotipo desarrollado a partir de una estructura modular.

La figura 14 muestra un logotipo diseñado a partir de una estructura modular y de referencia linear en el dibujo de las astas.

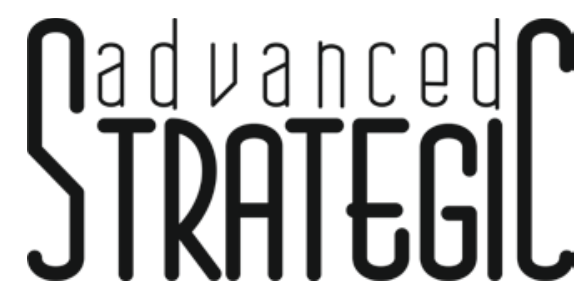

A7_Fig. 14 - Logotipo desarrollado a partir de una estructura modular con referencia linear.

La figura 15 muestra un ejemplo de alfabeto diseñado a través de una estructura modular con referencia linear. 


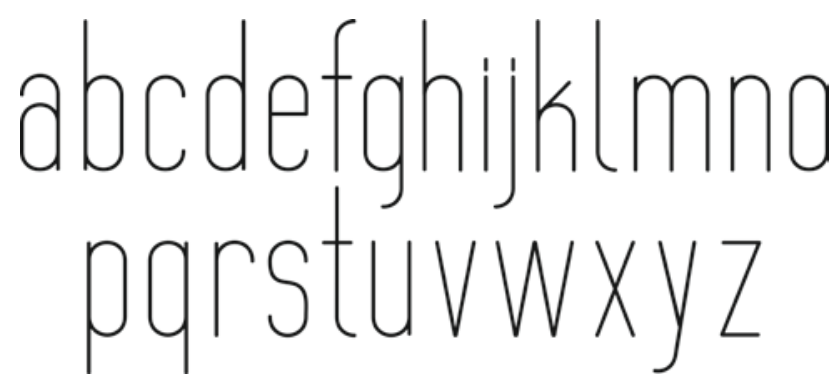

\section{A7_Fig. 15 - alfabeto diseñado a través de una estructura modular con referencia linear.}

\section{Conclusiones}

La documentación técnica que acompaña a un proyecto gráfico debe tener las referencias de construcción que permita la aplicación de sus elementos en el mayor número posible de mecanismos de reproducción, ampliación y reducción, incluso en lugares con limitaciones tecnológicas, tales como los pueblos más alejados de las grandes ciudades o pueblos pequeños.

Más allá de los aspectos técnicos involucrados en diversas tecnologías y procesos que subyacen a la actividad del diseñador gráfico, es importante tener en cuenta que el profesional también debe tener a su disposición herramientas metodológicas para apoyar su proceso creativo.

Este estudio busca contribuir al desarrollo ordenado de un proyecto gráfico que tenga al elemento tipográfico como parte esencial. El uso de múltiples métodos, referencias constructivas y aspectos técnicos de la tipografía constituyen el núcleo de la investigación con una propuesta de etapas que pueden ser utilizadas en el proceso de construcción de caracteres tipográficos.

La expectativa es que este artículo genere un debate acerca de los estudios metodológicos relacionados con la práctica del diseño gráfico, y llame la atención sobre el cuidado que debe darse a los elementos de diseño que son, aparentemente simples, pero llenos de cultura, historia, tradición y técnica como es el caso de la tipografía. 


\section{Direccionamiento para investigaciones futuras}

Los datos contenidos en este artículo abordan la tipografía en el ambiente académico de una manera más metodológica, con el fin de servir de base para el ejercicio práctico en la construcción de caracteres tipográficos y/ o para el diseño de logotipos.

La búsqueda de una metodología para el desarrollo de diseños gráficos también forma parte del centro de la investigación, ya que las referencias bibliográficas no presentan una gran variedad de estudios en relación a la importancia del diseño gráfico para la sociedad y el mercado, comparado con el gran número de profesionales, profesores y estudiantes de todo el mundo.

El estudio también forma parte de una de las etapas de la tesis doctoral que analiza la construcción de elementos caligráficos utilizados para la alfabetización de adultos en la Amazonia brasileña.

\section{Referencias}

CHENG, Karen. Diseñar tipografía. Gustavo Gili. Barcelona. 2006.

BAXTER, M. - Projeto de Produto - Guia Prático para o Desenvolvimento de Novos Produtos - São Paulo, Editora Edgar Blücher, 1998.

BOMFIM, G. A. - Metodologia para o Desenvolvimento de Projetos - João Pessoa, Editora Universitária/ UFPB, 1995.

BONSIEPE, G. - Metodologia Experimental: Desenho Industrial - Brasília, CNPq / Coordenação Editorial, 1984.

BONSIEPE, G. Teoría y práctica del diseño industrial. Barcelona: Gustavo Gili, 1978.

BUGGY, Leonardo Araújo da Costa. O MECOTipo: Método de ensino de desenho coletivo de caracteres tipográficos. BUGGY. Recife, 2007.

CROSS, N. (2004) Expertise in design: an overview. Design Studies, v. 25, n. 5, p. $427-441$.

FARIAS, P. L. Tipografia Digital: 0 impacto das novas tecnologias. 2. ${ }^{\text {Ed. Rio }}$ de J aneiro: $2 A B, 2000$.

FRUTIGER, Adrian. Sinais e símbolos. Desenho, projeto e significado. SP: Martins Fontes, 2001. 
Estudio de la construcción de los elementos caligráficos en el proceso de alfabetización de adultos en la Amazonia brasileña

GHYKA, Matila. Estética de las proporciones en la naturaleza y en las artes, Barcelona, Editorial Poseidon, 1980.

HEITLINGER, Paulo. Tipografia: origens, formas e uso das letras. Lisboa: Dinalivro, 2006.

HERNANDIS, B. "Desarrollo de una Metodología Sistémica para el Diseño de Productos Industriales". Tesis doctoral no publicada. Universidad Politécnica de Valencia. Valencia, España, 2003.

HERNANDIS ORTUNO, Bernabé y BRIEDE WESTERMEYER, Juan Carlos. Una aplicación educacional para el diseño de productos y sistemas de ingeniería utilizando modelos conceptuales integrados. Ingeniare. Rev. chil. ing. 2009, vol.17, n. 3, pp. 432-442.

IVINS, William M. - Prints and visual communication. Republic. 1st. ed. Cambridge, Mss. : Harvard University Press, 1953.

LEOPARDI, M.T. Metodologia da pesquisa na saúde. Santa Maria: Pallotti, 2001. 


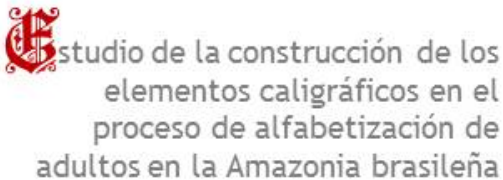
adultos en la Amazonia brasileña

\section{道apítulo 4}

\section{DISCUSIÓN FINAL}

4.1 Resultados generales

4.2. Conclusiones generales

4.3. Futuras líneas de investigación 



\section{Discusión final}

\subsection{Resultados generales}

\subsubsection{Comparativa sobre el grado de adecuación de la caligrafía enseñada en el proceso de alfabetización de adultos para el mundo contemporáneo.}

\section{a. Caligrafía cursiva}

De acuerdo con los datos e informaciones analizados y producidos para este tópico, la investigación averiguó que la caligrafía cursiva no es considerada como la forma más adecuada para orientar en la enseñanza y alfabetización de adultos, una vez que la misma presenta una serie de restricciones al proceso de construcción de caracteres, legibilidad de la escrita, comprensión y facilidad de lectura de las palabras.

La publicación realizada sobre ese tema, detectó que la legibilidad de la escrita es una calidad compleja que se constituye en la suma de varios aspectos, entre los cuales se destacan: el carácter pedagógico y los aspectos ergonómicos. Según estos dos principios, cada letra tiene una forma característica, donde la claridad de los trazos reside en escribir cada letra en su forma exacta, en cuanto que la letra cursiva deformada puede causar extrema ilegibilidad en la lectura e interpretación de la escrita.

En este contexto, muchas veces, las inadecuadas formas de las letras son consecuencia de la ausencia de orientación por parte del docente, por el mal uso o por el abuso de las copias y de los dictados o por la aceleración, sin necesidad, de la escrita para hacer los apuntes durante las clases, entre otros.

b. Diseño en la transición de la escrita manual a las tendencias de la tipografía en el ambiente tecnológico

Por otro lado, la ergonomía es el principal camino para la realización de un buen análisis tipográfico, donde el diseño, a través de sus estudios y actuación en este área, tiene la preocupación de medir la legibilidad mediante el uso de parámetros tipográficos, que consideran: el dibujo de los caracteres, el tamaño del cuerpo y espaciamiento entre líneas, letras y palabras. Por lo tanto, en lo que concierne a la tipografía cursiva y su percepción de uso y lectura, ésta puede presentar: 
Estudio de la construcción de los elementos caligráficos en el proceso de alfabetización de adultos en la Amazonia brasileña

- Con respecto a los demás tipos de letras, es compleja con palabras en versal (mayúscula o Caixa alta);

- El dibujo de las letras mayúsculas y minúsculas son diferentes entre sí, exhibiéndose en las más variadas formas de aplicaciones en carteles, revistas, periódicos etc.

- Confusión formal o similitud entre las letras.

Así siendo, según estudios realizados en algunos país, sobre estos aspectos de la caligrafía cursiva, y aunque algunos casos consideren el uso de ese tipo de escrita para la enseñanza de los niños (pasando por pequeños ajustes estructurales), igualmente no se puede utilizar en la alfabetización de adultos, una vez que estos aun necesitan trabajar su coordinación motora y conocer la construcción de los caracteres de manera que asocian y comprenden su representación estructural y visual a través de la lectura y de la escrita de las palabras. En este contexto, los diseñadores deben buscar ampliar y compartir los conceptos técnicos contenidos en su medio de conocimiento, de modo que involucre otras áreas del saber, donde el constructo resultante sea más provechoso que solamente una solución paliativa para una cuestión proyectual, y sí, convirtiéndose en una propuesta amplia y significativa.

\subsubsection{Aspectos formales de los caracteres y sus implicaciones en el proceso de alfabetización de adultos}

a. Morfología de caracteres caligráficos y sus implicaciones para el proceso de alfabetización de adultos

Según el análisis realizado sobre los aspectos formales de los caracteres y sus implicaciones en el proceso de la alfabetización de adultos, los resultados apuntaron que la escritura cursiva enseñada en las escuelas en el proceso de alfabetización presenta una gran complejidad de ejecución que, según la opinión de la mayoría de especialistas, tiene como uno de los objetivos principales, auxiliar en el desarrollo de la coordinación motora fina de los alumnos. No se puede afirmar que tal justificación sea tan relevante en la alfabetización de adultos, una vez que el adulto ya posee cierto grado de desarrollo psicomotor, además del hecho que la coordinación motora fina se refiere a la destreza a la hora de realizar movimientos precisos y suaves, principalmente con las manos y los dedos, como escribir, pintar, diseñar, recortar, montar, haciendo referencia a los aspectos viso motores. Así mismo, no todos los adultos alfabetizados mantienen el estilo caligráfico aprendido en la infancia y aquellos que lo mantienen tienen dificultades para ser comprendidos en cuanto a lo que se exige en su calidad de la escritura, por ejemplo, en exámenes selectivos de empleo o concursos públicos. 
En este contexto, a través de los estudios realizados, el formato que se considera ideal para la construcción de las letras, debe ser aquel que pasa por una simplificación de la forma, de modo a utilizar los caracteres con aspectos lineales, sin modulación, tornándose un resultado de la mezcla de líneas verticales, horizontales, diagonales, arcos y circunferencias y, aún, un tipo de caligrafía más simple de ejecutar y de acuerdo con el contexto comunicativo del entorno del alumno. Por lo tanto, para alcanzar este propósito es necesario basarse en distintos parámetros tipográficos como: diseño de las letras, tamaño del cuerpo, espacio entre líneas, letras y palabras; de esta manera, se trabajó la relación entre lo que el alumno escribe a mano y lo que lee en su entorno, involucrando aspectos correspondientes a: la legibilidad, la percepción, los aspectos de la ergonomía y sus restricciones técnicas.

De esta manera, el análisis consideró que relacionar los aspectos formales para la construcción de los caracteres tipográficos y los atributos del diseño (forma, función e ergonomía), como una actividad multidisciplinar, contribuye de forma significativa al proceso de la alfabetización para adultos.

b. Posicionamiento del diseño con relación a la construcción de los elementos caligráficos en el proceso de alfabetización de adultos en la Amazonia brasileña

De acuerdo con el posicionamiento de algunos diseñadores sobre la construcción de los elementos caligráficos en el proceso de alfabetización de adultos, es importante planear el estudio mediante el apoyo de dos factores fundamentales:

- Cognitivo - se resaltaron a los aspectos relacionados con la enseñanza de la escrita, donde se considera el diseño una herramienta estratégica para facilitar la construcción, comprensión y representación de los caracteres caligráficos (letras), que favorece la legibilidad, la lectura, la comunicación y la expresión del alfabetizando adulto.

- Psicológico - se destacó que la enseñanza está relacionada al factor de la afectividad, a partir de las influencias mutuas y sociales de un proceso interactivo, que involucra al docente y el discente. En este contexto, la interacción del diseño es pertinente a través de la formulación de materiales didácticos que auxilien el alumno a comprender y dibujar los caracteres caligráficos y, además, apoyaf al profesor en la determinación de estrategias para la enseñanzas de la escrita; la base se define en el uso de elementos del lenguaje visual y 
Estudio de la construcción de los elementos caligráficos en el proceso de alfabetización de adultos en la Amazonia brasileña

de los conceptos de la Gestalt (método de lectura visual de la forma), siendo este último un atributo fundamental en el proceso.

Para fortalecer la reciprocidad entre estos factores, es primordial trabajar los valores culturales comprendidos mediante el perfil del alfabetizando adulto, la interrelación de los códigos visuales tipográficos y los usos de la tríade del diseño (elementos básicos: circulo, cuadrado y triangulo), junto con las configuraciones reales y esquematizadas a ser trabajadas en el material didáctico. Estas aplicaciones conceptuales (como parte de un todo) comprende la proyección de imágenes como: instrumentos de comunicación, de información, de conocimiento, factor de motivación, de discurso, de enseñanza, medio de ilustración de clase, utensilio de memorización y de observación de los mensaj es que deben ser comprendidos por el alfabetizando adulto para orientarlo en el proceso de construcción de los caracteres caligráficos (dibujo de las letras) y, consecuentemente, para el aprendizaje de la escrita.

c. Estudio comparativo de la morfología de los caracteres de las cuartillas de caligrafía de algunos países y sus implicaciones en el proceso de alfabetización de adultos

El estudio demuestra la falta de uniformidad de las letras presentes en los libros de enseñanza de la escritura. El problema no está relacionado con el nivel educacional o económico de los países presentes en el estudio, ello estriba en el hueco pedagógico de presentar alternativas de la caligrafía que permitan una transición menos abrupta entre la escritura manual y la escritura en los ordenadores y/ u a través de dispositivos electrónicos.

Hay un sinnúmero de daños causados por la falta de una normalización de la escritura escolar, especialmente en continentes como Europa, donde la libre circulación de las familias pertenecientes a la comunidad, permite un constante cambio de país, sea por trabajo, estudio, factores económicos, etc. Los niños de estas familias podrán tener grandes dificultades al encontrar, en las nuevas escuelas, caracteres diferentes de los que estaban acostumbrados en su país.

Países como Brasil (antigua colonia de Portugal), Venezuela y Colombia (antiguas colonias de España) que comparten el mismo idioma de los colonizadores, y donde se produce un gran flujo de la inmigración, tienen grandes diferencias formales entre los caracteres presentes en sus libros de texto, como se comprobó en esto estudio.

La creación de una norma internacional para estandarizar alfabetos presentes en los libros escolares podría ayudar a minimizar los impactos negativos sobre 
la educación y la enseñanza de la escritura. Un análisis multidisciplinaria entre profesionales de la educación, la psicología y los desarrolladores de tipografías, como diseñadores, podría ser el primer paso para crear un estándar de la escritura en las escuelas.

\subsubsection{Parámetros necesarios para el desarrollo de una caligrafía más adecuada al proceso de alfabetización de adultos basada en los estudios realizados}

a. Posicionamiento de expertos en pedagogía, psicología y diseño con relación a la construcción de los elementos caligráficos en el proceso de alfabetización de adultos en la Amazonia brasileña.

De acuerdo con la opinión de los expertos consultados, saber escribir es necesario conocer y comprender las letras, coordinar las ideas, la posición de la mano para proceder con los movimientos de la representación de la escrita, la mente y los ojos, comprender que es preciso prestar la atención en los aspectos sonoros de la escrita como un todo. Para alcanzar el dominio de esa información, el alfabetizando necesita del apoyo del profesor, del soporte material didácticos y del incentivo del sistema educacional, para suplir las dificultades existentes en el proceso de construcción de los caracteres que, generalmente se trata de un reflejo de la falta de dominio y conocimiento por parte del alumno. Al respecto, además, de que aún existan algunos sistemas de enseñanza en la letra cursiva como una fuente de representación más rápida de ser dibujada, los expertos comprenden que ésta forma caligráfica dificulta significativamente, el aprendizaje de la escrita por las personas adultas, una vez que no poseen la seguridad en sostener un lápiz por el hecho de no tener lo suficientemente desarrollada y haber practicado tal habilidad durante la edad propicia.

Para los profesionales consultados, la letra romana es un instrumento facilitador para el entendimiento y representatividad de los caracteres en el contexto abordado, que contribuye al ejercicio y el dominio de los trazos y movimientos simples de la escrita por parte del alumno adulto y también para beneficiar su coordinación motora. Este tipo de letra favorece a la legibilidad y agilidad del alfabetizando para registrar la información, expresar lo que sabe y compartir ideas y conocimientos. Además que, a través de la legibilidad se observa la calidad de la escrita, la construcción y representación de los caracteres, así como de la facilidad de lectura. Siendo así, se entiende que para el proceso de alfabetización del adulto es necesario trabajar con el uso de elementos simples, de manera que la información sea clara y objetiva, a través del soporte de una comunicación gráfica compatible a la realidad del perfil social y cultural de estos alumnos. Por lo tanto, obtener apoyo a través de recursos didácticos con características referentes 
Estudio de la construcción de los elementos caligráficos en el proceso de alfabetización de adultos en la Amazonia brasileña

al universo vocabulario de los alfabetizando, donde se puedan explotar las características regionales y unificar las actividades pedagógicas coherentes, bien planeadas, donde se presente la interacción entre profesor y alumno, ciertamente la asociación de estos aspectos contribuirá para el mejoramiento de participación y aprendizaje del público objetivo de este estudio.

\subsection{Conclusiones generales}

El estudio basado en los elementos caligráficos y su más adecuada construcción para el proceso de alfabetización de adultos en la Amazonía brasileña, proporcionó un viaje al universo de las caligrafías y su uso en el proceso de alfabetización que, de acuerdo con los objetivos planteados por esta investigación, ha posibilitado conocer información pertinentes a la enseñanza y aprendizaje de la escrita para los alfabetizandos adultos, especialmente de la Amazonía brasileña.

La propuesta presentada, también ha considerado aspectos que involucran el factor tecnológico en frecuentes discusiones acerca de su uso en la enseñanza de la escritura y, por fin, cómo el diseño puede contribuir, mediante su conocimiento técnico-científico, al contexto pedagógico de la caligrafía, a través de la perspectiva de los estudios relacionados con la tipografía.

En el proceso de verificación de la investigación, gran parte de la información ha sido generada con el objeto de obtener respuestas sobre el grado de adecuación de la caligrafía enseñada en el proceso de alfabetización de adultos en tiempos contemporáneo; los aspectos formales de los caracteres y sus implicaciones en el proceso de alfabetización de adultos y; los parámetros necesarios para el desarrollo de una caligrafía más adecuada al proceso de alfabetización de adultos.

Entre los datos obtenidos, se halló una relación de artículos producidos y publicados en congresos, conferencias, eventos y revistas científicas (de ámbito internacional), cuyo contenido abordó estudios específicos relacionados con:

- Una reflexión sobre el uso de la caligrafía cursiva en el proceso del aprendizaje de la escrita, donde se verifica si es la única manera o la más eficiente en la alfabetización de niños o adultos;

- La participación del diseño en la enseñanza en la transición entre la escritura manual y las tendencias de la tipografía en el ambiente tecnológico;

- Una mirada del diseño sobre la morfología de caracteres caligráficos y sus implicaciones para el proceso de alfabetización de adultos; 
- Un análisis del posicionamiento del diseño con relación a la construcción de los elementos caligráficos en el proceso de alfabetización de adultos en la Amazonía brasileña;

- Un estudio comparativo de la morfología de los caracteres de las cuartillas de caligrafía de algunos países y sus implicaciones en el proceso de alfabetización de adultos;

- Un análisis del posicionamiento de expertos en pedagogía, psicología y diseño con relación a la construcción de los elementos caligráficos en el proceso de alfabetización de adultos en la Amazonía brasileña;

- Recomendaciones a través de técnicas de diseño para la construcción de un alfabeto caligráfico en el proceso de alfabetización de adultos en la Amazonía brasileña;

- Un reto morfológico para el diseñador, que involucra la caligrafía y la alfabetización de los adultos.

En este sentido, para dar respuesta a la problemática identificada, objetivos e hipótesis planteados de acuerdo con los resultados obtenidos, el estudio puede concluir que:

- La caligrafía cursiva no tiene el formato ideal para el analfabeto adulto aprender a escribir. Ella presenta una estructura que conduce el alumno a un formato de letra casi ilegible. En el proceso de enseñanza y aprendizaje de la escritura se debe garantizar que esta sea precisa y legible. Técnicamente la letra cursiva, por presentar una formación de letras ligadas unas con otras, las cuales forman una palabra que constituyen un solo bloque, muchas veces causa dificultades al alumno en el dibujo de las letras, mediante una representación que está unida.

- Muchos adultos alfabetizados tienen una letra distinta a la que aprendieron en la escuela; debido a razones que involucran aspectos sociales, culturales, profesionales y, principalmente, psicológicos, los cuales reflejan los trazos de la personalidad del individuo.

De acuerdo con esto, no se pueden olvidar los aspectos acerca del proceso de alfabetización y sus problemas, que aún necesitan atención por parte de los profesionales de pedagogía. Es importante generar una cantidad mayor de información científica a respecto de actividades didácticas inherente a la enseñanza y su adecuación a las nuevas tecnologías.

La falta de consenso acerca del uso de la caligrafía cursiva en el aprendizaje de la escritura, no es un tema exclusiva de determinado país, no existe un pensamiento definido y tampoco una investigación concreta que afirme 0 
Estudio de la construcción de los elementos caligráficos en el proceso de alfabetización de adultos en la Amazonia brasileña

rechace el uso de este tipo de escritura en el proceso de alfabetización de niños. Ahora bien, en el caso de los adultos iletrados, los interrogantes son mayores.

Solamente una investigación involucrando profesionales de varias áreas y países podría generar un punto de vista común, basado en una fundamentación científica, acerca de la letra ideal para la alfabetización. La complejidad de ejecución de caligrafías como la cursiva trasforma el acto de escribir un verdadero trastorno incentivando a los alumnos al uso, del ratón o mouse en lugar de utilizar el bolígrafo, entonces la transición de la escritura manual a la digital se presentará como un reto brusco y poco natural.

- En el mundo actual, tomado por la tecnología, donde la gente escribe cada vez menos con la mano, el adulto que es analfabeta, no es consciente de la de aprender a escribir rápido y de forma cursiva. En este contexto, la carencia se define en la orientación al conocimiento de los caracteres de forma simple, a través del apoyo de materiales que informen proporcionalmente al conocimiento del alumno que es analfabeta. Los beneficios proporcionados por aparatos tecnológicos deben ser adaptados a un proceso de enseñanza de la escrita de modo a desarrollar las habilidades motoras y de lectura del alfabetizando después de que éste ya haya adquirido los conocimientos básicos sobre la construcción de los caracteres tipográficos, la conformación y el significado de las palabras. En el primere momento del aprendizaje del alumno adulto, es fundamental familiarizarle con los elementos básicos de la comunicación visual a través del uso de la Gestalt, imágenes y/o formas asociativas que puedan contemplar la realidad de su vocabulario habitual y auxiliar en su coordinación motora, rapidez de raciocinio, creatividad, originalidad y dinamismo en el proceso de escribir.

Una vez consolidados éstos aspectos el alfabetizando podrá, más adelante, disfrutar de la tecnología para entrenar actividades más avanzadas en su prácticas educativas que van más allá de la escritura o los ejercicios manuales realizados en el aula de clases; como por ejemplo, el reto de desarrollar alguna investigación, la recolección de datos direccionados a algún estudio de caso o especifico, la búsqueda de referencias, consultas en internet, entre otras tareas básicas. Esto se refiere a la utilización de la tecnología como herramienta de apoyo al perfeccionamiento de su lectura y conocimiento general, sin ser un elemento electrónico encargado de su enseñanza en la escritura de modo muy avanzado, esta tarea corresponde al sistema de educación, al profesor, que con al apoyo de materiales caligráficos logran el desarrollo de finalidad.

- Se comprende que escribir con claridad y de manera rápida son aspectos esenciales para garantizar al alumno la posibilidad de registrar información, 
expresar lo que sabe y compartir ideas y conocimientos durante su proceso de aprendizaje. Sin embargo, al adoptar la letra cursiva para poner en práctica la alfabetización de adultos, el sistema de educación no atribuirá a éste público objetivo una escritura con calidad, una que vez que la información redactada en ésta investigación, afirma que la cursiva es una forma poco legible.

- La forma más apropiada de las letras para alfabetización de adultos debe ser aquella que presente buena legibilidad y cualidad de la escritura, siendo más simple de ejecutar y estando dentro del contexto comunicativo del entorno del alumno. El proceso de construcción para ese tipo de letra puede estar asociado a la enseñanza de las formas básicas (triángulo, círculo, cuadrado), para fácil y eficiente aprender y escribir los caracteres caligráficos. Sin embargo, ésta sugerencia de letra también se une a la necesidad de ser enseñada mediante el soporte de materiales didácticos, la interactividad profesor-alumno y, a través del conocimiento tecno científico del diseñador, sobre la morfología, Gestalt, semiótica y los detalles que permean el universo de la forma y la representación visual, podrán garantizar un mejor desempeño al alumno, en su proceso de aprendizaje.

El estudio determinó que las características formales de las letras pueden ser una herramienta de análisis, de gran interés, para el diseñador; sobre todo, en cuanto a lo que se refiere al proceso de enseñanza y aprendizaje de adultos. Sin embargo, en este caso, pertinente trabajar sobre los siguientes aspectos:

- Trabajar el proceso de alfabetización para adultos junto con los conceptos del diseño como una actividad multidisciplinar, de manera que contribuya significativamente en la construcción de los caracteres caligráficos y aprendizaje de la escrita.

- Planear y desarrollar recursos y materiales didácticos que estén identificados con el alfabetizando adulto, que los caracterice de acuerdo con su realidad social: sus creencias, valores, gustos artísticos, cotidiano, entre otros aspectos. Además de promover mejor interactividad entre profesor-alumno para que unificados puedan beneficiar en la buena adquisición de la lectura y de la escrita por parte del adulto iletrado.

- Contribuir con más aportes de tipo científico que puedan sumar acciones pedagógicas, psicológicas y del diseño, que minimice la estadística negativa con respecto a la educación básica, enseñanza, aprendizaje de personas de la Amazonía brasileña, sobre todo en lo que se refiere a la alfabetización de adultos. 
Estudio de la construcción de los elementos caligráficos en el proceso de alfabetización de adultos en la Amazonia brasileña

\subsubsection{Resumen de los problemas detectados en las publicaciones e} algunas recomendaciones:

\begin{tabular}{|c|c|c|}
\hline REFERENCIA & $\begin{array}{l}\text { PROBLEMA } \\
\text { DETECTADO }\end{array}$ & RECOMENDACIONES \\
\hline \multirow[t]{2}{*}{ - Artículo 1} & $\begin{array}{l}\text { - La caligrafía cursiva no } \\
\text { es considerada como la } \\
\text { forma más adecuada } \\
\text { para la enseñanza y } \\
\text { alfabetización de } \\
\text { adultos, una vez que la } \\
\text { misma presenta una } \\
\text { serie de restricciones al } \\
\text { proceso de construcción } \\
\text { de caracteres, } \\
\text { legibilidad de la escrita, } \\
\text { comprensión y facilidad } \\
\text { de lectura de las } \\
\text { palabras. }\end{array}$ & $\begin{array}{l}\text { - la tipografía elegida para } \\
\text { la enseñanza de la escritura } \\
\text { para adultos tiene que } \\
\text { contener aspectos formales } \\
\text { que contengan } \\
\text { simplificación de las } \\
\text { formas. (Ver Artículo 6) }\end{array}$ \\
\hline & $\begin{array}{l}\text { - La legibilidad de la } \\
\text { escrita es una calidad } \\
\text { complexa que se } \\
\text { constituye en la suma de } \\
\text { varios aspectos, entre los } \\
\text { cuales se destacan: el } \\
\text { carácter pedagógico y los } \\
\text { aspectos ergonómicos. } \\
\text { Según estos dos } \\
\text { principios, cada letra } \\
\text { tiene una forma } \\
\text { característica, donde la } \\
\text { claridad de los trazos } \\
\text { reside en escribir cada } \\
\text { letra en su forma exacta, } \\
\text { en cuanto que la letra } \\
\text { cursiva deformada puede } \\
\text { causar extrema } \\
\text { ilegibilidad en la lectura } \\
\text { e interpretación de la } \\
\text { escritura. }\end{array}$ & $\begin{array}{l}\text { - enfatizar el aspecto } \\
\text { ergonómico en la escolla } \\
\text { del alfabeto tipográfico } \\
\text { para el ej ercicio de la } \\
\text { lectura, teniendo en cuenta } \\
\text { los elementos constructivos } \\
\text { de los caracteres. (Ver } \\
\text { Artículo 3) }\end{array}$ \\
\hline
\end{tabular}




\begin{tabular}{|c|c|c|}
\hline \multirow[t]{2}{*}{ - Artículo 2} & $\begin{array}{l}\text { - La ausencia de un } \\
\text { estudio con el intuito de } \\
\text { facilitar una transición } \\
\text { un poco menos compleja } \\
\text { entre la escritura manual } \\
\text { y la escritura en los } \\
\text { medios digitales. }\end{array}$ & $\begin{array}{l}\text { - desarrollar un estudio } \\
\text { multidisciplinario para } \\
\text { elegir una tipografía que } \\
\text { tenga características más } \\
\text { apropiadas a la escritura } \\
\text { manual y los medios } \\
\text { digitales. (Ver Artículos } 5 \text { y } \\
\text { 6) }\end{array}$ \\
\hline & $\begin{array}{l}\text { - Confusiones entre } \\
\text { caracteres mayúsculos y } \\
\text { minúsculos en función } \\
\text { del distanciamiento } \\
\text { formal entre estos dos } \\
\text { tipos de letras. }\end{array}$ & $\begin{array}{l}\text { - el alfabeto usado en el } \\
\text { proceso de alfabetización } \\
\text { debe tener el máximo de } \\
\text { aproximaciones formales } \\
\text { entre caracteres } \\
\text { mayúsculos y minúsculos. } \\
\text { (Ver Artículos } 5 \text { y 6) }\end{array}$ \\
\hline - Artículo 3 & $\begin{array}{l}\text { - Los aspectos formales } \\
\text { de los caracteres usados } \\
\text { en el proceso de } \\
\text { enseñanza de la escritura } \\
\text { son mui complej os para } \\
\text { un adulto. }\end{array}$ & $\begin{array}{l}\text { - el formato considerado } \\
\text { ideal a la construcción de } \\
\text { las letras debe ser aquel a } \\
\text { pasar por una simplificación } \\
\text { de la forma, de modo a } \\
\text { utilizar los caracteres con } \\
\text { aspectos lineales, sin } \\
\text { modulación, tornándose un } \\
\text { resultado de la mezcla de } \\
\text { líneas verticales, } \\
\text { horizontales, diagonales, } \\
\text { arcos y circunferencias y, } \\
\text { aún, un tipo de caligrafía } \\
\text { más simple de ejecutar y de } \\
\text { acuerdo con el contexto } \\
\text { comunicativo del entorno } \\
\text { del alumno. (Ver Artículos } \\
5,6 \text { y } 7 \text { ) }\end{array}$ \\
\hline & $\begin{array}{l}\text { - Los caracteres } \\
\text { presentan grados } \\
\text { diferentes de } \\
\text { dificultades } \\
\text { constructivas. }\end{array}$ & $\begin{array}{l}\text { - tener en cuenta los } \\
\text { diferentes grados de } \\
\text { dificultades constructivas } \\
\text { en el proceso de enseñanza } \\
\text { de la escritura, priorizando } \\
\text { los más fáciles hasta llegar } \\
\text { en los más difíciles. (Ver }\end{array}$ \\
\hline
\end{tabular}


Estudio de la construcción de los elementos caligráficos en el proceso de alfabetización de adultos en la Amazonia brasileña

\begin{tabular}{|c|c|c|}
\hline & & Artículo 3) \\
\hline - Artículo 4 & $\begin{array}{l}\text { - Pocos estudios y } \\
\text { referencias científicas } \\
\text { sobre la forma ideal de } \\
\text { los caracteres para } \\
\text { enseñanza de la escritura } \\
\text { desde el punto de vista } \\
\text { del diseño. }\end{array}$ & $\begin{array}{l}\text { - Generar estudios sobre la } \\
\text { morfología de los } \\
\text { caracteres usados en la } \\
\text { enseñanza de la escritura. } \\
\text { (Ver Artículos 5, } 6 \text { y 7) }\end{array}$ \\
\hline & $\begin{array}{l}\text { - Pocos estudios y } \\
\text { referencias científicas } \\
\text { sobre la forma ideal de } \\
\text { los caracteres para } \\
\text { enseñanza de la escritura } \\
\text { desde el punto de vista } \\
\text { del diseño. }\end{array}$ & $\begin{array}{l}\text { - La participación del } \\
\text { diseñador en una discusión } \\
\text { multidisciplinaria con } \\
\text { aportes de conceptos de } \\
\text { diseño para el desarrollo } \\
\text { de letras y alfabetos más } \\
\text { adecuados a la enseñanza y } \\
\text { en la transición entre la } \\
\text { escritura manual y los } \\
\text { medios digitales (Ver } \\
\text { Artículos } 2,3,5,6 \text { y 7) }\end{array}$ \\
\hline - Artículo 5 & $\begin{array}{l}\text { - Los materiales } \\
\text { didácticos para la } \\
\text { alfabetización de adultos } \\
\text { son limitados y fuera del } \\
\text { entorno geográfico del } \\
\text { alumno. }\end{array}$ & $\begin{array}{l}\text { - Desarrollar material } \\
\text { didáctico de acuerdo con } \\
\text { las características } \\
\text { regionales del alumno. (Ver } \\
\text { Artículos } 2,6 \text { y } 7 \text { ) }\end{array}$ \\
\hline - Artículo 6 & $\begin{array}{l}\text { - El estudio demuestra la } \\
\text { falta de uniformidad de } \\
\text { las letras presentes en } \\
\text { los libros de enseñanza } \\
\text { de la escritura. }\end{array}$ & $\begin{array}{l}\text { - La creación de una norma } \\
\text { internacional para } \\
\text { estandarizar alfabetos } \\
\text { presentes en los libros } \\
\text { escolares podría ayudar a } \\
\text { minimizar los impactos } \\
\text { negativos sobre la } \\
\text { educación y la enseñanza } \\
\text { de la escritura. Un análisis } \\
\text { multidisciplinaria entre } \\
\text { profesionales de la } \\
\text { educación, la psicología y } \\
\text { los desarrolladores de } \\
\text { tipografías, como } \\
\text { diseñadores, podría ser el }\end{array}$ \\
\hline
\end{tabular}




\begin{tabular}{|l|l|l|}
\hline & & $\begin{array}{l}\text { primer paso para crear un } \\
\text { estándar de la escritura en } \\
\text { las escuelas. (Ver Artículos } \\
2,3,5 \text { y 7) }\end{array}$ \\
\hline - Artículo 7 & $\begin{array}{l}\text { - Dificultades } \\
\text { metodológicas para el } \\
\text { desarrollo de caracteres } \\
\text { tipográficos. }\end{array}$ & $\begin{array}{l}\text { - Este estudio busca } \\
\text { contribuir al desarrollo } \\
\text { ordenado de un proyecto } \\
\text { gráfico que tenga al } \\
\text { elemento tipográfico como } \\
\text { parte esencial. El uso de } \\
\text { múltiples métodos, } \\
\text { referencias constructivas y } \\
\text { aspectos técnicos de la } \\
\text { tipografía constituyen el } \\
\text { núcleo de la investigación } \\
\text { con una propuesta de } \\
\text { etapas que pueden ser } \\
\text { utilizadas en el proceso de } \\
\text { construcción de caracteres } \\
\text { tipográficos. (Ver Artículos } \\
5 \text { y 6) }\end{array}$ \\
\hline &
\end{tabular}

\subsection{Futuras líneas de investigación}

El trabajo desarrollado en la tesis por compendio de publicaciones y los resultados obtenidos, dan oportunidad a un amplio abanico de posibles trabajos como futuras líneas de investigación. A continuación, se destacan algunas:

- Desarrollo de una o más tipografías para la enseñanza de la escritura adaptada al perfil del adulto analfabeta;

- Planteamiento de una metodología para la enseñanza de la escritura a los adultos que son analfabetas;

- Estudio de la creación de una normativa para la estandarización de las letras utilizadas en el proceso de alfabetización de adultos; 
Estudio de la construcción de los elementos caligráficos en el proceso de alfabetización de adultos en la Amazonia brasileña

- Aproximación del diseño con la pedagogía y áreas afines para promover un discurso multidisciplinar enfocado en la alfabetización de los adultos;

- Propuesta de libros y materiales didácticos para la alfabetización de adultos;

- Desarrollo de un proyecto multidisciplinar destinados a la preparación de profesores y alumnos adultos para la transición entre la escritura manual y el universo digital;

- Sugerir la creación de una asignatura en los cursos de pedagogía acerca de la enseñanza de la escritura.

Estas son apenas algunas sugerencias de estudio futuros del tema abordado en esta tesis doctoral; sin embargo, la amplitud del presente trabajo tiene varias direcciones dependiendo del contexto, área o ubicación de la investigación. Los contenidos aquí presentados tienen la intención de poner la educación y la enseñanza de los adultos en el centro de una discusión multidisciplinar que pueda ir más allá del universo académico. 
E studio de la construcción de los elementos caligráficos en el proceso de alfabetización de adultos en la Amazonia brasileña

\section{A nexos}





\section{Anexos}

\subsection{Anexo I - Encuesta con expertos}

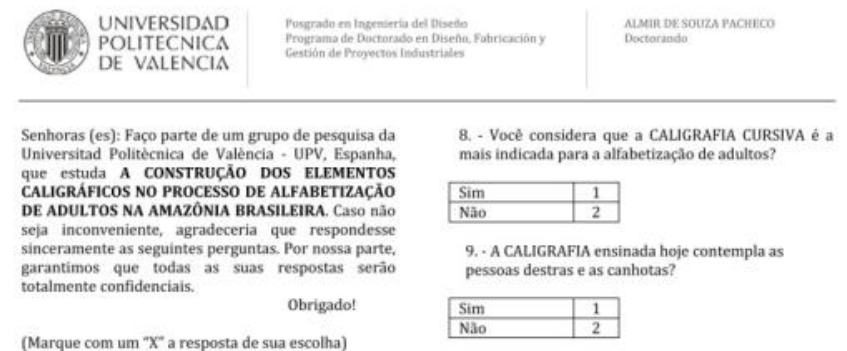

(Marque com um " $\mathrm{X}$ " a resposta de sua escolha)

A. Perguntas de classificaçào

1.- Pais:

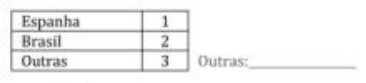

2. Cidade:

\begin{tabular}{|l|l|}
\hline Valência & 1 \\
\hline Manaus & 2 \\
\hline Outras & 3 \\
\hline
\end{tabular}

3.- Carreira Profissional em:

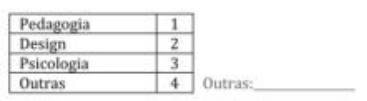

4.- Tipo de escola:

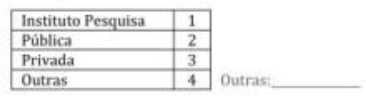

5.- Tempo de profissāo:

\begin{tabular}{|l|l|}
\hline 1 a 5 anos & 1 \\
\hline 5 a 10 anos & 2 \\
\hline Mais de 10 anos & 3 \\
\hline
\end{tabular}

6. - Vocé tem ou teve alguma experiência com o tema ou linha de pesquisa abordados pelo estudo?

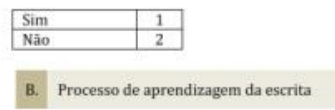

7. - Atualmente, você acredita que a CALIGRAFIA ensinada considerando o nivel de DIFICULDADE CONSTRUTIVA dos caracteres?

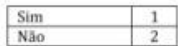

8. - Você considera que a CALIGRAFIA CURSIVA é a

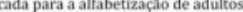

10.- Dentre as principais razōes para a MUDANÇA DA LETRA, entre as etapas escolares: de criança a adulto. como voce valora a dificuldade construtiva da caligrafia cursiva? Assinale de 1 a 4 qual o grau de importancia tem essa afrmaça para voce. (1= pouco importante, $4=$ muito importante)

\section{\begin{tabular}{|l|l|l|l|}
\hline 1 & 2 & 3 & 4 \\
\hline
\end{tabular}}

11. Você acredita que o material didático con positiva no processo de aprendizagem da escrita?

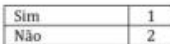

C. Construçâao da letra

- Representaçăo dos caracteres - Compreensào da escrita 12. Como você valora o uso da letra romana (de
forma) em versốes maiúsculas e minúsculas no processo de alfabetização de adultos? Assinale de 1 a 4 o grau de importância que tem essa afirmaçẩo. (1= pouco importante, $4=$ muito importante):

\section{\begin{tabular}{|l|l|l|l|}
\hline 1 & 2 & 3 & 4 \\
\hline
\end{tabular}}

13. - Como você avalia o uso de formas básicas (quadrado, circulo e triângulo) como base para a construção dos elementos caligráficos (letras)? afirmaçào. $(1=$ pouco importante, $4=$ muito importante):

14. - Dentre os vários aspectos da caligrafia, com॰ você valora a velocidade da escrita? Assinale de 1 a 4 - grau de importância que tem essa afirmaçăo. (1= pouco importante, $4=$ muito importante)

\section{\begin{tabular}{|l|l|l|l|}
\hline 1 & 2 & 3 & 4 \\
\hline
\end{tabular}}

15. - Você considera a legibilidade mais importante que a velocidade da escrita?

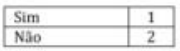
caracteristicas regionais pode influenciar de forma Assinale de 1 a 4 o grau de importancia que tem essa 


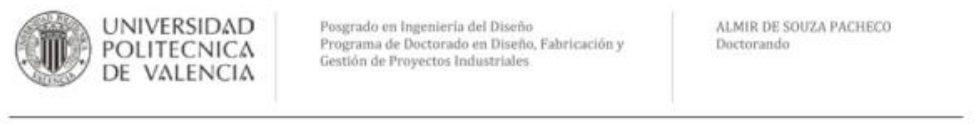

16. - Você acredita que a caligrafia cursiva contribui para o aluno ter uma escrita ilegivel em funçāo de sua complexidade construtiva?

\begin{tabular}{|l|l|}
\hline Sim & 1 \\
\hline Não & 2 \\
\hline
\end{tabular}

- Aspectos de afetividade

- Aspectos de Interatividade

17. - Como você avalia o material didático que valoriza a relação professor-aluno? Assinale de 1 a 4 o grau de importância que tem essa afirmação. (1= pouco importante, $4=$ muito importante):

\section{\begin{tabular}{|l|l|l|l|}
\hline 1 & 2 & 3 & 4 \\
\hline
\end{tabular}}

18. - Como você avalia a interatividade do aluno no processo pedagógico? Assinale de 1 a 4 o grau de importåncia que tem essa afirmação. (1= pouco importante, $4=$ muito importante):

E. - Recursos didáticos

19.- Você acredita que exista uma variedade suficiente de material didático direcionado para a alfabetizaçăo de adultos?

\begin{tabular}{|l|l|}
\hline Sim & 1 \\
\hline Não & 2 \\
\hline
\end{tabular}

20.- Você acredita que o material didático utilizado para a alfabetização de crianças pode ser utilizado com adultos iletrados?

\begin{tabular}{|l|l|}
\hline Sìm & 1 \\
\hline Não & 2 \\
\hline
\end{tabular}

21.- Como você valora a adaptação dos recursos didáticos, utilizados no processo de alfabetizaçâo de adultos, às características regionais? Assinale de 1 a 4 o grau de importância que tem essa afirmação para você. $(1=$ pouco importante, $4=$ muito importante):

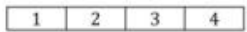

F. - Aspectos de Design

22.- Como você avalia a simplificação da forma dos caracteres utilizados para a alfabetizaçầo de adultos? Assinale de 1 a 4 o grau de importância que tem essa afirmação para você. $(1=$ pouco importante, $4=$ muito importante):

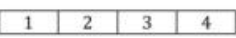

23.- Como você avalia o uso de letras com formas mais simples para a alfabetização de adultos? Assinale de 1 a 4 o grau de importância que tem essa afirmaçăo para você. $(1=$ pouco importante, $4=$ muito importante):

\begin{tabular}{|l|l|l|l|}
\hline 1 & 2 & 3 & 4 \\
\hline
\end{tabular}

\section{MUITO OBRIGADO PELA SUA COLABORAÇÃO}

\section{Dados do entrevistado}

Nome:

$\mathrm{n},{ }^{\circ}$ identidade:

Tel.

e-mail:

data: 


\subsection{Anexo II - Portada del Articulo 1 (publicado)}
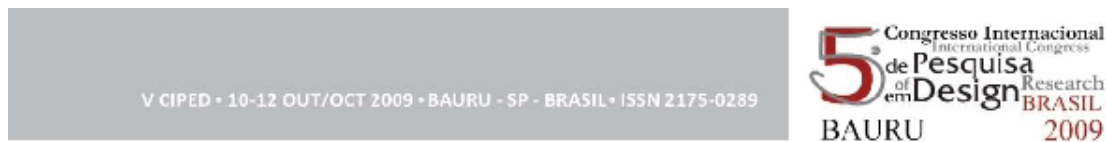

Caligrafia Cursiva: A única ou mais eficiente no processo de alfabetização? Cursive handwriting: The only or most efficient in the process of literacy?

PACHECO, Almir de Souza

Especialista em Design, Propaganda e Marketing - Universidade Federal do Amazonas - UFAM

PACHECO, Karla Mazarelo Maciel

Mestre em Engenharia Florestal e Ambiental - Universidade Federal do Amazonas - UFAM

ORTUÑo, Bernabé Hernandis

Doutor em Engenharia do Design - Universidade Politécnica de Valência/Espanha -UPV

Palavras-chave: Design, Tipografia, Alfabetização.

Este artigo visa questionar a imposição da letra cursiva nas escolas como processo de alfabetização. A intençao não é questionar o sistema educacional nem tão pouco propor a eliminação desse tipo de escrita mas provocar uma reflexão a respeito desse recurso pedagógico.

Kay-words: Design, Typography, Literacy.

This article aims to challenge the imposition of the letter cursive in schools as the literacy process. The intention is not to question the educational system or the proposed disposal of this type of writing but to cause a reflection about the use pedagogical recourse.

Caligrafia Cursiva: A única ou mais eficiente no processo de alfabetização?

1 - Introdução

Analisando aspectos da transcrição da linguagem segundo Frutiger (2001), estima-se que a escrita, como expressão do pensamento e da fala, teve origem no instante em que desenhos ou sinais surgiram relacionados diretamente com as silabas, palavras ou frases pronunciadas.

Os primeiros escribas teriam surgido 5.000 anos antes de Cristo. A comunicação dava-se através da esquematização de objetos, datas e ações através dos chamados pictogramas. A escrita, propriamente dita, teria surgido no momento em que começaram a organizar e alinhar os sinais lado a lado ou um sobre o outro, correspondendo à evolução linear dos seus pensamentos. Frutiger (2001)

A evolução e adaptações de escribas e monges no método de escrever conduziu ao surgimento do primeiro caderno de caligrafia na Itália no ano de 1522 por Ludovico Vicentino degle Arighi. Foi o grande responsável pela popularização da letra chamada chanceleresca ou itálica, e por estabelecê-la como a cursiva preferida pela tipografía. Arrighi era escriba papal e um dos caligrafos/tipógrafos que participaram diretamente na criação da cultura tipográfica ocidental durante o renascimento italiano. Convencionou-se então chamar de cursiva todo tipo de letra escrita à mão e de aspecto caligráfico.

A popularização da escrita cursiva foi tão grande que "invadiu" o sistema educacional do ocidente e, quase 500 anos depois, ainda permanece inconteste nos livros de caligrafía para alfabetização de crianças e adultos, embora o desenvolvimento tecnológico de igual periodo ter tomado esse tipo de escrita cada vez menos usual nos meios de comunicação modernos. Jury (2007) reforça esse pensamento afirmando que a partir da década de 1920, a máquina de escrever praticamente substituiu a escrita à mão para a produção da contabilidade e da correspondência das empresas e, portanto, a importância do ensino da caligrafía nas escolas diminuiu gradualmente.

Outro fator preponderante é a incipiente variedade de alternativas caligráficas no ensino, até como parâmetros de comparação de resultados. Para Heitlinger (2007), faltam fontes tipográficas adequadas às 
Estudio de la prospección del uso de la fibra de tucumã-i (Astrocaryum acaule) para el desarrollo de productos semi-industriales

\subsection{Anexo III - Aceptación del Artículo 2 en CIEPG2012}

hrt://isapg combr/2012/ciepg/selecionados.ply

\section{Codastro Unificado}

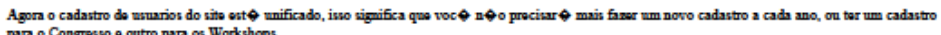
para o Congrenso 0 outro para os Werk shop:

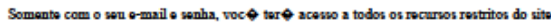

OEscoudar esto Painol

\section{Login do Usn rlo}

E-mail: Senha:

Eutrat

Enqueci minha vanhe

\section{$N \diamond 0 \diamond$ cadastrado atnda?}

Cadatro-ae agora!

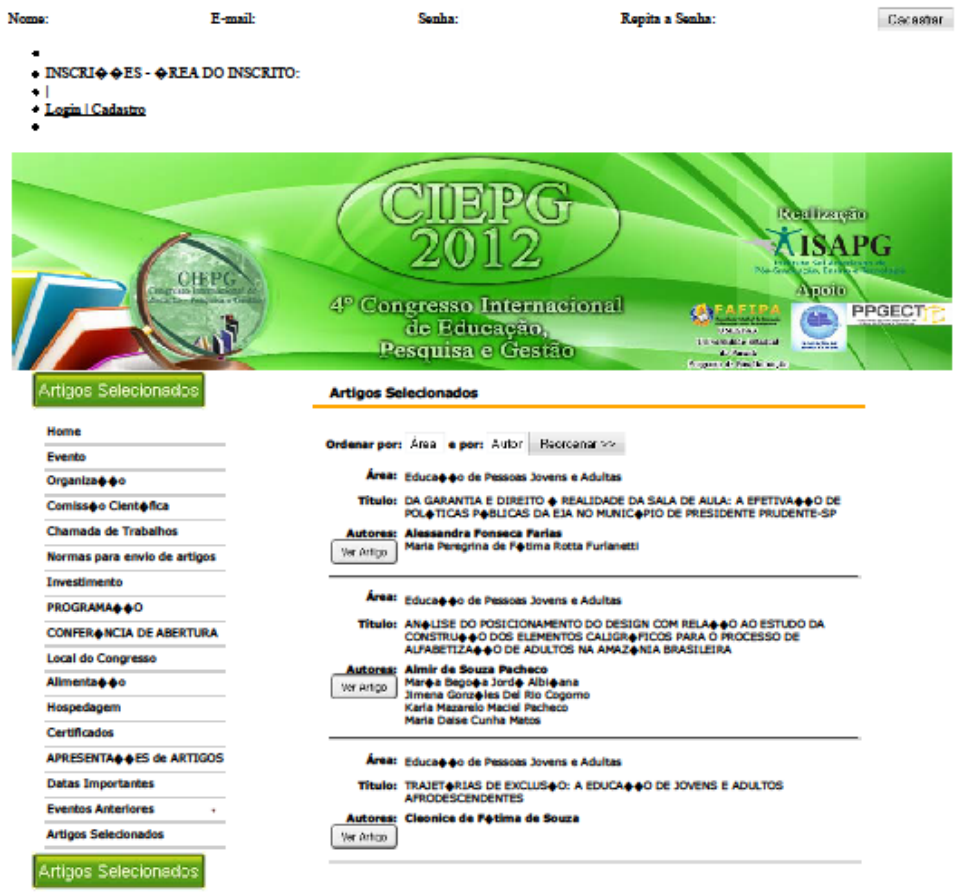




\subsection{Anexo IV - Carta aceptación para publicación del Artículo 3}
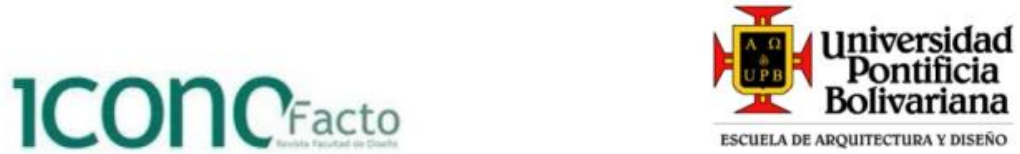

Medellin, 4 de septiembre de 2012

En mi calidad de editor y Director de la revista ICONOFACTO de la Escuela de Arquitectura y Diseño de la Universidad Pontificia Bolivariana Sede Medellín, certifico que Almir de Souza Pacheco, María Begoña Jordá Albiñana, Jimena Gonzáles del Rio Cogorno y Karla Mazarelo Maciel Pacheco, radicaron el artículo Um olhar do design sobre a morfologia de caracteres caligráficos e suas implicações para 0 processo de alfabetização de adultos. Dicho texto está en proceso de edición y será publicado en el Volumen 9 número 12 de enero- diciembre de 2013.

La revista ICONOFACTO tiene el aval de indexación de PUBLINDEX, LATINDEX y está siendo evaluada en EBSCO.

Sin otro particular,

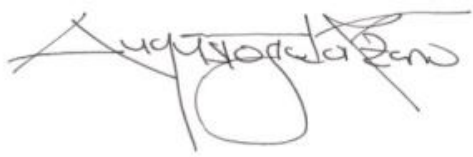

Augusto Solórzano

PhD. en Filosofía

Editor y Director de ICONOFACTO Revista de la Escuela de Arquitectura y Diseño U.P.B 
Estudio de la prospección del uso de la fibra de tucumã-i (Astrocaryum acaule) para el desarrollo de productos semi-industriales

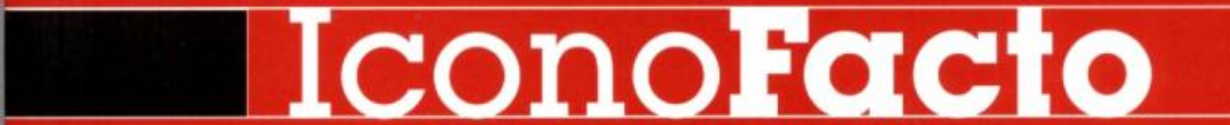

REVISTA DE LA ESCUELA DE ARQUITECTURA Y DISENNO · Volumen 7, nùmero ? 


\subsection{Anexo V - Programa presentación del artículo 4 en II CIDAG}

\begin{tabular}{|c|c|c|c|c|c|c|}
\hline \multirow{3}{*}{$\begin{array}{l}\text { Hora } \\
10 h 30 \\
\end{array}$} & \multicolumn{3}{|c|}{ AUDIÓRIO 1} & \multicolumn{3}{|c|}{ AUDITÓRIO 2} \\
\hline & \multirow{2}{*}{\begin{tabular}{|l|} 
Área \\
Bí \\
\end{tabular}} & \multicolumn{2}{|l|}{$\begin{array}{l}\text { Produção Gráfica I } \\
\text { Desafios em Tipografia }\end{array}$} & \multirow{2}{*}{\begin{tabular}{|l} 
Área \\
82
\end{tabular}} & \multicolumn{2}{|c|}{$\begin{array}{l}\text { Produção Gráfica I } \\
\text { Impressáo e Sistemas Hibridos + Materiais } \\
\text { e Embalagens + Normalizaçāo }\end{array}$} \\
\hline & & De Appolinnaire a McDonald's & $\begin{array}{l}\text { Paulo Alcobia, } \\
\text { Sérgio Martins }\end{array}$ & & $\begin{array}{l}\text { Propriedades e aditivos } \\
\text { do sistena de molha }\end{array}$ & Joato Botelho \\
\hline roh45 & $B_{1}$ & $\begin{array}{l}\text { Dobradura: Tipografia } \\
\text { dimensional experimental }\end{array}$ & $\begin{array}{l}\text { Cassia } \\
\text { Domiciano, } \\
\text { Thais Trizoli }\end{array}$ & 82 & $\begin{array}{l}\text { Avaliaç̆o de desempenho } \\
\text { na impressâo digital entre } \\
\text { perfil de cor genierico e perfil } \\
\text { de cor ger ado }\end{array}$ & $\begin{array}{l}\text { Rodrigo } \\
\text { Holdschip. } \\
\text { Joào Fernando } \\
\text { Marar }\end{array}$ \\
\hline 11 ho & B1 & Reiventando os tipos & $\begin{array}{l}\text { Flávio Vingol. } \\
\text { Ralael Neder }\end{array}$ & B2 & $\begin{array}{l}\text { Quality of offset prints on PVC } \\
\text { and pp substrates }\end{array}$ & $\begin{array}{l}\text { Rozalia } \\
\text { Szentgyorgywolgy }\end{array}$ \\
\hline $11 h 45$ & B1 & $\begin{array}{l}\text { Desenvolvimento de fonte } \\
\text { tipográfica display inspirada } \\
\text { na assinatur a de um artista }\end{array}$ & $\begin{array}{l}\text { Genilson Santos, } \\
\text { Paulo Souza }\end{array}$ & 82 & $\begin{array}{l}\text { Printabylity of recycled papers } \\
\text { by digital technologies }\end{array}$ & $\begin{array}{l}\text { Rozalia } \\
\text { Szentgyorgyvolgy, } \\
\text { Alvos Borbely }\end{array}$ \\
\hline $12 h 00$ & 81 & 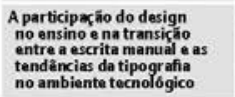 & $\begin{array}{l}\text { Almir Pacheco, } \\
\text { Begona Jorda, } \\
\text { Jimena Gonzalez, } \\
\text { Karla Pacheco }\end{array}$ & 83 & $\begin{array}{l}\text { A traduch̆o intersemiótca } \\
\text { como ferramenta na criaçăo } \\
\text { de projectos de design } \\
\text { de superficie }\end{array}$ & $\begin{array}{l}\text { Jonas Rosso, } \\
\text { Dego Medeiros, } \\
\text { Cristiane } \\
\text { Dagostin }\end{array}$ \\
\hline $12 \mathrm{~h} 15$ & & & & B4 & $\begin{array}{l}\text { Estandarización en la } \\
\text { impresión offset }\end{array}$ & $\begin{array}{l}\text { José Manuel } \\
\text { Martinez Bouza, } \\
\text { Angel Fernández } \\
\text { Gardia }\end{array}$ \\
\hline $12 h 30$ & & & & 84 & Teorias da luz e da cor & $\begin{array}{l}\text { Migual Sanches, } \\
\text { Duke Louçæa, } \\
\text { Fernando } \\
\text { Moreira da Silva }\end{array}$ \\
\hline $12 h 45$ & & & & 84 & $\begin{array}{l}\text { Gestalo de cor + Normalizaçăo } \\
\text { = Produtividade }\end{array}$ & Vitor Pedro \\
\hline
\end{tabular}

